$\operatorname{Argonne} \underset{\bigotimes}{\bigotimes}$

\title{
Final Corrective Action Study for the Former CCC/USDA Facility in Hanover, Kansas
}

\section{Environmental Science Division}


About Argonne National Laboratory

Argonne is a U.S. Department of Energy laboratory managed by UChicago Argonne, LLC under contract DE-AC02-06CH11357. The Laboratory's main facility is outside Chicago, at 9700 South Cass Avenue, Argonne, Illinois 60439. For information about Argonne and its pioneering science and technology programs, see www.anl.gov.

\section{Availability of This Report}

This report is available, at no cost, at http://www.osti.gov/bridge. It is also available on paper to the U.S. Department of Energy and its contractors, for a processing fee, from:

U.S. Department of Energy

Office of Scientific and Technical Information

P.O. Box 62

Oak Ridge, TN 37831-0062

phone (865) 576-8401

fax (865) 576-5728

reports@adonis.osti.gov

\section{Disclaimer}

This report was prepared as an account of work sponsored by an agency of the United States Government. Reference herein to any specific commercial product, process, or service by trade name, trademark, manufacturer, or otherwise, does not necessarily constitute or imply its endorsement, recommendation, or favoring by the United States Government or any agency thereof. The views and opinions of document authors expressed herein do not necessarily state or reflect those of the United States Government or any agency thereof, Argonne National Laboratory, or UChicago Argonne, LLC. 


\section{Final Corrective Action Study for the Former CCC/USDA Facility in Hanover, Kansas}

by

Applied Geosciences and Environmental Management Section

Environmental Science Division, Argonne National Laboratory

November 2013

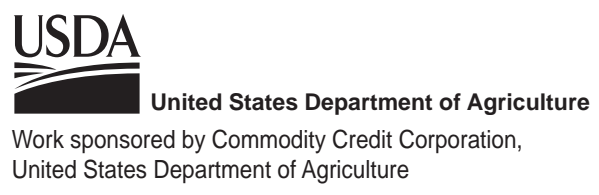




\section{Contents}

Notation. viii

Executive Summary ES-1

1 Introduction

2 Site Background.

2.1 Site Description.

2.2 Investigations of the Nature and Extent of Soil and Groundwater

Contamination.

2.2.1 Investigations Related to the Former CCC/USDA Facility, Conducted by the KDHE in 1998-2006...

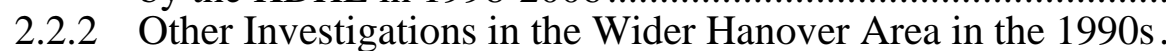

2.2.3 Limited Investigations at the Former CCC/USDA Facility, Conducted by Argonne in 2007 .

2.2.4 Objectives for Investigations Conducted by Argonne in 2009-2010..

2.2.5 Results of Argonne’s 2009-2010 Study....

2.3 Evaluation of Current and Future Human and Environmental Exposure Targets and Pathways

2.3.1 Water Sources for Hanover....

2.3.2 Groundwater Migration Pathways

Water-Supply-Related Exposure Pathways

2.3.4 Soil Exposure Pathway

2.3.5 Vapor Intrusion Exposure Pathway

2.3.6 Groundwater Seepage to Surface Water Exposure Pathway ..

3.1 Regulatory Considerations

3.1.1 Applicable or Relevant and Appropriate Requirements and Guidance to be Considered

3.1.2 Chemical-Specific ARARs

3.1.3 Action-Specific ARARs.

3.1.4 Advisories, Criteria, and Guidance.

3.1.5 Waivers and Variances

4 Identification and Screening of Technologies

4.1 Criteria for Identifying and Screening Technologies......................................... 4-2

4.2 Screening of Remedial Technologies ................................................................... $4-4$

4.2.1 No Action.

4.2.2 Kansas Environmental Use Controls 
4.2.3 Municipal Land Use Controls .................................................................... 4-6

4.2.4 Containment by Synthetic Vapor Intrusion Barriers ................................... 4-9

4.2.5 Containment by Engineered Physical Barriers to Groundwater Flow............ 4-10

4.2.6 Extraction and Treatment of Groundwater .................................................. 4-12

4.2.7 Subsurface Removal and Treatment of Volatile Contaminants by Soil Vapor Extraction, Air Sparging, or a Combination ........................................ 4-15

4.2.8 Removal and Treatment of Sub-Slab Volatile Contaminants......................... 4-17

4.2.9 In Situ Treatment by Permeable Reactive Barriers.......................................... 4-18

4.2.10 In-Situ Chemical Reduction Treatment ........................................................ 4-20

4.2.11 In Situ Treatment by Phytoremediation ...................................................... 4-22

4.3 Potentially Applicable Technologies ........................................................................... 4-25

5 Description of Alternatives ................................................................................... $5-1$

5.1 Alternative 1: No Action...................................................................................... 5-1

5.2 Alternative 2: Municipal Land Use Controls, Monitoring, and Well $\ldots$

5.2.1 Sitewide Groundwater Monitoring ............................................................... 5-2

5.2.2 Well Abandonment ..................................................................................... 5-3

5.2.3 Vapor Intrusion and Mitigation Monitoring ………………………………....... 5-3

5.2.4 Municipal Land Use Controls ........................................................................... 5-3

5.2.5 Five-Year Reviews.............................................................................. 5-5

5.3 Alternative 3: Targeted Groundwater Extraction and Treatment in Zone 1............... 5-5

5.3.1 Groundwater Extraction System Construction …………………………........ 5-6

5.3.2 Groundwater Extraction System Operations and Monitoring ....................... 5-8

6 Detailed Analysis of Corrective Action Alternatives ……………………………............ 6-1

6.1 Alternative 1: No Action..................................................................................... 6-2

6.1.1 Overall Protection of Human Health and the Environment........................... 6-3

6.1.2 Compliance with ARARs and TBCs ............................................................. 6-3

6.1.3 Long-Term Effectiveness and Permanence …............................................... 6-3

6.1.4 Reduction of Toxicity, Mobility, or Volume ……........................................ 6-4

6.1.5 Short-Term Effectiveness ………………….......................................... 6-4

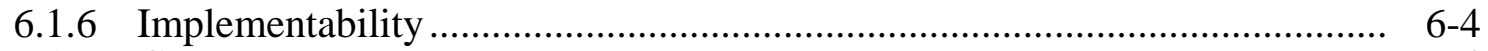

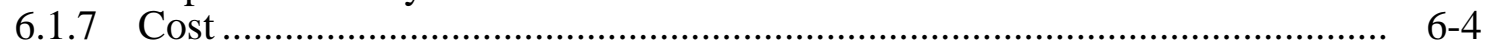

6.2 Alternative 2: Municipal Land Use Controls, Monitoring, and Well

Abandonment ................................................................................................... 6-5

6.2.1 Overall Protection of Human Health and the Environment........................... 6-5

6.2.2 Compliance with ARARs ……………………............................................ $6-5$

6.2.3 Long-Term Effectiveness and Permanence ………......................................... 6-5

6.2.4 Reduction of Toxicity, Mobility, or Volume ………...................................... 6-6

6.2.5 Short-Term Effectiveness …………………............................................. 6-6

6.2.6 Implementability ……………………………….................................... 6-6

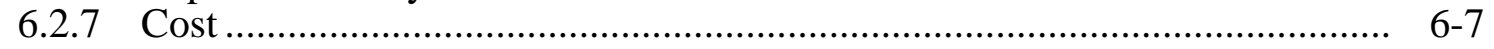

6.3 Alternative 3: Targeted Groundwater Extraction and Treatment in Zone 1............... 6-7

6.3.1 Overall Protection of Human Health and the Environment............................ 6-7

6.3.2 Compliance with ARARs ……………………....................................... 6-8

6.3.3 Long-Term Effectiveness and Permanence ................................................ 6-8

6.3.4 Reduction of Toxicity, Mobility, or Volume ……........................................ 6-8

6.3.5 Short-Term Effectiveness …………………............................................. 6-8 


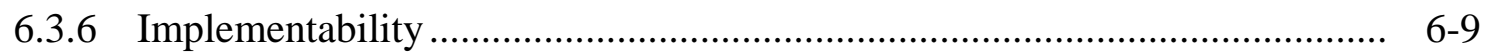

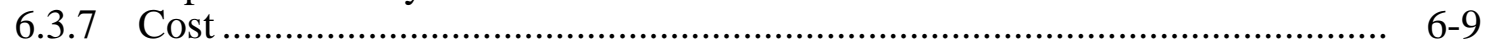

7 Comparative Analysis of Alternatives .............................................................................

7.1 Overall Protection of Human Health and the Environment....................................... 7-1

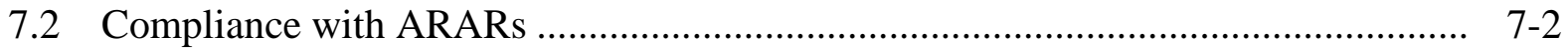

7.3 Long-Term Effectiveness and Permanence ................................................................ 7-2

7.4 Reduction of Toxicity, Mobility, or Volume ............................................................ 7-3

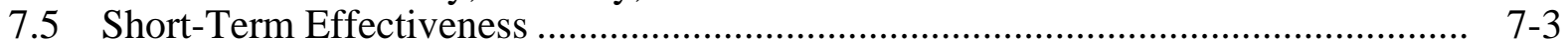

7.6 Implementability ……………………………………………………………... 7-4

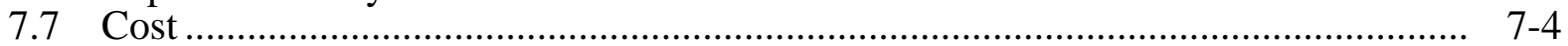

7.8 Stakeholder and State Acceptance ..................................................................... 7-4

7.9 Summary and Recommended Corrective Action …………………........................... 7-5

7.10 Contingency Plan ................................................................................................... 7-5

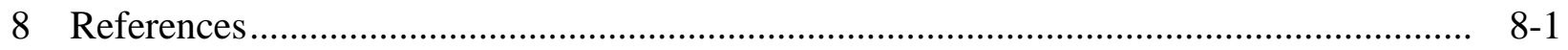

Appendix A: Summary of Investigation Activities and Response Actions at Hanover, 1998-2010 ......

Appendix B: Potential Federal and State Applicable or Relevant and Appropriate Requirements and State Guidance Documents "To Be Considered”

Appendix C: Phytotechnology Review

Appendix D: Estimation of the Operation Time Period for Groundwater Extraction in Alternative 3

\section{Figures}

2.1 Location of Hanover, Kansas, and the public water well field of Washington County RWD \#1 for the Hanover public water supply.

2.2 Location of the former CCC/USDA facility, the Farmers Co-op Association, and petroleum-contaminated sites.

2.3 Historical aerial photographs of the former CCC/USDA grain storage facility at Hanover taken in 1957, 1969, 1978, and 2006 


\section{Figures (Cont.)}

2.4 Surface topography in the Hanover area, the location of the former CCC/USDA facility, and water-bearing zones intercepted by private wells

2.5 General stratigraphic section in the investigation area at Hanover.

2.6 Interpretive west-to-east hydrogeologic cross section A-A'

2.7 Interpretive north-to-south hydrogeologic cross section B-B' ....

2.8 Maximum concentrations of carbon tetrachloride in soil samples collected at and near the former CCC/USDA facility during the 2009-2010 investigation.

2.9 Carbon tetrachloride concentrations in groundwater Zone 1, with the interpreted lateral extent of the carbon tetrachloride contamination, the potentiometric surface, and the estimated western limits of groundwater Zone 1

2.10 Interpreted lateral extent of carbon tetrachloride contamination, potentiometric surface, hydraulic conductivity, and preferred migration pathways in groundwater Zone 1

2.11 Carbon tetrachloride concentrations in groundwater Zone 2, with the interpreted lateral extent of the carbon tetrachloride contamination, the potentiometric surface, and the estimated western limits of groundwater Zone 2

2.12 Interpreted spatial configurations and sustainable pumping rates of Subsystems 1, 2, and 3 within the carbon tetrachloride distribution in groundwater Zone 1

2.13 Locations of residential structures tested during the on-site screening in the 2009-2010 investigations

2.14 Homes in which mitigation systems were installed to treat carbon tetrachloride in indoor air....

2.15 Locations of registered water wells within $1 \mathrm{mi}$ of the former CCC/USDA facility

2.16 Relative composition of major cations and anions in groundwater Zone 1 and Zone 2 ..... 


\section{Figures (Cont.)}

2.18 Interpreted lateral migration pathway 4 in groundwater Zone 2 .............................. 2-47

2.19 Vapor intrusion investigation Areas 1 and 2 (groundwater Zone 1), Area 3 (groundwater Zone 2), and Area 4 (schools)

4.1 Potential location for an extraction well in groundwater Zone 1

4.2 Distribution of depths from the ground surface to groundwater Zone 1, with carbon tetrachloride concentrations at monitoring wells on and near the former CCC/USDA property....

5.1 Locations of long-term monitoring wells for Alternative 2.....

5.2 Locations of treatment system components for Alternative 3, with property boundaries

5.3 North-to-south geologic cross section along the path of the proposed horizontal well, with well screen intervals and carbon tetrachloride concentrations in water-bearing Zone 1

5.4 Contaminant distribution in groundwater, with the location of the proposed horizontal extraction well in Zone 1, the well's radius of influence, the area targeted for source area reduction, and the mass reduction area monitoring wells

5.5 Locations of the mass reduction area monitoring wells and additional long-term monitoring wells

5.6 Locations of the long-term monitoring wells in groundwater Zone 1 and the proposed horizontal extraction well, with the western erosional limit of Zone 1, the expected radius of influence of pumping of the horizontal extraction well, the area with average hydraulic conductivity of $1 \mathrm{ft} /$ day, and interpreted preferential migration pathways.

5.7 Locations of the long-term monitoring wells in groundwater Zone 2, with the western erosional limit of Zone 2 and interpreted preferential migration pathway.

C.1 Vegetation sampling locations

C.2 Analytical results for carbon tetrachloride in branch tissue samples collected in July 2009 


\section{Figures (Cont.)}

C.3 Analytical results for carbon tetrachloride in leaf tissue samples collected in July 2009.

D.1 Proposed location for a horizontal well in the most permeable area of groundwater Zone 1, which is also the hot-spot area.

D.2 Estimated radius of influence for the proposed horizontal well in the most permeable area of groundwater Zone 1

\section{Tables}

2.1 Three subsystems of carbon tetrachloride contamination in groundwater Zone 1, with hydrogeologic characteristics and the feasibility of treatment technologies

2.2 Analytical results for water quality sampling in March and May 2011

2.3 Estimated geochemical properties of groundwater samples collected from groundwater Zone 1 and Zone 2

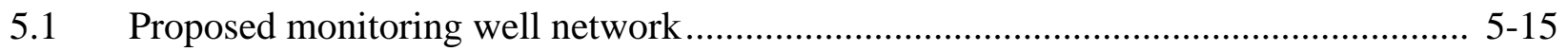

6.1 Comparative analysis of Hanover CAS alternatives............................................ 6-10

6.2 Cost comparison summary for Hanover CAS alternatives ...................................... 6-11

A.1 Summary of investigation activities and response actions at Hanover, 1998-2010 ..... A-2

B.1 Potential federal applicable or relevant and appropriate requirements and guidance to be considered for former CCC/USDA facilities

B.2 Potential state applicable or relevant and appropriate requirements and guidance to be considered for former CCC/USDA facilities in Kansas

D.1 Summary of volumetric analysis for Zone 1 


\section{Notation}

\begin{tabular}{ll} 
AMSL & above mean sea level \\
ARAR & applicable or relevant and appropriate requirement \\
AS & air sparging \\
BGL & below ground level \\
CAD & Corrective Action Decision \\
CAS & Corrective Action Study \\
CCC & Commodity Credit Corporation \\
CERCLA & Comprehensive Environmental Response, Compensation, and Liability Act \\
CERCLIS & Comprehensive Environmental Response, Compensation, and Liability \\
& Information System \\
COKR & Code of Kansas Regulations \\
EPA & U.S. Environmental Protection Agency \\
EUC & Environmental Use Control \\
ft & foot (feet) \\
GAC & granular activated carbon \\
gal & gallon(s) \\
gpm & gallon(s) per minute \\
hr & hour(s) \\
in. & inch(es) \\
ISCR & in situ chemical reduction \\
KDHE & Kansas Department of Health and Environment \\
$K_{h}$ & hydraulic conductivity \\
$\mu \mathrm{g} / \mathrm{kg}$ & microgram(s) per kilogram \\
$\mu \mathrm{g} / \mathrm{L}$ & microgram(s) per liter \\
$\mu \mathrm{g} / \mathrm{m}{ }^{3}$ & microgram(s) per cubic meter \\
meq/L & milliequivalent(s) per liter \\
mg/L & milligram(s) per liter \\
mi & mile(s) \\
MCL & maximum contaminant level \\
MLUC & municipal land use control \\
NAPL & non-aqueous phase liquid \\
NCP & National Oil and Hazardous Substances Pollution Contingency Plan \\
NEMA & National Electrical Manufacturers Association \\
NPV & net present value \\
pCi/L & picocurie(s) per liter \\
& \\
\hline
\end{tabular}


Hanover CAS

Version 05, 11/07/13

PRB permeable reactive barrier

RACER Remedial Action Cost Engineering and Requirements

RBSL risk-based screening level

ROI radius of influence

RWD Rural Water District

SVE soil vapor extraction

TBC to be considered

TDS total dissolved solids

USDA U.S. Department of Agriculture

VI vapor intrusion

VIB vapor intrusion barrier

VOC volatile organic compound

yr $\quad$ year(s) 


\section{Final Corrective Action Study for the Former CCC/USDA Facility in Hanover, Kansas}

\section{Executive Summary}

Low concentrations of carbon tetrachloride in groundwater and vapor intrusion into a limited number of residences (attributable to the contaminant concentrations in groundwater) have been identified in Hanover, Kansas, at and near a grain storage facility formerly leased and operated by the Commodity Credit Corporation of the U.S. Department of Agriculture (CCC/USDA). At the request of the Kansas Department of Health and Environment (KDHE 2009h), the CCC/USDA has prepared this Corrective Action Study (CAS) for the facility. The CAS examines corrective actions to address the contamination in groundwater and soil vapor.

Nine lithostratigraphic units and four groundwater-bearing zones (Zones 1-4, in order of increasing depth) were identified beneath the former CCC/USDA facility at Hanover. The carbon tetrachloride contamination in groundwater that is of concern for this CAS occurs only in the upper two water-bearing zones. Because of erosion of lithostratigraphic units, the uppermost water-bearing zone - groundwater Zone 1 - is restricted to the upland on which the former CCC/USDA facility was located. The highest contaminant concentrations occur in this thin unit. Its permeability and its groundwater production are extremely low. The second groundwaterbearing zone (Zone 2) extends toward the west from the former CCC/USDA facility. Zone 2 is thicker, more permeable, and more capable of groundwater production than Zone 1. Groundwater Zone 3 and Zone 4 lie deeper and are uncontaminated.

At present, no unacceptable human health or environmental exposure risks are associated with the contamination at the former CCC/USDA facility. The current and potential future water resources and exposure pathways were evaluated in order to define site-specific goals for remedial actions. Hanover residents have been served since 1974 by a public water supply system that obtains water from the Washington County Rural Water District \#1. The results of geochemical analyses (total dissolved solids $>1,200 \mathrm{mg} / \mathrm{L}$ ) of samples from the local groundwater Zone 2 in Hanover indicate that this water does not meet the specifications in policy BER-RS-045 (KDHE 2009b) for a potable water source. Further, water production from groundwater Zone 1, Zone 3, and Zone 4 is extremely limited $(<0.1 \mathrm{gpm})$ and is inadequate to supply the minimum household demand of 4-5 gpm (Suchy et al. 2011). 
Contaminant concentrations in soil at the former CCC/USDA facility are below the KDHE regulatory level. Consequently, soil is not a continuing source of groundwater contamination and does not require remedial action.

All of the possible exposure pathways (1) from contaminated soil to groundwater and (2) from contaminated groundwater to surface discharge and then to human or environmental receptors are incomplete. Consequently, these pathways pose no unacceptable health risks. However, a complete exposure pathway for carbon tetrachloride from contaminated groundwater to indoor air via vapor intrusion was confirmed by the results from the 2009-2010 investigation. Carbon tetrachloride concentrations exceeding the KDHE screening value of $4.06 \mu \mathrm{g} / \mathrm{m}^{3}$ in indoor air have been addressed by the installation of mitigation systems in the five affected residences. The five affected residences are being influenced by contaminated groundwater in Zone 1, and carbon tetrachloride was not detected in the indoor air of residences overlying Zone 2. Consequently, the corrective actions evaluated and discussed in this CAS are focused on Zone 1.

The site-specific remedial action goals for Hanover are as follows:

- In the relatively more permeable, more contaminated portion of Zone 1 where corrective action technologies would be effective and implementable, reduce the mass, mobility, and volume of contaminated groundwater that is serving as a vapor intrusion contamination source in Zone 1 and that is migrating from Zone 1 to Zone 2.

- Reduce the risk due to potential exposure to indoor air containing carbon tetrachloride at a concentration above the KDHE screening value.

- Minimize vertical and lateral migration of contaminated groundwater from the mass reduction area (i.e., the more permeable, more contaminated portion of Zone 1) to other areas of the site.

- Minimize vertical and lateral expansion of the contamination in groundwater outside the mass reduction area, as defined by the compliance groundwater monitoring network to be established. 
- Restore groundwater to allow for its most beneficial use.

In all, 4 general response actions and 11 individual technologies and practices, in addition to the required no-action option, were evaluated for their potential to meet the site-specific remedial action goals. The technologies and practices were further screened in detail against the KDHE (2001a) CAS guidance, which incorporates the following criteria: overall protection of human health and the environment; compliance with regulations and requirements; long-term effectiveness and permanence; reduction of contaminant toxicity, mobility, or volume; shortterm effectiveness; implementability; cost; state acceptance; and community acceptance.

As a consequence of this CAS evaluation, three alternatives were identified as appropriate for further consideration, as follows:

1. No action (required by the KDHE)

2. Municipal land use control, monitoring, and well abandonment

3. Targeted groundwater extraction and treatment in groundwater Zone 1

The preferred remedial alternative, selected from among the researched options, is the installation and operation of a groundwater extraction system consisting of a horizontal extraction well installed in the more permeable, highly contaminated portion of groundwater Zone 1, with treatment of the extracted groundwater through a tray aerator system and discharge to surface waters. This option will

- Capture and treat the main source of groundwater contamination in the relatively permeable and most contaminated portion of groundwater Zone 1,

- Help reduce contamination in groundwater in Zone 1 that is serving as a vapor intrusion contamination source,

- Reduce contaminant migration within Zone 1, and

- $\quad$ Reduce the migration of contaminated groundwater from Zone 1 to Zone 2. 
The recommended alternative also includes implementation of municipal land use controls to preclude future exposure to contaminated groundwater and the continued testing and maintenance of existing vapor intrusion mitigation systems in the homes having confirmed vapor intrusion risk due to carbon tetrachloride concentrations above the KDHE Tier 2 screening level. The chosen alternative includes the collection of air samples to assess the vapor intrusion mitigation systems; remuneration to homeowners for electric power required to operate the mitigation systems; and rigorous, long-term groundwater monitoring to assess the efficacy of the selected groundwater extraction system, including periodic reporting to the KDHE.

The recommended remedial alternative meets the state's criteria. It is the most protective alternative for human health and the environment. The alternative is designed to achieve compliance with regulatory requirements; will significantly decrease the toxicity, mobility, and volume of the contaminants; and will result in long-term protectiveness and permanence. The implementation of the remedial alternative is feasible and cost-effective, given the required access to private property, for the scale and complexity of the site. The approximate cost of this alternative is $\$ 1,688,000$ in current-year dollars (\$1,462,000 in net-present-value dollars). 


\section{Introduction}

The Commodity Credit Corporation of the U.S. Department of Agriculture (CCC/USDA) directed Argonne National Laboratory to prepare this Corrective Action Study (CAS), consistent with guidance of the Kansas Department of Health and Environment (KDHE 2001a), for the CCC/USDA grain storage facility formerly located in Hanover, Kansas.

Carbon tetrachloride levels in groundwater at the Hanover site are above the Kansas Tier 2 risk-based screening level (RBSL) and the U.S. Environmental Protection Agency (EPA) maximum contaminant level (MCL) of $5.0 \mu \mathrm{g} / \mathrm{L}$ (Kansas 2003, 2004). In addition, in 5 of approximately 60 residences evaluated, carbon tetrachloride levels attributable to vapor intrusion (VI) from impacted groundwater were above the KDHE indoor air screening level of $4.06 \mu \mathrm{g} / \mathrm{m}^{3}$. The KDHE therefore determined that corrective measures were warranted. The corrective measures for indoor air have already been implemented in the affected residences. To evaluate measures that reduce potential exposure to contaminated media at the site, this CAS compares a baseline "no-action" alternative and two additional active alternatives.

The history and nature of the contamination and previous investigations at Hanover are summarized in Section 2. Also in Section 2 is an evaluation of human and environmental targets and potential exposure pathways. Section 3 describes the corrective action goals and applicable or relevant and appropriate requirements. Section 4 identifies and screens candidate technologies for addressing the contamination. Section 5 describes the remedial alternatives, Section 6 analyzes the alternatives in detail, and Section 7 compares the alternatives. Section 7 also includes a summary and identifies the recommended corrective action. 


\section{Site Background}

\subsection{Site Description}

Hanover, Kansas, is a rural city in northeastern Washington County (Section 9, Township 2 South, Range 5 East), approximately 50-60 mi from Manhattan, Kansas, to the south and from Lincoln, Nebraska, to the north (Figure 2.1). Hanover is a state historic site known for the Hollenberg Pony Express Station. The city has numerous small businesses, the Farmers Cooperative Association, and a hospital. It also has public and private schools, churches, a library, a weekly newspaper, and a recreation facility.

The 2010 Census recorded 682 people in 314 housing units in the city of Hanover. The residents are served by a public water supply system that obtains water from the Washington County Rural Water District (RWD) \#1, which operates four well fields including 14 wells: Lanham (4 wells), Washington (2 wells), Marysville (4 wells), and Oketo (4 wells). The Hanover community receives its water supply primarily from the Lanham well field and will continue to do so, but the new Oketo wells will serve some of the customers presently receiving water from the Lanham field, and thus less pumping will be required from the Lanham wells (Schlabach 2011). The RWD can transfer water from one well field to the other if a problem occurs in any of the four fields.

The CCC/USDA operated a grain storage facility from 1950 to 1976 on approximately 6.5 acres in the northeast part of Hanover (Figure 2.2). During this time, commercial grain fumigants containing carbon tetrachloride were in common use by the grain storage industry. The facility reached its maximum operational scale in the late 1960s with 223 grain bins and 1 storage building (Figure 2.3). By 1978, all of the storage bins had been removed, four homes had been built within the footprint of the grain bin array, and a fifth home had been built on the southern boundary of the former CCC/USDA facility. By 2006, nine residences were located on or adjacent to the former CCC/USDA property.

The city of Hanover and its surroundings are located in an area that includes the upland lying northeast of the Little Blue River and its floodplain and northwest of Cottonwood Creek (Figure 2.4). The former CCC/USDA facility lies on the upland, at land surface elevations of approximately 1,310-1,330 ft above mean sea level (AMSL). Regional geologic information indicates that the geologic sequence at Hanover includes (1) surficial and near-surface 
Pleistocene eolian (wind-blown) deposits on upland areas and alluvial sediments in the floodplains along the Little Blue River, overlying (2) Permian bedrock, probably consisting of the Sumner Group and underlying Chase Group (Argonne 2008a). The Sumner Group consists principally of gray and red silty shale, limestone, dolomite, anhydrite, and gypsum, as well as salt, while the underlying Chase Group contains seven alternating shale and chert-bearing limestone units (Merriam 1963). The local geologic data obtained in this investigation confirm the presence of Pleistocene eolian deposits or alluvium unconformably overlying the Permian Sumner Group in the upper part of the subsurface sequence at Hanover and provide a detailed picture of the site-specific bedrock stratigraphy.

\subsection{Investigations of the Nature and Extent of Soil and Groundwater Contamination}

\subsubsection{Investigations Related to the Former CCC/USDA Facility, Conducted by the KDHE in 1998-2006}

Previous KDHE investigations at Hanover were described in detail in the Final Work Plan for the site investigation (Argonne 2008a). In the KDHE investigations, groundwater samples were collected from private wells in Hanover during a statewide USDA-funded private well sampling program (KDHE 1998). Carbon tetrachloride was found in groundwater from the A. Bruna and Ebeling wells in February and April 1998 at concentrations ranging from $0.5 \mu \mathrm{g} / \mathrm{L}$ to $1.3 \mu \mathrm{g} / \mathrm{L}$. The KDHE resampled the Bruna and Ebeling private wells and two additional lawn and garden wells (Meyn and Doebele) in July 1998 as part of a pre-CERCLIS site reconnaissance and evaluation. Carbon tetrachloride concentrations ranging from $0.6 \mu \mathrm{g} / \mathrm{L}$ to $5.9 \mu \mathrm{g} / \mathrm{L}$ were reported. Chloroform was also identified during all three private well sampling episodes, at levels up to $3.0 \mu \mathrm{g} / \mathrm{L}$.

During the site reconnaissance and evaluation in July 1998, the KDHE collected 11 nearsurface soil samples within the footprint of the former CCC/USDA facility. The samples were analyzed by a field laboratory. Samples positive for contaminants in the field analysis were sent to an off-site laboratory for confirmation analysis. Of the four samples sent for confirmatory analysis, one sample contained carbon tetrachloride at $7.1 \mu \mathrm{g} / \mathrm{kg}$. 


\subsubsection{Other Investigations in the Wider Hanover Area in the 1990s}

In addition to the activities performed to evaluate the environmental impact of the former CCC/USDA grain operation, two other investigations have been performed in the Hanover area: one focusing on the Washington County RWD \#1 water supply well fields (see Figure 2.1, which shows the location of the Lanham well field) and one focusing on Bill's Service Center (Figure 2.2).

In the past, trace levels of carbon tetrachloride were detected in groundwater from two of the four wells in the Lanham well field. At the request of the KDHE in a meeting on October 13, 2009, the CCC/USDA conducted a review of historical aerial photos and interviewed the Washington County Farmer Service Agency. There is no evidence indicating that any former grain storage facilities operated by the CCC/USDA were located at or near the Lanham well field. The historical aerial photos show that other commercial or private grain storage facilities were present in the past at and near the Lanham well field. It is anticipated that the KDHE will determine whether further investigation is warranted for the former commercial/private grain storage facilities at and near the Lanham well field.

In 1996, approximately 6,000 gal of unleaded gasoline was discovered to have leaked from a bulk aboveground storage tank at a gas station owned by Bill's Service Center, approximately $500 \mathrm{ft}$ east from the east edge of Hanover and approximately 1,000 ft southeast of the former CCC/USDA facility (Figure 2.2). The releases resulted in contamination of soil and groundwater by petroleum constituents. None of the petroleum-related contamination is associated with the former CCC/USDA facility.

In 1997 and 1999, GeoCore Services, Inc., conducted two limited environmental site assessments, on behalf of the Bill's Service Center location southeast of the former CCC/USDA facility (GeoCore 1997, 1999). The work included soil borings, hydrogeologic testing, and monitoring well installation. No analytical results for carbon tetrachloride or chloroform were reported. Groundwater was encountered in the Permian bedrock (gray-green to brown, redbrown shale) at approximately 41-45 ft below ground level (BGL). The estimated groundwater flow was reported as being generally toward the southeast, with an average hydraulic gradient of $0.016-0.026 \mathrm{ft} / \mathrm{ft}$. 
An additional release of petroleum occurred at the Bill's Service Center site approximately $1,100 \mathrm{ft}$ southwest of the former CCC/USDA facility (Figure 2.2). Leaking underground storage tanks were removed from this property in 1997.

\subsubsection{Limited Investigations at the Former CCC/USDA Facility, Conducted by Argonne in 2007}

Argonne’s 2007 investigation of contaminant sources at Hanover was implemented on behalf of the CCC/USDA and involved the collection of near-surface soil samples $(1.8-2.0 \mathrm{ft}$ BGL) at 61 locations across the former CCC/USDA facility. All samples were analyzed in an off-site laboratory. Although a screening (headspace) analytical method indicated the presence of carbon tetrachloride in some samples, no contamination was found by the more rigorous purgeand-trap analytical method.

In 2007 Argonne also collected indoor air samples from the basement areas of nine residences on or adjacent to the former CCC/USDA property. Carbon tetrachloride was detected in the air samples collected in four of the nine residences, at concentrations ranging from $1.4 \mu \mathrm{g} / \mathrm{m}^{3}$ to $4.8 \mu \mathrm{g} / \mathrm{m}^{3}$.

\subsubsection{Objectives for Investigations Conducted by Argonne in 2009-2010}

The 2009-2010 CCC/USDA-Argonne investigations were conducted at the request and with the concurrence of the KDHE (2008a-d). The primary goals of these investigations were to characterize soil and groundwater contamination at and near the former CCC/USDA facility and to identify potential intrusion of contaminant vapor to indoor air due to possible soil and groundwater contamination.

To meet these goals, the detailed technical objectives of the investigations were as follows:

- Identify contaminant sources and the extent of soil contamination beneath the former CCC/USDA facility.

- Characterize the groundwater-bearing system. 
- Delineate the vertical and areal extent of the groundwater contamination.

- Determine groundwater flow patterns.

- Evaluate the hydraulic properties of the groundwater-bearing system.

- Determine potential VI attributable to subsurface contamination.

- Perform an initial qualitative assessment of human health and environmental risks.

The 2009-2010 investigations were designed to generate the specific information required to address these technical objectives. The Final Work Plan (Argonne 2008a) for the overall investigation and the Supplemental VI Work Plan (Argonne 2008b) were approved by the KDHE (2008b,d). Subsequently, smaller work plans to guide specific activities were developed during the investigations and incorporated into the Final Work Plan and the Supplemental VI Work Plan as addenda, with the approval of the KDHE (2008e, 2009c-g,j, 2010a,b). The investigations were carried out in accordance with KDHE (2005c,f) guidance and with KDHE oversight.

The activities during the 2009-2010 investigation have been documented in detail (Argonne 2011). A chronological summary of the activities is in Table A.1 in Appendix A.

\subsubsection{Results of Argonne's 2009-2010 Study}

The key technical findings of the comprehensive geologic, hydrologic, and geochemical site characterization studies; the aquifer hydraulic testing; and the VI investigation programs conducted at the former CCC/USDA grain storage facility are summarized below with regard to the physical setting, the extent of the contamination, and VI.

\subsubsection{Physical Setting}

The geologic sequence in the Hanover area generally consists of unconsolidated Pleistocene eolian deposits (on upland areas) and alluvial sediments (in floodplains areas) 
overlying Permian bedrock. In the study area, a vertical sequence of nine primary lithostratigraphic units was recognized. In order of increasing depth, these units consist of (1) silt and clay with a lower section of sand and sandy silt, (2) weathered shale, (3) interbedded limestone and shale, (4) gray shale, (5) an upper red shale, (6) an interval that varies laterally in facies from evaporitic deposits to soft gray shale with limestone, (7) gray dolostone and shale, (8) a lower red shale, and (9) a lower evaporitic deposit (Figure 2.5).

A prominent erosional unconformity marks the top of the bedrock section. Together with more recent topographic downcutting, this erosional unconformity has influenced the lateral extent of the lithostratigraphic units. The complete sequence of units outlined above is present beneath a local upland area that extends southwestward from the former CCC/USDA property. On the eastern and western flanks of the upland area, erosion has progressively cut into, or locally removed, the shallower lithostratigraphic units. On the western flank of the uplift, Units 1-4 are completely absent, and erosion has partially removed Unit 5 (Figures 2.6 and 2.7).

Four groundwater-bearing intervals were identified in the bedrock sequence. Zone 1 the uppermost water-bearing unit - consists of a few discrete, thin, saturated horizons (each less than $1 \mathrm{ft}$ thick, with a total combined thickness of 1-3 ft) developed along bedding planes and fractures within the interbedded limestones and shales of Unit 3. The areal extent of Zone 1 is bounded by the erosional limits of Unit 3. Semi-radial groundwater movement was identified in Zone 1, with flows to the northwest, west, southwest, and south originating from a localized groundwater high (groundwater divide) beneath the upland area at the former CCC/USDA facility. Preferential groundwater flow to the southwest along a narrow, relatively permeable zone is evident, at an average velocity of approximately $14 \mathrm{ft} / \mathrm{yr}$ (greater by roughly one or two orders of magnitude than the rates of flow to the northwest, west, or south).

Zone 2 consists of relatively thick saturated intervals in the shale with limestone facies of Unit 6, or thin moist-wet intervals along bedding planes near the base of the upper red shale (Unit 5) where this interval overlies the evaporitic facies of Unit 6. Zone 2 is laterally more extensive than Zone 1, since it is located deeper in the stratigraphic sequence and hence has been less severely truncated by erosion. Semi-radial groundwater flow was also identified in groundwater-bearing Zone 2, originating from a localized high beneath the former CCC/USDA facility. Groundwater movement to the west, southwest, south, and southeast is indicated; however, the highest hydraulic gradients are observed in the westerly flow direction. 
Zone 3 is hosted by the gray dolomitic shale near the base of Unit 7. The thin moist-wet intervals in this unit, which are difficult to identify, have a combined thickness of less than $2 \mathrm{ft}$. Zone 4 is developed at the base of the lower red shale (Unit 8). The multiple thin, moist-wet intervals that form Zone 4 also have a total thickness of less than $2 \mathrm{ft}$. The existing observations for these wells indicate, however, that the capacity of Zone 3 and Zone 4 to transmit groundwater to wells is very limited.

Groundwater leakage from Zone 1 to Zone 2 is indicated in the area beneath the upland, where groundwater mounding is observed in both Zone 1 and Zone 2. This vertical leakage, however, is minimal, as indicated by the much lower concentrations of carbon tetrachloride and nitrate in Zone 2. The apparent mixing ratio of Zone 1 groundwater flowing into Zone 2 is estimated at $10 \%$ or less, on the basis of concentration data for both carbon tetrachloride and nitrate in the upland area.

Although equilibrium groundwater levels had not been achieved in all wells in Zone 3 as of May 2011 (at least 18 months after installation of recorders), recent groundwater level measurements in Zones 1-4 indicate an upward hydraulic gradient from Zone 4 to Zone 3 (and also from Zone 4 to Zone 2). These observations indicate that a natural hydraulic barrier exists to downward migration of Zone 2 groundwater into the deeper parts of the flow system beneath the upland area.

\subsubsection{Extent of the Contamination}

The residual concentrations of carbon tetrachloride and chloroform identified in soil were well below the KDHE Tier 2 soil-to-groundwater standards for these contaminants $(73.4 \mu \mathrm{g} / \mathrm{kg}$ and $850 \mu \mathrm{g} / \mathrm{kg}$, respectively; KDHE 2010f), indicating that the soils pose no unacceptable health or environmental risks and do not represent a continuing source of contamination to groundwater. Vertical-profile sampling of the vadose zone soils beneath the former CCC/USDA facility (for analyses for volatile organic compounds [VOCs]) was conducted at 38 locations. Carbon tetrachloride was detected at 8 locations only, at a maximum concentration of $35 \mu \mathrm{g} / \mathrm{kg}$ (Figure 2.8). Low levels of chloroform $(\leq 44 \mu \mathrm{g} / \mathrm{kg}$ ) were also detected at 2 locations (TI30 and TI05). 
Carbon tetrachloride contamination was identified in the groundwater in Zone 1 at concentrations up to $617 \mu \mathrm{g} / \mathrm{L}$ (Figure 2.9). The highest concentrations of carbon tetrachloride (> $500 \mu \mathrm{g} / \mathrm{L}$ ) were detected beneath the north central portion of the former CCC/USDA facility. Concentrations exceeding $100 \mu \mathrm{g} / \mathrm{L}$ generally underlie the topographic upland that extends to the south and southwest of the former facility, along the preferred groundwater flow pathway identified in this direction.

The lateral variations in carbon tetrachloride concentrations observed in Zone 1 (as a result of contaminant migration) show relatively close correlation to spatial variations in the hydraulic conductivity $\left(K_{h}\right)$ of the Zone 1 unit that were identified through extensive hydraulic testing. Specifically, carbon tetrachloride concentrations $>100 \mu \mathrm{g} / \mathrm{L}$ are generally associated with the regions of highest $K_{h}$ values in the unit (beneath the upland area), while progressively lower concentrations and $K_{h}$ values are generally observed toward the margins of the upland. Figure 2.10 depicts the lateral extent of carbon tetrachloride contamination, the potentiometric surface, hydraulic conductivity, and preferred migration pathways in Zone 1.

Elevated ratios of chloroform to carbon tetrachloride were observed, substantiating that some degradation of carbon tetrachloride (by reductive dechlorination under anaerobic conditions) is occurring in the Zone 1 groundwater along the leading, downgradient margins of the contaminant distribution, as well as in Zone 2. Chloroform was found in groundwater Zone 1 at a maximum concentration of $18 \mu \mathrm{g} / \mathrm{L}$. In the northern part of the former CCC/USDA facility, the relative abundance of chloroform to carbon tetrachloride was generally less than $2 \%$. However, near the margins of the carbon tetrachloride distribution, the ratios of chloroform to carbon tetrachloride in Zone 1 increased locally to values of $13 \%$ to $64 \%$ or more. A similar increase (to values of $9 \%$ to 22\%) is also evident in Zone 2.

Carbon tetrachloride was identified in Zone 2 along a relatively narrow pathway extending to the west and downgradient from the former CCC/USDA facility (Figure 2.11). The observed carbon tetrachloride concentrations ranged from $35 \mu \mathrm{g} / \mathrm{L}$ at the northern edge of the former facility to $11-28 \mu \mathrm{g} / \mathrm{L}$ near the downgradient toe of the distribution. Lower levels of carbon tetrachloride $(1.5-7.8 \mu \mathrm{g} / \mathrm{L})$ were also found in four private wells used for lawn and garden irrigation that are located near the apparent western edge of this distribution. The private lawn and garden wells extend into the deeper groundwater zones but are believed to be continuously gravel packed across Zone 2. Installation of a continuous gravel pack across water- 
bearing zones is not consistent with the Code of Kansas Regulations 28-30 well construction regulations discussed in Section 3.1.3.2.

No carbon tetrachloride was detected in Zone 3 or Zone 4 at monitoring wells completed exclusively in one of these zones. This observation is consistent with the interpretation that Zone 3 and Zone 4 receive little or no natural recharge via vertical infiltration from contaminated Zone 2. Carbon tetrachloride was, however, identified in the four private lawn and garden wells noted above, suggesting that the well gravel packs provide a conduit for contaminant migration to the deeper zones near the western, downgradient toe of the Zone 2 contaminant distribution.

The results of extensive hydraulic characterization studies (slug tests, step-drawdown pumping tests, and constant-rate pump testing) conducted for groundwater-bearing Zone 1 indicate that the production capacity of this unit is restricted by the total effective thickness (1-3 ft) of the few discrete, thin horizons that form the interval; the heterogeneous hydraulic conductivity of the interval (ranging from $0.001 \mathrm{ft} /$ day to $75 \mathrm{ft} /$ day); and the generally limited availability of groundwater in Zone 1 . The contaminated regions of the groundwater-bearing zones can be divided, on the basis of hydraulic conductivity values, into the following subsystems (Figure 2.12):

- Subsystem 1 of Zone 1 , a relatively permeable area $\left(K_{h}=34-75 \mathrm{ft} /\right.$ day $)$.

- Subsystem 2 of Zone 1 , a low-permeability area $\left(K_{h}=1-10 \mathrm{ft} /\right.$ day $)$.

- Subsystem 3 of Zone 1 , an extremely low-permeability area $\left(K_{h}=\right.$ 0.001-1 ft/day).

- The Zone 2 contaminated area $\left(K_{h}=7.9-43 \mathrm{ft} / \mathrm{day}\right)$, illustrated in Figure 2.11.

On the basis of the overall characteristics of the contaminant distribution in groundwater Zone 1, 94\% of the total contaminated area in Zone 1 (including Subsystem 2 and Subsystem 3) is not amenable to extraction or injection technologies that could restore groundwater to carbon tetrachloride concentrations below the MCL and the KDHE Tier 2 standard value of $5.0 \mu \mathrm{g} / \mathrm{L}$.

The results of extensive hydraulic testing conducted for groundwater-bearing Zone 2 indicate that this unit has a greater capacity than Zone 1 for groundwater production, because of 
the relatively greater total thickness (up to $5 \mathrm{ft}$ ) and generally less discrete nature of the Zone 2 water-bearing intervals, as well as the generally higher estimated $K_{h}$ values of Zone 2 (ranging from $7.9 \mathrm{ft} /$ day to $43 \mathrm{ft} /$ day).

\subsubsection{Vapor Intrusion}

On the basis of KDHE (2007) guidance, approximately 60 occupied residences were identified for the consideration of possible VI that might be linked to the carbon tetrachloride contamination identified in groundwater-bearing Zone 1 or in the western, more downgradient portion of Zone 2 (at depths $\leq 40 \mathrm{ft}$ BGL). Comprehensive indoor air testing and periodic air monitoring were conducted in the summer and/or winter at all identified, accessible structures (Figure 2.13).

No risk of upward VI could be demonstrated in association with the localized low residual levels of carbon tetrachloride detected in subsurface soils at the former CCC/USDA facility.

Five homes overlying the documented contamination in groundwater-bearing Zone 1 were identified as impacted by carbon tetrachloride VI at levels greater than the KDHE screening level of $4.06 \mu \mathrm{g} / \mathrm{m}^{3}$ for this contaminant in indoor air. No carbon tetrachloride at concentrations above the KDHE screening level was detected in the indoor air of residences overlying contaminated groundwater in Zone 2. No carbon tetrachloride was detected in indoor air at either the Hanover public school facility or St. John's School, which both lie outside the interpreted limits of the carbon tetrachloride distribution in Zone 1 and Zone 2.

With the approval of the KDHE (2009i, 2010e), the CCC/USDA installed mitigation systems in each of the five homes overlying Zone 1 determined to be impacted by VI (Figure 2.14). Performance testing of the installed systems has demonstrated that they are effectively reducing indoor air contaminant concentrations to acceptable levels. Therefore, no unacceptable health risks are currently associated with human exposure to indoor air contaminated with carbon tetrachloride and chloroform as a result of VI from contaminated groundwater in Zone 1 or Zone 2. 
Radon analyses identified unacceptable levels of radon that exceed the EPA standard (up to 7 times the EPA action level of $4.0 \mathrm{pCi} / \mathrm{L}$ ) in 22 of 25 homes tested for this contaminant, as well as at selected locations in the Hanover public school facility and St. John's School. These observations demonstrate that the upward intrusion of radon to levels associated with unacceptable health risk is a widespread phenomenon in the Hanover community. Radon is a naturally occurring substance that is unrelated to carbon tetrachloride contamination.

Additional information about radon, including options for radon testing and mitigation, is available from the following sources:

- Toll free: 1-866-865-3233 — KDHE Bureau of Environmental Health

- Toll free: 1-800-693-5343 — Kansas Radon Hotline

- URL: http://www.epa.gov/radon/pubs/citguide.html — EPA publication, A Citizen's Guide to Radon: The Guide to Protecting Yourself and Your Family from Radon

- URL: http://www.epa.gov/radon/pdfs/hmbuygud.pdf - EPA publication, Home Buyer's and Seller's Guide to Radon

- URL: http://www.epa.gov/radon/rnxlines.html — EPA web page of radon hotlines and information

\subsection{Evaluation of Current and Future Human and Environmental Exposure Targets and Pathways}

At present, no unacceptable human health or environmental exposure risks are associated with the contamination at the former CCC/USDA facility. Potential future human exposure pathways are related to groundwater. One pathway involves the use of contaminated groundwater for domestic or municipal water supply, while the other involves VI. 


\subsubsection{Water Sources for Hanover}

Since February of 1974, the residents of the city have been served by a public water supply system that obtains water from the Washington County RWD \#1. Prior to February of 1974, the city had its own wells in the Little Blue River valley, on the southwest side of the city, producing water from the alluvial aquifer. These wells have been abandoned. The water from the old city wells had a hardness of 99 grains per gallon (RWD 2009a), which is categorized as “very hard” water (Water Quality Association 2011). The hardness value of 99 grains per gallon is equivalent to a calcium carbonate $\left(\mathrm{CaCO}_{3}\right)$ concentration of $1,698 \mathrm{mg} / \mathrm{L}$. The high concentration of $\mathrm{CaCO}_{3}$ is apparently attributable to carbonate bedrock units underlying the alluvium aquifer. "Very hard" water can cause serious problems, including clogging of the delivery piping system, interference with cleaning tasks, and inefficient and costly operation of and damage to water-using appliances like water heaters, dishwashers, and washing machines.

As indicated in KDHE policy BER-RS-045 (KDHE 2009b), groundwater with concentrations of total dissolved solids (TDS) exceeding 1,200 mg/L is considered non-potable if the constituents are from a natural source. The TDS concentration is the sum of the cation and anion concentrations, including calcium $\left(\mathrm{Ca}^{2+}\right)$, magnesium $\left(\mathrm{Mg}^{2+}\right)$, and carbonate $\left(\mathrm{CO}_{3}{ }^{2-}\right)$, which are naturally abundant in the carbonate bedrock units at Hanover. High-level hardness of water (such as the $\mathrm{CaCO}_{3}$ concentration of 1,698 mg/L in water from the old Hanover wells) can result in a high concentration of TDS that is unacceptable for use as a potable water resource. Policy BER-RS-045 (KDHE 2009b) states that "the palatability of drinking water has been evaluated as poor for TDS levels of 900 to $1,200 \mathrm{mg} / \mathrm{L}$ and unacceptable for levels greater than $1,200 \mathrm{mg} / \mathrm{L} . ”$

In March 2009, the city of Hanover forfeited its water rights (Water Appropriation Program 2009). The water currently provided by RWD \#1 to the city has a hardness of 21 grains per gallon (equivalent to a $\mathrm{CaCO}_{3}$ concentration of $360 \mathrm{mg} / \mathrm{L}$ ), well within the acceptable range.

The Washington County RWD \#1 currently maintains four well fields, located in or near Lanham (4 wells), Washington (2 wells), Marysville (4 wells), and Oketo (4 wells). The Hanover community has received and continues to receive its water supply primarily from the Lanham well field. Before the recent addition of the Oketo well field, located approximately $12 \mathrm{mi}$ northeast of Hanover, in Marshall County, the Lanham well field was used almost exclusively to provide water for Hanover and also RWD customers in eastern Washington County. With the 
addition of the Oketo well field, the RWD has transferred many customers in eastern Washington County from the Lanham well field to the Oketo well field, greatly reducing the demand and strain on the Lanham well field.

The RWD can transfer water from one well field to the other if a problem occurs at any one of the four well fields. The RWD recently completed the connection of a 6-in. pipeline from the Washington well field to Hanover. Previously, Hanover residents could receive water from the Washington well field only through smaller RWD lines that looped to the north of Washington and then back to Hanover. Should the need arise now, the new connection will allow Hanover residents to receive water more rapidly and in greater volume than previously from the Washington well field. This is particularly important in the event of a water emergency, such as a fire, in Hanover.

In the past, trace levels of carbon tetrachloride were detected in groundwater from two of the four wells in the Lanham well field. In early 2011, an elevated nitrate concentration was detected in one of these wells. The RWD has been testing this well regularly since the initial detection. All results have shown nitrate concentrations below $10 \mathrm{mg} / \mathrm{L}$.

During the 2009-2010 site investigation, 25 accessible private wells were identified in and around the city, on the basis of state water well records and information provided by the local community. Except for 5 private water wells installed in the shallow alluvial aquifer in the floodplains along the Little Blue River, far west of Hanover, all of the private wells (including 6 monitoring wells) were constructed to access water in groundwater-bearing Zones 2-4 (Figure 2.15). No private wells were found to be installed in groundwater Zone 1. The A. Bruna well is screened in Zone 2 but is gravel packed across Zones 1 and 2. This well is used for lawn and garden purposes only.

Potential water uses for the local groundwater at Hanover are discussed briefly below in context of the characteristics of the four groundwater zones identified in Argonne's 2009-2010 site investigation, the water yield of these four zones, and the natural water quality of groundwater Zone 1 and Zone 2. 


\subsubsection{Groundwater Zone 1}

Groundwater Zone 1 (Figures 2.6 and 2.7) is the uppermost water-bearing zone in the bedrock sequence at Hanover. Zone 1 consists primarily of two or three discrete, thin, saturated intervals (each typically less than $1 \mathrm{ft}$ thick) within the interbedded limestone and shale (Unit 3). The saturated intervals were found in the upper to middle portion of Unit 3 in the northern part of the former CCC/USDA facility and in the middle to lower portion of Unit 3 near and to the south of the former facility. The combined thickness of the saturated horizons at each investigated location is limited (generally to 1-3 ft) and primarily reflects secondary porosity developed along bedding planes and fractures in the limestone and shale.

The lateral extent of groundwater Zone 1 is bounded by the erosional limits of Unit 3 . Zone 1 is therefore found primarily beneath the upland (Figure 2.6). Groundwater Zone 1, in general, has limited water availability and low, heterogeneous permeability because of its limited areal extent and the nature of the host bedrock formation. No active private (or public) wells are known to be completed in the Zone 1 unit. Water recovery from Zone 1 was extremely slow at many wells tested by Argonne. Near the lateral limits of Unit 3, groundwater accumulation sufficient for water sampling required days after installation of many wells. At the end of the groundwater sampling program for the 2009-2010 investigation (months after installation), six monitoring wells along the northwest, west, and southwest limits of the unit still remained dry. These locations and others with slow recovery were used to estimate boundaries of groundwater Zone 1 to the north, northwest, west, and southwest (Figures 2.9 and 2.10).

Groundwater Zone 1 is under confined to leaky-confined conditions; ${ }^{1}$ water level measurements confirmed that the potentiometric surface (water level) in each well is higher than the vertical position of the saturated intervals that host groundwater at that location. The multiple, thin, saturated bedding planes that form groundwater Zone 1 are confined mainly by the surrounding low-permeability bedrock matrix, with downward vertical leakage possibly occurring along fractures. This relationship is illustrated in Figures 2.6 and 2.7.

The observed groundwater levels in Zone 1 wells are mutually consistent and roughly mimic the local variations in surface topography. These relationships support the interpretation

1 In a confined condition, the rock layers above and below the water-bearing zone (the confining layers) are effectively impermeable to water. In a leaky-confined condition, the rock layers are somewhat less impermeable, and consequently some water can be lost, or gained, through the surrounding confining layers. 
that the multiple discrete moist-wet intervals along the bedding planes in Unit 3 are in hydraulic communication and together represent a single groundwater-bearing unit (Zone 1; Figures 2.6 and 2.7).

\subsubsection{Groundwater Zone 2}

Groundwater Zone 2 consists of relatively thick saturated intervals in the shale with limestone facies (Unit 6), or of thin, moist-wet intervals along bedding planes near the base of the overlying upper red shale (Unit 5). As illustrated in Figures 2.6 and 2.7, Unit 6 changes in facies from evaporitic deposits beneath the upland to shale with limestone along the upland flanks. With this change in facies, groundwater Zone 2 crosses the lithostratigraphic units from the base of Unit 5 (upland) and into Unit 6 (flanks of the upland). Where developed near the base of Unit 5, the combined thickness of the moist-wet bedding planes that host groundwater Zone 2 is limited to $1-2 \mathrm{ft}$. In contrast, where Zone 2 is found within the Unit 6 shale with limestone facies, the total thickness of the saturated intervals ranges from approximately $3 \mathrm{ft}$ to $5 \mathrm{ft}$ (Figures 2.6 and 2.7). At most locations, groundwater Zone 2 occurs at or above an elevation of $1,240 \mathrm{ft}$ AMSL.

The areal extent of groundwater Zone 2 is much broader than that of localized Zone 1. Zone 2 lies approximately $30 \mathrm{ft}$ or more below Zone 1, and hence Zone 2 has been less seriously truncated by the erosional unconformity. Figure 2.11 shows locations where Zone 2 has been penetrated by private wells. The presence of the water-bearing zone in these private wells suggests that Zone 2 extends significantly to the southeast, south, and west of the former CCC/USDA facility.

Groundwater Zone 2 is predominantly under leaky-confined conditions at most locations. The relationships among water levels in wells and the vertical positions of the saturated intervals in Zone 2 are depicted in Figures 2.6 and 2.7.

The mutual consistency of the water levels in Zone 2 monitoring wells indicates that the multiple discrete moist-wet intervals along bedding planes at the base of Unit 5 and the thicker saturated intervals developed in Unit 6 are in hydraulic communication, forming a single Zone 2 groundwater-bearing unit. The potentiometric surface in Zone 2 (beneath the upland area) lies approximately 35-40 ft below the corresponding surface in Zone 1. 


\subsubsection{Groundwater Zones 3 and 4}

Groundwater Zone 3 is hosted by the gray dolomitic shale near the base of Unit 7. The moist-wet intervals within this unit are difficult to identify. The combined thickness of the saturated horizons in Zone 3 is less than $2 \mathrm{ft}$. Zone 3 can be traced laterally in the subsurface at elevations between $1,210 \mathrm{ft}$ and 1,220 ft AMSL. This zone might be penetrated by most of the deep private water wells shown in Figure 2.11. Zone 3 appears to be confined by the massive overlying dolostone. Water recovery in the monitoring wells constructed in Zone 3 is extremely slow. The high variability observed among water levels in the Zone 3 monitoring wells to date suggests that the discrete, thin, saturated bedding planes that form Zone 3 do not communicate fully with each other hydraulically within the surrounding shale matrix (Figures 2.6 and 2.7).

Groundwater Zone 4 is developed at the base of the lower red shale (Unit 8), overlying the lower evaporitic deposit (Unit 9). The multiple thin, moist-wet intervals that form Zone 4 have a total thickness of less than $2 \mathrm{ft}$. These intervals occur at a relatively consistent elevation of 1,180-1,190 ft AMSL (Figures 2.6 and 2.7). Zone 4 lies approximately $30 \mathrm{ft}$ below Zone 3 . The groundwater present in Zone 4 is also under confined conditions, and the water levels measured to date in Zone 4 have been less variable than those in Zone 3.

\subsubsection{Potential Water Yield of Local Groundwater-Bearing Zones}

In the 2009-2010 study, extensive hydraulic testing was performed to support quantitative evaluation of the expected responses of the water-bearing zones to various groundwater restoration technologies. The results of the hydraulic testing were used to estimate the potential water yields of the local groundwater zones.

The production capacity of groundwater Zone 1 is expected to be highly restricted by the effective thickness of the few discrete, thin, moist-wet horizons along bedding planes (1-3 ft total thickness) that form the water-bearing interval, the heterogeneous hydraulic conductivity of the interval, and the generally limited availability of groundwater within Zone 1 . The results from slug, step-drawdown, and short-term constant-rate tests conducted in Zone 1 confirmed its extremely low productivity. Groundwater Zone 1 can be divided into three subsystems (Figure 2.12) characterized by various levels of hydraulic conductivity, from an area of extremely low permeability (Subsystem 3 ) to a relatively permeable area (Subsystem 1 ). The potential water yield is on the order of $10^{-2}$ to $10^{-3} \mathrm{gpm}$ in Subsystem 3 (63\% of groundwater 
Zone 1), < 0.3 gpm in Subsystem 2 (31\% of Zone 1), and < 1 gpm in Subsystem 1 (6\% of Zone 1), respectively (Table 2.1). The long-term sustainable production rate appears to be less than $0.1 \mathrm{gpm}$ in most of groundwater Zone 1. The low water yield in Zone 1 is consistent with the fact that no private wells completed in groundwater Zone 1 were identified. The yield is far below the minimum household water demand of 4-5 gpm defined by the Kansas Geological Survey (Suchy et al. 2011).

Groundwater Zone 2 has a greater capacity for groundwater production than Zone 1, as Zone 2 has relatively greater thickness and generally less discrete water-bearing intervals, as well as consistently higher estimated $K_{h}$ values throughout most of the unit. The results of the 24-hr pumping test conducted in groundwater Zone 2 indicate that the long-term sustainable production rate would be 2 gpm or more, possibly reaching the minimum household water demand. Because of the relative productivity of groundwater Zone 2 in this area, almost all of the private water wells found in the area were installed to intersect the intervals directly in or associated with Zone 2. The unique groundwater geochemistry of Zone 2, however, renders that water unpalatable. Details regarding the natural water quality are discussed in Section 2.3.1.5.

The capacity of Zone 3 and Zone 4 to produce groundwater is extremely limited. The slow recovery of water levels in wells (taking several weeks to months) reflects low water yields from these water-bearing zones. Sustainable yields in Zone 3 and Zone 4 are $10^{-2}$ to $10^{-3}$ gpm or less (values comparable to those for Subsystem 3 in groundwater Zone 1). These yields are far below the minimum household water demand (Suchy et al. 2011).

\subsubsection{Natural Water Quality of Groundwater Zone 1 and Zone 2}

As mentioned in Section 2.3.1.4, the local groundwater at Hanover has poor water quality. To identify and confirm the cause of the poor water quality, groundwater samples were collected for major ion analyses from selected wells representing Zone 1 (MW06 and MW08) and all monitoring wells installed in Zone 2 (MW44Z2, MW45Z2, MW48Z2, MW49Z2, MW50Z2, and MW51Z2). No water samples were collected for Zone 3 and Zone 4 wells, because the extremely low water recovery in those wells indicates inadequate productivity for domestic use. Major cations (metals) were analyzed by EPA Method 6010B. Bicarbonate alkalinity and carbonate alkalinity were analyzed as $\mathrm{CaCO}_{3}$ by EPA Method 2320B. Other major anions were analyzed by EPA Method 300. The analytical results are summarized in Table 2.2. 
In subsurface water-bearing units, the groundwater is electrically neutral (neither positively nor negatively charged). Consequently, the ion balance (a comparison of the sum of positive charges and the sum of negative charges for each sample) was calculated to evaluate the consistency of the analytical data. The ion balance between the sum of positive charges and the sum of negative charges, in milliequivalents per liter (meq/L), was estimated as shown in Table 2.3. Ideally, to reflect the electrically neutral condition in the subsurface, the sum of positive charges should equal the sum of negative charges, and the balance (the difference between the two) should be calculated as $0 \%$. The results in Table 2.3 indicate good ion balance for Zone 2 wells MW49Z2 and MW51Z2 ( $\leq 5 \%)$, a less satisfactory balance for Zone 2 wells MW44Z2 and MW45Z2 (<10\%), and poor balances for Zone 1 wells MW06 and MW08 and Zone 2 wells MW48Z2 and MW50Z2 (> 10\%). The imbalance of major ions (positive charges > negative charges, or cations > anions) for water samples from wells MW06 and MW08 might have been caused by conversion of $\mathrm{CO}_{3}{ }^{2-}$ and $\mathrm{HCO}_{3}{ }^{-}$to volatile $\mathrm{CO}_{2}$ after acidification of the samples in the laboratory. Thus, the analytical results for anions in the samples from Zone 1 wells MW06 and MW08 might underestimate the concentrations of $\mathrm{CO}_{3}{ }^{2-}$ and $\mathrm{HCO}_{3}{ }^{-}$.

To illustrate the overall distinctive water chemistry of groundwater samples from Zone 1 and Zone 2, a piper diagram (Figure 2.16) was constructed for the major cations $\left(\mathrm{Na}^{+}, \mathrm{Ca}^{2+}\right.$, and $\left.\mathrm{Mg}^{2+}\right)$ and anions $\left(\mathrm{Cl}^{-}, \mathrm{SO}_{4}{ }^{2-}\right.$, and $\left.\mathrm{HCO}_{3}{ }^{-}\right)$. The piper diagram indicates that groundwater in Zone 1 is of the $\mathrm{Ca}-\mathrm{Mg}-\mathrm{HCO}_{3}$ type, containing predominately the dissolved minerals calcite $\left(\mathrm{CaCO}_{3}\right)$ and dolomite $\left[\mathrm{CaMg}\left(\mathrm{CO}_{3}\right)_{2}\right]$ (Table 2.3). This interpretation is consistent with the composition of lithostratigraphic Unit 3 (interbedded limestone and shale), which hosts Zone 1. Groundwater in Zone 2 is of a distinctively different type, $\mathrm{CaSO}_{4}$ or Ca-Mg-SO${ }_{4}$, consisting primarily of the dissolved mineral anhydrite $\left(\mathrm{CaSO}_{4}\right)$. As summarized in Section 2.3.1.2, Zone 2 is developed primarily along the base of lithostratigraphic Unit 5 or in Unit 6, which are associated with evaporitic deposits. The distinctive water types for Zone 1 and Zone 2 can be attributed to the natural lithologies of the bedrock units that host Zone 1 and Zone 2.

Total hardness of the groundwater was estimated as the sum of $\mathrm{Ca}^{2+}$ and $\mathrm{Mg}^{2+}$, which can be precipitated from water as solid particles, expressed as $\mathrm{CaCO}_{3}$ in $\mathrm{mg} / \mathrm{L}$ (Table 2.3). Water from Zone 2 falls in the "very hard” category (Water Quality Association 2011), with a hardness of 692-2,255 mg/L $\left(\mathrm{CaCO}_{3}\right)$. The hardness value (99 grains per gallon or 1,698 mg/L; RWD 2009a) reported for the old city wells also falls within this range. In contrast, the Zone 1 water has relatively low hardness (350-435 mg/L). 
On the basis of major ion concentrations in water, TDS values were calculated by (1) summing the concentrations (mg/L) of major ions including $\mathrm{Na}^{+}, \mathrm{Ca}^{2+}, \mathrm{Mg}^{2+}, \mathrm{Cl}^{-}$, and $\mathrm{SO}_{4}{ }^{2-}$ and (2) adding the quantity of $\mathrm{HCO}_{3}{ }^{-}$and $\mathrm{CO}_{3}{ }^{2-}$ that would be precipitated as calcite and dolomite if the milliequivalents of $\mathrm{Ca}^{2+}$ plus $\mathrm{Mg}^{2+}$ exceeded the milliequivalents of $\mathrm{SO}_{4}{ }^{2-}$. The calculated TDS values for the water samples are in Table 2.3. The results indicate that groundwater in Zone 2 has a very high concentration of TDS, ranging from $928 \mathrm{mg} / \mathrm{L}$ to $3,101 \mathrm{mg} / \mathrm{L}$. The palatability of groundwater is "unacceptable" for potable use at most of the Zone 2 wells, specifically at wells MW44Z2 and MW48Z2-MW51Z2 (1,493 mg/L to $3,101 \mathrm{mg} / \mathrm{L}$, exceeding the level of $1,200 \mathrm{mg} / \mathrm{L}$ specified in policy BER-RS-045), and is considered "poor" at MW45Z2, as also specified in policy BER-RS-045 (KDHE 2009b). The major source of TDS in Zone 2 is the natural mineral anhydrite, which is dissolved in water as $\mathrm{Ca}^{2+}, \mathrm{Mg}^{2+}$ and $\mathrm{SO}_{4}{ }^{2-}$. The calculated TDS values for water in Zone 1 are relatively low, in the range of 494-745 mg/L (Table 2.3). However, the ion balance test suggests that the results for Zone 1 water might underestimate the quantity of $\mathrm{HCO}_{3}{ }^{-}$and $\mathrm{CO}_{3}{ }^{2-}$, and thus the TDS and the hardness.

\subsubsection{Potential Beneficial Use of Local Groundwater}

As outlined in policy BER-RS-045 (KDHE 2009b), "groundwater cleanup levels shall be based on the most beneficial use of the groundwater considering present and proposed future uses." The default assumption is that the most beneficial use of groundwater is for a potable water source. Kansas Administrative Regulation, K.A.R. 28-16-28b (uu) defines "Potable Water" to mean water that is suitable for drinking and cooking purposes in terms of human health and aesthetic considerations. The default potable designation results in drinking water MCLs as the default groundwater cleanup levels. However, per KDHE guidance, the KDHE can agree to an alternate cleanup level if groundwater at a property is considered non-potable because of poor natural groundwater quality and/or limited yield. Potential uses of groundwater from Zones 1-4 can be evaluated on the basis of water productivity and quality criteria, as described above. The potential uses are summarized as follows:

- No groundwater from Zones 1-4 at Hanover is presently used as a potable water source.

- Groundwater from Zone 1, Zone 3, and Zone 4 can be considered as nonpotable water because of the limited yields of these zones. The results of the 
2009-2010 study indicate that long-term sustainable production for most of Zone 1, Zone 3, and Zone 4 is less than 0.1 gpm. Groundwater-bearing zones producing in such low quantities cannot provide adequate supply for potable use (Suchy et al. 2011).

- Groundwater in Zone 2 cannot be considered potable water because of its poor natural water quality, even though the anticipated yield for Zone 2 is adequate. On the basis of analytical results for water geochemistry, the level of TDS in Zone 2 water at all but one of the sampled locations approaches or exceeds the acceptable level of 1,200 mg/L under policy BER-RS-045 (KDHE 2009b). Consequently, the palatability of Zone 2 water is unacceptable as a potable water source. The major source of TDS in Zone 2 is the natural mineral anhydrite, which is dissolved in water as $\mathrm{Ca}^{2+}, \mathrm{Mg}^{2+}$ and $\mathrm{SO}_{4}{ }^{2-}$.

- Groundwater in Zone 3 and Zone 4 may also not be potable because of poor natural water quality. Zone 3 groundwater is hosted by a dolomitic shale, a sedimentary carbonate rock composed of calcium magnesium carbonate, which is also likely to be a major TDS source in Zone 3. Zone 4 is also likely to have poor natural water quality, since groundwater is hosted in a gypsum formation, much like Zone 2.

As a result, for Zones 1-4 at Hanover, either poor yield or poor water quality indicates that the most beneficial use of the groundwater is not as a potable water source.

\subsubsection{Groundwater Migration Pathways}

The geologic, hydrogeologic, groundwater monitoring, geochemical, and contaminant distribution data presented previously (Argonne 2011) and discussed in this CAS provide the technical basis for development of an integrated conceptual model of groundwater flow and contaminant migration within the Hanover hydrogeologic system. The key elements of this working conceptual model are summarized as follows:

- Vertical infiltration in the identified contaminant source area (migration pathway 1). Vertical infiltration of carbon tetrachloride through the vadose 
zone (including the unconsolidated and bedrock lithostratigraphic Units 1, 2, and 3 [upper portion]) has occurred primarily along the north-south central axis of the former CCC/USDA facility, as shown in Figures 2.9 and 2.10. Little residual carbon tetrachloride contamination $(\leq 35 \mu \mathrm{g} / \mathrm{kg}$, a value less than the KDHE Tier 2 screening level of $73.4 \mu \mathrm{g} / \mathrm{kg}$ that designates a continuing groundwater contamination source) currently remains in the vadose zone soils (Figure 2.8), providing an insignificant current and future source to groundwater.

- Lateral migration in Zone 1 (migration pathway 2). Contaminants emanating from the source area outlined above would have entered the Zone 1 groundwater-bearing unit primarily on the western to southwestern side of the prominent groundwater divide beneath the upland area at the former CCC/USDA facility (Figure 2.17), preventing contaminant migration in the groundwater to the east of this area. Groundwater flow and contaminant migration within Zone 1 occurred preferentially to the southwest and northwest, along trends of relatively more permeable materials identified within the Zone 1 unit. Migration in other directions within Zone 1 is predicted to occur more slowly, because of the very low $K_{h}$ values identified in the areas away from these preferred pathways.

- Vertical migration from Zone 1 to Zone 2 (migration pathway 3). Vertical migration of contaminants from Zone 1 to Zone 2 is inferred primarily beneath the original vadose zone source area, where the highest Zone 1 hydraulic conductivities were identified (Figure 2.10) and where groundwater mounding is observed in Zone 2. The concentrations of carbon tetrachloride presently identified in Zone 2 (Figure 2.11) are lower than those in Zone 1 (Figure 2.9) by at least one order of magnitude, indicating that approximately $10 \%$ or less of the groundwater flow within Zone 2 might have originated as vertical recharge from Zone 1. This apparent mixing ratio is empirically consistent with the variations in nitrate concentrations that were also observed in the upland area between Zone 1 and Zone 2.

- Lateral migration in Zone 2 (migration pathway 4). Groundwater monitoring indicates that migration of carbon tetrachloride contamination within Zone 2 
from the inferred source area has been primarily toward the west, in keeping with the identified patterns of groundwater flow in this unit (Figure 2.18).

- Vertical migration to Zone 3 or Zone 4. No evidence is available to suggest that further vertical migration of contaminants from Zone 2 to Zone 3 or Zone 4 has occurred in the upland source area at the former CCC/USDA facility. An upward hydraulic gradient from Zone 4 to Zone 2 (and Zone 3) is presently indicated in this area, representing an apparent hydraulic barrier to further vertical downward migration.

In addition to the above-noted migration pathways, however, the present data suggest that localized contamination of the Zone 3 and Zone 4 groundwater might be possible in the western portions of these units, as a result of potential migration from overlying Zone 2 via artificial conduits provided by several continuously gravel-packed private lawn and garden wells to the west (Figure 2.4). As a result, these gravel-packed private wells have been integrated into the discussion of the water-supply-related exposure pathways in Section 2.3.3 and into the remedial alternatives discussed in Sections 5, 6, and 7.

\subsubsection{Water-Supply-Related Exposure Pathways}

The levels of carbon tetrachloride contamination detected in groundwater on and near the former CCC/USDA property (Figures 2.9 and 2.11) exceed the MCL for carbon tetrachloride. No active private (or public) wells are known to be present within the area of Zone 1 contamination or to be completed in this unit. Four identified private wells penetrate the contaminated portion of Zone 2; these are used only for lawn and garden purposes. No complete exposure pathways are known to exist from contaminated groundwater to human or environmental receptors, given the availability of the RWD connection; the unacceptable natural quality of groundwater in Zone 2 and the inadequate production of Zone 1, Zone 3, and Zone 4; the identified limited extent of the contaminated groundwater; and the absence of known drinking water supply wells that intercept the contamination associated with the former CCC/USDA facility. 


\subsubsection{Soil Exposure Pathway}

Soils at Hanover were sampled extensively to evaluate the former CCC/USDA facility as a source of the carbon tetrachloride contamination. The 2009-2010 studies included vertical soil profiling for VOCs analyses at 38 locations in and near the former CCC/USDA facility. Carbon tetrachloride was detected in soils at only 8 locations, at maximum concentrations up to $35 \mu \mathrm{g} / \mathrm{kg}$ (Figure 2.8). The depths to the residual contamination in the vadose zone soils ranged from $14 \mathrm{ft}$ to $33 \mathrm{ft} \mathrm{BGL}$; however, the identified concentrations of carbon tetrachloride were well below the KDHE (2010f) target value for soils $(73.4 \mu \mathrm{g} / \mathrm{kg})$. Therefore, no areas were identified as continuing soil sources of contamination to groundwater, or as posing a risk via direct exposure or VI in association with the identified soil contamination at the former CCC/USDA facility.

\subsubsection{Vapor Intrusion Exposure Pathway}

A complete VI pathway requires the movement of contaminant vapors (originating from a subsurface soil or groundwater source), (1) via soil gas within the unsaturated pore space of the vadose zone soil column and (2) from the soils through the foundation and into the interior air space of a residence or other inhabited structure. To demonstrate the presence of a complete VI migration pathway, the coincident occurrence of contaminant vapors both immediately outside (in soil gas surrounding the building footprint, in "sub-slab" vapor directly beneath the building foundation, or in both) and inside a target building must ideally be demonstrated.

To identify areas potentially susceptible to VI, the distributions and concentrations of carbon tetrachloride in the vadose zone soils and groundwater were screened on the basis of KDHE (2007) guidance regarding VI. The maximum carbon tetrachloride concentration detected in soils was $35 \mu \mathrm{g} / \mathrm{kg}$, significantly below the KDHE screening value of $73.4 \mu \mathrm{g} / \mathrm{kg}$; consequently, soils are eliminated as a source of concern for VI. For groundwater, areas within a lateral distance of $100 \mathrm{ft}$ and a vertical distance of $40 \mathrm{ft}$ from identified carbon tetrachloride contamination concentrations above $5.0 \mu \mathrm{g} / \mathrm{L}$ are potential areas of concern for VI (KDHE 2007). The depths to groundwater in Zone 1 and portions of Zone 2 are less than $40 \mathrm{ft}$, and multiple buildings are within $100 \mathrm{ft}$ laterally of the extent of the impacted groundwater, as illustrated in Figure 2.19. All buildings of concern under the KDHE (2007) guidance were assessed. Even though they lie outside the interpreted limits of the carbon tetrachloride distributions in groundwater Zone 1 and Zone 2, the Hanover public school facilities and St. Johns School were also evaluated, at the request of the community. This testing was 
recommended in Addendum 4 to the Supplemental VI Work Plan (Argonne 2008b) and was approved by the KDHE (2010b).

The VI investigation approach involved the collection, on-site screening, and off-site analysis of ambient air, sub-slab soil vapor, and indoor air samples. The results confirmed that a complete exposure pathway for carbon tetrachloride VI existed, whereby five residences had indoor air concentrations of carbon tetrachloride in excess of the KDHE (2010f) screening value of $4.06 \mu \mathrm{g} / \mathrm{m}^{3}$. The unacceptable indoor air concentrations are being addressed by the operation of mitigation systems installed by CCC/USDA in each of the affected residences, with the approval of the KDHE (2009i, 2010e).

\subsubsection{Groundwater Seepage to Surface Water Exposure Pathway}

The occurrence of Zone 1 is spatially limited to the area beneath the upland portion of the Hanover site. The lithostratigraphic unit that hosts Zone 1 is completely eroded at elevations below approximately 1,280 ft AMSL and hence is absent along the flanks of the upland area, as illustrated in Figures 2.6, 2.9, and 2.10. Field reconnaissance along the projected limits of the Zone 1 unit revealed no springs or seepage to suggest direct drainage from Zone 1 to the surface. The pathway for indirect exposure to contaminated groundwater via surface discharge from Zone 1 is therefore incomplete.

Zone 2 is more widely distributed than Zone 1 beneath the Hanover site. The estimated limit of Zone 2 along the identified contaminant migration pathways is shown in Figure 2.11. Detailed field reconnaissance in the projected area of Zone 2 groundwater migration and potential surface discharge west of monitoring wells MW44Z2 and MW45Z2 (Figure 2.11) identified no springs or seepage. The pathway for indirect exposure to contaminated groundwater via surface discharge from Zone 2 is therefore also incomplete.

The results indicate that no unacceptable health risks are associated with indirect human exposure to the contaminated groundwater in Zone 1 and Zone 2, via possible discharge of the groundwater to surface waters at Hanover. 


\subsubsection{Summary}

At present, no unacceptable human health or environmental exposure risks are associated with the contamination at the former CCC/USDA facility. The potential future water resources and exposure pathways are evaluated and summarized as follows:

- $\quad$ Residences of the city have been served since February 1974 by a public water supply system that obtains water from RWD \#1.

- Groundwater in all water-bearing zones (Zones 1-4) identified at Hanover is not considered a potable water source because of its extremely limited yield $(<0.1$ gpm in Zone 1, Zone 3, and Zone 4) or its poor natural water quality (TDS $>$ $1,200 \mathrm{mg} / \mathrm{L}$ in Zone 2).

- No complete pathways are known to exist from contaminated groundwater to human or environmental receptors, given the availability of the RWD connection; the unacceptable natural quality of groundwater in Zone 2 and the inadequate production of Zones 1, 3, and 4; the identified limited extent of the contaminated groundwater; and the absence of known drinking water supply wells that intercept the contamination associated with the former CCC/USDA facility.

- No continuing soil source of contamination was identified that could adequately support contaminant pathways to groundwater or could pose a risk via direct exposure or VI in association with the identified soil contamination at the former CCC/USDA facility.

- The results of the 2009-2010 investigation confirmed that a complete exposure pathway for carbon tetrachloride VI existed in five residences that had indoor air concentrations of carbon tetrachloride in excess of the KDHE (2010f) screening value of $4.06 \mu \mathrm{g} / \mathrm{m}^{3}$. The unacceptable indoor air concentrations are being addressed by the ongoing operation of mitigation systems installed by CCC/USDA in each of the affected residences.

- The pathway for indirect exposure to contaminated groundwater via surface discharge from Zone 1 and Zone 2 is incomplete. No unacceptable health risks are 
associated with indirect human exposure to the contaminated groundwater in Zone 1 and Zone 2, via possible discharge of the groundwater to surface waters at Hanover. 
TABLE 2.1 Three subsystems of carbon tetrachloride contamination in groundwater Zone 1, with hydrogeologic characteristics and the feasibility of treatment technologies.

\begin{tabular}{|c|c|c|c|c|c|c|c|c|}
\hline Subsystem & $\begin{array}{l}\text { Area } \\
\left(\mathrm{ft}^{2}\right)\end{array}$ & $\begin{array}{c}\text { Percent } \\
\text { of Total } \\
\text { Contaminated } \\
\text { Area }\end{array}$ & $\begin{array}{c}\text { Typical Carbon } \\
\text { Tetrachloride } \\
\text { Concentrations } \\
(\mu \mathrm{g} / \mathrm{L})\end{array}$ & $\begin{array}{l}\text { Average } K_{h} \\
\text { from } \\
\text { Slug Tests } \\
\text { (ft/day) }\end{array}$ & $\begin{array}{l}\text { K from } \\
\text { Pumping } \\
\text { Test } \\
\text { (ft/day) }\end{array}$ & $\begin{array}{l}\text { Sustainable } \\
\text { Pumping } \\
\text { Rate } \\
\text { (gpm) }\end{array}$ & $\begin{array}{l}\text { Radius of } \\
\text { Influence } \\
\quad(\mathrm{ft})\end{array}$ & $\begin{array}{c}\text { Extraction, Injection, or Containment } \\
\text { Technology }\end{array}$ \\
\hline 1 & 52,970 & 6 & $>500$ & $53-75$ & $34-64$ & $<1$ & $\sim 106$ & $\begin{array}{l}\text { Conventional technology is not feasible. } \\
\text { Potential logistic barriers need to be } \\
\text { identified and addressed for } \\
\text { horizontal technology. }\end{array}$ \\
\hline 2 & 273,200 & 31 & $100-500$ & $>1$ & - & $<0.3$ & $\begin{array}{l}<124 \text { to } \\
229\end{array}$ & $\begin{array}{l}\text { Technically and logistically impractical } \\
\text { to implement any available extraction } \\
\text { technology. Aquifer characteristics } \\
\text { make contaminant containment a } \\
\text { possibility. }\end{array}$ \\
\hline 3 & 557,570 & 63 & $\begin{array}{l}100-500(30 \%) \\
5-100(70 \%)\end{array}$ & $10^{-2}$ to $10^{-3}$ & - & $\begin{array}{l}10^{-2} \text { to } 10^{-3} \\
\text { or less }\end{array}$ & - & $\begin{array}{l}\text { Technically and logistically impractical } \\
\text { to implement any available extraction } \\
\text { technology. Aquifer characteristics } \\
\text { make contaminant containment a } \\
\text { possibility. }\end{array}$ \\
\hline
\end{tabular}


TABLE 2.2 Analytical results for water quality sampling (inorganic anions and cations) in March and May 2011. ${ }^{\mathrm{a}}$

\begin{tabular}{|c|c|c|c|c|c|c|c|c|c|c|c|c|}
\hline \multirow[b]{2}{*}{ Location } & \multirow[b]{2}{*}{ Sample } & \multirow[b]{2}{*}{$\begin{array}{l}\text { Sample } \\
\text { Date }\end{array}$} & \multirow[b]{2}{*}{$\begin{array}{l}\text { Sample } \\
\text { Depth } \\
\text { (ft BGL) }\end{array}$} & \multicolumn{9}{|c|}{ Concentration $(\mathrm{mg} / \mathrm{L})$} \\
\hline & & & & $\begin{array}{l}\text { Bicarbonate } \\
\text { Alkalinity } \\
\text { as } \mathrm{CaCO}_{3}\end{array}$ & $\begin{array}{l}\text { Carbonate } \\
\text { Alkalinity } \\
\text { as } \mathrm{CaCO}_{3}\end{array}$ & Aluminum & Bromide & Calcium & Chloride & Iron & Magnesium & Magnesium \\
\hline MW06 & HAMW06-W-30345 & 15Mar11 & $24-29$ & 380 & $<5$ & $<0.2$ & 0.33 & 81 & 19 & $<0.2$ & 36 & $<0.015\left(0.0032 \mathrm{~J}^{\mathrm{b}}\right)$ \\
\hline MW08 & HAMW08-W-30346 & 15Mar11 & $30-35$ & 410 & $<5$ & $<0.2$ & 0.5 & 97 & 31 & $<0.2$ & 47 & 0.22 \\
\hline MW44Z2 & HAMW44Z2-W-30347 & 15Mar11 & $30-40$ & 330 & $<5$ & $<0.2$ & 0.57 & 300 & 51 & $<0.2(0.031 \mathrm{~J})$ & 74 & $<0.015(0.014 \mathrm{~J})$ \\
\hline MW45Z2 & HAMW45Z2-W-30349 & 06May11 & $20-30$ & 320 & $<5$ & $<0.2$ & 0.27 & 170 & 23 & $<0.2$ & 68 & $<0.015(0.0045 \mathrm{~J})$ \\
\hline MW48Z2 & HAMW48Z2-W-30350 & 06May11 & $49-59$ & 330 & $<5$ & $<0.2$ & 0.7 & 180 & 78 & $<0.2$ & 59 & 0.19 \\
\hline MW49Z2 & HAMW49Z2-W-30351 & 06May11 & $55-65$ & 240 & $<5$ & $<0.2$ & $<0.2$ & 540 & 76 & $<0.2$ & 170 & 1.1 \\
\hline MW50Z2 & HAMW50Z2-W-30352 & 06May11 & $55-65$ & 350 & $<5$ & $<0.2$ & $<0.2$ & 170 & 600 & $<0.2$ & 97 & $<0.015(0.0068 \mathrm{~J})$ \\
\hline \multirow[t]{3}{*}{ MW51Z2 } & HAMW51Z2-W-30348 & 15Mar11 & $56-66$ & 280 & $<5$ & $<0.2$ & 1.7 & 640 & 120 & $<0.2(0.04 \mathrm{~J})$ & 160 & 0.1 \\
\hline & & & & \multicolumn{9}{|c|}{ Concentration $(\mathrm{mg} / \mathrm{L})$} \\
\hline & & & & Nitrate as $\mathrm{N}$ & Nitrite as $\mathrm{N}$ & $\begin{array}{c}\text { Orthophosphate } \\
\text { as P }\end{array}$ & Potassium & Phosphorus & Silicon & Sodium & Sulfate & Zinc \\
\hline MW06 & HAMW06-W-30345 & 15Mar11 & $24-29$ & 8.2 & $<0.10$ & $<0.2$ & 4.5 & $<0.25(0.058 \mathrm{~J})$ & 9.8 & 93 & 85 & $<0.020(0.0091 \mathrm{~J})$ \\
\hline MW08 & HAMW08-W-30346 & 15Mar11 & $30-35$ & 1.2 & $<0.10$ & $<0.2$ & 5.7 & $<0.25(0.011 \mathrm{~J})$ & 8.8 & 85 & 59 & $<0.02$ \\
\hline MW44Z2 & HAMW44Z2-W-30347 & 15Mar11 & $30-40$ & 3 & $<0.10$ & $<0.2$ & 3.1 & $<0.25(0.0054 \mathrm{~J})$ & 6.5 & 55 & 980 & $<0.020(0.0093 \mathrm{~J})$ \\
\hline MW45Z2 & HAMW45Z2-W-30349 & 06May11 & $20-30$ & 6.6 & $<1$ & $<0.2$ & 2.7 & $<0.25(0.018 \mathrm{~J})$ & 6.9 & 20 & 310 & $<0.020(0.0047 \mathrm{~J})$ \\
\hline MW48Z2 & HAMW48Z2-W-30350 & 06May11 & $49-59$ & 1.3 & $<1$ & $<0.2$ & 5.2 & $<0.25(0.016 \mathrm{~J})$ & 6.5 & 48 & 870 & $<0.020(0.016 \mathrm{~J})$ \\
\hline MW49Z2 & HAMW49Z2-W-30351 & 06May11 & $55-65$ & 0.31 & $<1$ & $<0.2$ & 8.6 & $<0.25(0.0093 \mathrm{~J})$ & 6.3 & 89 & 1800 & $<0.020(0.011 \mathrm{~J})$ \\
\hline MW50Z2 & HAMW50Z2-W-30352 & 06May11 & $55-65$ & 37 & $<1$ & $<0.2$ & 2.9 & $<0.25(0.011 \mathrm{~J})$ & 6.3 & 97 & 820 & $<0.020(0.0052 \mathrm{~J})$ \\
\hline MW51Z2 & HAMW51Z2-W-30348 & 15Mar11 & $56-66$ & $<0.1$ & $<2$ & $<0.2$ & 13 & $<0.25(0.015 \mathrm{~J})$ & 9.3 & 77 & 1800 & 0.03 \\
\hline
\end{tabular}

a Analysis was at TestAmerica Laboratories, Inc., University Park, Illinois, in sample delivery groups SDG 500-31800-1 and SDG 500-31800-2.

b Qualifier J indicates an estimated concentration below the indicated analysis quantitation limit. 
TABLE 2.3 Estimated geochemical properties of groundwater samples collected from groundwater Zone 1 and Zone 2.

\begin{tabular}{|c|c|c|c|c|c|c|c|c|}
\hline Location & $\begin{array}{l}\text { Groundwater } \\
\text { Zone }\end{array}$ & $\begin{array}{c}\text { Calculated Total } \\
\text { Hardness (as } \\
\left.\mathrm{CaCO}_{3}, \mathrm{mg} / \mathrm{L}\right)\end{array}$ & $\begin{array}{l}\text { Calculated } \\
\text { TDS (mg/L) }\end{array}$ & $\begin{array}{l}\text { Sum of } \\
\text { Anions } \\
\text { (meq/L) }\end{array}$ & $\begin{array}{l}\text { Sum of } \\
\text { Cations } \\
\text { (meq/L) }\end{array}$ & $\begin{array}{c}\text { Ion } \\
\text { Balance } \\
(\%)\end{array}$ & Water Type & $\begin{array}{c}\text { Predominant Dissolved } \\
\text { Minerals }\end{array}$ \\
\hline MW06 & Zone 1 & 350 & 494 & 8.7 & 11.3 & 13 & $\mathrm{Ca}-\mathrm{Mg}-\mathrm{HCO}_{3}$ & $\begin{array}{c}\text { Calcite, } \mathrm{CaCO}_{3} \\
\text { Dolomite, } \mathrm{CaMg}\left(\mathrm{CO}_{3}\right)_{2}\end{array}$ \\
\hline MW08 & Zone 1 & 435 & 745 & 8.8 & 12.7 & 18 & $\mathrm{Ca}-\mathrm{Mg}-\mathrm{HCO}_{3}$ & $\begin{array}{c}\left.\text { Calcite, } \mathrm{CaCO}_{3}\right) \\
\text { Dolomite, } \mathrm{CaMg}\left(\mathrm{CO}_{3}\right)_{2}\end{array}$ \\
\hline MW44Z2 & Zone 2 & 1,053 & 1,493 & 27.3 & 23.6 & -7.3 & $\mathrm{Ca}-\mathrm{SO}_{4}$ & Anhydrite, $\mathrm{CaSO}_{4}$ \\
\hline MW45Z2 & Zone 2 & 704 & 928 & 12.5 & 15.1 & 10 & $\mathrm{Ca}-\mathrm{Mg}-\mathrm{SO}_{4}-\mathrm{HCO}_{3}$ & $\begin{array}{c}\text { Anhydrite, } \mathrm{CaSO}_{4} \\
\text { Dolomite, } \mathrm{CaMg}\left(\mathrm{CO}_{3}\right)_{2}\end{array}$ \\
\hline MW48Z2 & Zone 2 & 692 & 1,249 & 25.8 & 16.1 & -23 & Ca-Mg-SO 4 & Anhydrite, $\mathrm{CaSO}_{4}$ \\
\hline MW49Z2 & Zone 2 & 2,047 & 2,795 & 43.6 & 45.1 & 2 & $\mathrm{Ca}-\mathrm{Mg}-\mathrm{SO}_{4}$ & Anhydrite, $\mathrm{CaSO}_{4}$ \\
\hline MW50Z2 & Zone 2 & 823 & 1,830 & 40.3 & 20.8 & -32 & $\mathrm{Ca}-\mathrm{Mg}-\mathrm{SO}_{4}-\mathrm{Cl}$ & Anhydrite, $\mathrm{CaSO}_{4}$ \\
\hline MW51Z2 & Zone 2 & 2,255 & 3,101 & 45.5 & 48.9 & 3.6 & $\mathrm{Ca}-\mathrm{SO}_{4}$ & Anhydrite, $\mathrm{CaSO}_{4}$ \\
\hline
\end{tabular}




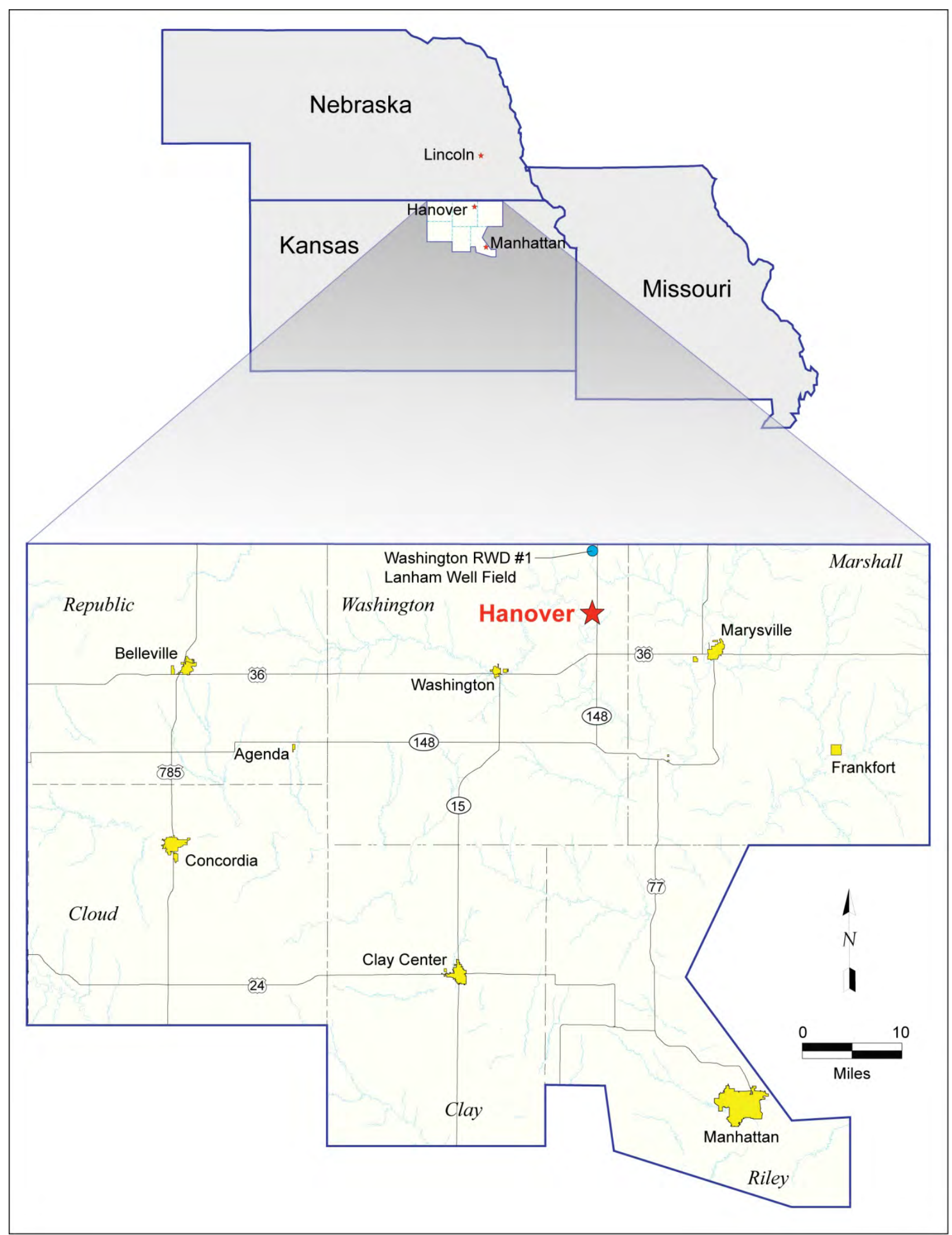

FIGURE 2.1 Location of Hanover, Kansas, and the public water well field of Washington County RWD\#1 for the Hanover public water supply. 


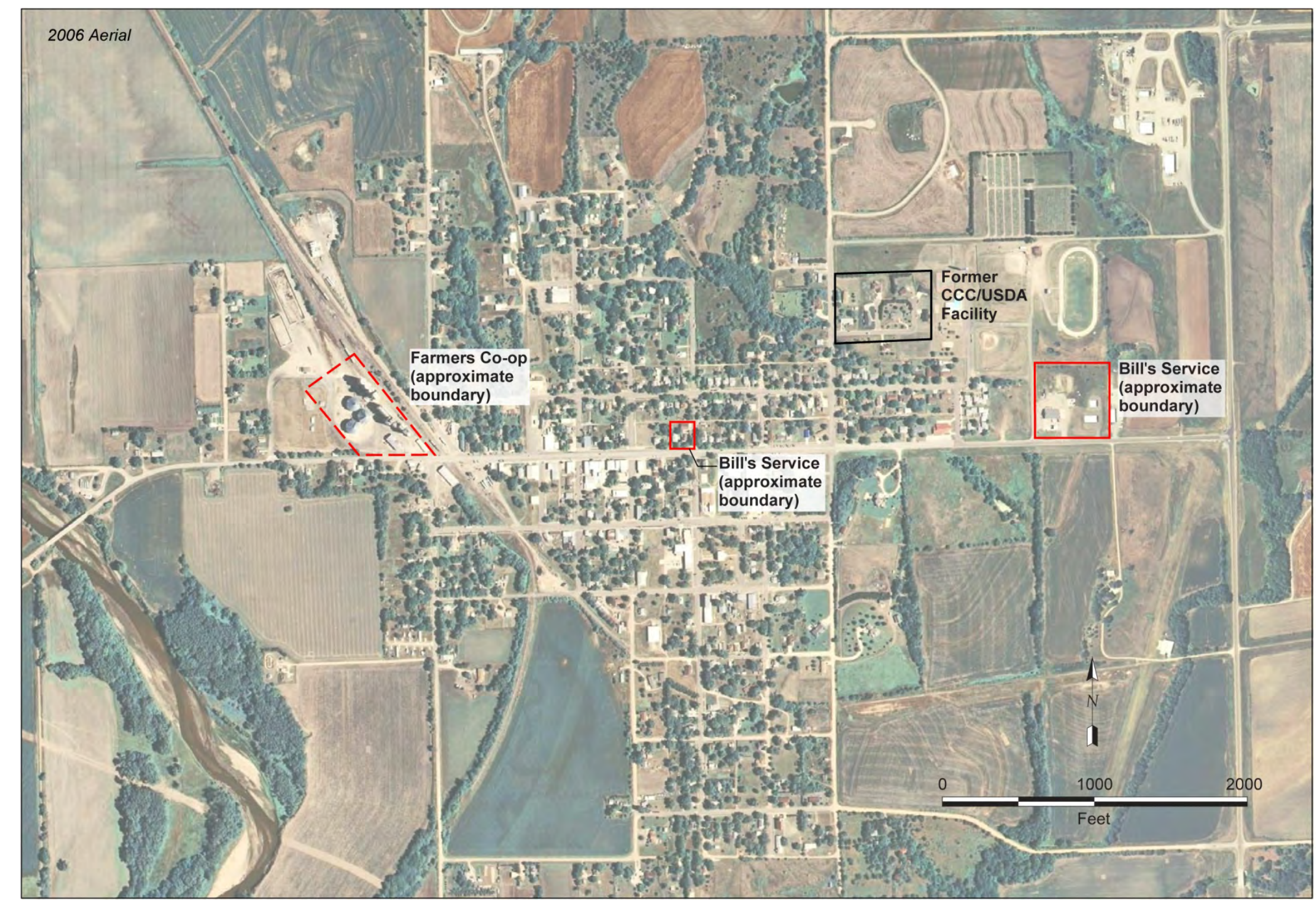



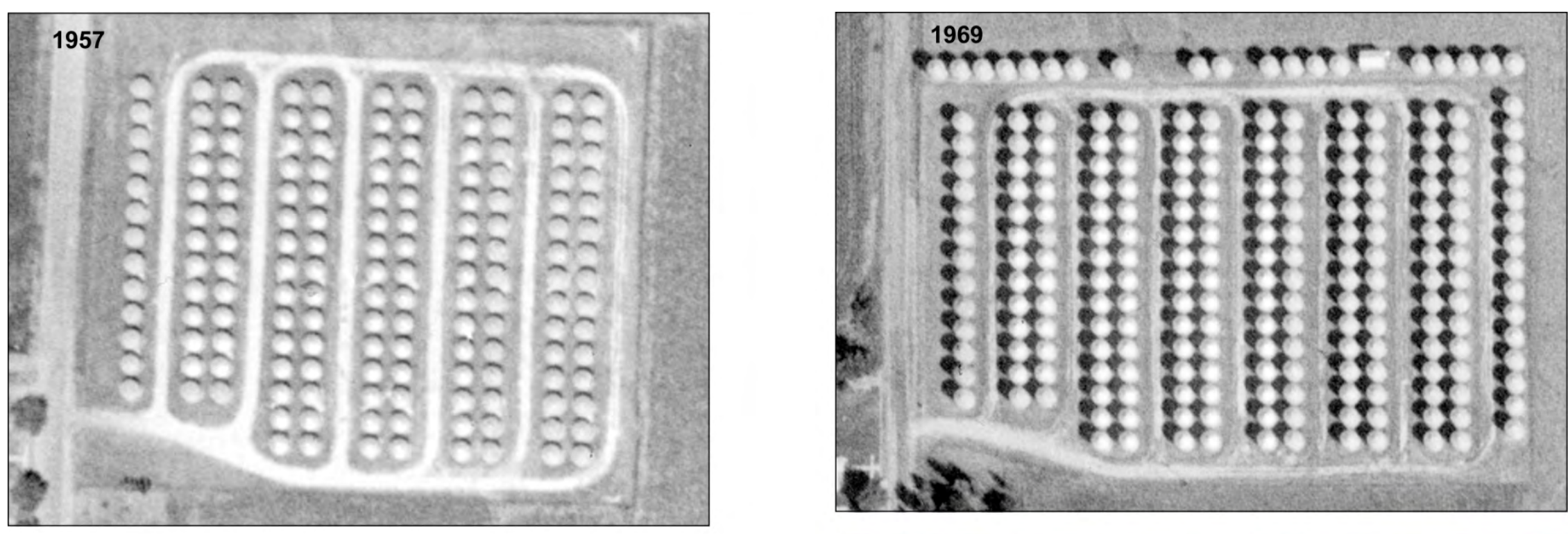

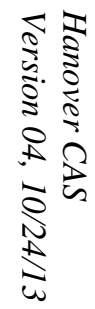
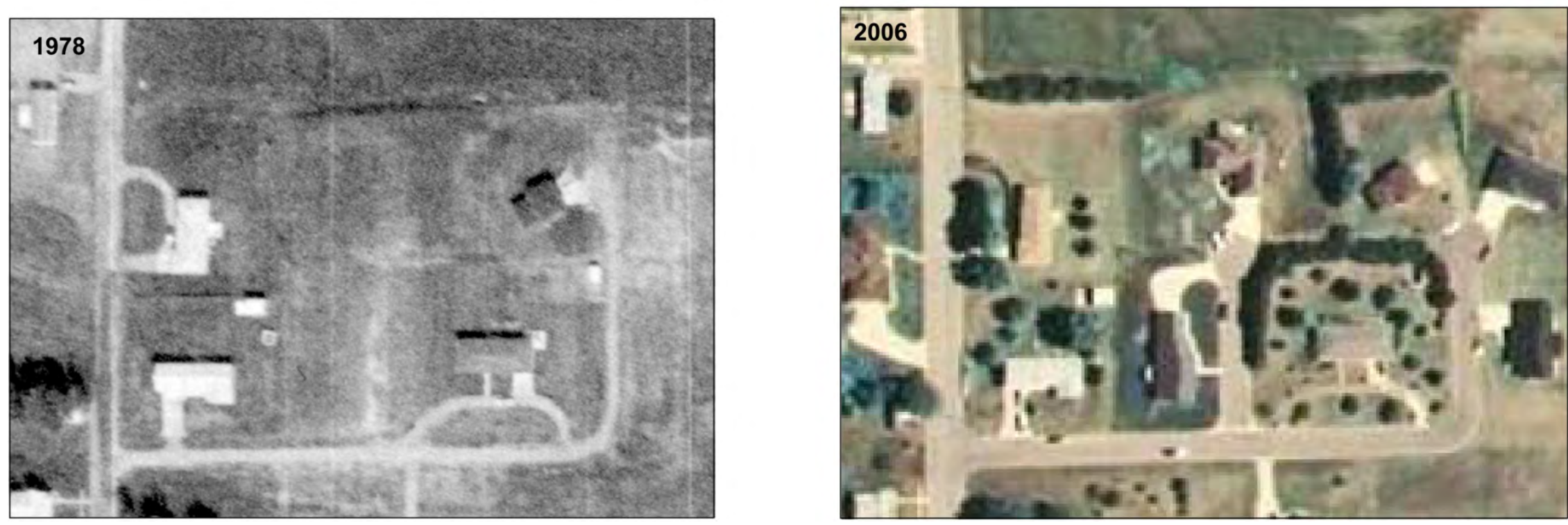

FIGURE 2.3 Historical aerial photographs of the former CCC/USDA grain storage facility at Hanover taken in 1957, 1969, 1978, and 2006. Sources of photographs: USDA (1957, 1969, 1978); NAIP (2006). 


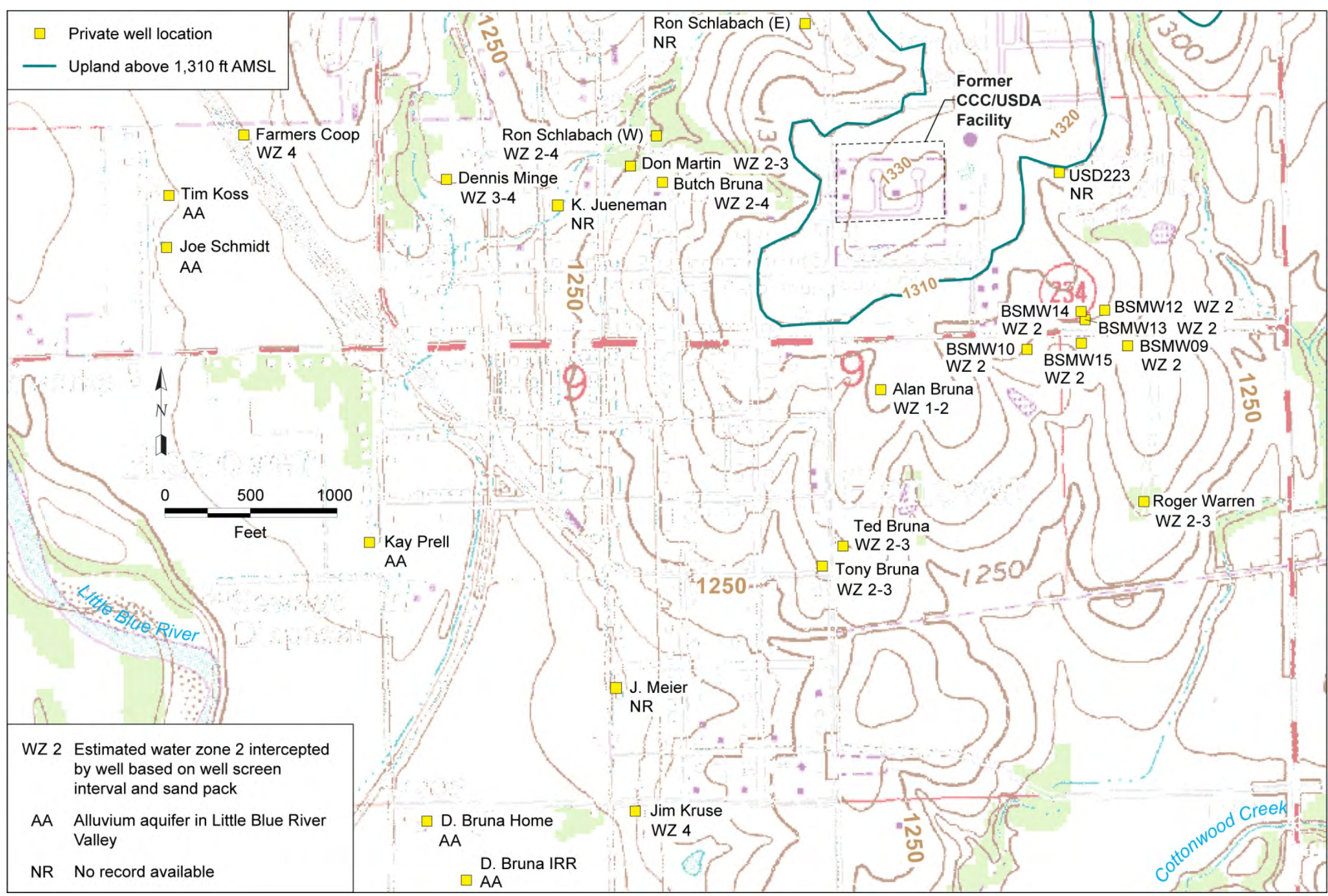

FIGURE 2.4 Surface topography in the Hanover area, the location of the former CCC/USDA facility, and water-bearing zones intercepted by private wells. Source of map: USGS (1997). 

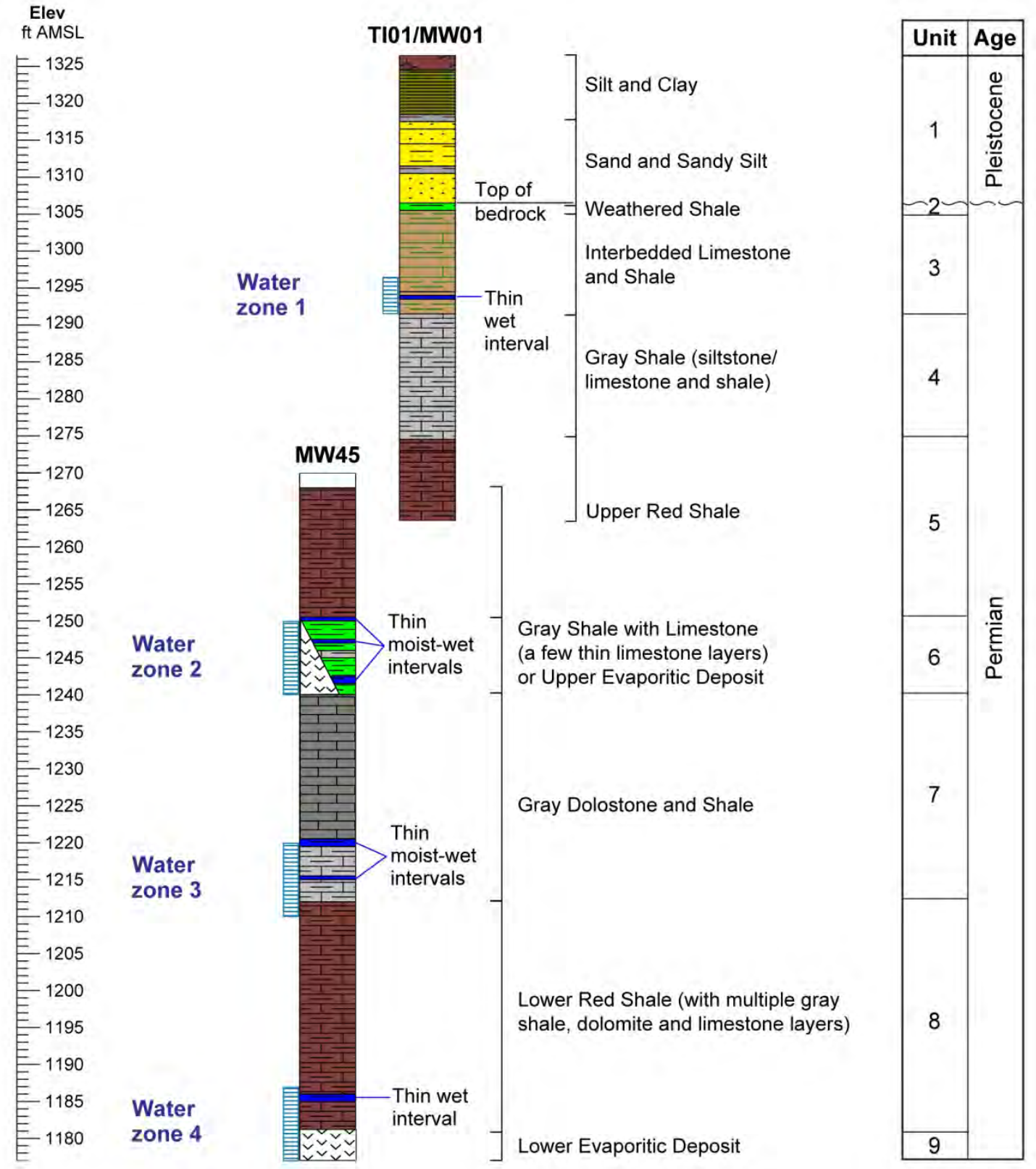

FIGURE 2.5 General stratigraphic section in the investigation area at Hanover. 


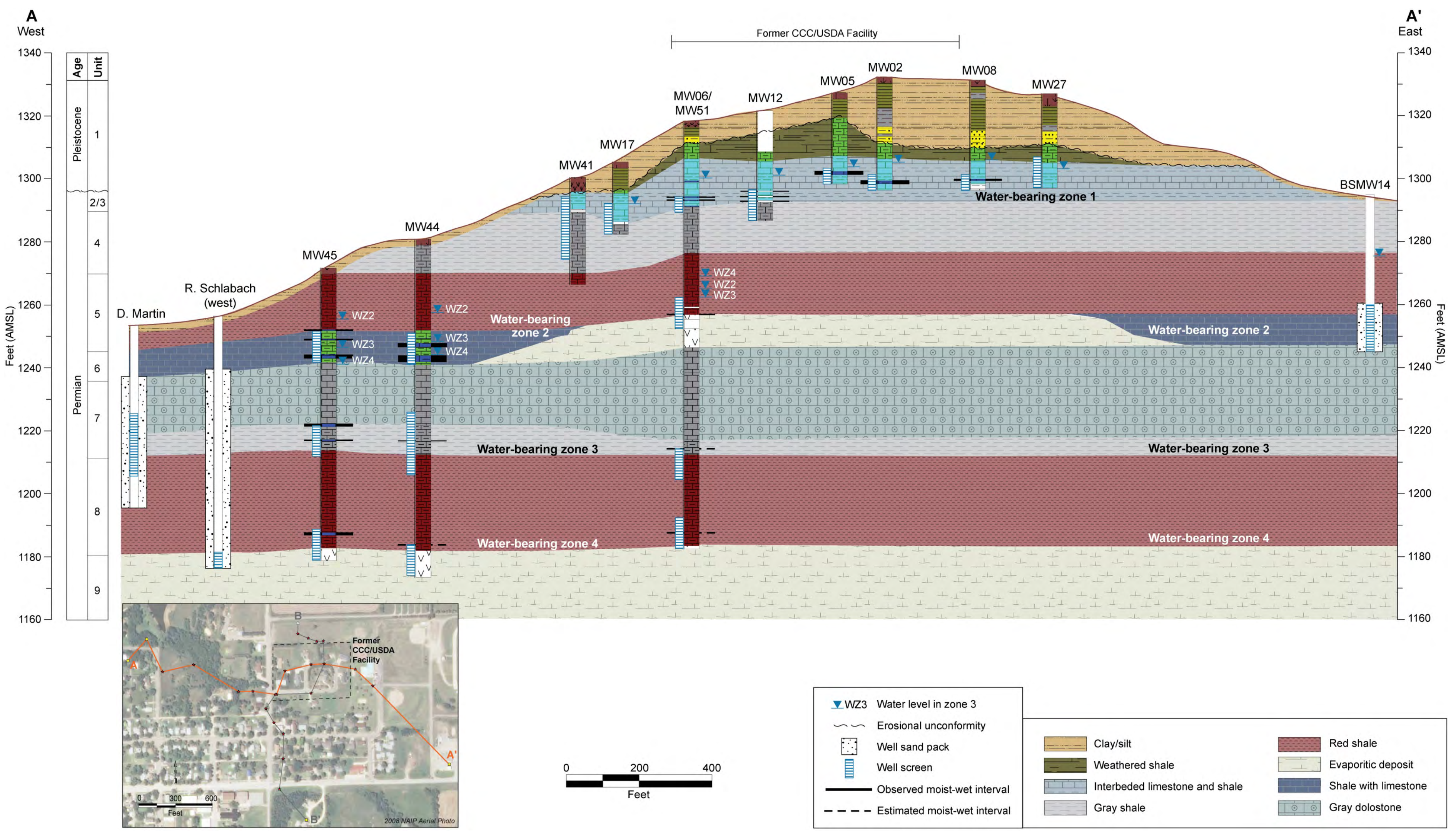

FIGURE 2.6 Interpretive west-to-east hydrogeologic cross section A-A'. 


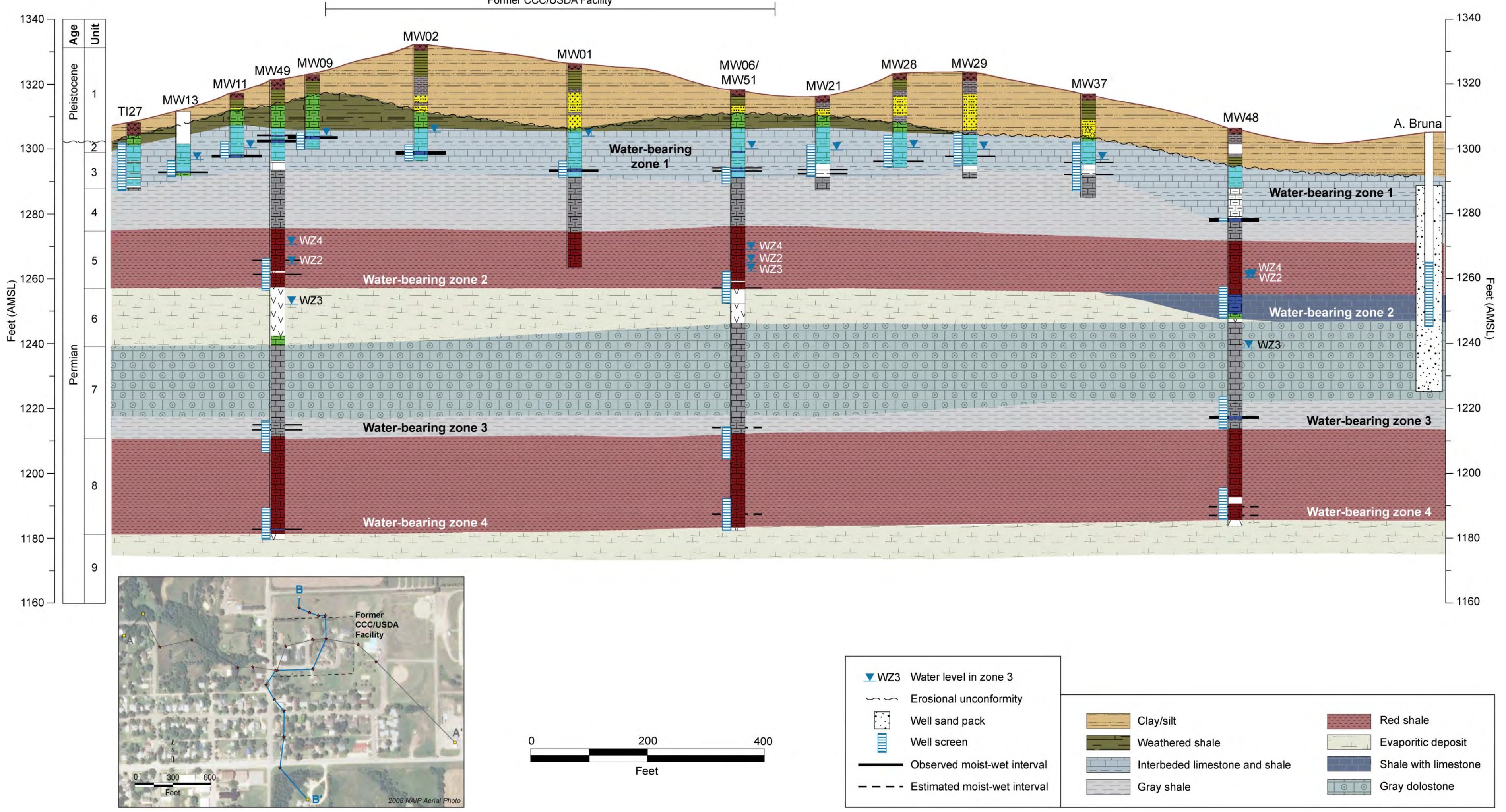




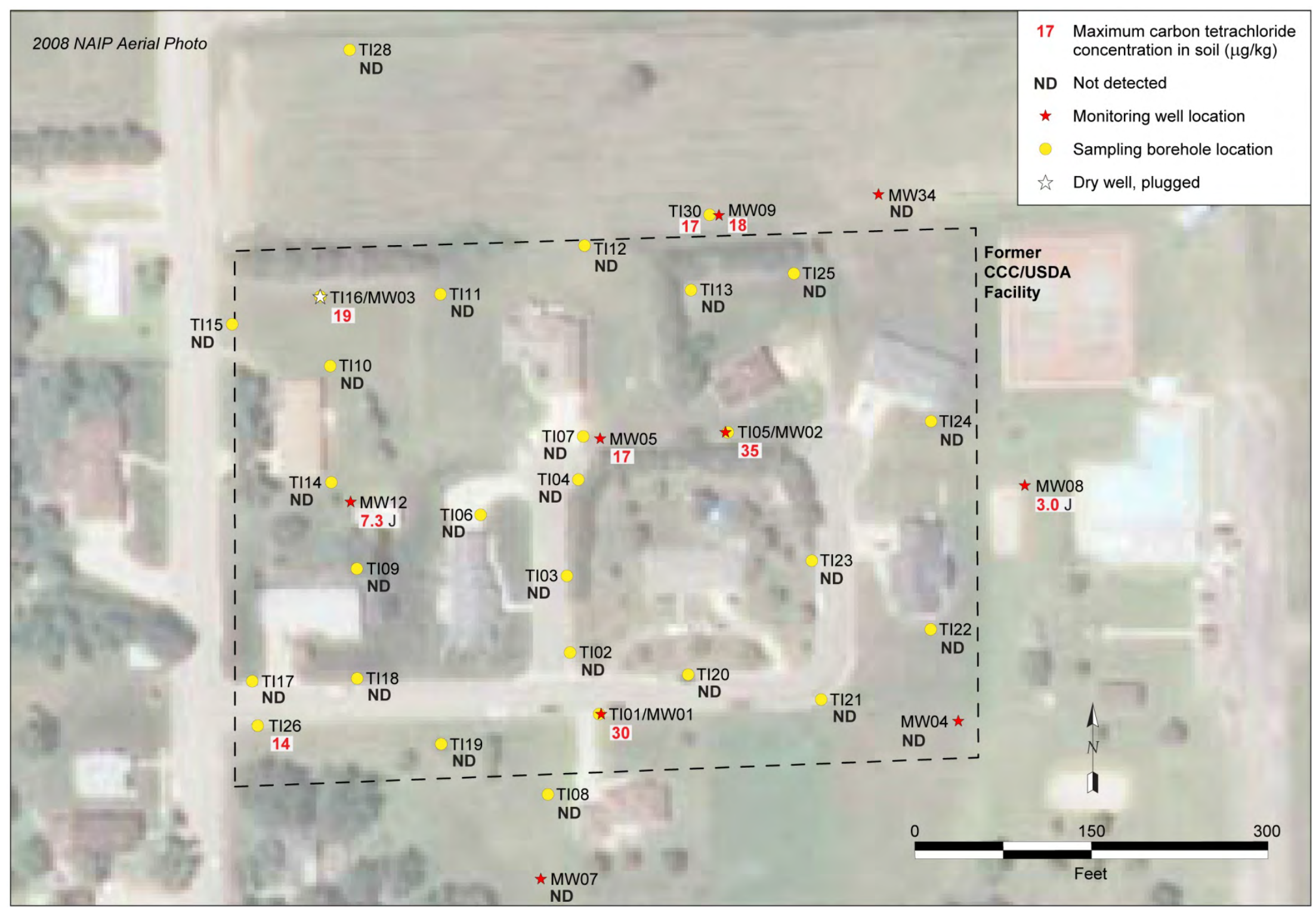

FIGURE 2.8 Maximum concentrations of carbon tetrachloride in soil samples collected at and near the former CCC/USDA facility during the 2009-2010 investigation. Source of photograph: NAIP (2008). 


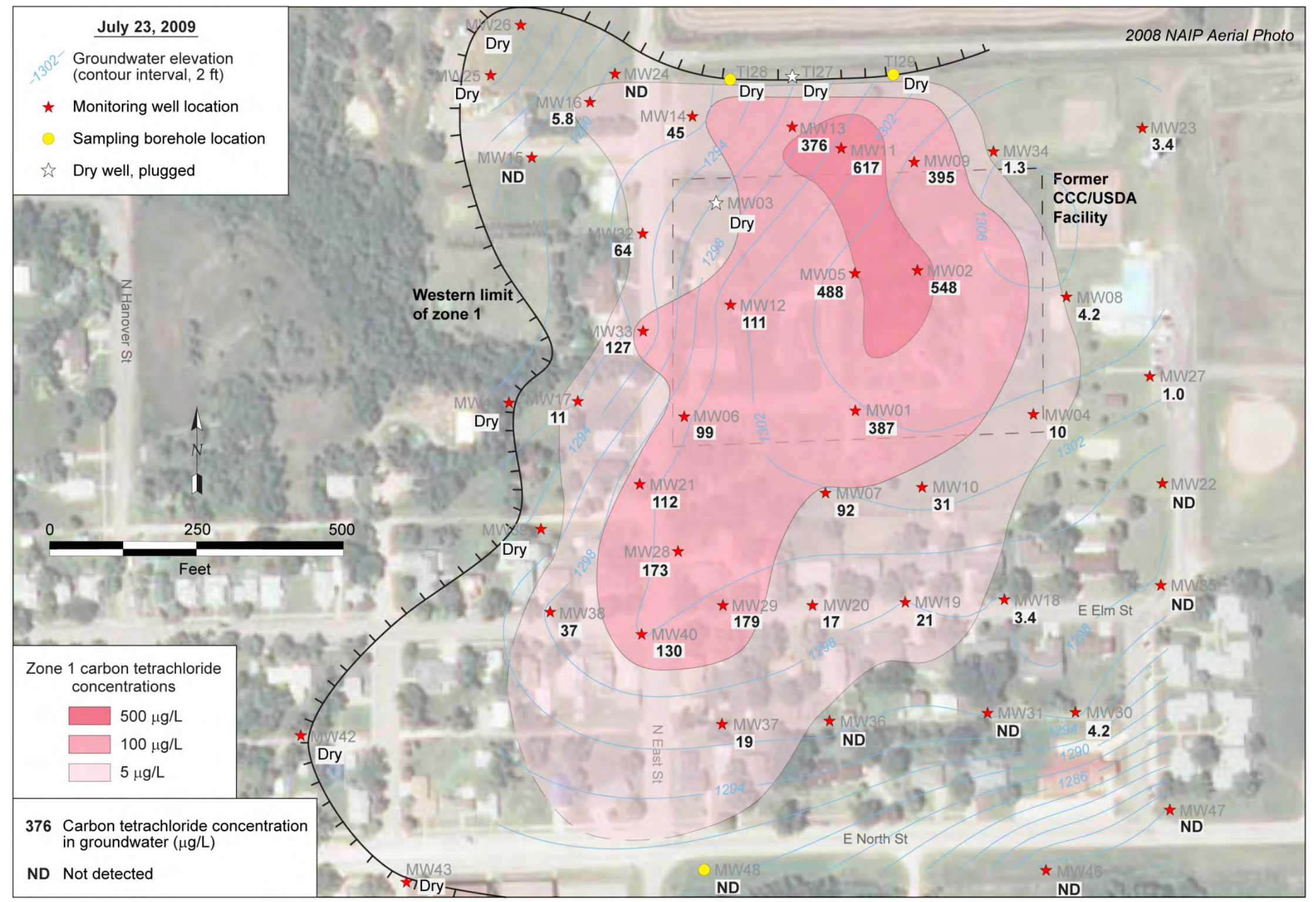

FIGURE 2.9 Carbon tetrachloride concentrations in groundwater Zone 1, with the interpreted lateral extent of the carbon tetrachloride contamination, the potentiometric surface, and the estimated western limits of groundwater Zone 1. Source of photograph: NAIP (2008). 


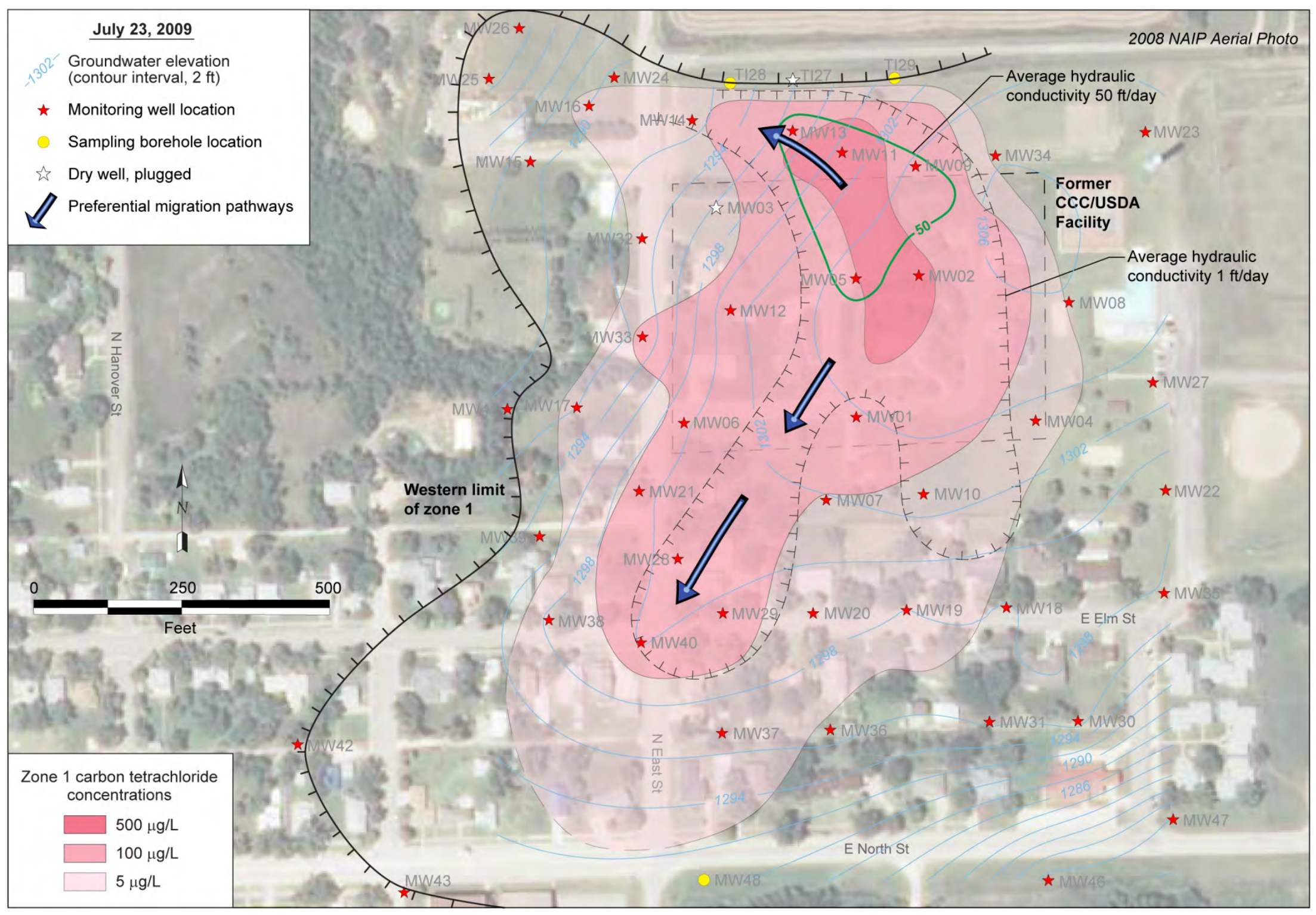

FIGURE 2.10 Interpreted lateral extent of carbon tetrachloride contamination, potentiometric surface, hydraulic conductivity, and preferred migration pathways in groundwater Zone 1. Source of photograph: NAIP (2008). 


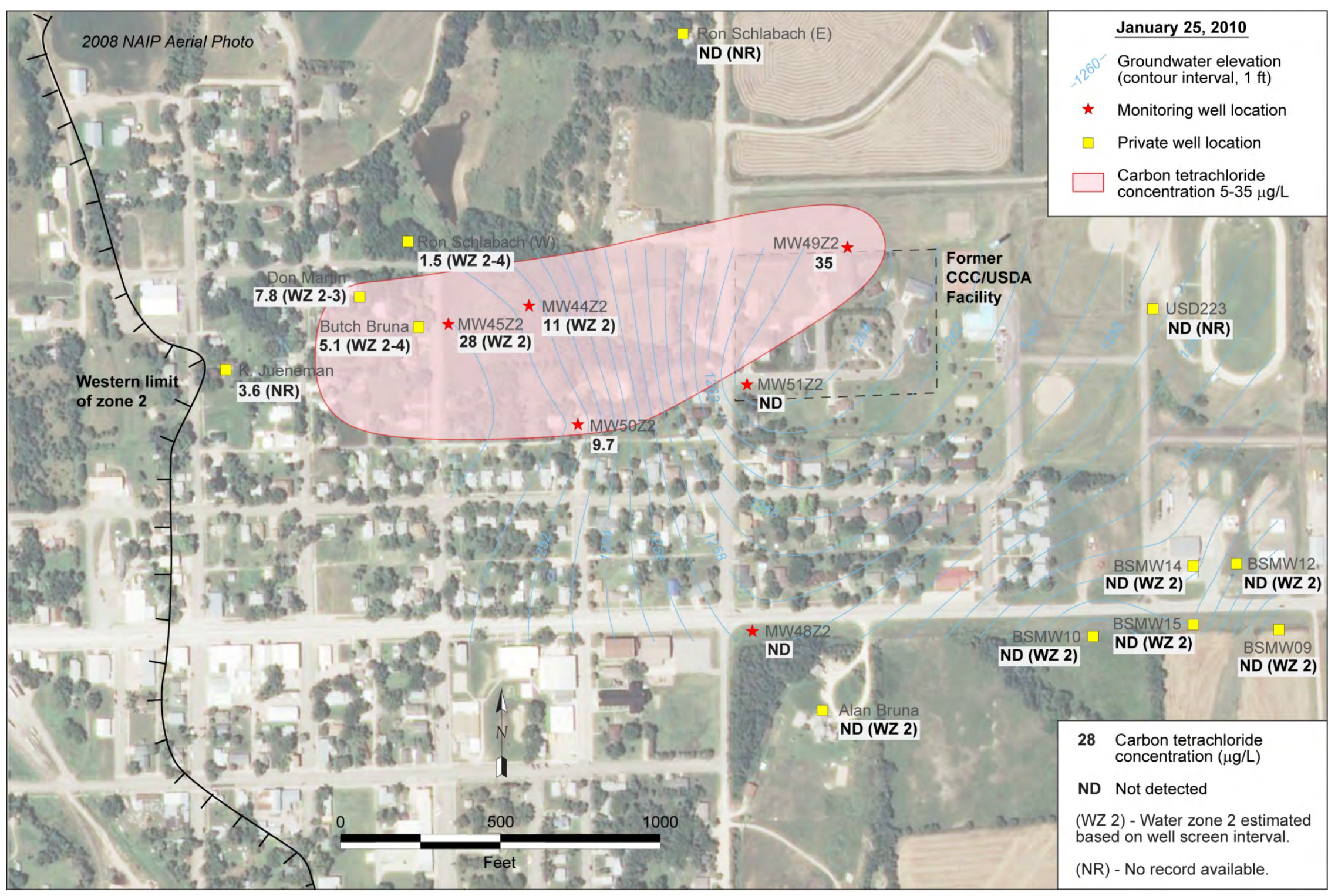

FIGURE 2.11 Carbon tetrachloride concentrations in groundwater Zone 2, with the interpreted lateral extent of the carbon tetrachloride contamination, the potentiometric surface, and the estimated western limits of groundwater Zone 2. Source of photograph: NAIP (2008). 


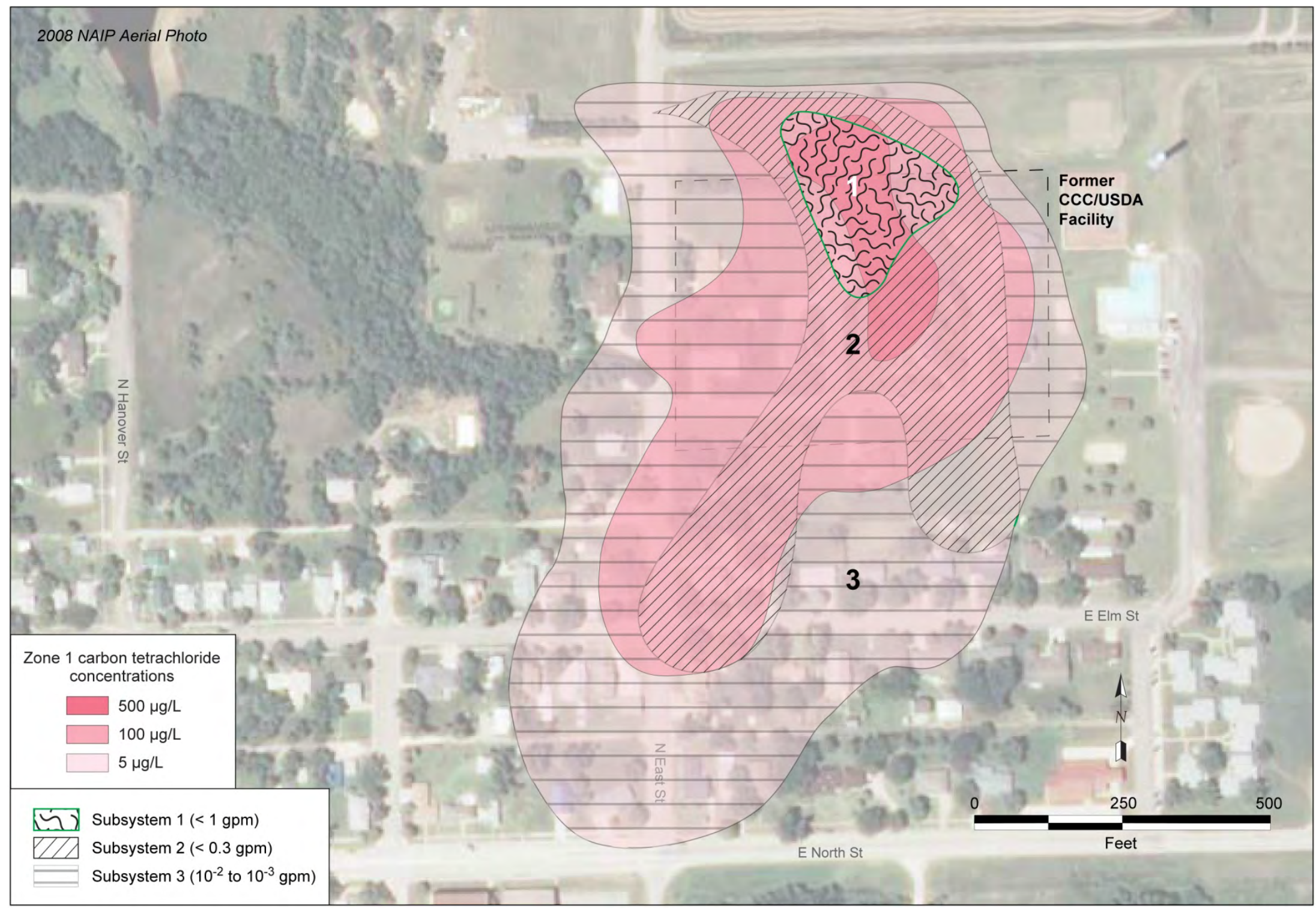

FIGURE 2.12 Interpreted spatial configurations and sustainable pumping rates of Subsystems 1, 2, and 3 within the carbon tetrachloride distribution in groundwater Zone 1. The characteristics of the subsystems are summarized in Table 2.1. Source of photograph: NAIP (2008). 


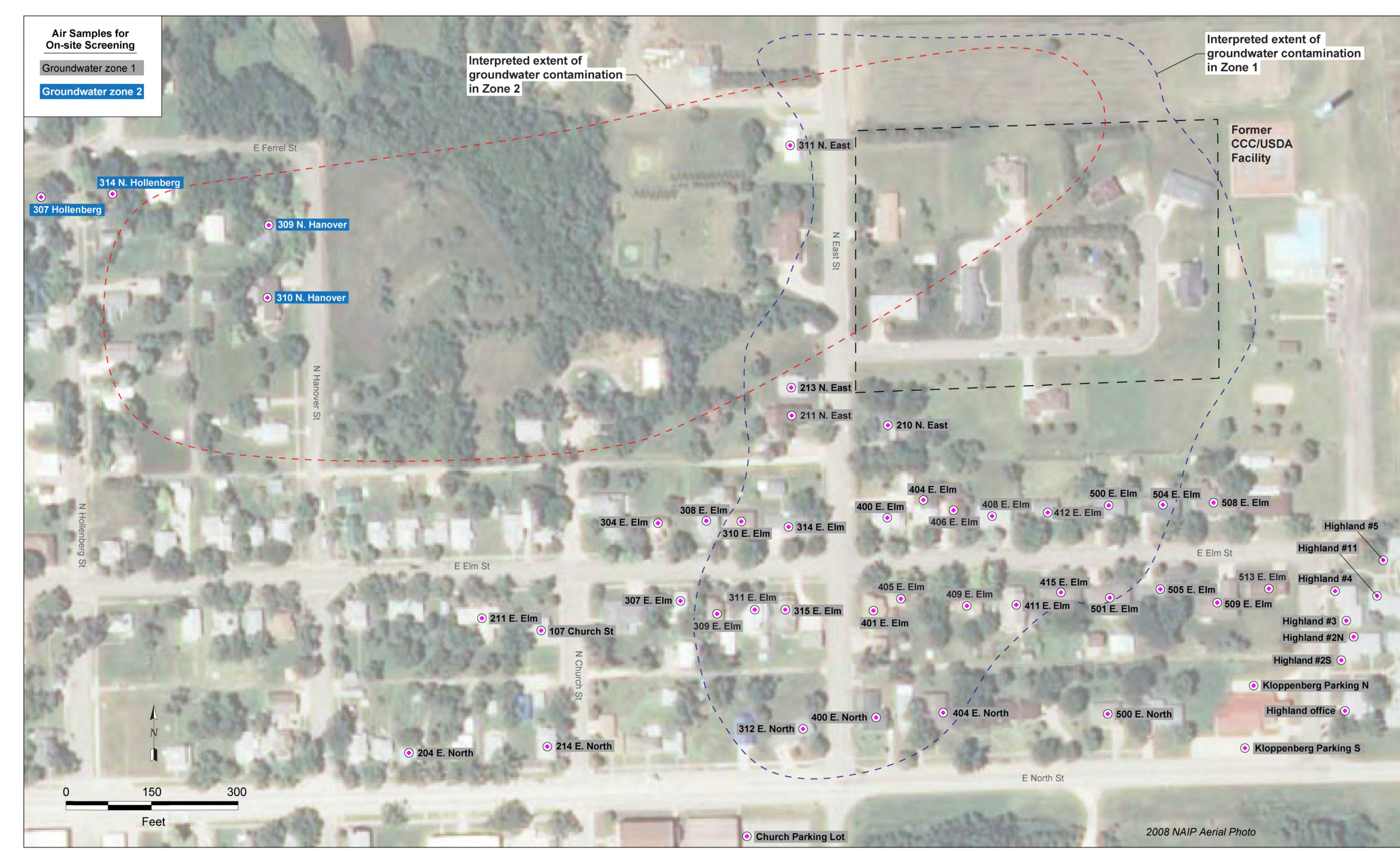

FIGURE 2.13 Locations of residential structures tested during the on-site screening in the 2009-2010 investigations. Source of photograph: NAIP (2008). 


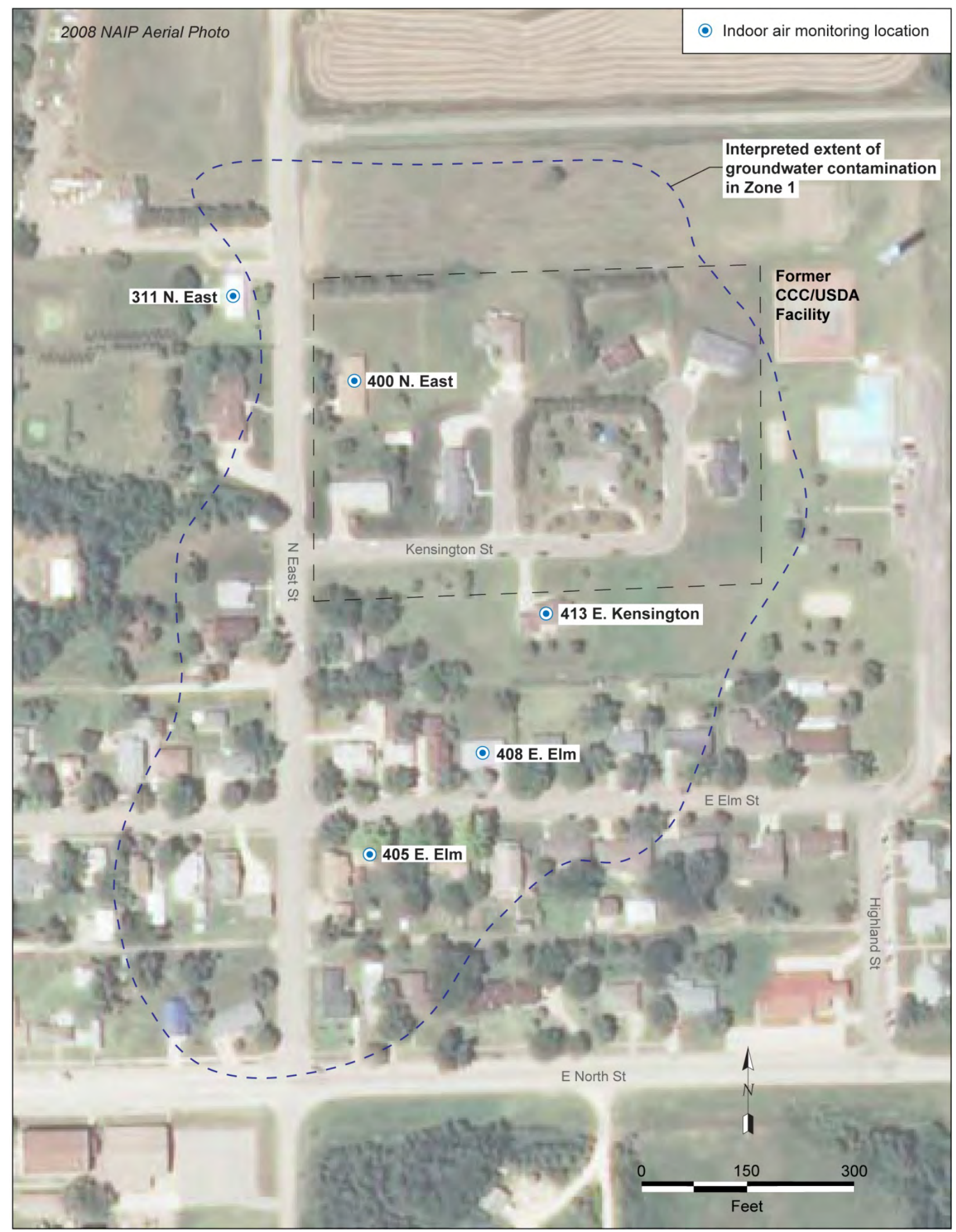

FIGURE 2.14 Homes in which mitigation systems were installed to treat carbon tetrachloride in indoor air. Source of photograph: NAIP (2008). 


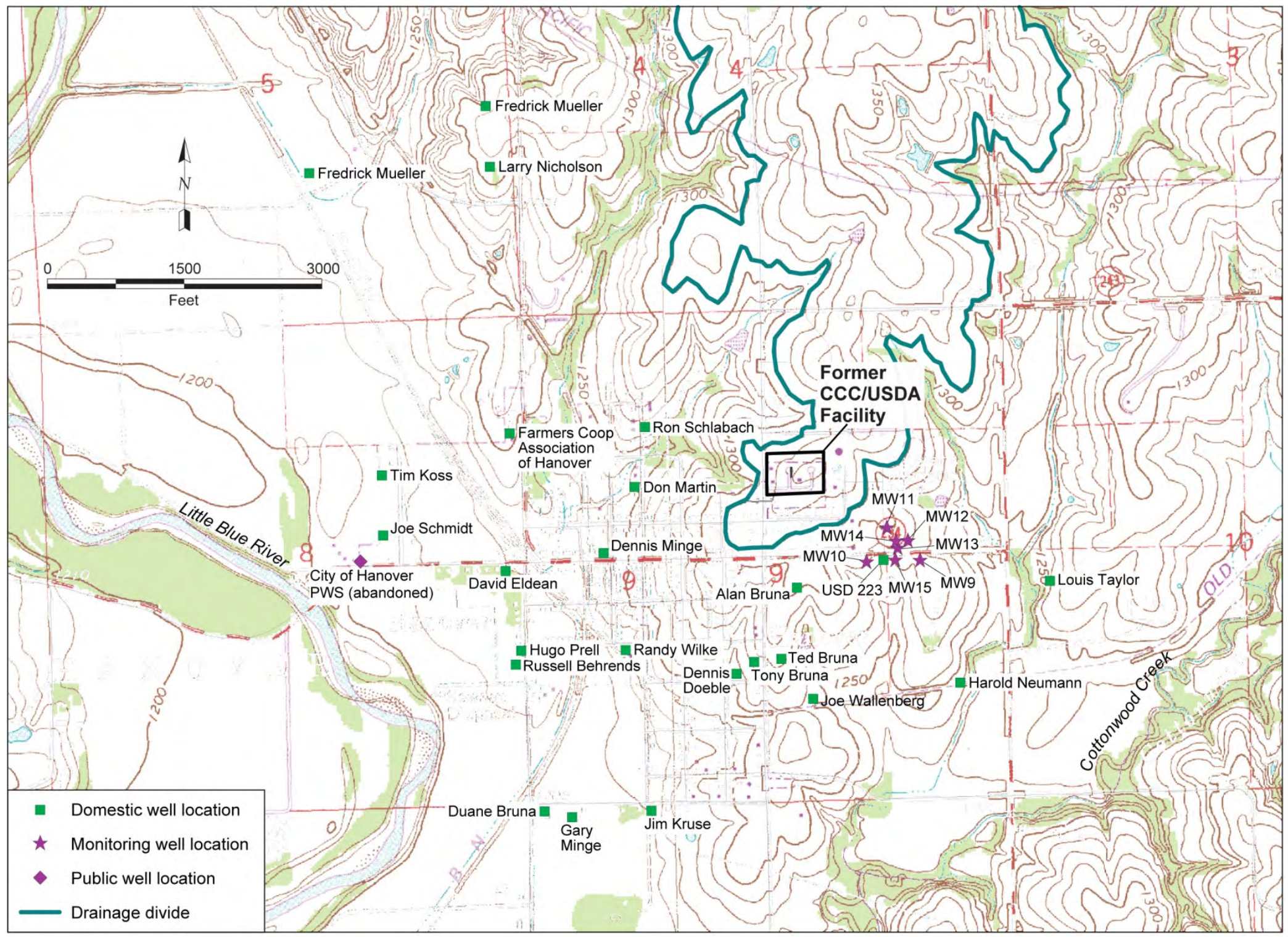

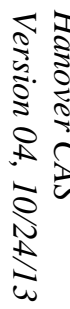

FIGURE 2.15 Locations of registered water wells within $1 \mathrm{mi}$ of the former CCC/USDA facility. Source of map: USGS (1997). 


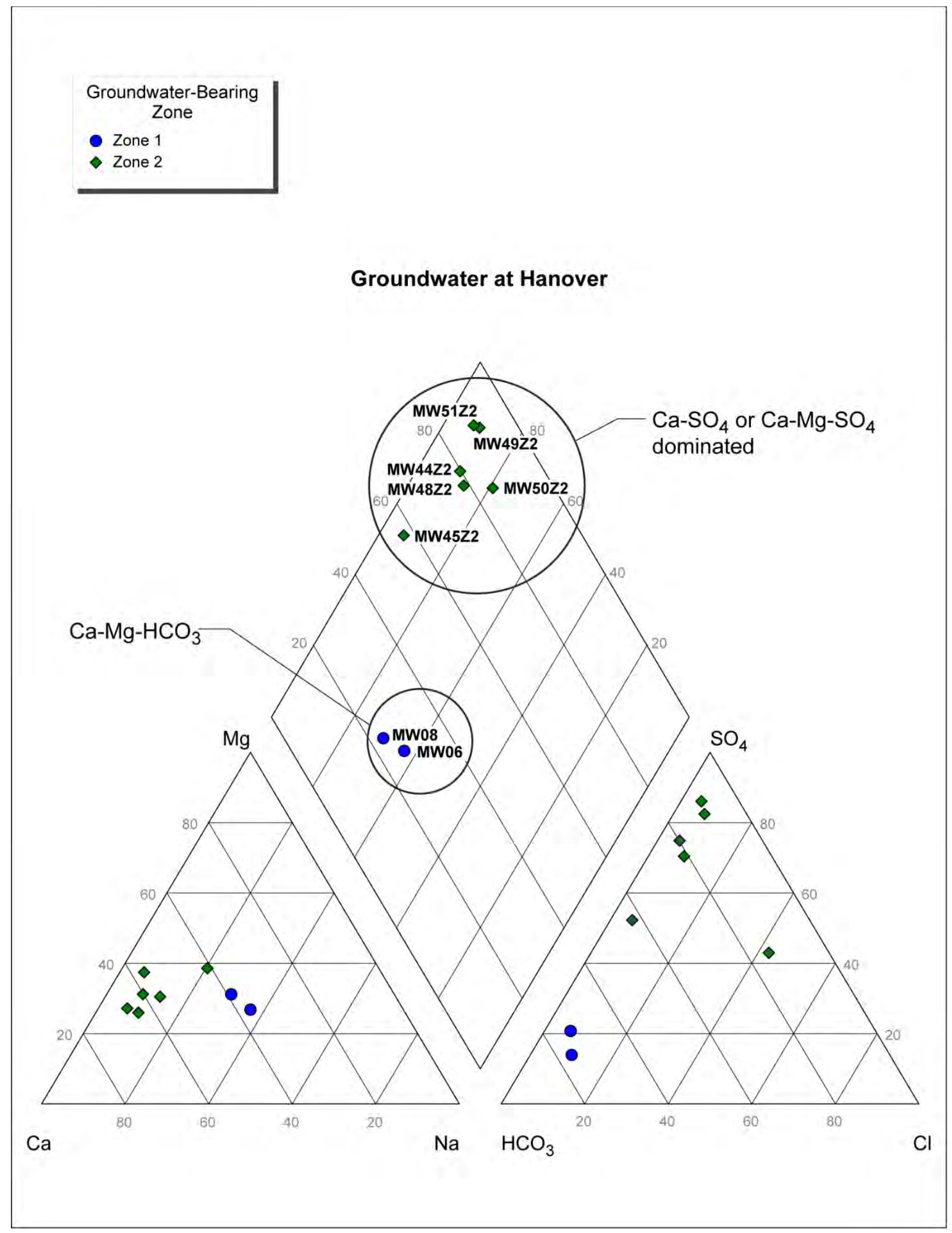

FIGURE 2.16 Relative composition of major cations and anions in groundwater Zone 1 and Zone 2. 


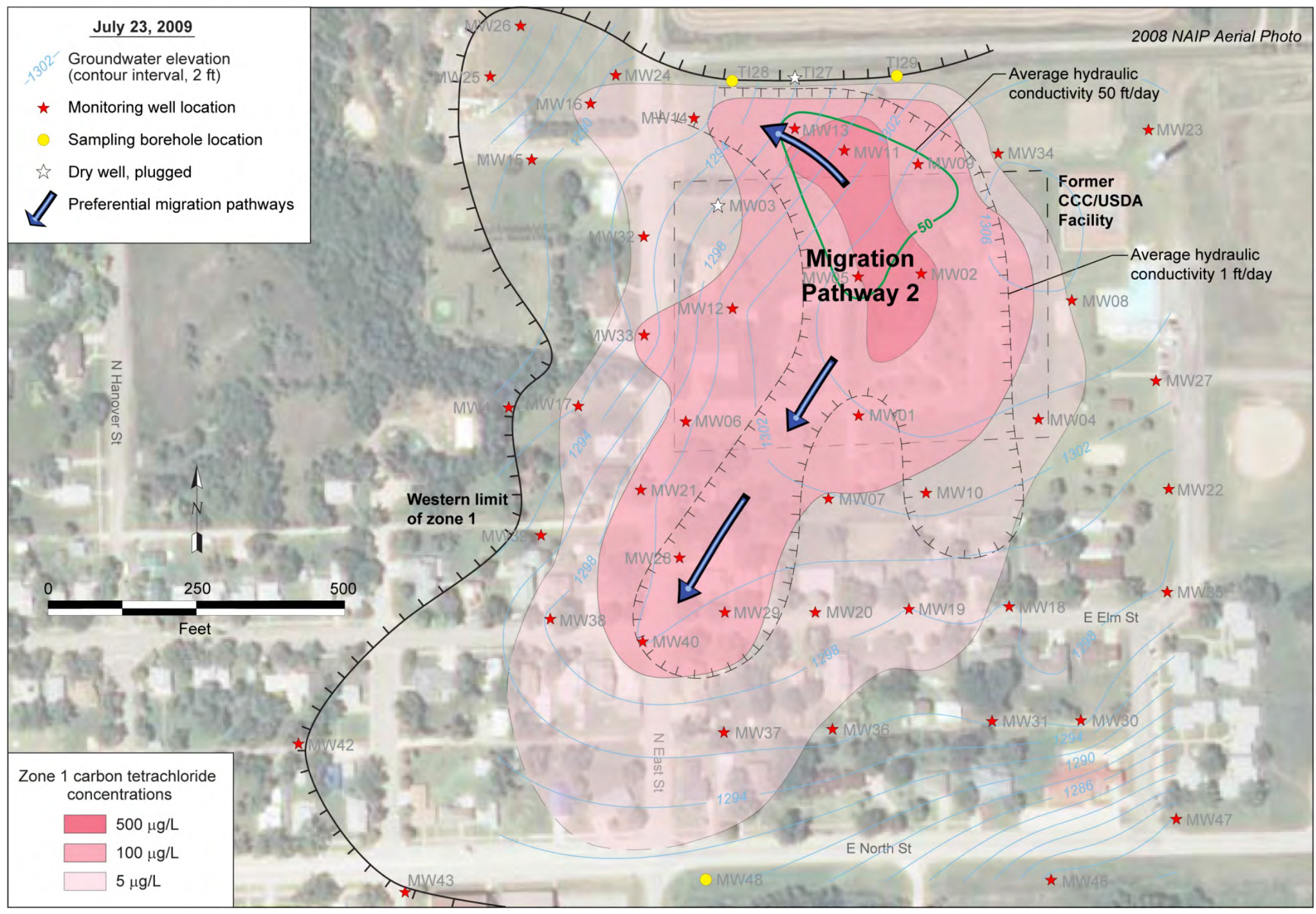




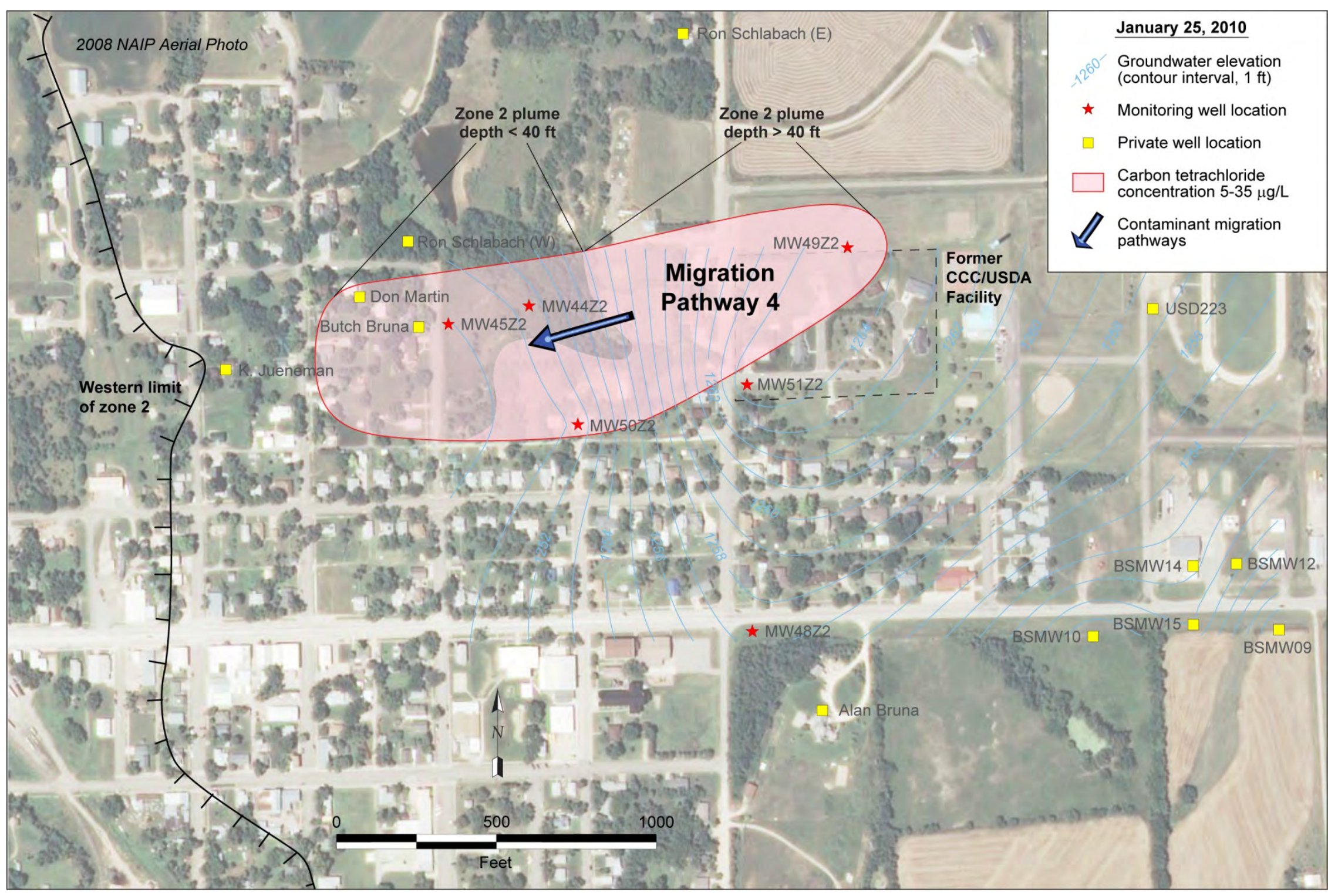




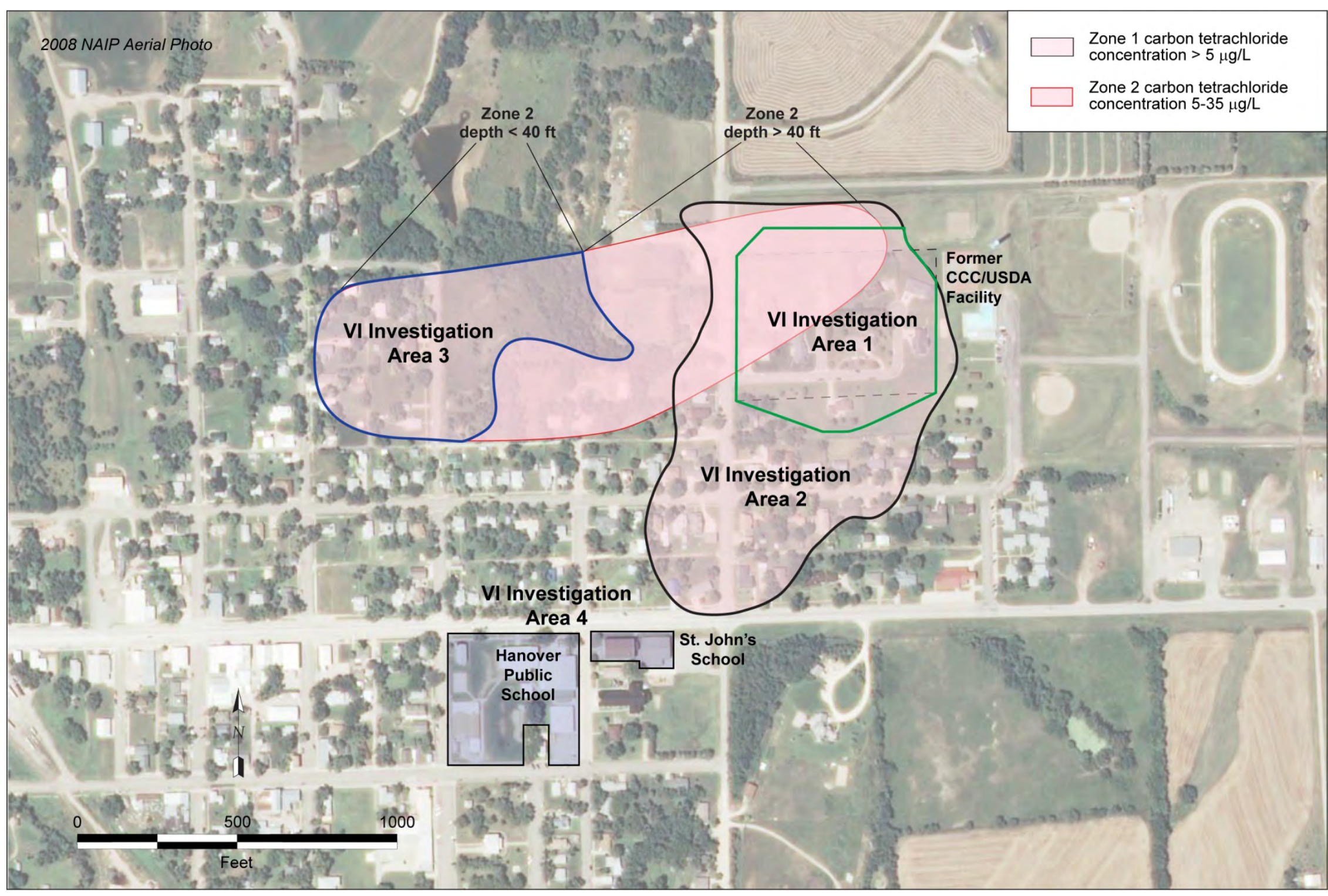

FIGURE 2.19 Vapor intrusion investigation Areas 1 and 2 (groundwater Zone 1), Area 3 (groundwater Zone 2), and Area 4 (schools). Source of photogaph: NAIP (2008). 


\section{Regulatory Considerations and Corrective Action Goals}

The corrective action goals for the Hanover site were developed to achieve compliance with Kansas state and federal environmental regulatory requirements, as well as with selected KDHE guidance documents that are pertinent to the conditions at Hanover. The regulatory requirements and guidance documents that were specifically considered are described below.

\subsection{Regulatory Considerations}

\subsubsection{Applicable or Relevant and Appropriate Requirements and Guidance to be Considered}

The KDHE guidance for the preparation of a CAS (KDHE 2001a) lists “compliance with Federal and State applicable, or relevant and appropriate requirements (ARARs)" as one of the criteria that must be evaluated in the CAS process. The CAS guidance also refers to and adopts several regulations and guidance documents related to the Comprehensive Environmental Response, Compensation, and Liability Act (CERCLA). Section 121 of CERCLA and provisions of the National Oil and Hazardous Substances Pollution Contingency Plan (the NCP; EPA 1990) generally require that cleanup actions implemented under CERCLA achieve ARARs, unless they are waived. Applicable requirements are cleanup standards, standards of control, and other substantive environmental protection requirements, criteria, or limitations promulgated under federal or state environmental or facility siting laws that specifically address a hazardous substance, pollutant, contaminant, remedial action, location, or other circumstance. Only those state standards that are identified by a state in a timely manner and that are more stringent than federal requirements may be applicable.

Relevant and appropriate requirements are cleanup standards, standards of control, and other substantive environmental protection requirements, criteria, or limitations promulgated under federal or state environmental or facility siting laws that, while not attaining the status of being "applicable” to a hazardous substance, pollutant, contaminant, remedial action, location, or other circumstance, nevertheless address problems or situations sufficiently similar so that their use is well suited to the particular site. Only those state standards that are identified by a state in a timely manner and that are more stringent than federal requirements may be relevant and appropriate. 
As described by the EPA (1990), ARARs can be placed in three categories: chemicalspecific, location-specific, and action-specific. Chemical-specific ARARs address certain chemical species or classes of contaminants and relate to the allowable limits of contaminant concentrations in various environmental media (soil, groundwater, surface water, air). These ARARs can be used to determine cleanup levels. Location-specific ARARs are based on the specific setting and nature of the site, such as proximity to wetlands, floodplains, or archaeological resources. Action-specific ARARs relate to specific response actions (e.g., excavation or treatment activities) proposed for implementation at the site.

In addition to ARARs, the NCP (EPA 1990) provides for the use of other advisories, criteria, or guidance "to be considered" (TBC). The TBCs are advisories, criteria, and standards that are issued by the federal or state regulatory body but are not legally binding because they have not been promulgated. The identification of TBCs is not mandatory; however, they are to be used, as appropriate, to complement the ARARs.

Potential ARARs for the proposed actions described in Sections 4, 5, and 6 were identified on the basis of the nature of the contamination, the site location, and the proposed activities. A comprehensive list of potential ARARs and TBCs, including both federal (Table B.1) and Kansas (Table B.2) requirements, is in Appendix B. For each entry, the tables include a relevant regulatory or statutory citation; a designation as location specific, action specific, or chemical specific; and a categorization as applicable, relevant and appropriate, or a TBC. The ARARs and TBCs are also discussed below in relation to the Hanover site.

\subsubsection{Chemical-Specific ARARs}

Cleanup levels are generally established on the basis of chemical-specific ARARs, which are requirements or risk-based numerical limits establishing the allowable amount or concentration of a hazardous substance that may exist in or be released to the environment. The contaminants of concern in this case are carbon tetrachloride and chloroform. A relevant and appropriate chemical-specific ARAR would be the Kansas-administered Federal Safe Drinking Water Regulations, which establish MCLs pertaining to public water supplies. The MCL for carbon tetrachloride is $5.0 \mu \mathrm{g} / \mathrm{L}$, as is the Kansas Tier 2 RBSL. The MCL for chloroform is $80 \mu \mathrm{g} / \mathrm{L}$, as is the Kansas Tier 2 RBSL. 
However, MCLs and RBSLs may not be relevant and appropriate as cleanup levels for Hanover, given the guidance in KDHE policy BER-RS-045 (KDHE 2009b). Policy BER-RS-045 (discussed further in Section 3.1.4) details aquifer characteristics, including water quality and groundwater yield characteristics, to be considered by the Bureau of Environmental Remediation to substantiate a deviation from MCL and RBSL cleanup levels in cases where groundwater is not suitable for potable use. As described in KDHE Policy BER-RS-045, aquifer characteristics for Zones 1-4 indicate that groundwater at Hanover could not serve as a drinking water source, thus calling into question the relevance of MCLs and RBSLs as cleanup target goals.

\subsubsection{Action-Specific ARARs}

\subsubsection{Cross-Connection Control Regulations}

Some of the homes located above the inferred extent of groundwater contamination in Zone 2 have private water wells that are used for watering lawns and gardens (Figure 2.11). Washington County RWD \#1 has regulations controlling cross-connection that are considered applicable for this CAS. These regulations affect residents who have water supply wells on their properties and whose residences are also connected to the RWD system. The RWD \#1 crossconnection control regulations (RWD 2009b) protect the public potable water supply of the RWD from pollution or contamination by prohibiting cross-connections between a private water source and the public potable water system. The specific regulation is in Section 3 (Requirements, Item 4, Individual Water Supplies) of the document (RWD 2009b). Thus, the RWD system that supplies Hanover should not be affected by a private water supply well that might intercept groundwater contamination at or near the former CCC/USDA facility.

\subsubsection{Well Placement and Construction Regulations}

Regulations included in the Code of Kansas Regulations (COKR) 28-30 - Water Well Contractor's License; Water Well Construction and Abandonment (http:/www.nekes.org/ uploads/State_Regs_28-30.pdf) — are considered applicable for this CAS. The regulation provides protective measures for the installation of new water supply wells. Included in the construction regulations for wells that are not used for a public water supply (and thus are applicable to the construction of a private water well) are a well placement component and a well 
construction component. More specifically, COKR 28-30-6 (a), (d), and (l) specify the following:

(a) Each water well shall be so located as to minimize the potential for contamination of the delivered or obtained groundwater and to protect groundwater aquifers from pollution and contamination.

(d) Waters from two or more separate aquifers shall be separated from each other in the bore hole by sealing the bore hole between aquifers with grout.

(I) All groundwater producing zones that are known or suspected to contain natural or manmade pollutants shall be adequately cased and grouted off during construction of the well to prevent the movement of polluted groundwater to either overlying or underlying fresh groundwater zones.

\subsubsection{Licensing and Professional Certifications}

Regulations included in COKR 66-6-1 through 66-14-12, Kansas Board of Technical Professions, establish requirements for the licensing of professionals such as engineers, land surveyors, and geologists. This regulation will be applicable if the services of a geologist, engineer, or land surveyor are required to implement a corrective action alternative.

\subsubsection{Water Appropriation Regulations}

Regulations included in COKR 5-1-1 through 5-10-6 and COKR 5-50-1 through 5-50-8 establish requirements for obtaining water. If water appropriations are required for the implementation of a corrective action, this regulation will be applicable.

\subsubsection{Advisories, Criteria, and Guidance}

The Kansas VI guidance (KDHE 2007) defines “buildings of concern” for chlorinated VOCs as those within $100 \mathrm{ft}$ laterally and $40 \mathrm{ft}$ vertically of the contamination. Many homes are 
located within these distances of the contamination identified in groundwater. Consequently, the KDHE (2007) VI guidance is considered TBC guidance.

The KDHE Bureau of Environmental Remediation policy regarding consideration of groundwater use in developing groundwater cleanup levels is considered TBC guidance. The default assumption of KDHE Policy BER-RS-045 (KDHE 2009b) — that the most beneficial use of groundwater is for a potable water source - would suggest that MCLs and RBSLs might be reasonable target cleanup goals. However, KDHE policy BER-RS-045 also outlines considerations that should be applied to substantiate deviations from MCLs and RBSLs. One such consideration is whether the groundwater in question is potable. The criteria that the KDHE will consider to substantiate deviation from the MCL and RBSL cleanup standards include the groundwater quality and quantity required for potable use. Although, as noted in Section 2.3.1, aquifer characteristics cause the groundwater at Hanover to be non-potable, Section E of KDHE policy BER-RS-045 states that the potential for groundwater to pose a threat via other exposure pathways (for example, the VI pathway) may necessitate the remediation of groundwater to residential standards (i.e., MCL and RBSL values).

The KDHE Bureau of Environmental Remediation policy BER-RS-028, Consideration for Hydraulic Containment (KDHE 2005e), provides TBC guidance if a remedy employing active remediation is accomplished through groundwater withdrawal and treatment. This policy specifies KDHE requirements for the hydraulic containment of contamination in discrete portions of a site undergoing active remediation. The minimum requirements for KDHE approval of hydraulic containment as a remedy component include a clearly stated remedial objective, the delineation of a three-dimensional target capture zone, an interior monitoring network near the capture zone boundaries, compliance monitoring, source control measures, and environmental use controls for impacted areas.

Other Kansas action-specific TBC guidance includes several KDHE Bureau of Environmental Remediation policies (KDHE 2001b, 2002, 2005b,d,g). An additional Kansas action-specific TBC advisory for this CAS is Kansas Geological Survey Public Information Circular 23, Drilling a Water Well on Your Land: What You Should Know (Suchy et al. 2011). Circular 23 describes the process a landowner should follow to evaluate the potential for a productive water well on a specific property and the process for well installation. Among the points highlighted are the fact that a yield of at least 4-5 gpm is considered the minimum amount necessary to provide adequate water for domestic household use, the need to select a reputable 
and responsible well driller, and the need to check with local and state regulatory agencies for permitting and construction regulations.

\subsubsection{Waivers and Variances}

Remedial alternatives that do not meet the requirements of an ARAR under CERCLA may qualify for a waiver or variance. Waivers apply only to the attainment of the ARAR; other statutory requirements (e.g., that remedies be protective of human health and the environment) cannot be waived (CERCLA §121[d][4]).

- Interim Remedy. An interim remedial action will not attain all ARARs. The interim remedy must be followed by a complete measure that will attain all ARARs.

- Equivalent Standard of Performance. Equivalent or better results can be obtained by using a design or method different from that specified in the ARAR.

- Greater Risk. Compliance with an ARAR will cause greater risk to human health and the environment than noncompliance.

- Technical Impracticability. Achieving an ARAR(s) is impracticable from an engineering perspective.

- Inconsistent Application of State Requirements. Regarding a state standard, requirement, criterion, or limitation, the state has not consistently applied (or demonstrated the intention to apply consistently) the standard, requirement, criterion, or limitation in similar circumstances for other remedial actions.

- Fund Balancing. The costs associated with meeting an ARAR to obtain an added degree of protection or decrease in risk would jeopardize the funds for remedial actions at other sites (EPA 1990). 


\subsection{Site-Specific Goals}

The site-specific goals of any proposed remedial action at the former CCC/USDA facility concern groundwater and indoor air impacted by groundwater. These goals are as follows:

- In the relatively more permeable, more contaminated portion of Zone 1 where corrective action technologies would be effective and implementable, reduce the mass, mobility, and volume of contaminated groundwater that is serving as a VI contamination source in Zone 1 and that is migrating from Zone 1 to Zone 2.

- Reduce the risk due to potential exposure to indoor air containing carbon tetrachloride at a concentration above the KDHE screening value.

- Minimize vertical and lateral migration of contaminated groundwater from the mass reduction area (i.e., the more permeable, more contaminated portion of Zone 1) to other areas of the site.

- Minimize vertical and lateral expansion of the contamination in groundwater outside the mass reduction area, as defined by the compliance groundwater monitoring network to be established.

- Restore groundwater to allow for its most beneficial use.

These site-specific goals guided the identification of suitable remedial technologies and practices, the formulation of a suite of remedial alternatives combining the technologies and practices, and further evaluation of the remedial alternatives. The results are described in subsequent sections. 


\section{Identification and Screening of Technologies}

All of the possible exposure pathways (1) from contaminated soil to groundwater and (2) from contaminated groundwater to surface discharge and then to human or environmental receptors are incomplete. Consequently, these pathways pose no unacceptable health risks. However, a complete exposure pathway for carbon tetrachloride from contaminated groundwater to indoor air via VI was confirmed by the results from the 2009-2010 investigation. Carbon tetrachloride concentrations exceeding the KDHE screening value of $4.06 \mu \mathrm{g} / \mathrm{m}^{3}$ in indoor air have been addressed by the installation of mitigation systems in the five affected residences. These residences are being influenced by contaminated groundwater in Zone 1, and carbon tetrachloride was not detected in the indoor air of residences overlying Zone 2. Consequently, technologies that specifically address Zone 1 have been identified and are screened in this section.

The objective of this CAS is to identify remedial technologies and practices that can meet the site-specific goals for addressing contamination in Zone 1 identified in Section 3.2, then combine the technologies and practices into a suite of remedial alternatives for further evaluation. A list of potential corrective actions for the former CCC/USDA facility was developed by identifying technology types and practices that are potentially applicable to addressing groundwater in Zone 1 impacted by carbon tetrachloride. The technology types were then screened for applicability to the Hanover site in accordance with KDHE (2001a) and EPA (1988) guidance. Technology types retained after the screening were assembled into remedial alternatives that are evaluated further in Sections 5 and 6, along with the no-action alternative required by the KDHE.

The following types of general response actions were considered for mitigation of risk, in addition to the required no-action option:

- Land use controls to restrict access to impacted groundwater and soil vapor.

- Containment to restrict contaminant migration. Containment technologies evaluated were VI barriers and engineered physical barriers to groundwater flow. 
- Removal of the contamination or contaminated media for ex situ treatment (as needed) and discharge or disposal. Removal technologies for groundwater and volatile contaminants were evaluated.

- In situ implementation of chemically or biologically mediated processes within or downgradient from impacted areas. In situ technologies evaluated were permeable reactive barriers, in situ chemical reduction, and phytoremediation.

\subsection{Criteria for Identifying and Screening Technologies}

Technologies identified here were screened on the basis of site-specific conditions and the current understanding of the former CCC/USDA facility. Section 121 of CERCLA identifies a strong statutory preference for remedial actions that are highly reliable and provide long-term protection.

The primary requirements for a selected remedy are that it

- Protects human health and the environment and

- Meets the objectives of the proposed action in a cost-effective manner.

Additional selection criteria include the following:

- Preferred remedies achieve permanent or significant reduction of the toxicity, mobility, or volume of hazardous substances, pollutants, or contaminants.

- Where practical treatment technologies are available, off-site transport and disposal without treatment is the least preferred alternative.

- Permanent solutions and innovative treatment technologies or resource recovery technologies are preferred whenever practicable. 
These criteria were considered in identifying and screening technologies to determine the appropriate components of the remedial action alternatives for the Hanover site.

Potentially applicable technology types and process options were screened on the basis of effectiveness, implementability, and cost, defined as follows:

- Effectiveness in terms of protecting human health and the environment in both the short term and the long term. Measures of effectiveness include (1) reduction of long-term impacts to human health and the environment; (2) reduction of contaminant toxicity, mobility, or volume through treatment; (3) control of potential impacts to human health and the environment during the action period; (4) timeliness; and (5) consistency with regulatory requirements.

- Implementability in terms of technical and administrative feasibility and resource availability. Technical feasibility is related to the practicability of construction, the reliability of operation, and the ability to meet technologyspecific regulations. Technical feasibility also addresses potential constraints associated with the site environment. Administrative feasibility concerns the acceptability of an alternative to relevant agencies and the public, the availability of needed access to private property, and the effects of limitations imposed by permits and other restrictions. Resource availability addresses physical and logistic requirements for implementing specific components.

- Cost, considered in a comparative manner (low, moderate, or high) for technologies of similar performance and/or implementability.

These screening criteria were applied, as discussed below, to the individual technologies and practices under consideration. Combinations of technologies to address site-specific contamination were evaluated after the technologies were assembled into alternatives, as presented in Section 5. 


\subsection{Screening of Remedial Technologies}

The following sections document the screening of candidate remedial technologies and practices.

\subsubsection{No Action}

The KDHE requires evaluation of a no-action alternative as a baseline for comparison with other actions. Under this alternative, the site is left unchanged. For Hanover, operation of the five residential vapor mitigation systems already installed by the CCC/USDA with KDHE approval (Section 2.3.5) would continue. The vapor mitigation systems would continue to be inspected annually by the CCC/USDA, and an air sampling event involving the collection of sub-slab, indoor air, and background air samples would be performed every $5 \mathrm{yr}$. The CCC/USDA would continue to compensate the owners of the five residences for the electric power required to operate the vapor mitigation systems. Protective regulations for the water supply, such as the RWD cross-connection regulations and the Kansas well placement and construction regulations (Sections 3.1.3.1 and 3.1.3.2) that are already in force would continue to preclude exposure to the contamination in groundwater. On the basis of poor natural water quality in Zone 2 and extremely limited water yield in Zone 1, Zone 3, and Zone 4, local groundwater at Hanover is not suitable as a potable water source. Thus, the carbon tetrachloride contamination does not affect a potable water source at Hanover. The no-action alternative is discussed further in Section 5.1.

\subsubsection{Kansas Environmental Use Controls}

The Kansas Environmental Use Control (EUC) program (KDHE 2009a) was established by Kansas House Bill 2247 (Kansas 2003), which became law on April 21, 2003. An EUC is defined as an institutional or administrative control - a restriction, prohibition, or control - for one or more uses of, or activities on, a specific property. The EUC is requested by a property owner to ensure future protection of public health and the environment when contamination exceeding standards for unrestricted use remains on the property. Obtaining an EUC involves completing an application that details property information, applicant information, the nature of the existing or potential contamination, requested restrictions, and a signature by the site owner or a designated representative. As part of the EUC, the applicant must agree to register an 
approved, notarized EUC agreement with the registrar of deeds in the county in which the property is located. The EUC can be removed if contamination is reduced below environmental standards.

As explained in the KDHE (2005a) guidance (pages 150-151), EUC sites are classified by the KDHE in one of three categories, on the basis of property size, the toxicity and mobility of residual contamination, and necessary KDHE inspection frequency. The approval of an EUC agreement involves either a one-time payment to the KDHE or a long-term care agreement with the KDHE. Category 1 sites have a one-time payment of \$2,000, while Category 2 sites have a one-time payment not to exceed $\$ 10,000$. The long-term care agreement required for Category 3 sites can be funded at the outset or as costs are incurred by the KDHE (KDHE 2005a, 2009a, 2010c,d).

\subsubsection{Effectiveness of Kansas Environmental Use Controls}

Although EUCs do not actively reduce contaminant toxicity, mobility, or volume, they can be effective in reducing the potential for exposure to contaminated material. When they are implemented in a timely manner and remain in effect until contaminant concentrations reach acceptable regulatory levels, these controls can provide both short- and long-term protection of human health and the environment. In general, the effectiveness depends on monitoring and enforcement. The reduction in toxicity, mobility, and volume of groundwater contamination would result from the ongoing natural degradation processes evidenced by the increased ratios of chloroform to carbon tetrachloride observed along the leading, downgradient margins of the contaminant distributions in Zones 1 and 2 (Section 2.2.5.2). The Kansas EUC program has a proven record of managing risk at single properties affected by contamination.

The existing RWD \#1 cross-connection control regulations (Section 3.1.3.1) and the Kansas well placement and construction regulations (Section 3.1.3.2) provide protection comparable to that of an EUC in protecting citizens from potential exposure to contamination via the domestic use of groundwater. 


\subsubsection{Implementability of Kansas Environmental Use Controls}

Implementation of EUCs for the approximately 60 properties involved at Hanover would be problematic. To be protective, all of the landowners within the footprint of the contamination would have to participate in the EUC program and agree to the establishment of propertyspecific deed restrictions that would prevent certain activities on their properties, such as construction of habitable structures or drinking water wells. In addition, applicable EUC administrative fees, such as the EUC application fee, would apply for each participating landowner.

\subsubsection{Cost of Kansas Environmental Use Controls}

The KDHE determines the category of EUCs. However, for planning purposes, the CCC/USDA assumes that the $\$ 10,000$ administrative fee per EUC application for Category 2 properties would be required. The CCC/USDA would pay the fee(s) for each participating landowner. The costs are considered to be high, considering the existence of the RWD connection, which offers comparable protection.

\subsubsection{Kansas Environmental Use Controls — Eliminated}

On the basis of uncertain implementability and high costs, EUCs are eliminated from further consideration.

\subsubsection{Municipal Land Use Controls}

Site-specific controls imposed on land use to prevent or reduce the exposure of human receptors to contamination (in this case, carbon tetrachloride in groundwater) are intended to protect the public from levels of contamination that exceed acceptable health risks, by administratively prohibiting or limiting certain activities at specific locations. Land use controls include the following:

- Physical controls (e.g., fencing). 
- Restrictions on the use of land or natural resources, well construction or installation, or building construction. Restrictions include permitting requirements and state, county, and local registries.

- $\quad$ Requirements for signage or distribution of information to the public.

- $\quad$ Restrictive covenants, municipal ordinances, or deeds.

Land use controls that are already available at Hanover include the RWD \#1 crossconnection control rules and regulations (Section 3.1.3.1) and the Kansas well placement and construction regulations (Section 3.1.3.2).

\subsubsection{Effectiveness of Municipal Land Use Controls}

Although municipal land use controls (MLUCs) do not actively reduce contaminant toxicity, mobility, or volume, they can be effective in reducing the potential for exposure to contaminated material. When they are implemented in a timely manner and remain in effect until contaminant concentrations reach acceptable regulatory levels, these controls can provide both short- and long-term protection of human health and the environment. In general, the effectiveness of a land use control depends on the dissemination of information, monitoring, enforcement, and (if needed) risk mitigation. Reduction in the toxicity, mobility, and volume of the groundwater contamination would result from the ongoing natural degradation processes evidenced by the increased ratios of chloroform to carbon tetrachloride observed along the leading, downgradient margins of the contaminant distributions in Zones 1 and 2 (Section 2.2.5.2).

\subsubsection{Implementability of Municipal Land Use Controls}

To implement an MLUC program, the city of Hanover would do the following:

- Establish and enforce ordinances to regulate the construction of habitable structures in the VI impact zone (within $100 \mathrm{ft}$ laterally and $40 \mathrm{ft}$ vertically of contaminated groundwater). 
- Require a VI assessment before occupancy of new residences in the affected area. As needed, require VI mitigation (such as installation of synthetic VI barriers; Section 4.2.4) during construction.

- Ensure compliance with the Washington County RWD \#1 cross-connection regulations and the Kansas well placement and construction regulations (Sections 3.1.3.1 and 3.1.3.2).

If the municipality does not establish controlling ordinances, an alternate land use control program could be established, involving information dissemination, monitoring, and (if needed) risk assessment and mitigation. Stakeholders could receive periodic fact sheets describing existing state and county regulations and describing risks associated with inadvertent exposure to groundwater contamination via either VI or improper well siting or construction. Under this alternate control program, the status of building and well construction activities in Hanover could be assessed periodically by the municipality or by the CCC/USDA through communication with the County Appraiser's office regarding property development, monitoring of water well completion records in the Kansas Geological Survey's online database, and on-site observation. If the periodic assessment revealed the potential for exposure, the alternate control program could provide for the sampling and analysis of either indoor air or a groundwater supply by a third party. If an exposure pathway was found to exist, VI mitigation or well abandonment could occur, with the CCC/USDA's assistance.

\subsubsection{Costs of Municipal Land Use Controls}

The costs associated with an MLUC option cannot be readily quantified, but they will be relatively low if the city administration and residents support the needed restrictions and their enforcement. Costs for an alternate land use control program not involving controlling municipal ordinances would also be relatively low.

\subsubsection{Municipal Land Use Controls - Retained}

On the basis of effectiveness, implementability, and costs, MLUCs are retained for further consideration. 


\subsubsection{Containment by Synthetic Vapor Intrusion Barriers}

Vapor intrusion barriers (VIBs) are synthetic materials used to preclude direct contact with contaminated soil vapor by inhibiting the infiltration of vapors into indoor air spaces. A synthetic VIB is typically placed below a building slab to prevent vapor entry. Such barriers are usually considered for incorporation in new construction. Barrier materials consist of liners or sheets of varying thickness made of high-density polyethylene or spray-on materials. Synthetic VIBs are usually installed with a passive venting layer that can be modified to facilitate active venting if necessary.

\subsubsection{Effectiveness of Synthetic Vapor Intrusion Barriers}

The synthetic VIB technology would not actively reduce contaminant toxicity or volume but would have an impact on the mobility of contaminated vapor. The reduction in toxicity or volume would result from ongoing natural degradation processes (Section 2.2.5.2). Synthetic VIBs are not generally used to retrofit existing structures, except during major reconstruction. For new construction, however, the barriers could be implemented in a timely manner and would provide both short- and long-term protection from exposure via the VI pathway.

\subsubsection{Implementability of Synthetic Vapor Intrusion Barriers}

For habitable locations in which no construction has yet occurred or for properties undergoing major reconstruction, synthetic VIBs are readily implementable.

\subsubsection{Cost of Synthetic Vapor Intrusion Barriers}

Costs for implementing synthetic VIBs in new construction are low. 


\subsubsection{Synthetic Vapor Intrusion Barriers - Retained}

On the basis of effectiveness in limiting the mobility of contaminated vapors and their ready implementability and low cost for new construction, synthetic VIBs are retained for further consideration.

\subsubsection{Containment by Engineered Physical Barriers to Groundwater Flow}

Engineered physical barriers to contain groundwater flow can reduce contaminant mobility and the associated potential for exposure, but they do not reduce contaminant toxicity or volume. Examples of such barriers include cryogenic barriers designed to freeze moisture in a relatively limited discrete area within the soil horizon and thus immobilize soluble contaminants; slurry walls installed by backfilling trenches or borings with an expanding material (e.g., bentonite) to form either a continuous or discrete wall; and sheet pilings constructed by driving interlocking steel or plastic sheets into the subsurface to the desired depth.

\subsubsection{Effectiveness of Engineered Physical Barriers}

Engineered physical barriers would not actively reduce contaminant toxicity or volume but could impact mobility. The reduction in contaminant toxicity or volume would result from ongoing natural degradation processes (Section 2.2.5.2).

The potential for engineered physical barriers to achieve containment of the contamination in groundwater at Hanover is extremely limited. Most notably, the existing areal extent of the contamination in Zone 1 , the extent of the recharge zone from Zone 1 to Zone 2, plus the multiple groundwater flow directions identified in Zone 1, would make it very difficult to control the patterns of contaminant migration in these zones.

The presence of cultural features (residences and utilities) across most of the area overlying the groundwater contamination in Zone 1 severely limits the range of candidate physical barrier placement sites, primarily to the downgradient, leading area of the Zone 1 groundwater contamination along North East Street. Since contaminant interception takes place only via the physical barrier, this remedial approach would have no effect on contaminant reduction (and hence the potential for VI) across the lateral extent of Zone 1 upgradient of any 
engineered physical barrier. Thus, the technology offers no added protection to the upgradient residences.

One or more physical barriers might be employed to reduce horizontal contaminant mobility locally, in a preferred area or direction, but without additional groundwater control measures (such as groundwater extraction, discussed in Section 4.2.6), such structures could have potentially detrimental effects, including contaminant migration around, over, or under the barrier, or localized groundwater mounding upgradient of the barrier. Any mounding effects could drive contaminated groundwater closer to the surface, conceivably increasing VI hazards, or could increase vertical migration of contaminated groundwater from Zone 1 to Zone 2. In addition, the engineered physical barrier — which mainly serves to reduce local contaminant mobility - has limited effect and little added benefit, because natural groundwater mobility is extremely low in most of Zone 1.

\subsubsection{Implementability of Engineered Physical Barriers}

The locations potentially available for implementation of subsurface barrier technologies to address the groundwater contamination in Zone 1 are logistically restricted across most of the Hanover site by the presence of cultural features, including private homes, other structures, roads, and subsurface utilities. Although the depth to the contaminated interval in Zone 1 is typically within $40 \mathrm{ft}$ BGL, specialized excavation and wall construction techniques would be required to attain the 40-ft depth and for effective penetration of the bedrock lithologies that overlie and host the target groundwater-bearing unit. The excavation would require shoring and benching, for example. Construction of a physical barrier would cause relatively short-term disruption to the daily activities of nearby residents, but it would result in significant damage (requiring restoration) to private properties affected by the installation activities.

\subsubsection{Costs of Engineered Physical Barriers}

Costs for engineered physical barriers would be moderate to high. 


\subsubsection{Engineered Physical Barriers — Eliminated}

Because engineered physical barriers (1) could create uncontrolled vertical and horizontal groundwater flow components, (2) do not offer added protection to residents in the upgradient area, (3) would significantly disrupt the community and residents' private properties, and (4) would require the use of costly and hazardous excavation techniques, this technology is eliminated from further consideration.

\subsubsection{Extraction and Treatment of Groundwater}

Groundwater extraction technologies can effectively reduce the mobility and volume of contaminants by coupling groundwater (and contaminant) removal with the potential for hydraulic control of the contaminant migration patterns near the extraction site. Groundwater extraction is most typically accomplished by the installation and pumping of either conventional vertical or horizontal wells.

Groundwater extracted from impacted portions of the water-bearing zones at Hanover would require treatment prior to discharge or disposal.

\subsubsection{Effectiveness of Groundwater Extraction and Treatment}

Groundwater extraction wells (vertical or horizontal) could be installed in a timely manner, and operation of the wells could result in permanent reduction in the mobility and volume of the dissolved carbon tetrachloride contamination in Zone 1. Hydraulic testing of these intervals (Section 2.2.5.2) has demonstrated, however, that the potential for effective use of groundwater extraction is restricted to only a portion of Zone 1 (primarily Subsystem 1, Figure 2.12). Groundwater extraction does not represent an effective technology for sitewide remediation of the groundwater contamination in Zone 1, but it could be used in selected locations for mass removal and contaminant reduction. Potential installation locations are illustrated in Figure 4.1. Active removal of groundwater contaminants from the highconcentration area in Zone 1, as shown in Figure 4.1, would 
- Directly address the contamination that is the source of the only complete exposure pathway causing indoor air to exceed KDHE guidelines - VI from groundwater to residences above the contaminated groundwater in Zone 1;

- Reduce the volume of contaminant available for migration within Zone 1 (migration pathway 2 in Section 2.3.2); and

- Reduce the migration of contamination from Zone 1 to Zone 2 (migration pathway 3 in Section 2.3.2).

The contamination in Zone 2 is inferred to be the result of vertical migration from the vadose zone source area where the highest Zone 1 hydraulic conductivities were observed. Strategic placement of a groundwater extraction system in the high-concentration area in Zone 1 would mitigate or preclude the migration of contamination to Zone 2 and would reduce the already low concentrations of carbon tetrachloride in Zone 2 (which are lower by an order of magnitude than the concentrations in Zone 1), because the most permeable part of Zone 1 appears to be the location where leakage occurs from Zone 1 to Zone 2 .

\subsubsection{Implementability of Groundwater Extraction and Treatment}

The installation of groundwater extraction wells (vertical or horizontal) in the most permeable area of Zone 1 could be accomplished by using conventional braced or un-braced trench construction methods or vertical or horizontal boring techniques. The installation is logistically feasible, subject to access to private property.

Locations suitable for the use of trenching construction methods for extraction well placement would be limited by the depth to groundwater in Zone 1 and the presence of residences, other buildings, streets, and driveways. An undeveloped land parcel north of the property at 300 Westminster Drive (Figure 4.2), where Zone 1 is present at $20 \mathrm{ft}$ BGL, could provide a suitable location logistically (though not optimal technically) for a horizontal extraction well installed with conventional trenching methods. However, where the depth to the contaminated interval in Zone 1 exceeds approximately $25 \mathrm{ft}$ BGL, specialized trenching techniques would be required, including shoring and benching. Construction with these 
specialized techniques would significantly disrupt existing community facilities and services and residents’ private properties and would raise significant safety issues.

Directional boring techniques, in contrast, offer the possibility of optimizing placement of an effective groundwater extraction system while significantly reducing detrimental impacts to the community and safety concerns. Directional boring techniques would allow placement of extraction well(s) as follows:

- Immediately beneath the former CCC/USDA facility and the likely previous vadose zone source area.

- In Subsystem 1, the most permeable and most contaminated (> $500 \mu \mathrm{g} / \mathrm{L}$ ) portion of Zone 1.

- Parallel to the preferential flow path (migration pathway 2; Section 2.3.2), thus impacting the leading edge contamination migrating south and southwest in Zone 1.

- In the area where Zone 1 recharges Zone 2 (migration pathway 3; Section 2.3.2).

Volatile compounds such as carbon tetrachloride and chloroform can be removed from extracted groundwater by using a number of technologies. Two of the most common technologies involve adsorption by granular activated carbon (GAC) and "air stripping." The use of GAC represents an effective technology for the removal of organic contaminants from groundwater. This technology requires little energy for operation; however, periodic replacement of the GAC medium is required, as it becomes depleted during the treatment process. Air stripping involves the removal of VOCs from contaminated groundwater via exposure of the water to a high-volume forced-air flow. This process is typically conducted by using a packed tower or tray aeration unit.

\subsubsection{Cost of Groundwater Extraction and Treatment}

Costs for the groundwater extraction technology are expected to be moderate. 


\subsubsection{Groundwater Extraction and Treatment - Retained}

Because it is effective in suitable locations, groundwater extraction and treatment will directly address the source of VI (the only complete exposure pathway resulting in an exposure route that exceeds levels in KDHE guidelines), is readily implementable, and has moderate costs, groundwater extraction is retained for further consideration.

\subsubsection{Subsurface Removal and Treatment of Volatile Contaminants by Soil Vapor Extraction, Air Sparging, or a Combination}

In contrast to approaches that physically remove contaminated soil or groundwater for $e x$ situ treatment, removal technologies such as soil vapor extraction (SVE) and air sparging (AS) target the removal of volatile contaminants from soil and groundwater in the subsurface environment. Employed alone, SVE is typically used to address vadose zone soil contamination in relatively permeable soils. In this application, SVE is accomplished by "pumping" vertical or horizontal wells to induce a subsurface vacuum and thus extract contaminated soil vapors. Although SVE can remove contaminant vapors arising from an underlying saturated zone, SVE alone does not represent an effective technology for remediating contaminated groundwater.

The AS technology for removal of VOCs from subsurface groundwater is typically implemented by installing one or more (vertical or horizontal) wells screened in the saturated zone, from which air is forced to percolate through the adjacent (contaminated) groundwater column. The air released from an AS system either is allowed to escape naturally to the surface or is collected by a coupled SVE system.

To enhance the removal of contaminants from both groundwater and vadose zone soil, in certain situations SVE can be performed in conjunction with AS. Contaminated soil gas extracted via SVE technologies (or combined SVE-AS systems) might require treatment before release to the air.

\subsubsection{Effectiveness of Subsurface Soil Vapor Extraction and Air Sparging}

No unacceptable levels of contamination have been identified in the vadose zone soils beneath the former CCC/USDA facility that could be targeted for removal via SVE alone. 
Combined SVE-AS could result in a small, localized, permanent reduction of the volume of the contamination in the saturated zone. The existing areal extent of the contamination in Zone 1, however, coupled with the generally low permeabilities and thin, discrete nature of the bedrock groundwater-bearing horizons identified in Zone 1, would make the effective use of coupled SVE-AS for removal of groundwater contamination very difficult to impossible. Air sparging (if used alone) could exacerbate the documented migration of contaminated soil vapor from groundwater into multiple residences.

\subsubsection{Implementability of Subsurface Soil Vapor Extraction and Air Sparging}

Installation of the facilities and equipment required for a combined SVE-AS system at selected locations in Zone 1 might be technically and logistically feasible, but the potential for successful operation of this technology appears extremely limited because of the site's geologic and hydrologic conditions (noted above).

In an interim remedy approved by the KDHE, the CCC/USDA and Argonne have applied combined SVE-AS in large-diameter boreholes for extraction of contaminants from both vadose zone soil and groundwater at Agra, Kansas. The experience at Agra indicates that, in view of the limited radius of influence of each treatment point, small spacing between SVE-AS points is required to achieve reasonably effective removal of contaminants from both soil and groundwater. On the basis of the areal extent of the relatively permeable portions of the contaminated areas in Zone 1 at Hanover, a large number of densely distributed SVE-AS points would be required for this application at Hanover. The presence of residences and other cultural features, however, would make the application difficult to impossible to implement in Zone 1.

\subsubsection{Cost of Subsurface Soil Vapor Extraction and Air Sparging}

Costs for the coupled SVE-AS technologies would be moderate to high. 


\subsubsection{Subsurface Soil Vapor Extraction and Air Sparging - Eliminated}

Because of the absence of unacceptable contamination in vadose zone soil and the potentially limited effectiveness of SVE-AS technologies under the defined conditions at Hanover, these technologies are eliminated from further consideration.

\subsubsection{Removal and Treatment of Sub-Slab Volatile Contaminants}

Although it does not represent a potential site-scale remediation technology, sub-slab vapor extraction, performed by using one or more small-diameter vacuum points to recover shallow soil vapor from directly beneath the building foundation, can be used to mitigate the effects of VI in individual structures.

\subsubsection{Effectiveness of Sub-Slab Vapor Extraction}

Sub-slab vapor extraction, as currently employed in the VI mitigation systems installed and operating at five residences in Hanover, has proven to be an effective risk mitigation technology. This technology can be installed in a timely manner, and it provides both short-term and long-term protection from the effects of VI by reducing contaminant mobility and volume.

\subsubsection{Implementability of Sub-Slab Vapor Extraction}

Sub-slab vapor extraction has been shown to be readily implementable at the Hanover site, as evidenced by the ongoing successful operation of the VI mitigation systems installed in five Hanover residences.

\subsubsection{Cost of Sub-Slab Vapor Extraction}

The demonstrated costs for the sub-slab VI mitigation technology are low. 


\subsubsection{Sub-Slab Vapor Extraction — Retained}

On the basis of effectiveness, implementability, and low cost, the sub-slab VI mitigation technology is retained for further consideration.

\subsubsection{In Situ Treatment by Permeable Reactive Barriers}

Permeable reactive barrier (PRB) technology has been used to treat both organic (including carbon tetrachloride) and inorganic contaminants. A permeable "wall” or barrier containing a chemically and/or biologically active treatment medium capable of interacting with the target groundwater contaminant(s) is constructed in the subsurface, across the groundwater migration pathway. The technology is passive, in that the design relies on natural hydraulic gradients to carry groundwater through the PRB, where the treatment occurs. The thickness of the PRB must be sufficient so that groundwater passes through with adequate residence time for treatment or removal of the contaminants (EPA 2002).

Construction methods used to install PRBs include conventional excavation, continuous trenching, and slurry wall techniques; deep soil mixing; horizontal or large-diameter boring; hydraulic fracturing; and injection. The depth limit for conventional excavation and trenching techniques is typically about $40 \mathrm{ft}$ BGL (Hocking 2004).

Reactive constituents (such as zero-valent iron) are frequently used in barrier construction for the treatment of VOCs. The reactive constituents are often mixed with materials such as guar gum, sand, gravel, or native soil to increase barrier permeability, or in some cases to help promote biological activity. Other potentially reactive media include edible oil, mulch, and hydrogen- or oxygen-releasing compounds. These materials can negatively affect the potability of groundwater in the treatment area.

\subsubsection{Effectiveness of Permeable Reactive Barriers}

Where applicable, the PRB technology is capable of reducing the toxicity, mobility, and volume of contaminants in groundwater. The potential for effective use of this technology to remediate the carbon tetrachloride contamination in groundwater Zone 1 at Hanover, however, is 
extremely limited. Most notably, the identified areal extent of the contamination in Zone 1, plus the multiple groundwater flow directions affecting contaminant migration in this zone, would make effective sitewide interception of the contaminated groundwater by stationary PRBs very difficult. In addition, the presence of cultural features (residences and utilities) across most of the area overlying the groundwater contamination in Zone 1 severely limits the range of candidate PRB placement sites, primarily to portions of Zone 1 having very low hydraulic conductivity (about $0.001 \mathrm{ft} /$ day). One or more PRBs might possibly be employed locally to intercept the contamination in Zone 1 at a restricted number of locations, subject to available property access. Since the PRB technology relies, however, on natural groundwater flow to transport contaminants toward and through the subsurface PRB, the identified low permeabilities would result in a prolonged remediation time frame and would detract from the effectiveness of the technology. Finally, because contaminant reduction takes place only within the PRB itself, this passive remedial approach would have no effect on the levels of groundwater contamination (and hence the potential for VI) remaining upgradient of any constructed PRB throughout the life of the Zone 1 restoration effort. Implementation of $\mathrm{PRB}(\mathrm{s})$ in the limited suitable locations at Hanover would not address VI potential or offer added protection to the residences upgradient of the installations.

\subsubsection{Implementability of Permeable Reactive Barriers}

As noted in Section 4.2.9.1, the number of locations potentially available for implementation of the PRB technology to address groundwater Zone 1 is restricted logistically across most of the Hanover site by the presence of cultural features including private homes, other structures, roads, and subsurface utilities. Recognizing this limitation, the depth to the contaminated interval in Zone 1 is typically less than $40 \mathrm{ft}$ BGL; however, specialized PRB construction techniques would be required for effective penetration of the bedrock lithologies that overlie and host the target groundwater-bearing unit. Construction of a PRB would cause relatively short-term disruption to the daily activities of nearby residents, but it could result in significant damage to private properties and a requirement for restoration. Long-term access to any constructed PRB location(s) would be required for periodic renewal of the subsurface treatment medium as it became depleted over time. 


\subsubsection{Costs of Permeable Reactive Barriers}

Costs for the PRB technology would be high.

\subsubsection{Permeable Reactive Barriers - Eliminated}

On the basis of its limited effectiveness in the low-permeability setting of Zone 1, its failure to offer protection for residences upgradient of the installation, difficulty in implementation due to the presence of cultural features including residences, and high cost, PRB technology is eliminated from further consideration.

\subsubsection{In Situ Chemical Reduction Treatment}

For contaminants (such as carbon tetrachloride) that are amenable to anaerobic biodegradation processes, the introduction into the subsurface (by means other than the construction of a PRB) of materials that promote either abiotic or biologically mediated in situ chemical reduction (ISCR) can be a viable remedial approach. Existing or newly installed wells, or (in some cases) direct-push technologies, can be used to deliver the treatment chemicals to the impacted groundwater zone via pressure injection or by passive placement within the borehole or casing. The applicability of ISCR is determined primarily by the nature of the contaminant(s) and the availability of suitable treatment media. Successful implementation is also strongly influenced, however, by the site-specific geologic and hydrologic characteristics of the target treatment zone, as these parameters largely determine the potential for effective emplacement and dispersion of the treatment material.

\subsubsection{Effectiveness of In Situ Chemical Reduction Treatment}

Where applicable, the ISCR technology is capable of reducing the toxicity, mobility, and volume of contaminants in groundwater. Active delivery of the ISCR technology throughout the high-concentration area in Zone 1 is one approach. Another approach involves placement of ISCR points in focused treatment zones similar to the placement of PRBs, as discussed in Section 4.2.9. For the active delivery approach, a prohibitively large number of densely distributed application points would be required to achieve effective in situ treatment throughout 
the high-concentration area in Zone 1. In addition, the presence of residences and other cultural features would make the active delivery application difficult to impossible in this area. For the focused treatment zone approach, application of ISCR faces many of the site-specific limitations to effectiveness that are outlined in Section 4.2.9.1 for the PRB technology. Specifically, because the ISCR approach is effectively "passive” in relying on the natural movement of groundwater to the treatment area, its implementation would be expected to result in a prolonged remediation time frame and only localized effects at the margins of Zone 1, where the lateral extent of Zone 1 is diminished. In addition, ISCR implementation with the passive approach would have little to no active influence on groundwater contaminant levels at locations upgradient of the implementation area throughout the lifetime of the projected remediation effort.

The wide areal distribution and multiple groundwater flow directions affecting the contamination in Zone 1 would be formidable obstacles to effective sitewide interception of the contaminated groundwater in this interval by an array of ISCR treatment points (pressure injection or passive in-well placement).

\subsubsection{Implementability of In Situ Chemical Reduction Treatment}

The ISCR technology could be implemented at Hanover with readily available equipment and materials. In Zone 1, the installation of boreholes (for one-time placement of treatment materials or the construction of permanent treatment wells) would require the use of conventional drilling techniques (in lieu of direct-push technologies) to penetrate the bedrock lithologies that overlie and host the target groundwater-bearing units. If pressurized injection of the ISCR materials was employed, specialized equipment might be required because of the limited thickness and generally low permeability of the Zone 1 intervals. Effective dispersal of the ISCR materials into the contaminated lithologies (with either injection or passive placement) could be highly problematic, resulting in a small radius of influence for the treatment medium. Drilling and ISCR placement operations would likely cause significant disruption to the daily activities of nearby residents, and they could result in damage to private property that would require restoration. Long-term access to the ISCR placement locations would be required for periodic renewal of the subsurface treatment medium as it became depleted over time.

With the approval of the KDHE, the CCC/USDA and Argonne have pilot-tested the use of the $\mathrm{EHC}^{\circledR}$ material developed by the Adventus Group for the in situ treatment of carbon 
tetrachloride at the former CCC/USDA facility in Centralia, Kansas (Argonne 2009a). The EHC material is available in forms suitable for injection or for passive placement in boreholes and wells (A-SOX ${ }^{\mathrm{TM}}$ technology). The experience at Centralia has indicated that effective contaminant removal requires close spacing of $15 \mathrm{ft}$ or less between application points. The areal extent of high-concentration areas in Zone 1 and the small expected radius of influence indicate that a large number of application points would be required for active in situ treatment at Hanover. In addition, residences and other cultural features would restrict treatment locations, and the use of the ISCR technology to address carbon tetrachloride contamination can result in persistent fouling of the groundwater being treated.

\subsubsection{Costs of In Situ Chemical Reduction Treatment}

Expected costs for the ISCR treatment technology would be low in the less aggressive inwell application and moderate to high for injection in a treatment field.

\subsubsection{In Situ Chemical Reduction Treatment — Eliminated}

On the basis of very limited effectiveness and significant implementability issues, cost, and the potential for negative impacts to groundwater quality, the ISCR treatment technology is eliminated from further consideration.

\subsubsection{In Situ Treatment by Phytoremediation}

Phytoremediation, as considered for this CAS, is the use of growing plants to treat contamination in environmental media, most commonly in soils, surface waters, or relatively shallow groundwater. For the treatment of VOCs in groundwater, the processes associated with phytoremediation that can result in contaminant removal include groundwater (and contaminant) uptake, transpiration, and volatilization; degradation of contaminants in plant tissues; and enhanced microbial activity in the root zone.

The potential for successful use of phytoremediation to treat groundwater is influenced by many site-specific factors, including geology, hydrogeology, groundwater flow, land surface topography, local climate, altitude, soil salinity, available nutrient levels, and soil fertility. 
Candidate plant species for phytoremediation must be selected for growth and water use characteristics suited to the site conditions.

The depth to the contaminated groundwater and the physical/mechanical characteristics of the intervening materials from the land surface to the groundwater-bearing zone are critical parameters affecting the ability of plant roots to reach the targeted contamination. Although prairie grasses and forbs have root systems that can reach 10-15 ft BGL, most active phytoremediation plantations employ relatively quick-growing, water-loving trees to address groundwater contamination. Through the use of specialized planting techniques, selected tree species can be capable of accessing groundwater at depths of 15-25 ft BGL under suitable site conditions.

With the approval of the EPA and the Nebraska Department of Environmental Quality, the CCC/USDA and Argonne are using phytoremediation as a component in the restoration of groundwater contaminated by carbon tetrachloride at the former CCC/USDA facility in Murdock, Nebraska (Argonne 2009b and references therein). A review of phytotechnology and the extensive baseline studies conducted to evaluate the potential for successful implementation of phytoremediation at Hanover is in Appendix C. Major experts in the phytoremediation field participated in the design and implementation of the very comprehensive baseline study, as well as in evaluation of the study's results and of the effectiveness and implementability of the technology at Hanover.

\subsubsection{Effectiveness of Phytoremediation}

Where applicable, phytoremediation technology is capable of reducing the toxicity, mobility, and volume of contaminants in groundwater, but it faces many of the site-specific limitations outlined in Section 4.2.9.1 for PRB technology. Specifically, because it is effectively "passive" in relying on the natural movement of groundwater to the treatment area, the implementation of phytoremediation could be expected to result in a prolonged remediation time frame and highly localized effects. In addition, phytoremediation would have little to no active influence on groundwater contaminant levels at locations upgradient of the implementation area throughout the lifetime of the remediation effort. 
The wide areal distribution and multiple groundwater flow directions affecting the contamination in Zone 1 would be formidable obstacles to effective sitewide interception of the contaminated groundwater in this interval with an array of phytoremediation groves. The presence of cultural features (residences and utilities) across most of the area overlying the groundwater contamination in Zone 1 severely limits the range of locations that would be amenable to phytoremediation.

The results of the extensive baseline study conducted to evaluate the potential effectiveness of phytoremediation at Hanover (Appendix C) indicated less correlation than anticipated between carbon tetrachloride concentrations in tree branch tissues and known contamination in groundwater Zone 1 . This lack of correlation was particularly noticeable in the northern portion of the former CCC/USDA property, where the highest concentrations were found in groundwater Zone 1. These results raised concerns about the potential effectiveness of phytoremediation as a treatment option for Zone 1.

\subsubsection{Implementability of Phytoremediation}

The generally recommended target remediation depth for phytotechnology is less than $15 \mathrm{ft} \mathrm{BGL}$, while the maximum practical depth is generally $25 \mathrm{ft}$ BGL (ITRC 2009).

Groundwater in Zone 1 generally occurs (at roughly $17 \mathrm{ft}$ BGL) near the maximum recommended target depth for phytoremediation. However, residences and other cultural features limit the number of locations potentially available for the planting of phytoremediation areas to address Zone 1. The existing open surface areas primarily overlie the portions of the Zone 1 water-bearing zone with low hydraulic conductivities (approximately $1 \mathrm{ft} /$ day). Even in the portions of Zone 1 with higher permeability values, extensive hydraulic testing has demonstrated that the expected capacity of the few discrete, thin, moist-wet intervals in Zone 1 to provide sufficient groundwater to support healthy tree growth is limited. This limitation is detrimental to the effectiveness of the technology.

\subsubsection{Cost of Phytoremediation}

Costs for the phytoremediation technology would be moderate to high. 


\subsubsection{Phytoremediation - Eliminated}

On the basis of limited effectiveness, significant implementability issues, and moderate to high cost, the phytoremediation treatment technology is eliminated from further consideration.

\subsection{Potentially Applicable Technologies}

The screening process for potentially applicable methods for addressing the contaminated soil vapor and groundwater in Zone 1 at the Hanover site resulted in retention of the following technologies and practices for further consideration:

- Municipal land use controls

- Vapor intrusion barriers

- Groundwater extraction and treatment

- Sub-slab vapor extraction

These technologies and practices that were retained through the screening analysis were used to develop the remedial action alternatives for the site that are identified and discussed in Section 5. 


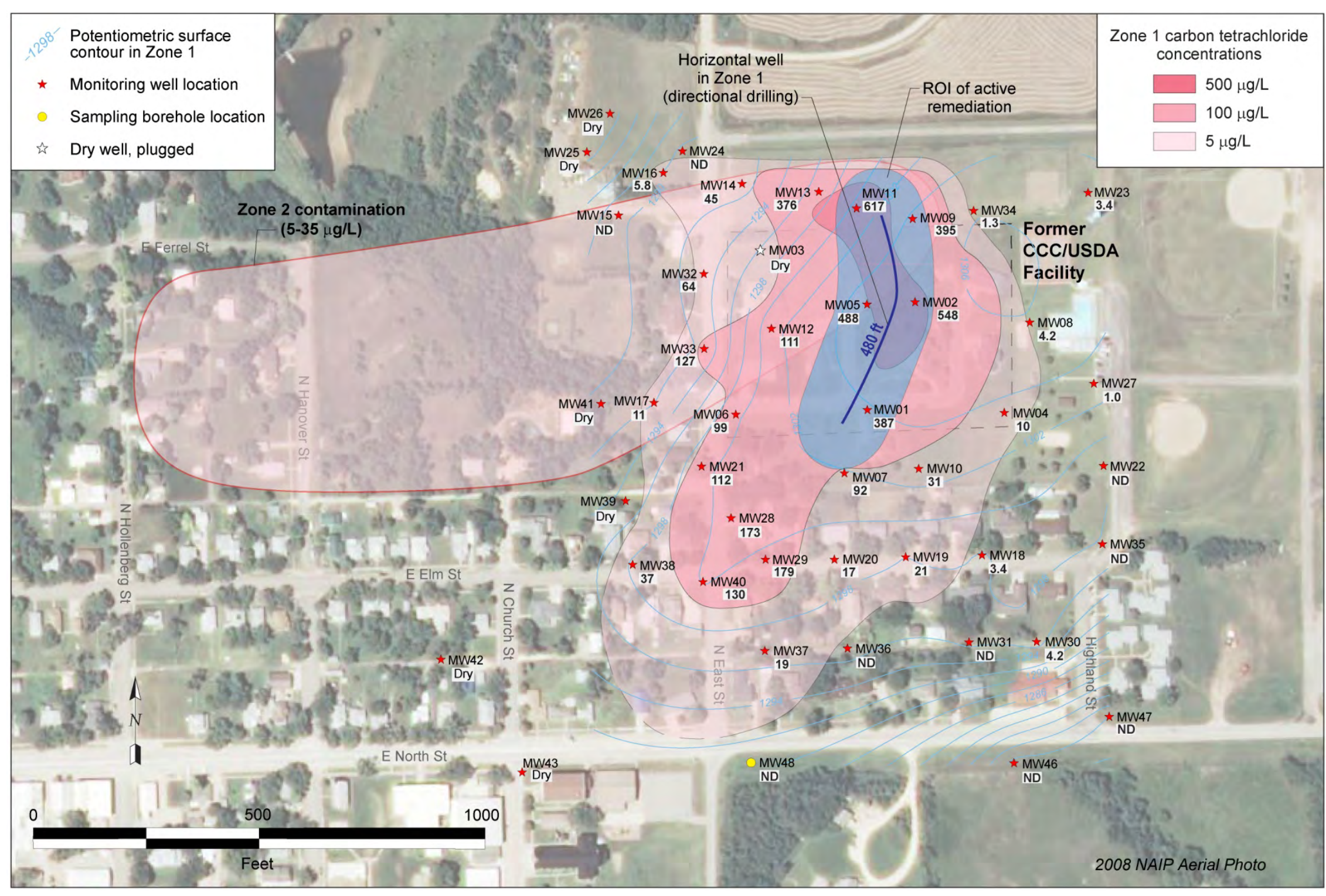

FIGURE 4.1 Potential location for an extraction well in groundwater Zone 1. Source of photograph: NAIP (2008). 


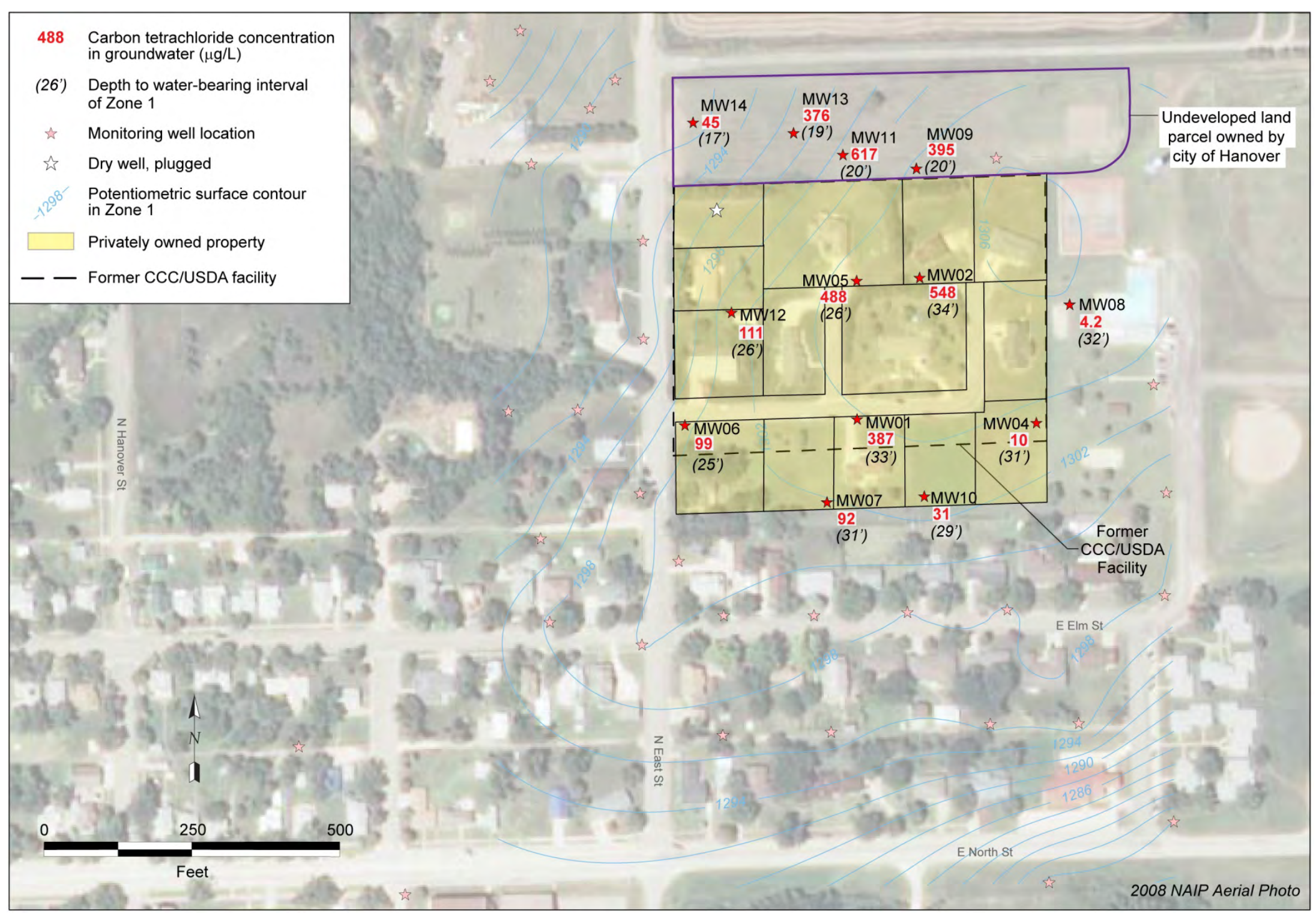

FIGURE 4.2 Distribution of depths from the ground surface to groundwater Zone 1, with carbon tetrachloride concentrations at monitoring wells on and near the former CCC/USDA property. Source of photograph: NAIP (2008). 


\section{Description of Alternatives}

Corrective action alternatives for the former Hanover CCC/USDA facility were developed on the basis of the remedial technologies that were retained following the initial screening process described in Section 4, conducted in accordance with EPA (1988) and KDHE (2001a, 2009b) guidance. The resulting candidate technologies for addressing groundwater in Zone 1 and soil vapor contamination attributable to groundwater Zone 1 were combined to create two remedial alternatives, in addition to the no-action alternative, for further consideration. This section describes the three evaluated remedial alternatives in detail.

\subsection{Alternative 1: No Action}

The no-action response is a required component of the CAS evaluation under KDHE (2001a) guidance, to provide a baseline for comparison. The no-action response is evaluated as Alternative 1 in Sections 5 and 6.

Under this alternative, no action would be taken at the former CCC/USDA facility, and the contaminated groundwater would remain in place. However, the no-action alternative would include continued operation and maintenance of the sub-slab vapor mitigation systems that have already been installed at five residences in Hanover. The systems would continue to be inspected annually by the CCC/USDA, and an air sampling event involving the collection of sub-slab, indoor air, and ambient air samples would be performed every 5 yr. The CCC/USDA would continue to compensate the owners of the five residences for the electric power required to operate the systems.

Under the no-action alternative, all existing water supply protective measures are assumed to remain in effect. These include the constraints established under the RWD \#1 crossconnection control regulations and KDHE regulations governing the location and construction of water supply wells (Sections 3.1.3.1 and 3.1.3.2).

The former CCC/USDA facility and areas within the footprint of the groundwater contamination identified in Zones 1 and 2 would continue to be a residential area. Local groundwater in Zone 2 is non-potable, and the production from Zones 1, 3, and 4 is inadequate 
for domestic water supply. Consequently, the groundwater contamination at Hanover does not affect potable water use under this alternative.

\subsection{Alternative 2: Municipal Land Use Controls, Monitoring, and Well Abandonment}

Alternative 2 would have the following components:

- $\quad$ Sitewide groundwater monitoring

- Abandonment of lawn and garden wells

- Inspection of established and future sub-slab VI mitigation systems

- Remuneration for power costs to operate the VI mitigation systems

- Municipal land use controls

- Five-year reviews, including the collection of indoor air samples to assess the efficacy of the VI mitigation systems

\subsubsection{Sitewide Groundwater Monitoring}

A comprehensive groundwater monitoring program would be implemented at and near the former CCC/USDA facility to evaluate groundwater quality. For cost estimation, a 30-yr planning horizon has been used. The monitoring program would include the collection of groundwater samples from 18 of 64 existing monitoring wells (Figure 5.1), laboratory analysis for selected VOCs, data evaluation, and reporting. The samples would be analyzed for field parameters ( $\mathrm{pH}$, temperature, and conductivity) at the wellhead and for carbon tetrachloride, chloroform, and methylene chloride by a qualified laboratory. The 18 wells would be sampled every year in years 1-10 and in alternate years in years 11-30. A summary of the results would be sent to the KDHE for each sampling event. Data analyses, evaluations, and interpretations would be delivered to the KDHE every $5 \mathrm{yr}$ as a component of the 5-yr reviews (Section 5.2.5). The 
18 monitoring wells include 14 wells in Zone 1 and 4 wells in Zone 2. These wells were selected for continued monitoring of the area of highest contamination (the "hot spot") and the boundaries of the current contaminant distribution in the impacted zones. The wells, the well depths, and the selection basis are summarized in Table 5.1.

\subsubsection{Well Abandonment}

An underlying assumption for this alternative is continued compliance with RWD \#1 cross-connection regulations (Section 3.1.3.1) and KDHE well construction regulations (Section 3.1.3.2) that are protective of the water supply. As an additional protective measure, this alternative would include the proper abandonment of four existing private lawn and garden wells installed with continuous gravel packs connecting contaminated Zone 2 and deeper groundwaterbearing Zones 3 and 4. The four lawn and garden wells are on properties owned by B. Bruna, K. Jueneman, D. Martin, and R. Schlabach (Figure 2.11).

\subsubsection{Vapor Intrusion and Mitigation Monitoring}

Sub-slab soil vapor mitigation systems have been installed in five homes (Figure 2.14). The program of inspection and periodic air sampling already implemented to document the continued successful operation of these mitigation systems would continue under this alternative. Indoor air samples are collected in the basement and the living area of each home. Ambient air samples are also collected. The indoor air sampling, laboratory analysis for selected VOCs, data evaluation, and reporting are being performed every $5 \mathrm{yr}$. The mitigation system equipment is being tested annually.

\subsubsection{Municipal Land Use Controls}

Alternative 2 involves the establishment of MLUCs to augment the risk management mechanisms that are already in place.

To implement MLUCs, the CCC/USDA would work with the Hanover municipal authorities and the KDHE to develop a control mechanism for the Hanover municipality as a 
whole. The controls would be crafted as a municipal ordinance to address both the groundwater and upward VI exposure routes. The ordinance would prohibit the installation of a water supply well within the contamination footprint or otherwise enforce the existing water supply protective measures. The municipal ordinance would also require that any new habitable structure constructed (or to be constructed) within $100 \mathrm{ft}$ laterally and $40 \mathrm{ft}$ vertically of impacted groundwater be assessed for VI hazards by a third party and that any unacceptable exposure to VI hazards be mitigated (at the expense of the CCC/USDA). A city agency would be empowered to monitor and enforce the ordinance(s) created; the CCC/USDA would underwrite any specific costs to the city associated with these activities.

As an element of the MLUCs, the CCC/USDA would work with the city to create a public outreach program consisting of public meetings, notices, and/or letters that emphasize the existing regulations and guidelines related to (1) well permitting, siting, and construction; (2) private well cross-connections to the public supply; (3) the potential risks of VI within $100 \mathrm{ft}$ laterally and $40 \mathrm{ft}$ vertically of contamination; and (4) VI monitoring.

The outreach program would reinforce, by means of meetings, newspaper notices, letters, public service announcements, etc., the following existing regulations (Section 3.1.3):

1. The requirements for well permits, as outlined in the Washington County Sanitation Code.

2. The RWD \#1 rules and regulations that protect the public water supply by prohibiting any cross-connection of private water supply wells to the public distribution system.

3. The KDHE well construction and siting regulations, which are meant to minimize the potential for contamination of delivered or obtained groundwater, as well as to protect groundwater aquifers from pollution and contamination.

Although these existing regulations would preclude exposure to contaminated groundwater via domestic water use, no similar regulations address potential exposure via an upward VI pathway. However, in association with efforts to ensure compliance with cross- 
connection prohibitions and well construction/installation requirements, the CCC/UDSA would work with the municipality to address the upward VI pathway. The outreach program would be the mechanism for informing residents that a third party would be responsible for assessing and mitigating (if necessary, at CCC/USDA expense) - any newly constructed habitable structure within $100 \mathrm{ft}$ laterally and $40 \mathrm{ft}$ vertically of impacted groundwater.

If the municipality does not establish controlling ordinances, an alternate land use control program could be established, involving information dissemination, monitoring, and (if needed) risk assessment and mitigation. The outreach aspects discussed above would occur. Under this alternate control program, the status of building and well construction activities could be assessed periodically by either the municipality or a third party. If the periodic assessment revealed the potential for exposure, the control program could provide for the sampling and analysis of indoor air or a groundwater supply by a third party. If an exposure pathway was found to exist, VI mitigation or well abandonment would occur, with the CCC/USDA's assistance.

\subsubsection{Five-Year Reviews}

For sites (like Hanover) where contamination is expected to remain at levels that do not allow for unrestricted residential use of the site, the KDHE suggests reviews at least every 5 yr to ensure that remedial actions remain protective of human health and the environment. The 5-yr reviews for Hanover would include document review, interviews, a site inspection, and a report of findings. Documents to be reviewed by the CCC/USDA and Argonne include the Corrective Action Decision (CAD), groundwater monitoring results, and records associated with monitoring MLUCs. The report is expected to include the corrective action objectives established by the CAD, a summary of the site visit, an evaluation of groundwater monitoring and VI mitigation monitoring results, any areas of noncompliance, and a summary of the protectiveness of the established corrective action.

\subsection{Alternative 3: Targeted Groundwater Extraction and Treatment in Zone 1}

In this alternative, targeted groundwater extraction is proposed to focus on the contamination that is the source of the only complete exposure pathway, resulting in indoor air 
concentrations of carbon tetrachloride above KDHE guidelines - VI from groundwater to residences above the contaminated groundwater in Zone 1. Alternative 3 would (1) reduce the potential for contaminant migration in Zone 1 (migration pathway 2 in Section 2.3.2) and (2) reduce the migration of contamination from Zone 1 to Zone 2 (migration pathway 3 in Section 2.3.2), leading to accelerated decreases in the contaminant levels in Zone 2.

The detailed geologic, hydrologic, and contaminant distribution properties of the Zone 1 groundwater-bearing unit, together with the results of extensive hydraulic testing conducted for this interval (summarized in Section 2.2.5), demonstrate the difficulties of using extraction technologies in Zone 1. However, extraction technologies can be deployed selectively in Subsystem 1, the relatively more permeable and highly contaminated (> $500 \mu \mathrm{g} / \mathrm{L}$ ) portion of Zone 1. In this alternative, targeted groundwater extraction is therefore proposed to focus on the following priorities, in keeping with the corrective action goals developed in Section 3:

- Preferentially reduce the highest carbon tetrachloride concentrations in Zone 1, to remove contaminant mass and thus mitigate further increases in downgradient contaminant concentrations (and hence possible VI risk) in Zone 1.

- By reducing the contaminant concentrations in Zone 1, mitigate the potential for continued vertical contaminant migration from Zone 1 to Zone 2.

\subsubsection{Groundwater Extraction System Construction}

This alternative involves extraction of groundwater from Zone 1 by using a horizontal well constructed in the relatively permeable portion of Zone 1, treating the water with an air stripping unit, and discharging the treated groundwater to a surface drainage feature. The most permeable part of Zone 1 includes the primary area in which groundwater (and contaminant) leakage occurs from Zone 1 to Zone 2.

The relatively permeable region of Zone 1 (Subsystem 1 in Figure 2.12) will be targeted for contaminant removal. In general, this area coincides with the distribution of the highest carbon tetrachloride concentrations (> $500 \mu \mathrm{g} / \mathrm{L}$ ) in Zone 1 (Figures 2.9 and 2.10). However, the identified groundwater production capacity of the Zone 1 interval in this area is insufficient to 
support effective groundwater extraction by conventional vertical wells. Consequently, a horizontal extraction well will be employed.

Directional boring methods will be used to install a continuous, surface-to-surface horizontal well boring aligned (as closely as logistically possible) with the interpreted threedimensional location of maximum carbon tetrachloride concentrations in Zone 1 (Figure 4.1). The boring path will be designed to follow the variable depths and lateral positions of the contaminated interval without passing directly beneath habitable structures.

The directional boring equipment will be positioned at an insertion point on city property north of 300 Westminster Street, near the northern boundary of the former CCC/USDA facility (Figure 5.2). The boring will enter the subsurface on the side of the hill, at a ground surface elevation of approximately 1,314 ft AMSL, to reach the targeted contamination in Zone 1 at an elevation of approximately 1,298 ft AMSL near MW11 (Figure 5.3). When it reaches the targeted depth, the boring will be advanced southward with an upward slope for a distance of $180 \mathrm{ft}$, to an elevation of approximately 1,302 ft AMSL. The boring will then trend to the southsouthwest with a downward slope for an additional $300 \mathrm{ft}$, to an elevation of approximately 1,294 ft AMSL. In the area south of Kensington Street near MW01, the boring will exit to the surface, emerging on a currently unoccupied land parcel to allow for boring servicing and completion (Figures 5.2 and 5.3). The boring will constitute a total proposed length of approximately $660 \mathrm{ft}$.

The extraction well casing will be pulled through the horizontal boring from the southern boring exit point back to the northern boring entrance point. A 6-in. extraction well will be installed in the 10-in. boring (approximately $660 \mathrm{ft}$ long). The well's screen length will be $480 \mathrm{ft}$ (180 ft trending southward and upward and $300 \mathrm{ft}$ trending south-southwestward and downward).

Two vertical recovery wells, one at each end of the horizontal screened casing, will be installed and tied into the horizontal boring. A submersible pump installed in each vertical recovery well will be used to pump groundwater from the 480-ft horizontal well to the surface and then into the piping system, which will route the recovered contaminated groundwater northward to a treatment facility and then to a discharge point intersecting the existing surface drainage west of North East Street (Figure 5.2). Effluent from the treatment will be monitored monthly. 
Collected groundwater from each of the vertical recovery wells will be conveyed via underground piping to a stainless steel, low-profile tray aerator system on a community-owned land parcel north of the property at $400 \mathrm{~N}$. East Street. The approximate location of the piping route (Figure 5.2) will be adjusted as needed to accommodate local utilities and accessibility.

The tray aerator will be located in a custom wood-framed, heated structure ( $8 \mathrm{ft}$ by $10 \mathrm{ft}$ ) on a concrete slab. The aerator will be operated 12 months/year. The submersible pump status, control, and communication units will be housed in the heated structure. The control panel for the tray aerator system will be mounted in the building, within an enclosure rated by NEMA (the National Electrical Manufacturers Association). Underground piping will run from the aerator to the discharge point on the intermittent creek west of the former CCC/USDA facility. Figure 5.2 shows the locations of the treatment building and the effluent discharge point.

\subsubsection{Groundwater Extraction System Operations and Monitoring}

The groundwater extraction system will be operated to provide for hydraulic containment (KDHE 2005e) in a predicted target capture zone represented as the radius of influence (ROI) created in Zone 1 by pumping of the proposed 480-ft-long horizontal well (Figure 5.4). Operation of the groundwater extraction system will reduce the highest carbon tetrachloride concentrations in Zone 1, remove contaminant mass, and thus mitigate further increases in downgradient contaminant concentrations in Zone 1 - ultimately reducing those concentrations and hence eliminating possible VI risk. Operations are also expected to mitigate the potential for continued vertical contaminant migration from Zone 1 to Zone 2.

\subsubsection{Monitoring of the Mass Reduction System and Its Components}

Alternative 3 will significantly reduce the highest contaminant concentrations in groundwater in Subsystem 1 and possibly in a larger area of adjacent Subsystem 2 of Zone 1. The active groundwater extraction and treatment proposed in this alternative will reduce contaminant mass that is potentially migrating downgradient and accelerate sitewide groundwater restoration and will be consistent with the criteria for hydraulic containment outlined in KDHE Policy BER-RS-028 (KDHE 2005e). 
The required components of the active groundwater extraction and treatment system (KDHE 2005e) are as follows:

- Source Area Reduction. This goal can be achieved by installing and operating the groundwater extraction system proposed in Alternative 3, targeted to treat the most elevated carbon tetrachloride concentrations in water-bearing Zone 1. The lateral extent of the mass reduction area (Figure 5.4) includes most of the former CCC/USDA facility. The vertical extent of the mass reduction area is limited by the extent of groundwater Zone 1 .

- Mass Reduction Area Monitoring Network. Six existing monitoring wells completed in Zone 1 (MW01, MW02, MW05, MW09, MW11, and MW13; Figure 5.4) are recommended as the mass reduction area monitoring network. These wells are evenly distributed near or within the expected radius of influence of the proposed horizontal extraction well - and hence are well placed to monitor the process of mass reduction in response to the pumping of this well.

- Land Use Controls. A land use control program (Section 5.2.4) will be implemented sitewide.

The recommended groundwater extraction program is specifically targeted to reduce the mass and concentration of carbon tetrachloride in the most highly contaminated portion of Zone 1 (Figure 2.9). The high contaminant levels are primarily associated with Subsystem 1 (Figure 2.12), the more permeable portion of the Zone 1 unit, as defined by hydraulic conductivity values derived through extensive field testing (Section 2.2.5.2). The proposed mass reduction area (Figure 5.4) encompasses Subsystem 1 and immediately adjacent portions of the Zone 1 groundwater-bearing unit.

The estimated target capture zone for the groundwater extraction system (Figure 5.4; discussed in detail in Appendix D) is located near the groundwater divide (Figure 2.17) and across the portion of Zone 1 with the highest carbon tetrachloride concentrations (>500 $\mu \mathrm{g} / \mathrm{L})$. Operation of the groundwater extraction system will decrease contaminant concentrations in the entire defined mass reduction area. The groundwater flow pattern (Figure 5.4) indicates that 
removal of carbon tetrachloride by the treatment system will prevent further contaminant migration toward the west and northwest (in the mass reduction area) and toward the southwest (exiting the mass reduction area), consistent with the criteria for hydraulic containment outlined in KDHE Policy BER-RS-028 (KDHE 2005e).

\subsubsection{Extraction System Operation}

Conservative estimates of the anticipated production rates for the Zone 1 horizontal well in relation to the potential volumes and distribution of contaminated groundwater present in this interval (outlined in Appendix D) indicate that pumping under Alternative 3 will have the most significant impact on groundwater contaminant levels within approximately $5 \mathrm{yr}$, with diminishing benefits thereafter.

The proposed operating period for the groundwater extraction system is not recommended arbitrarily. The operating time is based on an analysis of the pore volume exchange required to remove carbon tetrachloride contamination from the Subsystem 1 waterbearing zone to the reasonably expected point of diminishing returns. The parameters considered in this analysis (Appendix D) include the following:

- Site-specific hydrogeologic and geochemical analysis results from the 20092012 investigations at Hanover (Argonne 2011).

- Carbon tetrachloride retardation factors (1) determined by Argonne for similar soils at other CCC/USDA facilities in Kansas and Nebraska and (2) reported in the literature.

- Variations in contaminant migration time as a result of lithologic heterogeneity.

- Volumetric analysis of the expected cone of depression that will be induced by pumping in Zone 1. 
The results of this technical analysis indicate that an operating period of approximately $5 \mathrm{yr}$ is expected to yield the maximum benefit from the groundwater extraction component of Alternative 3. The treatment system is not designed to extract contaminants from Subsystem 3 of Zone 1 because of its extremely low permeability (Table 2.1), and thus an extended operation period will have little effect on the Subsystem 3 area.

The first 5-yr review will assess the impact of the extraction program in Zone 1 and evaluate whether continued groundwater extraction is technically warranted. The CCC/USDA anticipates that significant source area reduction will be achieved in the mass reduction area wells within the first $5 \mathrm{yr}$ of the 30-yr duration of Alternative 3. Intrinsic remediation is expected to continually reduce contaminant concentrations in the remaining $25 \mathrm{yr}$ of the alternative. Potential continued operation of the groundwater extraction system beyond a planned 5-yr time frame is discussed in Section 5.3.2.3.

\subsubsection{Groundwater Monitoring}

A comprehensive groundwater monitoring program will be implemented at and near the former CCC/USDA facility to evaluate groundwater quality. Groundwater will be monitored at the proposed 6 mass reduction area wells (described in Section 5.3.2.1) and 12 additional sitewide monitoring wells (8 in Zone 1 and 4 in Zone 2; see Figure 5.5). The wells, the well depths, and the selection basis are summarized in Table 5.1.

The 12 proposed sitewide monitoring wells were selected by considering the following site-specific information obtained during the comprehensive Hanover site investigation: (1) the three-dimensional boundaries of the contaminant distribution; (2) the limited lateral extent of groundwater-bearing Zone 1 and Zone 2, which are bounded by the physical erosional limits of the local stratigraphic Unit 3 and Unit 6, respectively (Section 2.2.5.1; Figures 2.6 and 2.7); (3) their locations along the directions of preferential groundwater flow and contaminant migration; (4) the distances from the current edge of groundwater contamination to the erosional limits of Zone 1 and Zone 2; and (5) the extremely low permeability of much of Zone 1 $\left(<10^{-2} \mathrm{ft} /\right.$ day; Table 2.1 and Figure 2.12), resulting in extremely low mobility of contaminants near the edge of the contamination. 
The proposed sitewide monitoring wells are widely distributed, covering the contaminated areas outside the treatment zone (Figure 5.4), and are situated close to both the leading edges of the contamination and the erosional limits of Zone 1 and Zone 2 along the preferred directions of migration (Figures 5.6 and 5.7). These monitoring locations are expected to capture any changes resulting from natural attenuation processes, as well as any potential contaminant movement along the migration pathways. The number of wells is adequate for the monitoring of contaminants and their migration, given the laterally constraining erosional limits of these zones.

The monitoring program will involve the collection and analysis of groundwater samples, data evaluation, and reporting. The samples will be analyzed for the following parameters:

- Dissolved oxygen.

- Oxidation-reduction potential.

- $\quad \mathrm{pH}$, temperature, and conductivity at the wellhead.

- Carbon tetrachloride and its degradation products (chloroform and methylene chloride) by a qualified laboratory.

A one-time baseline monitoring event will be conducted before the groundwater extraction system is installed. In this baseline monitoring, the 6 mass reduction area wells and the 12 sitewide monitoring wells will be sampled, with analysis for the parameters noted above. Subsequently, when the groundwater extraction system is operating, comparison of the results from the baseline monitoring event and the results of periodic monitoring of the mass reduction area and sitewide monitoring wells will document changes in the levels of the contaminants in response to (1) the groundwater extraction component of the proposed remedy and (2) intrinsic remediation processes, including the reductive dechlorination of carbon tetrachloride. However, changes in response to intrinsic remediation are expected to be much slower than changes in response to groundwater extraction during effective operation.

The 6 mass reduction area wells will be sampled twice in year 1, 6 months after start-up of the groundwater extraction, and $1 \mathrm{yr}$ after start-up. Thereafter, the 6 mass reduction area wells 
will be sampled annually for 4 yr. The 12 sitewide long-term monitoring wells will be sampled annually in years 1-10 and then every $2 \mathrm{yr}$ in years 11-30 (Table 5.1). This sampling frequency is proposed with consideration for the following site-specific characteristics of the contaminated groundwater zone:

- Extremely poor permeability. Of the contaminated Zone 1 area, 94\% has low to extremely low hydraulic conductivity (Table 2.1).

- Low production rates. The sustainable pumping rate is less than $1 \mathrm{gpm}$ for $6 \%$ of the contaminated Zone 1 area and less than $0.3 \mathrm{gpm}$ for the remaining $94 \%$ of the area.

- Extremely low average groundwater flow velocity, ranging from $0.11 \mathrm{ft} / \mathrm{yr}$ to $13.97 \mathrm{ft} / \mathrm{yr}$.

Under these site-specific conditions, any significant changes will be captured by the monitoring program at the proposed frequency.

In addition, monitoring results for the mass reduction area wells and the sitewide wells will be evaluated to determine whether the proposed sampling frequencies are adequate. A summary of the results will be sent to the KDHE for each sampling event. Data analyses, evaluations, and interpretations will be delivered to the KDHE every $5 \mathrm{yr}$ as a component of the 5-yr reviews (Section 5.2.5).

The 5-yr reviews will serve as a project management mechanism. As part of the first 5-yr review, a decision will be made whether to extend the operation of the active treatment beyond the initially planned $5 \mathrm{yr}$ on the basis of documented system performance and the concentrations attained in the six mass reduction area wells. Similarly, the progress of continued reduction of contamination via intrinsic remediation will be evaluated in conjunction with the ongoing 5-yr review process, on the basis of the concentrations observed with time in the sitewide monitoring well network. 


\subsubsection{Additional Alternative 3 Components}

Alternative 3 will include the following components already described for Alternative 2 (Section 5.2):

- Abandonment of lawn and garden wells

- Inspection and maintenance of sub-slab VI mitigation systems

- Remuneration for power requirements to operate the VI mitigation systems

- Five-year reviews, including the collection of indoor air samples to assess the efficacy of the VI mitigation systems

- Land use control program 
TABLE 5.1 Proposed monitoring well network.

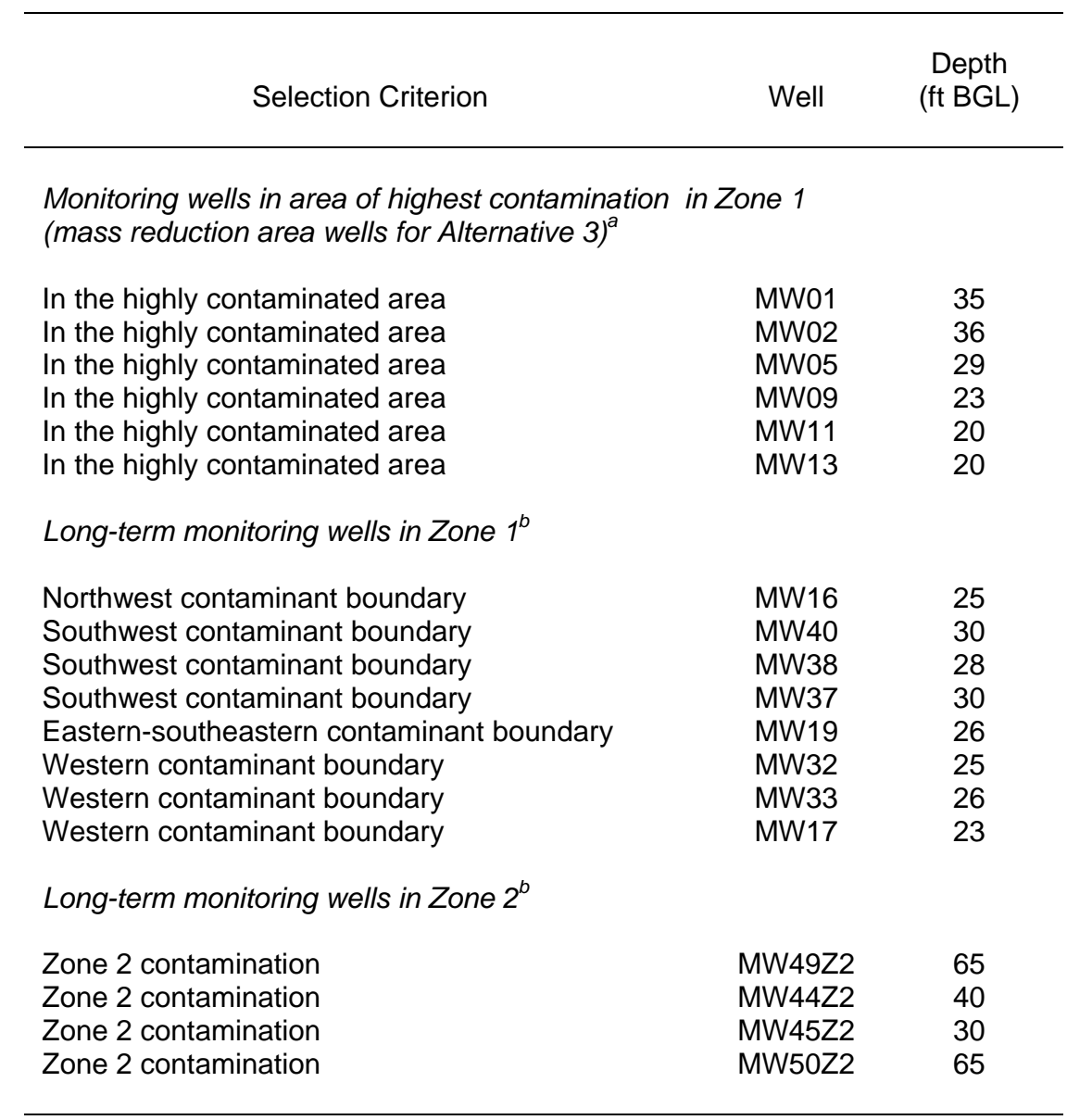

a These wells will be sampled twice in year 1 (6 months and 12 months after startup) and thereafter annually for $4 \mathrm{yr}$.

b These wells will be sampled annually in years 1-10 and then every $2 \mathrm{yr}$ in years 11-30. 


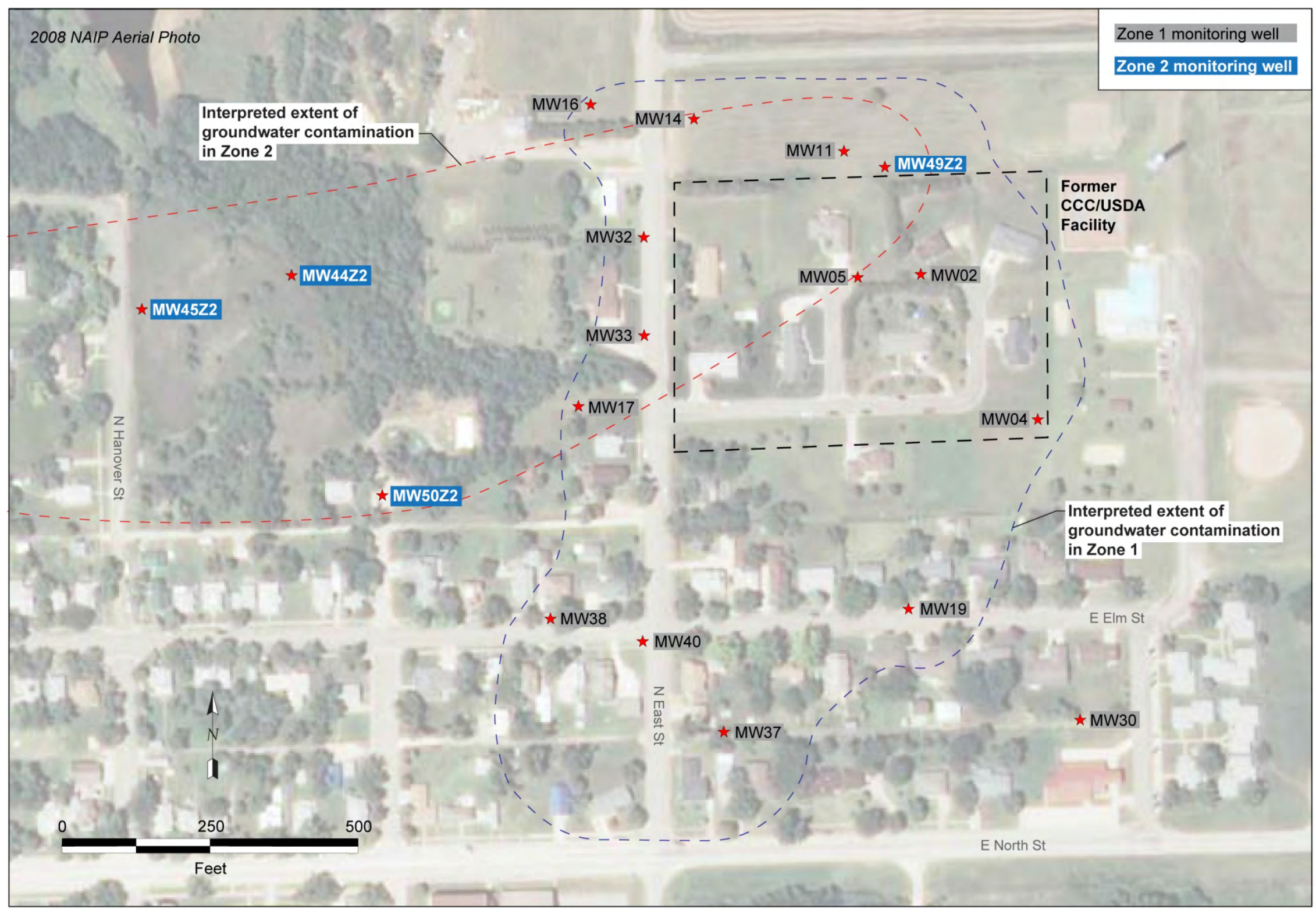

FIGURE 5.1 Locations of long-term monitoring wells for Alternative 2. Source of photograph: NAIP (2008). 


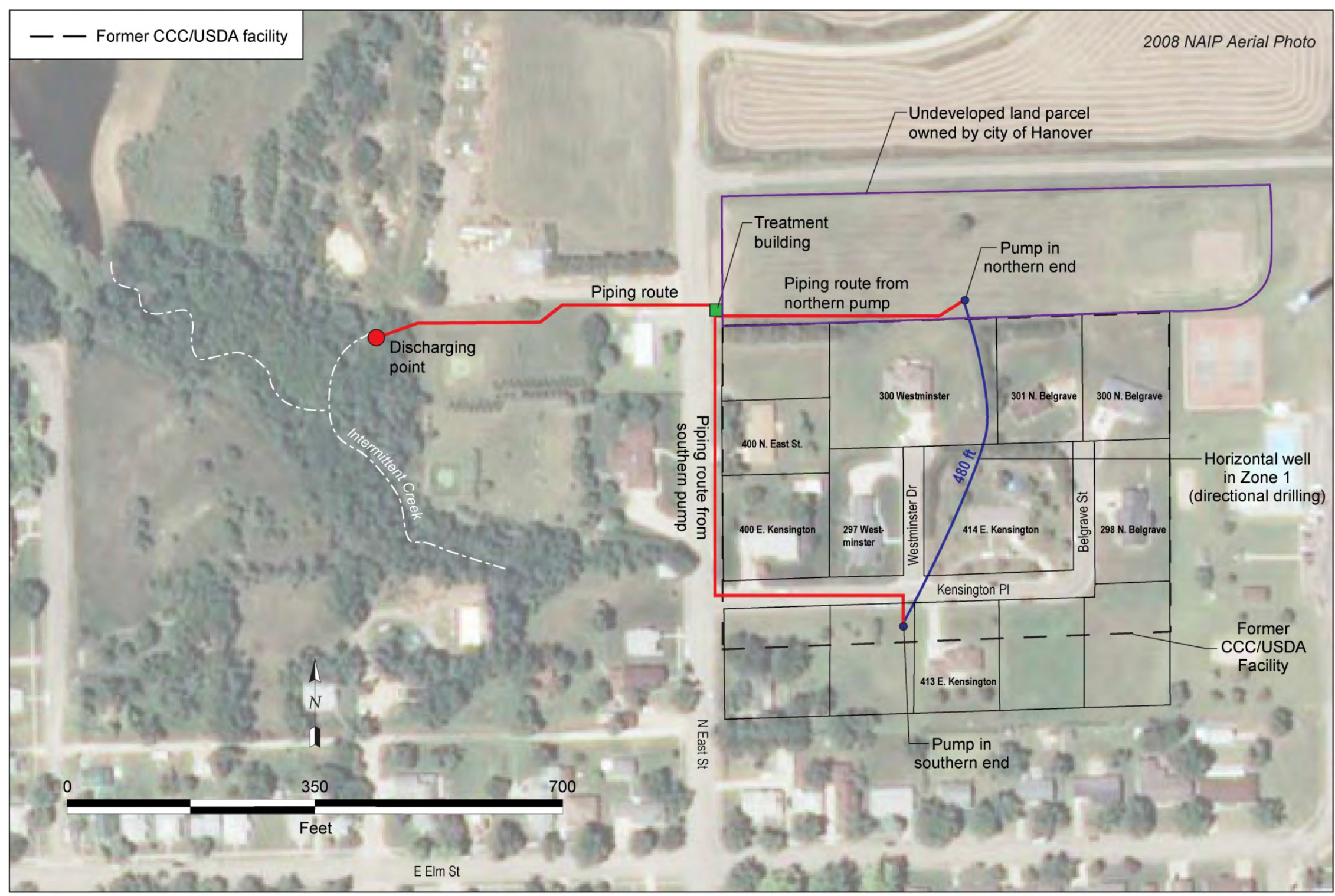




\section{Geological Cross-Section}

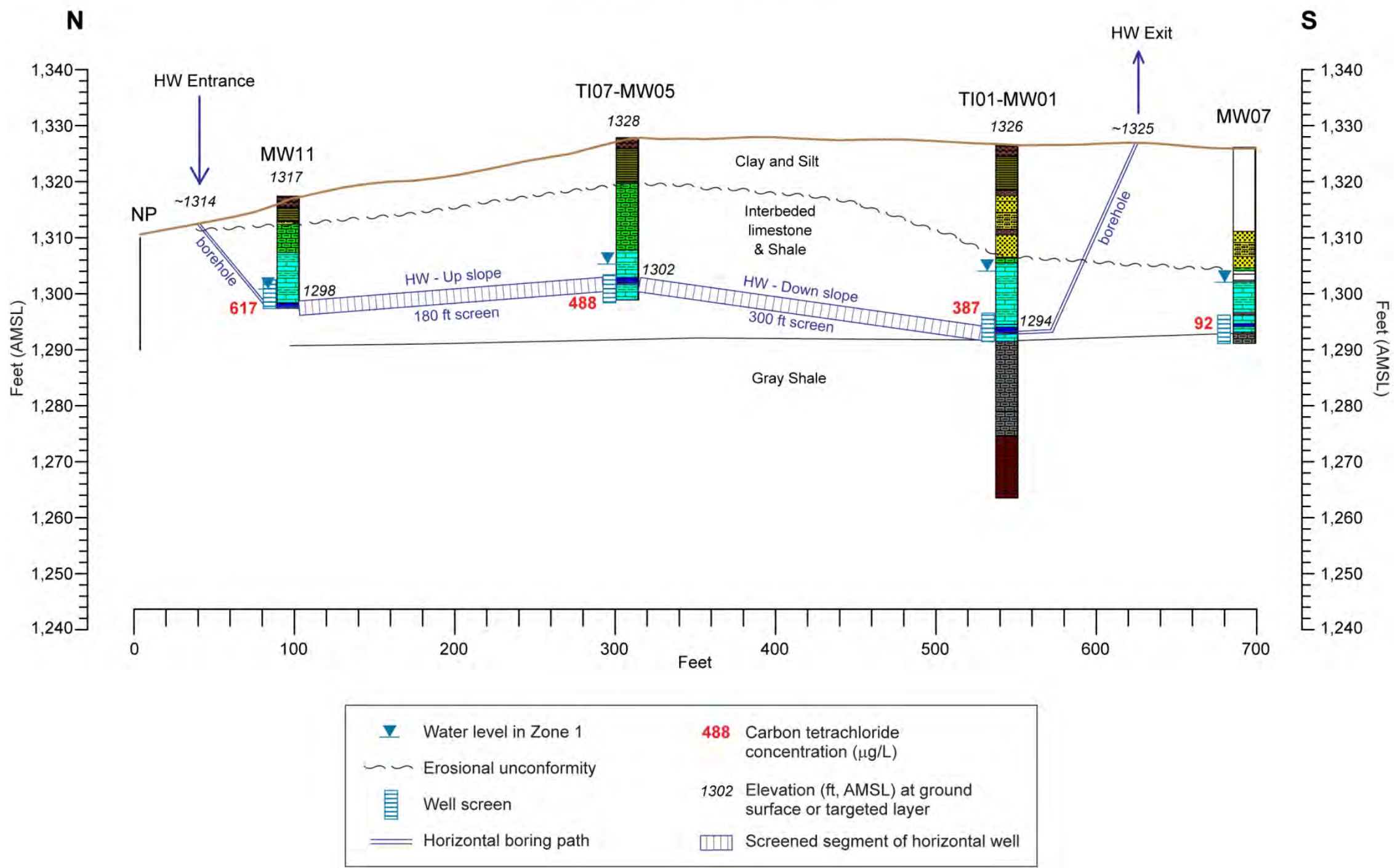




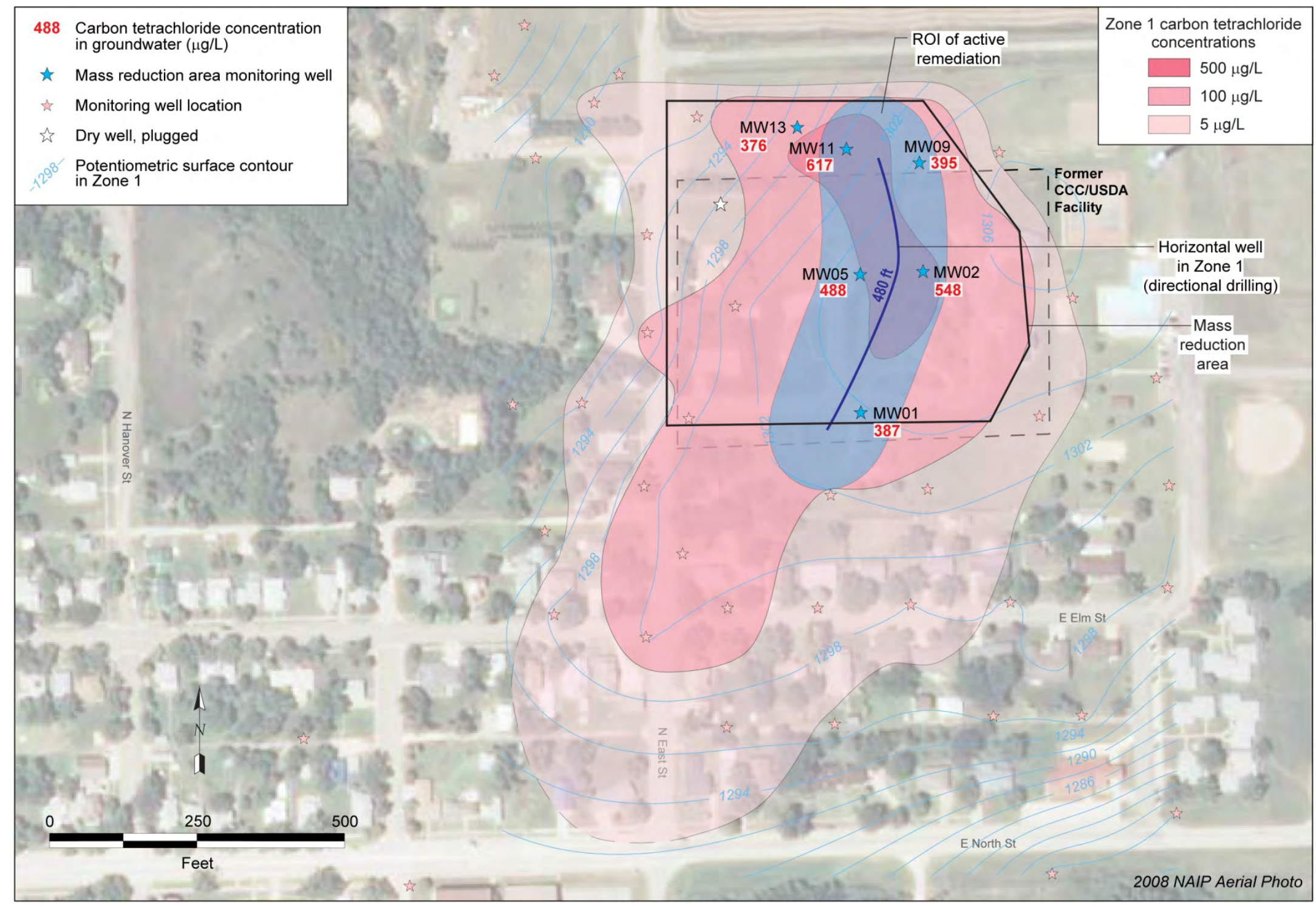

FIGURE 5.4 Contaminant distribution in groundwater, with the location of the proposed horizontal extraction well in Zone 1, the well's radius of influence $(\mathrm{ROI})$, the area targeted for source area reduction, and the mass reduction area monitoring wells. Source of photograph: NAIP (2008). 


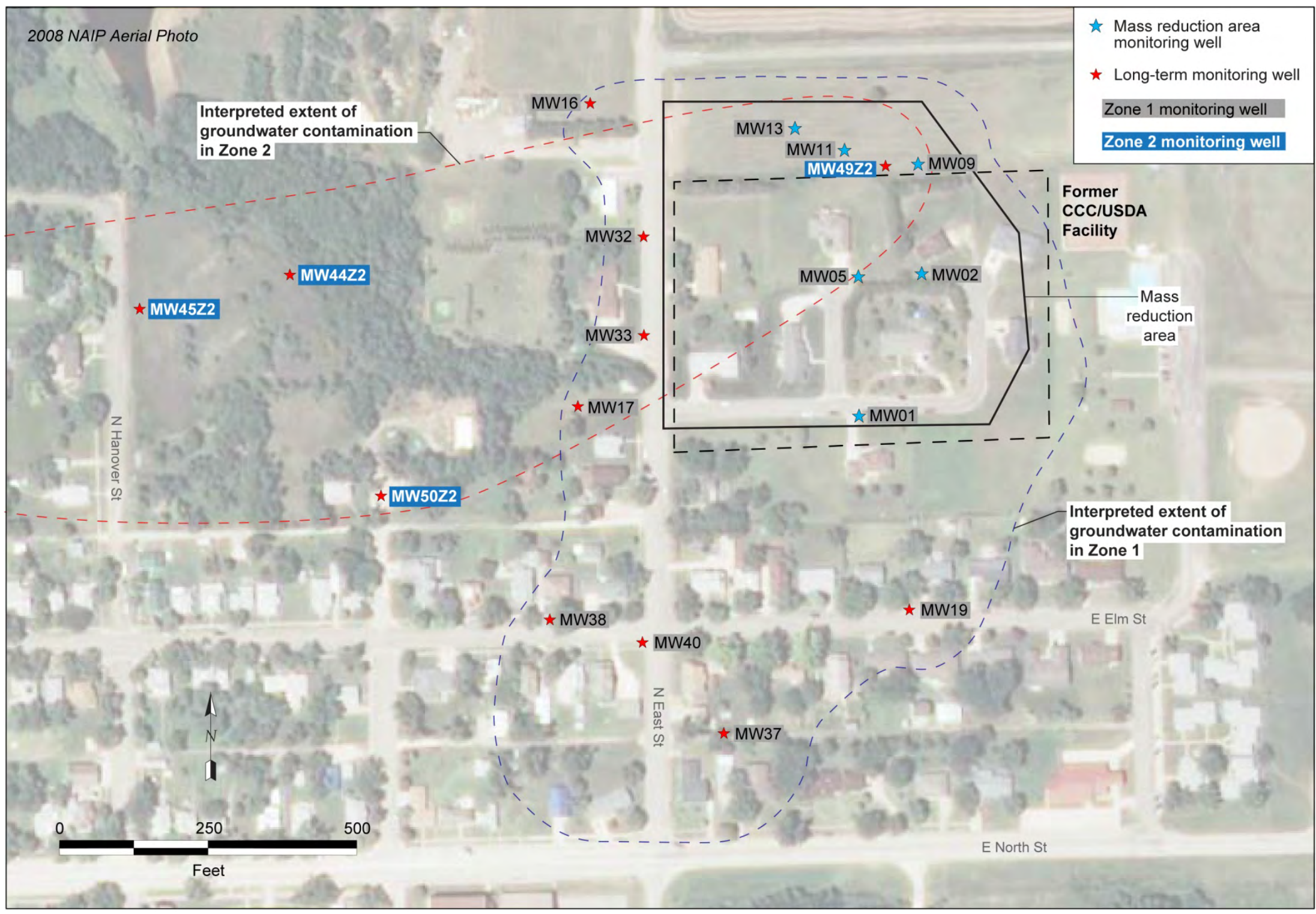

FIGURE 5.5 Locations of the mass reduction area monitoring wells and additional long-term monitoring wells. Source of photograph: NAIP (2008). 


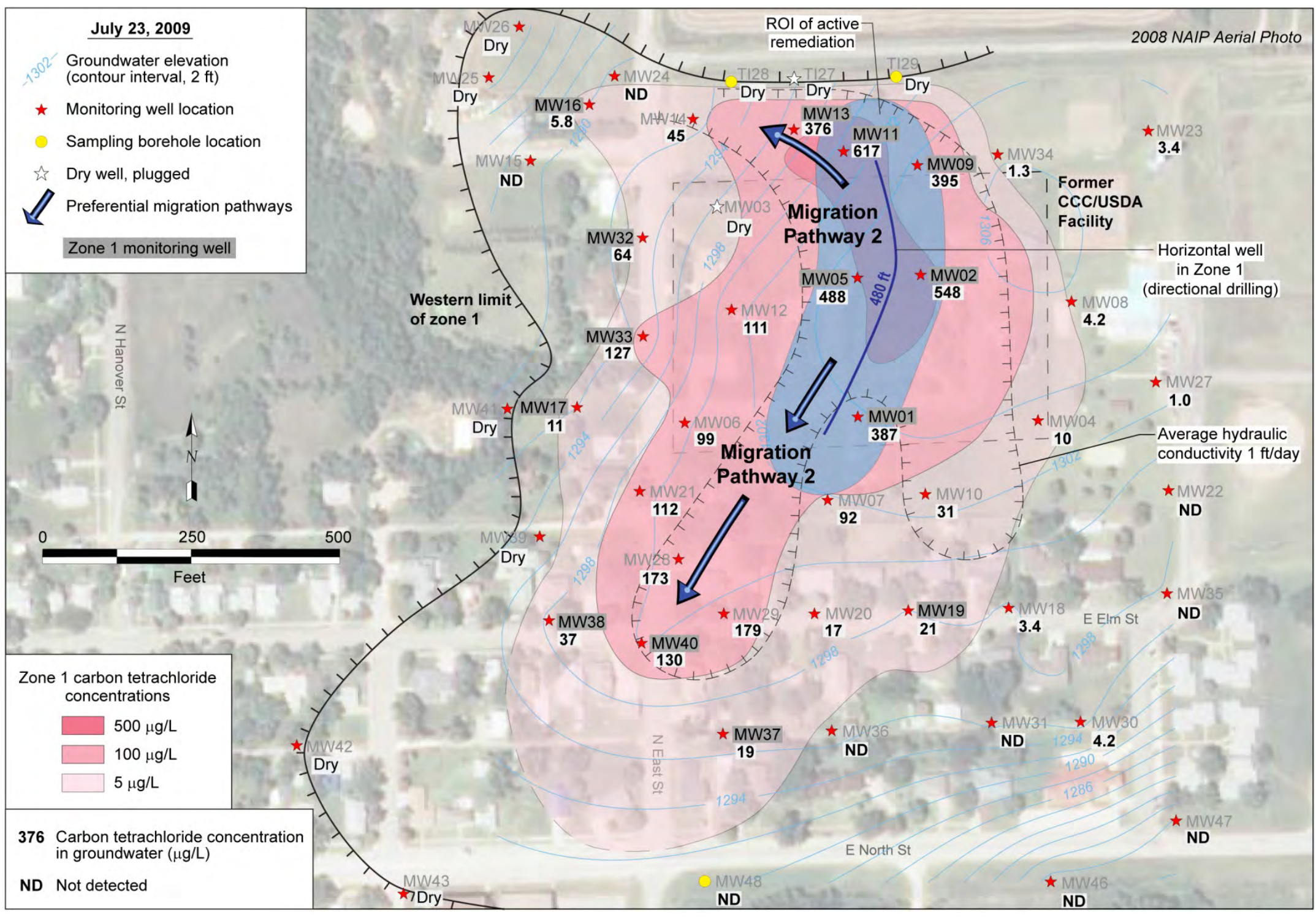

FIGURE 5.6 Locations of the long-term monitoring wells in groundwater Zone 1 and the proposed horizontal extraction well, with the western erosional limit of Zone 1, the expected radius of influence of pumping of the horizontal extraction well, the area with average hydraulic conductivity of $1 \mathrm{ft} /$ day, and interpreted preferential migration pathways. 


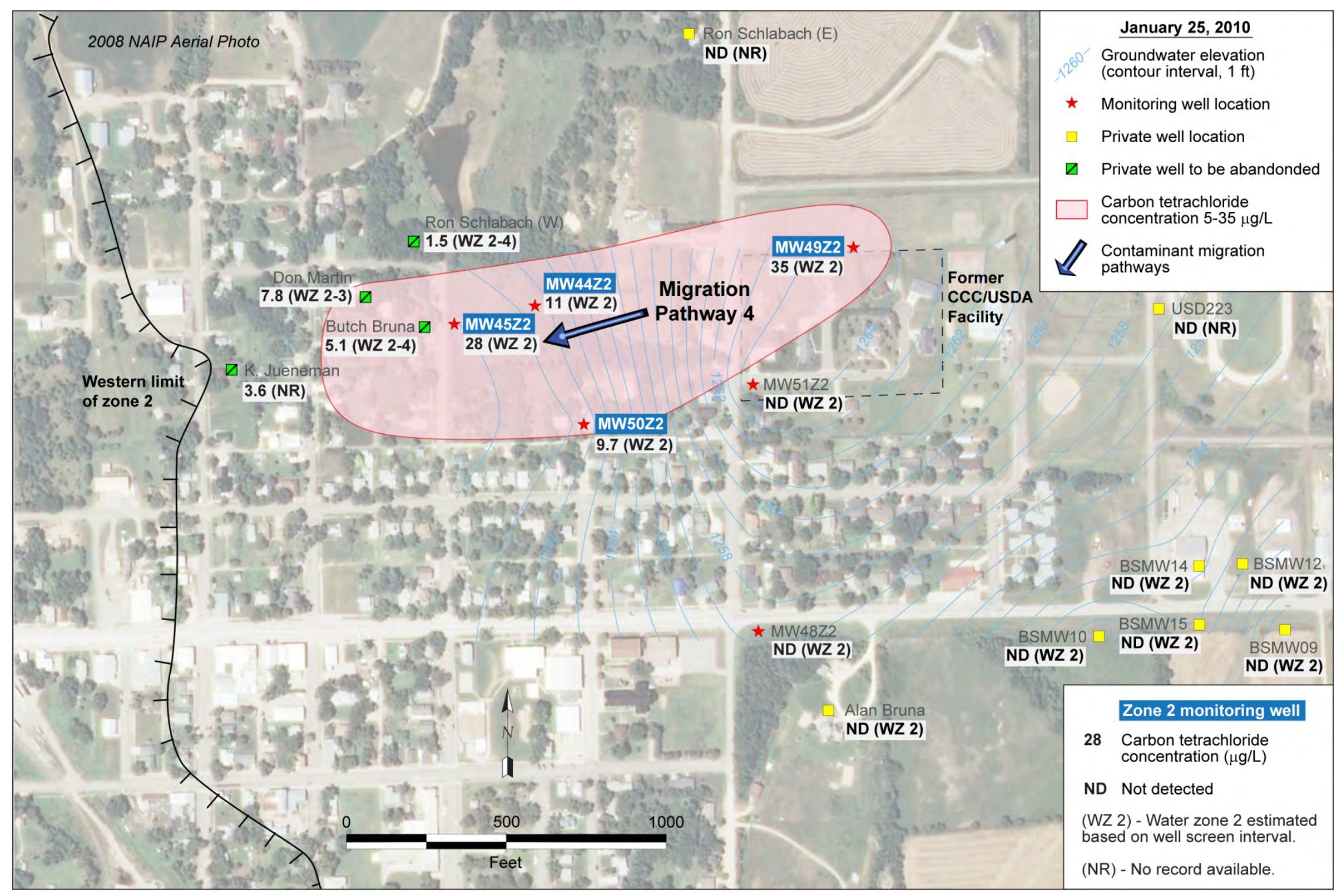

FIGURE 5.7 Locations of the long-term monitoring wells in groundwater Zone 2, with the western erosional limit of Zone 2 and interpreted preferential migration pathway. 


\section{Detailed Analysis of Corrective Action Alternatives}

In its CAS guidance, the KDHE (2001a) adopts by reference nine EPA-defined criteria that must be evaluated for each alternative. The criteria are as follows:

1. Overall protection of human health and the environment, which addresses protection from unacceptable risks in both the short term and the long term by minimizing exposures, in accordance with the purpose and objectives of the proposed actions. Because of its broad scope, this criterion also reflects the focus of criteria 2-5.

2. Compliance with ARARs, which addresses the attainment of federal and state environmental requirements determined to be either applicable or relevant and appropriate to the alternative, on the basis of site-specific considerations. Potential ARARs and TBCs are listed in Appendix B.

3. Long-term effectiveness and permanence, which addresses residual risks remaining after completion of a remedial action. The EPA (1991) guidance states that it is usually sufficient to indicate whether an alternative has the potential to achieve the preliminary cleanup levels and not necessary to quantify the risk that would remain after implementation.

4. Reduction of contaminant toxicity, mobility, or volume, which addresses the degree to which treatment addresses the principal threat(s) at the site; the amount of material treated; the magnitude, significance, and reversibility of the given reduction; and the nature and quantity of treatment residuals.

5. Short-term effectiveness, which addresses the potential impacts to site workers, the general public, and the environment from implementing the alternative; the effectiveness and reliability of mitigative measures; and the time required to achieve protectiveness.

6. Implementability, which addresses technical feasibility, including the availability and reliability of required resources (such as specific technologies, 
materials and equipment, facility capacities, and skilled workers); ease of implementation; and the ability to monitor effectiveness. This criterion also addresses administrative feasibility. The actual determination of administrative feasibility would not be made until after the CAS is completed.

7. Cost, which addresses both capital and annual operation and maintenance costs. Costs for the individual components of the alternatives are also considered. The costs presented were estimated by using a combination of actual costs, a preliminary bid from a lead contractor and several subcontractors for the remedial action construction associated with Alternative 3, costs from similar projects, and the RACER cost estimating model (AECOM 2009). Additional information about the cost estimates and assumptions used is in Appendix E.

8. State acceptance, which addresses KDHE comments on the alternatives being considered. State acceptance is deferred pending issuance of this document.

9. Community acceptance, which addresses the comments made by the community on the alternatives being considered. Because these comments will not be received until this report has been issued for public review, the community acceptance criterion is deferred.

In the following sections, each of the three alternatives outlined in Section 5 is evaluated in detail on the basis of criteria 1-7 above. A comparative analysis is described in the following narrative and is summarized in Table 6.1.

\subsection{Alternative 1: No Action}

In compliance with the CAS requirements, the no-action alternative is included to provide a baseline for comparison with the other alternatives. Under this alternative, no action would be taken at the former CCC/USDA facility. 


\subsubsection{Overall Protection of Human Health and the Environment}

Under the current use conditions, Alternative 1 offers some degree of protection for human health and the environment, because there are no complete exposure pathways to human or ecological receptors. Vapor mitigation measures are installed and operating where VI monitoring indicated possible risks to human health. No active private (or public) wells are known to be present within the area of Zone 1 contamination or to be completed in this unit. The four identified private wells that penetrate the contaminated portion of Zone 2 are used for lawn and garden purposes only. Local groundwater at Hanover is not potable because of poor natural water quality in Zone 2 and limited quantity of yield for Zone 1. Hanover residents are connected to the RWD \#1 water supply system, and RWD \#1 regulations prohibit the cross-connection of private water supply wells to the public delivery system. As a result, under current use conditions, residents would not be exposed to groundwater or indoor air at concentrations above regulatory thresholds.

Under future use conditions, except for the homes with functioning VI mitigation systems, if the contaminant concentrations or the configuration of the contaminated groundwater changes, upward VI could potentially result in carbon tetrachloride concentrations exceeding the indoor air threshold $\left(4.06 \mu \mathrm{g} / \mathrm{m}^{3}\right)$ in existing or newly constructed habitable structures.

\subsubsection{Compliance with ARARs and TBCs}

Because of the unacceptable natural quality of the Zone 2 groundwater and the inadequate production from Zone 1, policy BER-RS-045 (KDHE 2009b) would be operative. No active measures are associated with Alternative 1, and there are no location- or action-specific ARARs. Compliance with the KDHE VI guidance TBC has been achieved, because a VI assessment has been completed, and VI mitigation systems have been installed and are in operation, where needed.

\subsubsection{Long-Term Effectiveness and Permanence}

Alternative 1 would involve no treatment of the contaminated groundwater and thus would not be considered permanent. However, contaminant levels will be reduced through 
natural processes. Elevated ratios of chloroform to carbon tetrachloride observed in the Zone 1 groundwater along the leading, downgradient margins of the contaminant distribution, as well as in Zone 2, substantiate that some degradation of carbon tetrachloride is occurring by reductive dechlorination under anaerobic conditions (Section 2.2.5.2).

Under Alternative 1, the level of contamination and risks to terrestrial biota over the long term would be similar to current levels. These risks are considered insignificant, because there would be no exposure to the impacted groundwater.

\subsubsection{Reduction of Toxicity, Mobility, or Volume}

Implementation of Alternative 1 would not directly address the toxicity, mobility, or volume of contaminants at the site; however, continued intrinsic remediation is likely to result in a long-term decrease in the toxicity and volume of the contaminants present. The lateral mobility of the contaminants in Zone 1 is limited by the relatively low permeability and restricted areal extent of this unit.

\subsubsection{Short-Term Effectiveness}

Implementation of Alternative 1 would not impact the general public or the environment. No mitigation measures would be required.

\subsubsection{Implementability}

Implementation of Alternative 1 would be straightforward. The former CCC/USDA facility would continue to be used as at present.

\subsubsection{Cost}

Costs associated with Alternative 1 include expenses for inspecting the sub-slab VI mitigation systems once each year and compensation to the owners for electricity to power the systems. Other costs are associated with the collection and analysis of indoor air samples every 
$5 \mathrm{yr}$ to evaluate the efficacy of the VI mitigation systems. The estimated 30-yr cost for Alternative 1 is approximately $\$ 67,000$ in current-year dollars, with markups. There are no capital costs. The costs of annual inspection of the VI mitigation systems for $30 \mathrm{yr}$ and compensation for the electric power to operate the VI mitigation systems for $30 \mathrm{yr}$ would be approximately $\$ 16,500$ and $\$ 10,500$, respectively. The indoor air sample collection, analysis, and reporting of results every $5 \mathrm{yr}$ would cost about $\$ 40,000$. Costs are summarized in Table 6.2.

\subsection{Alternative 2: Municipal Land Use Controls, Monitoring, and Well Abandonment}

\subsubsection{Overall Protection of Human Health and the Environment}

Under Alternative 2, as a protective measure, four existing lawn and garden wells installed with continuous gravel packs connecting contaminated Zone 2 and deeper groundwaterbearing Zones 3 and 4 will be properly abandoned, thus eliminating a potential contaminant migration pathway. Under future use conditions, Alternative 2 would reduce the potential for exposure to contaminants in groundwater and soil vapor, because the city would (1) prohibit the installation of water supply wells and (2) require VI assessments and installation of VI mitigation measures, as necessary, in conjunction with any future new construction or major property redevelopment.

\subsubsection{Compliance with ARARs}

Because of the unacceptable natural quality of the Zone 2 groundwater and the inadequate production from Zone 1, policy BER-RS-045 (KDHE 2009b) would be operative. Alternative 2 would comply with other pertinent ARARs and TBCs as appropriate.

\subsubsection{Long-Term Effectiveness and Permanence}

Alternative 2 would involve no treatment of contaminated groundwater, although contamination will decrease through natural processes. Alternative 2 offers some degree of protection for human health and the environment over the long term. The MLUCs associated 
with this alternative would eliminate potential exposure to contaminated groundwater and soil vapor. Abandoning the four existing private lawn and garden wells installed with continuous gravel packs connecting contaminated Zone 2 and deeper groundwater-bearing Zones 3 and 4 will result in the permanent elimination of a migration pathway created by the well construction method.

\subsubsection{Reduction of Toxicity, Mobility, or Volume}

Alternative 2 would not directly address the toxicity, mobility, or volume of contaminants at the site; however, continued intrinsic remediation will result in a long-term decrease in the toxicity and volume of the contaminants present. The lateral mobility of the contaminants is limited by the relatively low permeabilities and the restricted extents of impacted groundwaterbearing Zones 1 and 2.

\subsubsection{Short-Term Effectiveness}

No mitigation measures would be required under Alternative 2; however, administrative measures would immediately be implemented to prevent potential future exposure to contaminated groundwater and soil vapor. Site workers involved in monitoring would be protected by adherence to health and safety requirements associated with workplace health and safety plans.

\subsubsection{Implementability}

If suitable city ordinance(s) were implemented and enforced, Alternative 2 would provide an administrative mechanism for the management of risk.

Implementation of the groundwater monitoring, well abandonment, VI mitigation monitoring, and reporting components of Alternative 2 would be straightforward and could be performed with readily available resources. 


\subsubsection{Cost}

The estimated 30-yr cost for Alternative 2 is approximately \$999,663 in current-year dollars. Costs are estimated at $\$ 111,364$ for the abandonment of four existing lawn and garden wells and residual waste management. Six 5-yr reviews and six VI mitigation system air sampling events would be performed at costs of $\$ 217,225$ and $\$ 40,000$, respectively. Also included is \$83,910 for establishing and monitoring MLUCs, \$532,234 for sampling 18 existing monitoring wells annually for $10 \mathrm{yr}$ and every $2 \mathrm{yr}$ for $20 \mathrm{yr}$, and $\$ 10,500$ for compensating homeowners for power costs associated with operation of the VI mitigation systems. The VI inspection activities in years when the site is not otherwise visited would cost approximately $\$ 4,400$. Costs are summarized in Table 6.2.

\subsection{Alternative 3: Targeted Groundwater Extraction and Treatment in Zone 1}

\subsubsection{Overall Protection of Human Health and the Environment}

Under the current use conditions, Alternative 3 is considered the most protective of human health and the environment, because it would address the source of the contamination in groundwater Zone 1 that is responsible for the VI pathway from groundwater to residential air.

The groundwater extraction and treatment component of Alternative 3 provides for significant mass removal from the most contaminated portion of Zone 1 and for active reduction of the carbon tetrachloride concentrations, thereby reducing the risk of potential VI. Further, the significant decreases in carbon tetrachloride concentrations in Zone 1 will decrease contaminant migration from Zone 1 to Zone 2 and thus will gradually reduce the already low concentrations in Zone 2. In the sitewide long-term monitoring wells, final contaminant levels may decrease below the RBSL and MCL values or an alternative cleanup level commensurate with a determination that groundwater at Hanover is not potable per KDHE policy BER-RS-045 (KDHE 2009b).

As a protective measure, four existing private lawn and garden wells installed with continuous gravel packs connecting contaminated Zone 2 and deeper groundwater-bearing 
Zones 3 and 4 will be properly abandoned, thus permanently eliminating a potential migration pathway.

\subsubsection{Compliance with ARARs}

Because of the unacceptable natural quality of the Zone 2 groundwater and the inadequate production from Zone 1, policy BER-RS-045 (KDHE 2009b) would be operative. Alternative 3 would comply with other pertinent action-specific ARARs and TBCs as appropriate. Alternative 3 would comply with the hydraulic containment TBC. No locationspecific ARARs and TBCs apply.

\subsubsection{Long-Term Effectiveness and Permanence}

Alternative 3 offers the greatest degree of protection for human health and the environment. The extraction and treatment would reduce the mass of carbon tetrachloride in the Zone 1 mass reduction area and approach the regulatory level sitewide more rapidly than would intrinsic remediation alone. Alternative 3 would result in a permanent response that would directly and irreversibly reduce the carbon tetrachloride contamination in groundwater.

\subsubsection{Reduction of Toxicity, Mobility, or Volume}

Under Alternative 3, carbon tetrachloride contamination would be actively removed, thereby decreasing contaminant toxicity, mobility, and volume. In addition, continued intrinsic remediation would result in a long-term decrease in the toxicity and volume of any residual contaminants present. The lateral mobility of the contaminants is further limited by the relatively low permeabilities and restricted extent of impacted groundwater-bearing Zones 1 and 2.

\subsubsection{Short-Term Effectiveness}

Implementation of Alternative 3 would pose no short-term risks to the general public or the environment. Site workers involved in the construction of the groundwater extraction wells and treatment system and subsequent monitoring would be protected by adherence to a site- 
specific health and safety plan. Installation of the required well and underground piping and construction of the tray aerator facility are expected to have a short-term impact.

\subsubsection{Implementability}

Implementation of Alternative 3 is feasible. Resources and well-established protocols are available for well abandonment. Installation of a 6-in. groundwater extraction well with a $480-\mathrm{ft}$ screen in a 10-in. horizontal boring $660 \mathrm{ft}$ long will require the use of specialized techniques but is within the scope of industry practice. A tray aerator can be manufactured easily for the expected volume and quality of extracted groundwater.

To date, Hanover residents have graciously granted access to all of the properties required for soil, groundwater, and soil vapor sampling and for the installation of monitoring wells and VI mitigation systems. Nevertheless, access to install the proposed extraction wells and the piping and treatment system will need to be negotiated among the KDHE, the CCC/USDA, and the affected private property owners.

\subsubsection{Cost}

The estimated 30-yr cost for Alternative 3 is approximately $\$ 1,688,298$ in current-year dollars. Costs are summarized in Table 6.2. 
Evaluation Criterion

Alternative $1-$
No Action

Alternative 2

Use Controls, Monitong, and Well Abandonment $\begin{array}{ll}\text { Overall protection of } & \begin{array}{l}\text { Protective under current use. Residences within } 100 \mathrm{ft} \text { laterally and } 40 \mathrm{ft} \\ \text { human health and the } \\ \text { vertically of contaminated groundwater (the } \mathrm{VI} \text { potential zone) have been }\end{array}\end{array}$ assessed for $V I$ hazards. Where indicated, $V I$ mitigation has been installed.
mitigation systems are inspected annually and assessed periodically by air mitigation systems are inspected annually and assessed periodically by air
sampling. All residences within the delineated footprint of the contaminated groundwater (Figure 2.13) are connected to the RWD \#1 system. Water supply location and construction regulations) are meant to preclude exposure to migration results in additional VI hazards in existing or new residences.

Compliance with Local groundwater is non-potable water source because of poor water quality deral and state

ARARs in Zone 2 and low production in Zone 1. An alternate water supply is provided by the RWD. The KDHE VI guidance applies and has been addressed via VI
monitoring and, where needed, VI mitigation. This alternative complies with all monitoring and, where $\mathrm{V}$

Long-term The long-term effectiveness of this alternative depends on the absence of

effectiveness and contaminant migration that may trigger additional VI risks. Intrinsic remediation
permanence could eventually bring carbon tetrachloride concentrations permanently below
regulatory thresholds (for example, $5 \mu \mathrm{g} / L$ in groundwater or an alternative
threshold commensurate with the non-potable nature of the groundwater a Hanover and $4.06 \mu \mathrm{g} / \mathrm{m}^{3}$ for indoor air).

Protective under current use. Residences in the $\mathrm{VI}$ potential zone have been
assessed for $\mathrm{VI}$ hazards. Where indicated, $\mathrm{VI}$ mitigation has been installed. $\mathrm{V}$ mitigation systems are inspected annually and assessed periodically by ai sampling. All residences within the impacted groundwater footprint are connected to the RWD supply. Water supply protective regulations are mean supplement existing water supply protective regulations. Moniting in supplement existing water supply protective regulations. Monitoring, in
conjunction with the municipal land use controls, provides data for use in triggering VI monitoring or mitigation for any newly impacted residences. Abandonment of continuously gravel packed residential lawn and garden wells will remove a potential contannant migration pathway from contaminated to

groundwater is non-potable water source because of poor water quality in Zone 2 and low production in Zone 1 . An alternate water supply is provided by the RWD. The KDHE VI guidance applies and has been addressed via VI monitoring and, where needed, $V$, nitgalion. This alen adde complies with Municipal land use controls are effective in eliminating the potential for exposure to contamination in groundwater or in indoor air. Intrinsic remediation could eventually bring carbon tetrachloride concentrations permanently below regulatory thresholds (for example, $5 \mu \mathrm{g} / \mathrm{L}$ in groundwater or an alternative
threshold commensurate with the non-potable nature of the groundwater at Hanover and $4.06 \mu \mathrm{g} / \mathrm{m}^{3}$ for indoor air).

o reduction of TMV occurs in this alternative, except through intrinsic remediation.

No reduction of toxicity, mobility, and volume (TMV) occurs in this alternative, Reduction of toxicity, except through intrinsic remediation.

through treatment

mplementation can be accomplished with no additional risk to workers, the

\section{Short-term}

Implementation can be accom
community, or the environmen

Can be implemented readily.

Implementability

Preliminary cost

stimate (current-year

dollars)

$\$ 67,000$

$N P V$ cost

$\$ 37,749$

$(15-y$ r discount rate
Implementation can be accomplished with no additional risk to workers, the community, or the environment.

No active restoration measures are taken; risk is managed by implementing and enforcing administrative municipal land use controls. Feasibility depends
on cooperation of private property owners and/or municipal, county, and state agencies.

$\$ 999,663$

$\$ 660,276$
Alternative 3 (with Monitoring and Well Abandonment)

Protective under current use. Residences in the $\mathrm{VI}$ potential zone have been assessed for VI hazards. Where indicated, VI mitigation has been installed. mitigation systems are inspected annually and assessed periodically by connected to the RWD supply. Water supply protective regulations are mean
coln potential for reducing add contioninal VI hazards in existing or new residences contaminant migration. Groundwater extraction and treatment in Zone 1 will actively eliminate a significant amount of contamination that would otherwise migrate downgradient. Abandonment of continuously gravel packed residential awn and garden wells will remove a polential conty

Local groundwater is non-potable water source because of poor water quality in Zone 2 and low production in Zone 1. An alternate water supply is provided by the RWD. The KDHE VI guidance applies and has been addressed via VI

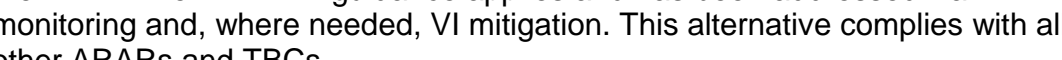

Active groundwater extraction and treatment is expected to reduce carbo etrachloride concentrations more rapidly than would intrinsic remediation alone. Active treatment of Zone 1 would have the greatest impact over a localized area but would also have an impact on carbon tetrachloride long-term effectiveness depends on the reduction and absence of contaminan migration that could trigger additional VI risks. Intrinsic remediation could eventually bring carbon tetrachloride concentrations in the rest of Zones and 2 permanently below regulatory thresholds (for example, $5 \mu \mathrm{g} / \mathrm{L}$ in groundwater or an alternative threshold commensurate with the non-potable nature of the groundwater at Hanover and $4.06 \mu \mathrm{g} / \mathrm{m}^{3}$ for indoor air).

Alternative 3 uses active, engineered processes to extract and treat the contaminated groundwater in Zone 1. Together, these processes actively reduce the contaminant TMV in groundwater in Zone 1 and reduce the migration of contamination from Zone 1 to Zone 2. Reductions in carbon tetrachloride would also occur in both zones through intrinsic remediation epresent a short-term inconvenience for the community. Implementation
be accomplished with no additional, unacceptable risk to workers, the community, or the environment

Readily implemented by using standard, readily available techniques and Rosources. Access to private property is required for successful implementation.

$\$ 1,688,298$

$\$ 1,462,515$ 
TABLE 6.2 Cost comparison summary for Hanover CAS alternatives.

Budget Component Total $(\$) \quad$ Net Present Value ${ }^{\mathrm{a}}(\$)$

Alternative 1 (for $30 \mathrm{yr}$ )

Annual inspection of VI mitigation systems

Electric power for VI mitigation systems

16,500

VI mitigation indoor air sampling and reporting

10,500

40,000

Alternative 1 Total

67,000

37,749

Alternative 2 (for $30 \mathrm{yr}$ )

Well abandonment

111,364

Groundwater monitoring (annual sampling of 18 wells) and

532,234 annual inspection of sub-slab VI mitigation systems

Electric power for VI mitigation systems

VI mitigation indoor air sampling and reporting

10,500

Inspection of VI mitigation systems in non-sampling years

40,000

Five-year reviews

4,400

Municipal land use controls

217,225

83,910

Alternative 2 Total

999,663

660,276

Alternative 3 (groundwater extraction and treatment in Zone 1 for 5 yr; sitewide monitoring for 30 yr)

Remedial design and permitting

Construction (horizontal boring, extraction well, recovery wells, underground piping, tray aerator [contractor exploratory bid])

Construction (professional labor management)

Residual waste management (system construction)

Well abandonment (construction)

Well abandonment (professional labor management)

Residual waste management (well abandonment)

Operations and maintenance (power for wells and aerator)

Aerator discharge monitoring (monthly)

Monitoring plan preparation, with $1 \mathrm{yr}$ of baseline monitoring for 18 wells

Groundwater monitoring (sampling of 6 mass reduction area wells, annually for $5 \mathrm{yr}$ )

Groundwater monitoring (sampling of 6 mass reduction area wells 6 months after start-up)

Groundwater monitoring (sampling of 12 sitewide wells, annually for $10 \mathrm{yr}$ and every $2 \mathrm{yr}$ for $20 \mathrm{yr}$ )

Municipal land use controls

Electric power for VI mitigation systems

VI mitigation indoor air sampling and reporting

Inspection of VI mitigation systems in non-sampling years

Five-year reviews

Alternative 3 Total
97,254

422,626

45,647

10,957

88,835

18,561

3,968

1,500

136,500

79,711

67,205

13,441

379,848

13,985

10,500

40,000

4,400

253,360

$1,688,298$

a Net present value is based on a $4 \%$ discount rate. 


\section{Comparative Analysis of Alternatives}

This section evaluates the relative performance of the three alternatives with respect to criteria 1-7, as described at the beginning of Section 6.

\subsection{Overall Protection of Human Health and the Environment}

Under the current-day scenario, Alternatives 1-3 provide varying degrees of protection. For residences with a substantiated VI hazard, VI mitigation systems have been installed and are in operation. Under future use scenarios, Alternative 1 places no constraint on the installation of a water supply well in the impacted portions of groundwater Zones 1 and 2 beyond those already incorporated in the existing water supply protective measures. However, local groundwater from Zone 2 is not acceptable for potable use because of its poor natural quality, and the quantity yielded by Zone 1 is inadequate for minimum domestic use (Suchy et al. 2011). Continued intrinsic remediation will result in a long-term decrease in the toxicity and volume of contaminants present.

Under current use scenarios, the existing sub-slab VI mitigation systems will be inspected annually and assessed periodically by an air sampling program. Alternatives 2 and 3 provide a limited degree of protection of human health and the environment under future use scenarios. Alternative 2 provides for well abandonment, which would remove a contaminant migration pathway, and MLUCs would create and enforce administrative constraints to augment the already existing water supply protective measures. Alternative 2 would also address the potential for VI hazards by (1) including monitoring to detect any changes in the contaminant distribution in groundwater with time; (2) requiring VI assessment, and mitigation if necessary, in conjunction with any new construction or major reconstruction; and (3) continuing the periodic inspection and assessment of the VI mitigation systems that have already been installed. Alternative 3 would incorporate all of the well abandonment, VI mitigation system assessment, and monitoring elements outlined for Alternative 2 and would also implement active groundwater extraction and treatment to directly address the contamination that is the source of the only complete exposure pathway - VI from groundwater into residences located above the contaminated groundwater in Zone 1. Alternative 3 would also reduce the potential for contaminant migration within Zone 1 (migration pathway 2 in Section 2.3.2) and reduce the 
migration of contamination from Zone 1 to Zone 2 (migration pathway 3 in Section 2.3.2), leading to accelerated improvement in the contaminant levels in Zone 2.

Alternative 3 offers the greatest degree of protection by removing contaminant mass in and near the source area and minimizing further migration of groundwater contamination.

\subsection{Compliance with ARARs}

Alternatives 1 and 2 would not actively reduce contaminant concentrations, but intrinsic remediation processes would help to reduce the contaminant levels. Under Alternative 3 active removal and treatment would decrease the carbon tetrachloride concentrations in Zone 1 and Zone 2 more rapidly.

Under Alternatives 2 and 3, all measures implemented would be conducted in accordance with applicable location- and action-specific ARARs. In particular, Alternative 3 would comply with the hydraulic containment TBC policy.

Attainment of the MCLs is unlikely for any of these alternatives, given the physical characteristics of the site. However, Alternative 3 would permanently reduce the contaminant levels in water-bearing Zone 1 through extraction and treatment and would eventually lead to a reduction in contaminant levels in Zone 2. As the concentrations of carbon tetrachloride in these zones decrease with time, the potential for unacceptable levels of VI will be permanently reduced.

\subsection{Long-Term Effectiveness and Permanence}

Alternatives 1 and 2 would not involve active treatment to decrease the toxicity, mobility, or volume of contaminated groundwater. Naturally occurring processes are expected to reduce carbon tetrachloride concentrations in time. Alternatives 1 and 2 offer a limited degree of protection for human health and the environment over the long term, given the operating record of the VI mitigation systems, the unacceptable natural quality of local groundwater from Zone 2, the inadequate production from the other groundwater-bearing zones, and the existing water supply protective measures that prevent impacted groundwater from being used as a water 
supply source. Field surveys have substantiated that neither Zone 1 nor Zone 2 groundwater discharges into surface water features or otherwise creates potential risks to ecological resources. The CCC/USDA has made a commitment to ensuring the continued effective operation and maintenance of the existing VI mitigation systems installed in five homes.

Alternative 2 offers additional long-term risk management in that MLUCs would provide administrative mechanisms to supplement the existing water supply protective measures. The planned groundwater and VI monitoring components of Alternative 2 would document the evolution of the contaminant distributions in groundwater, and hence potential changes that might affect VI risks, to ensure that the controls implemented remain effective.

Alternative 3 incorporates all of the well abandonment, monitoring, and MLUC elements outlined for Alternative 2. Alternative 3 would also implement active groundwater extraction and treatment to permanently reduce the contaminant levels in water-bearing Zone 1, eventually leading to a reduction in contaminant levels in Zone 2. As the concentrations of carbon tetrachloride in these zones decrease with time, the potential for unacceptable levels of VI will be permanently reduced.

\subsection{Reduction of Toxicity, Mobility, or Volume}

Although continued intrinsic remediation is expected to result in a long-term decrease in the toxicity and volume of the contamination in groundwater, Alternatives 1 and 2 would not directly address the toxicity, mobility, or volume of carbon tetrachloride present in Zones 1 and 2. Alternative 3 would actively decrease the toxicity, mobility, and volume of the contaminants.

\subsection{Short-Term Effectiveness}

Alternative 1 would have no short-term effectiveness. Alternatives 2 and 3 would implement risk mitigation measures that could take effect immediately, to provide increased levels of protection for the local community. During the monitoring activities associated with Alternatives 2 and 3 and during the construction activities associated with Alternative 3, site workers would be protected by adherence to a site-specific health and safety plan. 


\subsection{Implementability}

Alternative 1 would require no implementation; however, the potential for administrative acceptance of this alternative is questionable, because no active measures would be taken to mitigate site risks. For Alternatives 2 and 3, the implementation of MLUCs would require the enactment of land use restrictions by the city or establishment of an alternate land use control mechanism, with community acceptance. The well abandonment and monitoring components of Alternatives 2 and 3 and the groundwater extraction and treatment components of Alternative 3 could be implemented by using available techniques, materials, and equipment, subject to the successful attainment of property access as necessary.

\subsection{Cost}

Preliminary costs were estimated for each alternative for comparison of costs and effectiveness. The costs presented were estimated by using a combination of vendor estimates, actual costs, and the RACER model (AECOM 2009).

Alternative 1 (no action) has no incremental costs above monitoring and maintenance of the VI mitigation systems already installed in five homes. Of the two remaining alternatives, Alternative 2 would be the least costly in the short term. For Alternative 3, additional costs above expenses related to the well abandonment effort, the 5-yr reviews, and the groundwater and VI monitoring include the design, capital, and implementation costs associated with installing and operating the horizontal extraction well, the vertical recovery wells, the underground piping, and the tray aerator.

\subsection{Stakeholder and State Acceptance}

State acceptance will be reflected in the KDHE comments on this CAS and in the final corrective action selected. Community acceptance will be affected by the content of this CAS. As a result, stakeholder and state acceptance cannot be determined at this time. 


\subsection{Summary and Recommended Corrective Action}

The CCC/USDA recommends Alternative 3 for the former CCC/USDA facility at Hanover. At the present time, when the former CCC/USDA property is occupied by residences, Alternative 3 offers the largest degree of protection for human health and the environment and is focused on addressing carbon tetrachloride contamination in Zone 1, the groundwater zone that is the root cause of the upward VI pathway creating a potential risk to human health. For the future, Alternative 3 is consistent with state and federal regulatory requirements, and it will preclude exposure to contaminated groundwater and to VI-related contamination above KDHE guidelines. Alternative 3 further offers the greatest degree of long-term protectiveness and permanence. Alternative 3 will result in a decrease in the toxicity, mobility, and volume of the contaminants and is implementable technically. Access to private properties for the system installation will have to be negotiated, however.

In terms of cost, Alternative 3 is more costly than Alternatives 1 and 2. However, aside from the improvement of groundwater quality via intrinsic remediation, the need for continued monitoring beyond the estimated remediation time frame for Alternative 3 could eventually make Alternative 2 as costly as Alternative 3 and possibly more costly.

\subsection{Contingency Plan}

At the direction of the KDHE (2011), if an evaluation of the monitoring results from the mass reduction area monitoring network indicates that groundwater contaminant concentrations are not decreasing, the CCC/USDA will review the current site conditions and historical data to determine the most appropriate approach for addressing the contamination, including extending the operation of the groundwater extraction system beyond the proposed 5-yr time frame. Additional contingency plans will be evaluated in conjunction with the KDHE if such plans become necessary. 


\section{References}

AECOM, 2009, Remedial Action Cost Engineering and Requirements System, AECOM Technology Corporation, Los Angeles, California.

Argonne, 2002, Final Master Work Plan: Environmental Investigations at Former CCC/USDA Facilities in Kansas, 2002 Revision, ANL/ER/TR-02/004, prepared for the Commodity Credit Corporation, U.S. Department of Agriculture, Washington, D.C., by Argonne National Laboratory, Argonne, Illinois, December.

Argonne, 2005, Draft Engineering Evaluation/Cost Analysis for the Murdock Groundwater Contamination Site, Murdock, Nebraska, ANL/ER/TR-05/005, prepared for the Commodity Credit Corporation, U.S. Department of Agriculture, Washington, D.C., by Argonne National Laboratory, Argonne, Illinois, April.

Argonne, 2008a, Final Work Plan: Investigation of Potential Contamination at the Former CCC/USDA Grain Storage Facility in Hanover, Kansas, ANL/EVS/AGEM/TR-08-10, prepared for the commodity Credit Corporation, U.S. Department of Agriculture, Washington, D.C., by Argonne National Laboratory, Argonne, Illinois, November (including Addenda 1-3; called Final Work Plan in text).

Argonne, 2008b, Final Work Plan: Supplemental Upward Vapor Intrusion Investigation at the Former CCC/USDA Grain Storage Facility in Hanover, Kansas, ANL/EVS/AGEM/TR-08-14, prepared for the Commodity Credit Corporation, U.S. Department of Agriculture, Washington, D.C., by Argonne National Laboratory, Argonne, Illinois, December (including Addenda 1-4; called Supplemental VI Work Plan in text).

Argonne, 2009a, Progress Report and Technical Evaluation of the ISCR Pilot Test Conducted at the Former CCC/USDA Grain Storage Facility in Centralia, Kansas, ANL/EVS/AGEM/TR-0818, prepared for the Commodity Credit Corporation, U.S. Department of Agriculture, Washington, D.C., by Argonne National Laboratory, Argonne, Illinois, January. 
Argonne, 2009b, Summary of Operations and Performance of the Murdock Site Restoration Project in 2008, ANL/EVS/AGEM/TR-09-06, prepared for the Commodity Credit Corporation, U.S. Department of Agriculture, Washington, D.C., by Argonne National Laboratory, Argonne, Illinois, June.

Argonne, 2011, Final Report: Hanover Environmental Site Investigation, 2009-2010, ANL/EVS/AGEM/TR-10-06, prepared for the Commodity Credit Corporation, U.S. Department of Agriculture, Washington, D.C., by Argonne National Laboratory, Argonne, Illinois, April.

Boulding, R., 1996, EPA Environmental Engineering Sourcebook, Ann Arbor Press, Inc., Chelsea, Michigan.

Cohen, R.M., A.H. Vincent, J.W. Mercer, C.R. Faust, and C.P. Spalding, 1994, Methods for Monitoring Pump-and-Treat Performance, EPA/600/R-94/123, Robert S. Kerr Environmental Research Laboratory, Office of Research and Development, U.S. Environmental Protection Agency, Ada, Oklahoma.

EarthTech, 2005, Overview of the Remedial Action Cost Engineering Requirements (RACER) System (linked at http://www.afcee.af.mil/resources/restoration/racer/index.asp), accessed July 28, 2010.

EPA, 1988, Guidance for Conducting Remedial Investigations and Feasibility Studies under CERCLA, Interim Final, EPA/540/G-89/004 (OSWER Directive 9355.3-01), U.S. Environmental Protection Agency, Washington, D.C., October (http://www.epa.gov/ superfund/ policy/remedy/ pdfs/540g-89004-s.pdf).

EPA, 1990, National Oil and Hazardous Substances Contingency Plan: Final Rule (40 CFR Part 300, U.S. Environmental Protection Agency, Washington, D.C., (linked at http://www.epa.gov/OEM/lawsregs.htm\#ncp).

EPA, 1991, Risk Assessment Guidance for Superfund, Vol. 1, Human Health Evaluation Manual Part C, Risk Evaluation of Remedial Alternatives, EPA/540/R-92/004, Office of Emergency and Remedial Response, U.S. Environmental Protection Agency, Washington, D.C., December. 
EPA, 2002, Evaluation of Permeable Reactive Barrier Performance, prepared for the Federal Remediation Technologies Roundtable by the tri-Agency Permeable Reactive Barrier Institute (U.S. Department of Defense, U.S. Department of Energy, U.S. Environmental Protection Agency, and Interstate Technology and Regulatory Council), December 9 (http://www.epa.gov/tio/download/rtdf/2-prbperformance_web.pdf).

EPA, 2005, Use of Field-Scale Phytotechnology for Chlorinated Solvents, Metals, Explosives and Propellants, and Pesticides, EPA 542-R-05-002, Solid Waste and Emergency Response, U.S. Environmental Protection Agency, Washington, D.C., April.

Fatherly, N., M. O’Neill, and A. Glemza, 2008, Formerly Used Sites Remedial Action Program (FUSRAP): W.R. Grace Feasibility Study (FS) Alternative Development Process Challenges and Successes, Waste Management Conference, Phoenix, Arizona, February 24-28.

GeoCore, 1997, Environmental Site Assessment Report of Bill's Service Center, 1/4 Mile East of Town, Hanover, Kansas, KDHE UST Project Code A5 101 40078, prepared by GeoCore Services, Inc., Salina, Kansas, March 17.

GeoCore, 1999, Environmental Site Assessment Report of Bill's Service Center, 1/4 Mile East of Town, Hanover, Kansas, KDHE UST Project Code A5 101 40078, prepared by GeoCore Services, Inc., Salina, Kansas, September 24.

Hocking, G., 2004, “Deep Permeable Reaction Barriers,” Pollution Engineering, March 1 (http://www.pollutionengineering.com/Articles/Cover_Story/84a8506eced68010VgnVCM10000 0f932a8c0___ $)$.

ITRC, 2009, Phytotechnology Technical and Regulatory Guidance and Decision Trees, Revised, PHYTO-3. Technical/Regulatory Guidance, Phytotechnologies Team, Interstate Technology and Regulatory Council, Washington, D.C., February (http://www.itrcweb.org/Documents/PHYTO3.pdf).

Kansas, 2003, Kansas Statutes Annotated, Chapter 65. Public Health, Article 1. Secretary of Health and Environment, Activities, Statutes 65-1,221 to 65-1,235 (linked at http://www.kslegislature.org/legsrv-statutes/index.do). 
Kansas, 2004, Kansas Administrative Regulations, 28-15a-61 Maximum Contaminant Levels for Organic Contaminants (http://www.kslegislature.org/ksadminregs/28-15a-61.html) and 28-15a62 Maximum Contaminant Levels for Inorganic Contaminants (http://www.kslegislature.org/ ksadminregs/28-15a-62.html).

KDHE, 1998, Site Reconnaissance and Evaluation: Hanover USDA/CCC Site, Hanover, Kansas, KDHE Identification Number P5-101-70430, prepared by the Kansas Department of Health and Environment, Bureau of Environmental Remediation, Topeka, Kansas, July.

KDHE, 2001a, Scope of Work for a Corrective Action Study, Policy BER-RS-019, Remedial Section, Bureau of Environmental Remediation, Kansas Department of Health and Environment, Topeka, Kansas, March 29 (http://www.kdheks.gov/ber/policies/BER_RS_019_SOW.pdf).

KDHE, 2001b, Reclassification Plan, Policy BER-RS-024, Remedial Section, Bureau of Environmental Remediation, Kansas Department of Health and Environment, Topeka, Kansas, December 19 (http://www.kdheks.gov/ber/policies/BER_RS_033.pdf).

KDHE, 2002, Standards for Property Identification for Issuance of No Further Action Determinations, Policy BER-RS-VCP-003, Remedial Section, Bureau of Environmental Remediation, Kansas Department of Health and Environment, Topeka, Kansas, August 7 (http://www.kdheks.gov/ber/policies/BER_RS_VCP_003.pdf).

KDHE, 2005a, “KDHE’s Environmental Use Control Program,” Section 19 in Voluntary Cleanup and Property Redevelopment Program (VCPRP) Manual), Remedial Section, Bureau of Environmental Remediation, Kansas Department of Health and Environment, Topeka, Kansas, May 20 (http://www.kdheks.gov/remedial/vcp/download/vcprpmanualsection19.pdf).

KDHE, 2005b, Potential Applicable or Relevant and Appropriate Requirements (ARARs), Policy BER-RS-015, Remedial Section, Bureau of Environmental Remediation, Kansas Department of Health and Environment, Topeka, Kansas, August 9 (http://www.kdheks.gov/ber/policies/ BER_RS_015.pdf). 
KDHE, 2005c, Scope of Work (SOW) for a Comprehensive Investigation, policy BER-RS-018, Bureau of Environmental Remediation, Kansas Department of Health and Environment, Topeka, Kansas, revised December 19 (linked at http://www.kdheks.gov/ber/policies.htm).

KDHE, 2005d, Evaluating Future Land Use, Policy BER-RS-005, Remedial Section, Bureau of Environmental Remediation, Kansas Department of Health and Environment, Topeka, Kansas, December 19 (http://www.kdheks.gov/ber/policies/BER_RS_005.pdf).

KDHE, 2005e, Consideration for Hydraulic Containment, Policy BER-RS-028, Remedial Section, Bureau of Environmental Remediation, Kansas Department of Health and Environment, Topeka, Kansas, December 27 (http://www.kdheks.gov/ber/policies/BER_RS_028.pdf).

KDHE, 2005f, Scope of Work for a Remedial Investigation (RI)/Feasibility Study (FS), policy BER-RS-025, Bureau of Environmental Remediation, Kansas Department of Health and Environment, Topeka, Kansas, December 30 (linked at http://www.kdheks.gov/ber/policies.htm).

KDHE, 2005g, Considerations for Remedial Standards, Policy BER-RS-033, Remedial Section, Bureau of Environmental Remediation, Kansas Department of Health and Environment, Topeka, Kansas, December 30 (http://www.kdheks.gov/ber/policies/BER_RS_024.pdf).

KDHE, 2007, Kansas Vapor Intrusion Guidance: Chemical Vapor Intrusion and Residential Indoor Air, Bureau of Environmental Remediation, Kansas Department of Health and Environment, Topeka, Kansas, June (http://www.kdheks.gov/ber/download/Ks_VI_ Guidance.pdf).

KDHE, 2008a, letter from C. Carey (Bureau of Environmental Remediation, Kansas Department of Health and Environment, Topeka, Kansas) to C. Roe (Commodity Credit Corporation, U.S. Department of Agriculture, Washington, D.C.), regarding indoor air sampling at Hanover, March 26.

KDHE, 2008b, letter from E. McWilliams (Bureau of Environmental Remediation, Kansas Department of Health and Environment, Topeka, Kansas) to C. Roe (Commodity Credit Corporation, U.S. Department of Agriculture, Washington, D.C.), regarding Supplemental VI Work Plan, July 17. 
KDHE, 2008c, electronic mail message from E. McWilliams (Bureau of Environmental Remediation, Kansas Department of Health and Environment, Topeka, Kansas) to C. Roe (Commodity Credit Corporation, U.S. Department of Agriculture, Washington, D.C.), concurring with plan for site characterization in fall 2008 and sub-slab sampling of homes in winter 2008-2009, August 6.

KDHE, 2008d, letter from E. Finzer (Bureau of Environmental Remediation, Kansas Department of Health and Environment, Topeka, Kansas) to C. Roe (Commodity Credit Corporation, U.S. Department of Agriculture, Washington, D.C.), regarding site investigation Work Plan, November 18.

KDHE, 2008e, letter from E. Finzer (Bureau of Environmental Remediation, Kansas Department of Health and Environment, Topeka, Kansas) to C. Roe (Commodity Credit Corporation, U.S. Department of Agriculture, Washington, D.C.), regarding addendum to Supplemental VI Work Plan, December 23.

KDHE, 2009a, Final Regulation: Article 73 - Environmental Use Controls Program, Kansas Department of Health and Environment, Topeka, Kansas, January 15 (http://www.kdheks.gov/ remedial/euc/download/euc_regs.pdf).

KDHE, 2009b, Considerations for Groundwater Use and Applying RSK Standards to Contaminated Groundwater, Policy BER-RS-045, Remedial Section, Bureau of Environmental Remediation, Kansas Department of Health and Environment, Topeka, Kansas, June 19 (http://www.kdheks.gov/ber/policies/BER_RS_045.pdf).

KDHE, 2009c, letter from E. Finzer (Bureau of Environmental Remediation, Kansas Department of Health and Environment, Topeka, Kansas) to C. Roe (Commodity Credit Corporation, U.S. Department of Agriculture, Washington, D.C.), regarding Addendum 2 to Supplemental VI Work Plan, July 7.

KDHE, 2009d, letter from E. Finzer (Bureau of Environmental Remediation, Kansas Department of Health and Environment, Topeka, Kansas) to C. Roe (Commodity Credit Corporation, U.S. Department of Agriculture, Washington, D.C.), regarding plans for vegetation sampling at Hanover, July 20. 
KDHE, 2009e, letter from E. Finzer (Bureau of Environmental Remediation, Kansas Department of Health and Environment, Topeka, Kansas) to C. Roe (Commodity Credit Corporation, U.S. Department of Agriculture, Washington, D.C.), regarding Addendum 1 to Final Work Plan, July 22.

KDHE, 2009f, letter from E. Finzer (Bureau of Environmental Remediation, Kansas Department of Health and Environment, Topeka, Kansas) to C. Roe (Commodity Credit Corporation, U.S. Department of Agriculture, Washington, D.C.), regarding Addendum 2 to Final Work Plan, August 18.

KDHE, 2009g, letter from E. Finzer (Bureau of Environmental Remediation, Kansas Department of Health and Environment, Topeka, Kansas) to C. Roe (Commodity Credit Corporation, U.S. Department of Agriculture, Washington, D.C.), regarding Figure 4 in Addendum 2 to Final Work Plan, August 28.

KDHE, 2009h, electronic mail message from E. Finzer (Bureau of Environmental Remediation, Kansas Department of Health and Environment, Topeka, Kansas) to C. Roe (Commodity Credit Corporation, U.S. Department of Agriculture, Washington, D.C.), regarding prioritization list for 2010-2011, October 14.

KDHE, 2009i, letter from E. Finzer (Bureau of Environmental Remediation, Kansas Department of Health and Environment, Topeka, Kansas) to C. Roe (Commodity Credit Corporation, U.S. Department of Agriculture, Washington, D.C.), regarding the VI mitigation work plan for three Hanover homes, November 2.

KDHE, 2009j, letter from E. Finzer (Bureau of Environmental Remediation, Kansas Department of Health and Environment, Topeka, Kansas) to C. Roe (Commodity Credit Corporation, U.S. Department of Agriculture, Washington, D.C.), regarding Addendum 3 to Final Work Plan, November 17.

KDHE, 2010a, electronic mail message from C. Carey (Bureau of Environmental Remediation, Kansas Department of Health and Environment, Topeka, Kansas) to C. Roe (Commodity Credit Corporation, U.S. Department of Agriculture, Washington, D.C.), regarding Addendum 3 to Supplemental VI Work Plan, January 21. 
KDHE, 2010b, letter from C. Carey (Bureau of Environmental Remediation, Kansas Department of Health and Environment, Topeka, Kansas) to C. Roe (Commodity Credit Corporation, U.S. Department of Agriculture, Washington, D.C.), regarding Addendum 4 to Supplemental VI Work Plan, February 15.

KDHE, 2010c, electronic mail message from C. Carey (Bureau of Environmental Remediation, Kansas Department of Health and Environment, Topeka, Kansas) to L.M. LaFreniere (Environmental Science Division, Argonne National Laboratory, Argonne, Illinois), March 4.

KDHE, 2010d, electronic mail message from S. Aller (Bureau of Environmental Remediation, Kansas Department of Health and Environment, Topeka, Kansas) to L.M. LaFreniere (Environmental Science Division, Argonne National Laboratory, Argonne, Illinois), March 5.

KDHE, 2010e, letter from C. Carey (Bureau of Environmental Remediation, Kansas Department of Health and Environment, Topeka, Kansas) to C. Roe (Commodity Credit Corporation, U.S. Department of Agriculture, Washington, D.C.), regarding the VI mitigation work plan for two Hanover homes, May 4.

KDHE, 2010f, Risk Based Standards for Kansas: RSK Manual - 5th Version, Bureau of Environmental Remediation, Kansas Department of Health and Environment, Topeka, Kansas, June (www.kdheks.gov/remedial/rsk_manual_page.htm).

KDHE, 2011, letter from H. Burke (Bureau of Environmental Remediation, Kansas Department of Health and Environment, Topeka, Kansas) to C. Roe (Commodity Credit Corporation, U.S. Department of Agriculture, Washington, D.C.), regarding corrective action for the Hanover site, October 24.

Keely, J.F., 1989, Performance Evaluations of Pump-and-Treat Remediation, EPA/540/489/005, Robert S. Kerr Environmental Research Laboratory, Office of Research and Development, U.S. Environmental Protection Agency, Ada, Oklahoma.

Merriam, D.F., 1963, The Geologic History of Kansas, Bulletin 162, Kansas Geological Survey, University of Kansas, Lawrence, Kansas (http://www.kgs.ku.edu/Publications/Bulletins/ 162/index.html). 
NAIP, 2006, aerial photograph of Hanover, Kansas, naip_1-1_1n_s_ks201_2006_1, National Agricultural Imagery Program, Field Service Agency, U.S. Department of Agriculture, Salt Lake City, Utah, August 31 (http://www.apfo.USDA.gov/NAIP.html).

NAIP, 2008, aerial photograph of Hanover, Kansas, ortho_1-1_1m_j_ks201_2008_2, National Agricultural Imagery Program, Field Service Agency, U.S. Department of Agriculture, Salt Lake City, Utah, October 30 (linked at http://www.fsa.usda.gov/FSA/).

Negri, M.C., E.G. Gatliff, J.J. Quinn, and R.R. Hinchman, 2003, "Root Development and Rooting at Depths,” in Phytoremediation: Transformation and Control of Contaminants, edited by S.C. McCutcheon and J.L. Schnoor, John Wiley and Sons, Inc.

Palmer, C.D., and W. Fish, 1992, Chemical Enhancements to Pump-and-Treat Remediation, Ground Water Issue Paper EPA/540/S-92/001, Robert S. Kerr Environmental Research Laboratory, Office of Research and Development, U.S. Environmental Protection Agency, Ada, Oklahoma.

Price-Waterhouse Coopers, LLP, 2001, RACER Accreditation Recommendation, prepared for the Department of the Air Force, Civil Engineering Support Agency, Tyndall Air Force Base, July.

Quinn, J.J., 2010, personal communication from Quinn (Environmental Science Division, Argonne National Laboratory, Argonne, Illinois) to with L. Martino (Environmental Science Division, Argonne National Laboratory, Argonne, Illinois), September 30.

Riley, R.G., J. E. Szecsody, D.S. Sklarew, A.V. Mitroshkov, C.F. Brown, C.J. Thompson, and P.M. Gent, 2005, Carbon Tetrachloride and Chloroform Partition Coefficients Derived from Aqueous Desorption of Contaminated Hanford Sediments, PNNL-15239, prepared for the U.S. Department of Energy, Washington, D.C., by Pacific Northwest National Laboratory, Richland, Washington, July.

RWD, 2009a, telephone conversations between E. Pralee (Washington County Rural Water District \#1, Hanover, Kansas) and J. Hansen (Environmental Science Division, Argonne National Laboratory, Argonne, Illinois), May 13 and June 23. 
RWD, 2009b, “Individual Water Supplies," Requirement 4 in Section 3, Cross Connection Control - Rules and Regulations, Rural Water District No. 1, Washington County, Kansas, September 1.

Schlabach, D., 2011, telephone conversation between Schlabach (representative of Washington County Rural Water District \#1, Hanover, Kansas) and J. Hansen (Environmental Science Division, Argonne National Laboratory, Argonne, Illinois), February 22.

Suchy, D.R., R. Buchanan, and M. Sophocleous, 2011, Drilling a Water Well on Your Land: What You Should Know, Public Information Circular 23, Kansas Geological Survey, University of Kansas, Lawrence, Kansas (http://www.kgs.ku.edu/Publications/PIC/pic23.html).

USDA, 1957, Aerial photograph YV-6T-59L, U.S. Department of Agriculture, Washington, D.C., July 12.

USDA, 1969, Aerial photograph YV-2KK-146D, U.S. Department of Agriculture, Washington, D.C., September 20.

USDA, 1978, Aerial photograph 20201-177-294L, U.S. Department of Agriculture, Washington, D.C., October 11.

USGS, 1997, Digital Raster Graphics (DRG) UTM NAD 83 of Washington County, Kansas, (created from USGS 1982 7.5-minute topographic maps), U.S. Geological Survey, Reston, Virginia.

Water Appropriation Program, 2009, telephone conversation between K. Kopp (Water Appropriation Program, Kansas Department of Agriculture, Topeka, Kansas), and J. Hansen (Environmental Science Division, Argonne National Laboratory, Argonne, Illinois), May 14.

Water Quality Association, 2011, Water Quality Answers, International Headquarters and Laboratory, Lisle, Illinois (http://www.wqa.org/sitelogic.cfm?ID=362), accessed April 12. 


\section{Appendix A:}

Summary of Investigation Activities and Response Actions at Hanover, 1998-2010 
TABLE A.1 Summary of investigation activities and response actions at Hanover, 1998-2010.

\section{Prior investigation by the KDHE to evaluate potential carbon tetrachloride contamination}

February 17, $1998 \quad$ Private well sampling by the KDHE under the joint KDHE-CCC/USDA private well sampling program.

July 1998

KDHE completion of SRE report for the former CCC/USDA grain storage facility.

April 26, 2006

KDHE private well sampling
Determine whether carbon tetrachloride is present in groundwater as a result of former CCC/USDA grain storage operations.

Identify site contamination and potentially responsible party.

Update the previously identified groundwater contamination.

Methodology

Sample collection from 3 private wells located within $1 \mathrm{mi}$ of the former CCC/USDA grain storage facility.

Subsurface soil sampling with Geoprobe private well sampling.

Sample collection from Bruna and Meyn private wells (also sampled in 1998).

Investigation by the CCC/USDA to address residents' concerns regarding former grain storage operations

April 18, 2007

July $10-11,2007$

October 11, 2007

October 18, 2007

December 5, 2007
Near-surface soil sampling in response to resident concerns regarding potential carbon tetrachloride contamination due to former CCC/USDA grain storage operations.

Indoor air sampling in the basements of 9 residences on the former CCC/USDA

property, in response to resident concerns.

Conduct an initial evaluation of indoor ai contamination.

Evaluate the potential for subsurface soi contamination and for human exposure.

Submittal to the KDHE of results of nearsurface soil sampling (April 2007) and indoor air sampling (July 2007).

Submittal to the KDHE of an evaluation of indoor air carbon tetrachloride

concentrations measured in July 2007.

Issuance of $\mathrm{KDHE}$ response regarding evaluation of indoor air results and request for VI work plan
Near-surface soil sampling at 61 locations across the former CCC/USDA property, with preservation on dry ice and analysis for VOCs at the AGEM Laboratory.

Air collection over $24 \mathrm{hr}$ in Summa canisters; analysis by TestAmerica, Burlington, Vermont, by EPA Method TO-15.

Although no immediate health risk was evident, investigation was recommended to determine whether the detected concentrations were due to $\mathrm{VI}$ from contaminated subsurface soil or groundwater.

Additional sampling or installation of mitigation systems requested. 


\begin{tabular}{ll}
\hline Date $\quad$ Activity $\quad$ Objective \\
\hline
\end{tabular}

Investigation by the CCC/USDA to characterize the nature and extent of site contamination and potential response actions

March 26, 2008

July 9,2008

July 17,2008

August 15, 2008

September 9, 2008

October 13, 2008

November 18, 2008

December 15, 2008

December 23, 2008

January 13-15, 2009
Issuance of $\mathrm{KDHE}$ request to develop a $\mathrm{VI}$ work plan.

Submittal to the KDHE of the draft VI investigation work plan.

Issuance of KDHE approval for the VI work plan.

Submittal to the KDHE of the draft site characterization work plan.

Issuance of KDHE comments on the draft site characterization work plan.

Submittal to the KDHE of the revised site characterization work plan and a response to KDHE comments.

Issuance of KDHE approval for the site characterization work plan.

Submittal to the KDHE of a plan for indoor air and ambient air sampling.

Issuance of KDHE comments on the indoor air sampling plan.

mplementation of Phase 1 of the site characterization work plan, on the former CCC/USDA property.
Evaluate the potential for VI.

Evaluate the potential for VI by comparison of sub-slab and indoor air concentrations.

Characterize soil and groundwater contamination associated with past use of carbon tetrachloride-based grain fumigants at the former CCC/USDA facility.

Evaluate the potential for $\mathrm{VI}$ in 4 homes on the former CCC/USDA facility.

Identify potential soil sources and determine the vertical and lateral distribution of carbon tetrachloride contamination in soil.
Investigation under the KDHE-CCC/USDA Inter-Governmental Agreement.

Phased investigation in conjunction with the site characterization investigation.

Phased investigation of the nature and extent of carbon tetrachloride contamination in soil and groundwater on and adjacent to the former CCC/USDA property.

Sub-slab and indoor air sampling for carbon tetrachloride, chloroform, and radon (as a tracer).

Subsurface soil sampling to bedrock based on 2007 surface soil results; sampling at 25 locations (TI01-TI25), approximately every $4 \mathrm{ft}$; preservation on dry ice and analysis for VOCs at the AGEM Laboratory. 


Date Activity Objective Methodology

Investigation by the CCC/USDA to characterize the nature and extent of site contamination and potential response actions (cont.)

January 28-

February 10, 2009

February 2-4, 2009

February 18, 2009

February 23-

March 6, 2009

March 12-13, 2009

March 25-27, 2009

March 24-

April 3, 2009

April 1, 2009

April 7-10, 2009
Implementation of Phase 2 of the site characterization work plan, on the former CCC/USDA property.

Investigation of upward VI in 3 residences on the former CCC/USDA property where carbon tetrachloride was detected in July 2007.

\section{KDHE-CCC/USDA teleconference.}

Implementation of Phase 3 of the site characterization work plan, outside the former CCC/USDA property.

Investigation of upward $\mathrm{VI}$ in the remaining 6 residences on the former CCC/USDA property, where carbon tetrachloride was not detected in July 2007.

$\mathrm{VI}$ evaluation at residences outside the former CCC/USDA property (completed April 7-10, 2009).

Continuation of groundwater investigation; confirmation of multiple-zone model.

\section{KDHE-CCC teleconference.}

Continuation of the VI evaluation at residences outside the former CCC/USDA property.
Determine the vertical and lateral extent of groundwater contamination, and obtain data to characterize the site lithology, hydrostratigraphy, and groundwater flow.

Evaluate indoor air contamination during optimal winter sampling period when homes are most closed to outside air.

Present results of site investigation to date.

Characterize water-bearing Zone 1; delineate associated contamination; develop a monitoring system to evaluate groundwater flow patterns.

Evaluate indoor air contamination during the optimal winter sampling period when homes are most closed to outside air.

Screen all residences in the identified groundwater contaminant distribution area for potential vapor intrusion.

Complete characterization of groundwaterbearing Zone 1; extend the investigation to deeper Zones 2-4.

Present results for indoor air sampling at 9 homes in February-March.

Screen all residences in the identified groundwater contamination area for potential VI.
Additional subsurface soil sampling and installation of 12 monitoring wells (MW01, MW02, MW04-MW13) on and adjacent to the former CCC/USDA facility.

Collection of vapor/air samples from subslab, basement, and first-floor spaces for analysis of VOCs and tracer radon.

Installation and sampling of 28 additional monitoring wells (MW14-MW41); sampling of existing private wells.

Collection of basement and first-floor indoor air samples for analysis by TestAmerica with EPA Method TO-15.

Collection of vapor/air samples from subslab, basement, and first-floor spaces for on-site analysis, with submittal of selected samples for off-site verification analysis.

Installation of 10 additional monitoring wells: MW42, MW43, MW44S, MW44M, MW44D, MW45S, MW45M, MW45D, MW46, and MW47.

$-$

Collection of vapor/air samples from subslab, basement, and first-floor spaces for on-site analysis, with submittal of selected samples for off-site verification analysis. 


Date Activity Objective Methodology

Investigation by the CCC/USDA to characterize the nature and extent of site contamination and potential response actions (cont.)

May 7, 2009

KDHE-CCC teleconference.

May 29, 2009

June 16, 2009

June 22, 2009

July 7, 2009

July 15, 2009

July 15, 2009

July 17, 2009

July 22, 2009

July 23-24, 2009
Public availability session in Hanover.

Submittal to the KDHE of a plan for indoor air sampling in 16 homes (subsequently expanded to 17 homes).

Sampling of 4 additional private wells identified during community meeting.

Issuance of KDHE approval of the plan for indoor air sampling at 17 homes.

Submittal to the KDHE of two addenda to the site characterization work plan, for hydrogeologic testing under Phase 4 of the site characterization work plan.

Issuance of KDHE approval for vegetation sampling, with request for location map.

Submittal to the KDHE of a plan for vegetation sampling.

Issuance of KDHE approval for the plan for groundwater Zone 1 slug testing.

Vegetation sampling of mature trees across the investigation area.
Discuss VI investigation results and proposed mitigation.

Present the results of site investigation to date to Hanover residents.

Monitor indoor air contamination at homes where the potential for VI had been identified.

Determine potential carbon tetrachloride contamination in active private wells; verify use of wells.

Evaluate aquifer properties and determine the pumping capacity of the identified contaminated water-bearing zones.

Determine the potential for phytoremediation as a response technology.

Determine whether carbon tetrachloride uptake in vegetation is occurring, to evaluate the potential for phytoremediation of the identified groundwater contamination.
Community meeting led by the KDHE.

Indoor air and ambient air sampling with analysis by TestAmerica.

Sample collection for analysis by the AGEM Laboratory.

Addendum 1: Slug testing for groundwater Zone 1; Addendum 2: Further investigation for groundwater Zone 2 .

Collection of branch and leaf samples from existing mature trees across the investigation area, with analysis at the AGEM Laboratory.

Branch and leaf sampling at 171 locations across the investigation area; preservation on dry ice, with analysis at the AGEM

Laboratory for carbon tetrachloride and chloroform by modified EPA Method 3810. 


Date Activity Objective Methodology

Investigation by the CCC/USDA to characterize the nature and extent of site contamination and potential response actions (cont.)

August 5, $2009 \quad$ Submittal to the KDHE of a plan for vapor mitigation of 3 homes.

August 10, 2009

August 12-13, 2009

August 10-14, 2009

August 25-27, 2009

August 28, 2009

September 15, 2009

September 28, 2009

September 21-

October 16, 2009

October 13, 2009

October 28, 2009
Meeting of CCC/USDA and KDHE in

Topeka.

Issuance of KDHE approval of plan for vapor mitigation of 3 homes.

Monitoring of 17 residences where carbon tetrachloride was identified in prior indoor air sampling.

Slug testing of wells in groundwaterbearing Zone 1.

Completion of vapor mitigation of 3 homes.

Issuance of KDHE approval for plan for investigation of groundwater Zones 2-4.

Issuance of KDHE electronic mail message outlining expectations for future monitoring and remediation.

Retesting of indoor air in 3 homes after installation of sub-slab vapor intrusion mitigation systems in August.

Zone 2-4 groundwater investigation.

Submittal to the KDHE of results of August 2009 Zone 1 slug testing.
Reduce identified carbon tetrachloride contamination in indoor air.

$-$

Conduct summertime monitoring of indoor air.

Evaluate hydraulic properties and identify critical factors that govern groundwater flow and contaminant migration in the Zone 1 unit.

Reduce identified carbon tetrachloride contamination in indoor air.

$-$

Verify elimination of identified carbon tetrachloride contamination in indoor air.

Characterize the deep groundwater system in water-bearing Zones 2-4.

Present results of investigation to date.
Installation of sub-slab depressurization systems.

Collection of basement and first-floor indoor air samples for analysis by TestAmerica with EPA Method TO-15.

Slug testing in 20 Zone 1 monitoring wells: MW01, MW02, MW04-MW07, MW09MW13, MW16, MW18, MW20, MW21,

MW28, MW29, MW34, MW37, and MW38.

Indoor air sampling

Installation and sampling of 12 monitoring wells: MW48Z2, MW48Z3, MW48Z4,

MW49Z2, MW49Z3, MW49Z4, MW50Z2, MW50Z3, MW50Z4, MW51Z2, MW51Z3, and MW52Z4. 


Date Activity Objective Methodology

Investigation by the CCC/USDA to characterize the nature and extent of site contamination and potential response actions (cont.)

November 18, 2009 Submittal to the KDHE of Addendum 3 to the site characterization work plan, for performance testing of selected Zone 1 monitoring wells.

November 23-25, 2009

Single-well step-drawdown testing at 3 wells selected per the August 2009 slug test responses.

January 25-26, 2010 Monitoring of 17 residences where carbon tetrachloride was identified in prior indoor air sampling.

January 26-27, 2010 Slug testing of wells in groundwaterbearing Zone 2.

January 29, 2010

Submittal to the KDHE of results of the November 2009 Zone 1 pumping test.

February 22-24, 2010

February 22-25, 2010

Constant-rate pumping test at Zone 1 well MW05, selected per the November 2009 step-drawdown test results.

Indoor air sampling at Hanover public school and St. John's School, at the
Assess the technical and logistic feasibility of groundwater pumping from groundwater Zone 1 as a potential corrective action technology.

Determine the specific capacity and radius of influence of selected Zone 1 wells.

Conduct wintertime monitoring of indoor air contamination.

Evaluate the hydraulic properties of Zone 2 and the potential effectiveness of localized groundwater extraction as a corrective action technology.

Evaluate the potential effectiveness of localized groundwater extraction from groundwater Zone 1 as a corrective action technology.

Determine the long-term sustainable pumping rate for water-bearing Zone 1 well MW05, to evaluate the potential effectiveness of localized groundwater extraction as a corrective action technology. request of residents; sampling of 9 residences potentially at risk for VI from groundwater Zone 2.

Determine the potential for upward VI of carbon tetrachloride, chloroform, and radon contamination from the subsurface to indoor air.
Step-drawdown testing at Zone 1

monitoring wells MW05, MW09, and MW10.

Step pumping testing at water-bearing Zone 1 wells MW05, MW09, and MW10.

Collection of basement and first-floor indoor air samples for analysis at TestAmerica with EPA Method TO-15.

Slug testing in 6 Zone 2 monitoring wells: MW44Z2, MW45Z2, MW48Z2, MW49Z2, MW50Z2, and MW51Z2.

Step pumping testing at water-bearing Zone 1 wells MW05, MW09, and MW10.

Measurement of water level response and recovery during sustained pumping of water-bearing Zone 1 monitoring well MW05.

Indoor air sampling with on-site analysis in accessible rooms in the schools, with follow-up sampling and quantitative analysis for rooms selected per the screening results; quantitative VOCs analysis by TestAmerica with EPA Method TO-15. 


\begin{tabular}{|c|c|c|c|}
\hline Date & Activity & Objective & Methodology \\
\hline March 17-20, 2010 & $\begin{array}{l}\text { Constant-rate pumping test at Zone } 2 \text { well } \\
\text { MW44, selected per the January } 2010 \text { slug } \\
\text { test results. }\end{array}$ & $\begin{array}{l}\text { Determine the long-term sustainable } \\
\text { pumping rate for water-bearing Zone } 2 \text {. }\end{array}$ & $\begin{array}{l}\text { Measurement of water level response and } \\
\text { recovery during sustained pumping of } \\
\text { water-bearing Zone } 2 \text { monitoring well } \\
\text { MW44. }\end{array}$ \\
\hline April 26, 2010 & $\begin{array}{l}\text { Submittal to the KDHE of results of the } \\
\text { January } 2010 \text { Zone } 2 \text { slug testing. }\end{array}$ & $\begin{array}{l}\text { Evaluate the potential effectiveness of } \\
\text { localized groundwater extraction from } \\
\text { groundwater Zone } 2 \text { as a corrective action } \\
\text { technology. }\end{array}$ & - \\
\hline April 27, 2010 & $\begin{array}{l}\text { Submittal to the KDHE of a plan for vapor } \\
\text { mitigation of } 2 \text { homes. }\end{array}$ & $\begin{array}{l}\text { Reduce identified carbon tetrachloride } \\
\text { contamination in indoor air. }\end{array}$ & $\begin{array}{l}\text { Installation of sub-slab depressurization } \\
\text { systems. }\end{array}$ \\
\hline April 30, 2010 & $\begin{array}{l}\text { Submittal to the KDHE of results of the } \\
\text { February } 2010 \text { constant-rate pumping test } \\
\text { for Zone } 1 \text { monitoring well MW05 } \\
\text { submitted to the KDHE. }\end{array}$ & $\begin{array}{l}\text { Evaluate the potential effectiveness of } \\
\text { localized groundwater extraction from } \\
\text { groundwater Zone } 1 \text { as a corrective action } \\
\text { technology. }\end{array}$ & - \\
\hline May 4, 2010 & $\begin{array}{l}\text { Issuance of KDHE approval of plan for } \\
\text { vapor mitigation of } 2 \text { homes. }\end{array}$ & - & - \\
\hline May 12-13, 2010 & Completion of vapor mitigation of 2 homes. & $\begin{array}{l}\text { Reduce identified carbon tetrachloride } \\
\text { contamination in indoor air. }\end{array}$ & - \\
\hline June 17, 2010 & $\begin{array}{l}\text { Retesting of indoor air in } 2 \text { homes after } \\
\text { installation of sub-slab vapor intrusion } \\
\text { mitigation systems in May } 2010 .\end{array}$ & $\begin{array}{l}\text { Verify elimination of identified carbon } \\
\text { tetrachloride contamination in indoor air. }\end{array}$ & Indoor air sampling. \\
\hline June 17, 2010 & $\begin{array}{l}\text { Sampling of selected monitoring wells for } \\
\text { nitrate analysis. }\end{array}$ & $\begin{array}{l}\text { Indicate subsurface infiltration to water- } \\
\text { bearing zones. }\end{array}$ & Groundwater sampling. \\
\hline July 29, 2010 & $\begin{array}{l}\text { Submittal to the KDHE of results of the } \\
\text { March } 2010 \text { constant-rate pumping test for } \\
\text { Zone } 2 \text { monitoring well MW } 44 Z 2 \text {. }\end{array}$ & $\begin{array}{l}\text { Evaluate the potential effectiveness of } \\
\text { localized groundwater extraction from } \\
\text { groundwater Zone } 2 \text { as a corrective action } \\
\text { technology. }\end{array}$ & - \\
\hline
\end{tabular}

March 17-20, $2010 \quad$ Constant-rate pumping test at Zone 2 well
MW44, selected per the January 2010 slu test results.

Submittal to the KDHE of results of the

Submittal to the KDHE of a plan for vapor tion of 2 homes. ate pumping test

ssuance of KDHE approval of plan fo vapor mitigation of 2 homes.

Retesting of indoor air in 2 homes afte installation of sub-slab vapor intrusion in 2010. nitrate analysis.

Submittal to the KDHE of results of the March 2010 constant-rate pumping test fo technology. 
Appendix B:

Potential Federal and State Applicable or Relevant and Appropriate Requirements and State Guidance Documents "To Be Considered" 
TABLE B.1 Potential federal applicable or relevant and appropriate requirements (ARARs) and guidance to be considered for former CCC/USDA facilities.

\begin{tabular}{|c|c|c|c|c|c|}
\hline Title & Citation $^{\mathrm{a}}$ & Description & Comment & Type $^{b}$ & Determination \\
\hline $\begin{array}{l}\text { Comprehensive Environmental } \\
\text { Response, Compensation, and } \\
\text { Liability Act (CERCLA) }\end{array}$ & $\begin{array}{l}42 \text { USC } 9601 \\
\text { et seq. }\end{array}$ & & & $A$ & $\begin{array}{l}\text { Relevant and } \\
\text { appropriate }\end{array}$ \\
\hline $\begin{array}{l}\text { National Oil and Hazardous } \\
\text { Substances Pollution } \\
\text { Contingency Plan (NCP) }\end{array}$ & 40 CFR Part 300 & $\begin{array}{l}\text { Provides the federal government's blueprint for } \\
\text { responding to both oil spills and hazardous } \\
\text { substance releases. }\end{array}$ & $\begin{array}{l}\text { Applicable to releases } \\
\text { into the environment of } \\
\text { hazardous substances } \\
\text { and pollutants or } \\
\text { contaminants that may } \\
\text { present an imminent and } \\
\text { substantial danger to } \\
\text { public health or the } \\
\text { national welfare. }\end{array}$ & $A$ & $\begin{array}{l}\text { Relevant and } \\
\text { appropriate }\end{array}$ \\
\hline Off-Site Rule & 40 CFR 300.440 & $\begin{array}{l}\text { Establishes procedures for planning and } \\
\text { implementing off-site response actions. }\end{array}$ & $\begin{array}{l}\text { Applicable to response } \\
\text { actions involving off-site } \\
\text { transfers of hazardous } \\
\text { substances, pollutants, } \\
\text { or contaminants. }\end{array}$ & $A$ & $\begin{array}{l}\text { Relevant and } \\
\text { appropriate }\end{array}$ \\
\hline $\begin{array}{l}\text { Emergency Planning and } \\
\text { Community Right-to-Know } \\
\text { Regulations }\end{array}$ & $\begin{array}{l}49 \text { CFR } 350,355 \\
\text { and } 372\end{array}$ & $\begin{array}{l}\text { Allows state and local planning for chemical } \\
\text { emergencies, provides for notification of } \\
\text { emergency releases of chemicals, and addresses } \\
\text { communities' right to information about toxic and } \\
\text { hazardous chemicals. }\end{array}$ & $\begin{array}{l}\text { Applicable if hazardous } \\
\text { chemicals are stored or } \\
\text { otherwise used as part of } \\
\text { the corrective action. }\end{array}$ & $A$ & $\begin{array}{l}\text { Relevant and } \\
\text { appropriate }\end{array}$ \\
\hline $\begin{array}{l}\text { Safe Drinking Water Act (SDWA) } \\
\text { (Public Health Service Act) }\end{array}$ & $\begin{array}{l}42 \text { USC } 300(f) \\
\text { et seq. }\end{array}$ & & & & \\
\hline $\begin{array}{l}\text { National Primary Drinking } \\
\text { Water Standards }\end{array}$ & $\begin{array}{l}40 \text { CFR Part 141, } \\
\text { Subparts B } \\
\text { and G }\end{array}$ & $\begin{array}{l}\text { Establishes maximum contaminant levels (MCLs), } \\
\text { which are health-based standards for public water } \\
\text { systems. The MCL for carbon tetrachloride is } \\
5 \mu \mathrm{g} / \mathrm{L} \text {. The MCL for chloroform (total } \\
\text { trihalomethanes) is } 80 \mu \mathrm{g} / \mathrm{L} \text {. }\end{array}$ & $\begin{array}{l}\text { Applicable to organic } \\
\text { groundwater } \\
\text { contamination in a sole- } \\
\text { source aquifer. }\end{array}$ & & \\
\hline
\end{tabular}

National Oil and Hazardous

Substances Pollution

Contingency Plan (NCP)

. Right-to-Know

Regulations

Safe Drinking Water Act (SDWA)

National Primary Drinking

Water Standards responding to both oil spills and hazardous

hazardous substances

le to response actions involving off-site

substances, pollutants,

contaminants.

Applicable if hazardous micals are stored or

mergency releases of chemicals, and addresses

communities' right to information about toxic and

which are health-based standards for public water groundwater

$5 \mu \mathrm{g} / \mathrm{L}$. The MCL for chloroform (tota

source aquifer. 


\begin{tabular}{llll}
\hline Title & Citation & Description & Typetermination \\
\hline
\end{tabular}

\section{Safe Drinking Water Act (cont.)}

National Secondary Drinking Water Regulations (NSDWRs)

Maximum Contaminant Leve Goals (MCLGs)

Standards for Owners and Operators of Public Water Supply Systems

Underground Injection Control Regulations

Sole-Source Aquifers
40 CFR Part 143

Establishes secondary maximum contaminant levels (SMCLs) for public water systems to protect the aesthetic quality of the water. The

40 CFR Part 141, Establishes non-enforceable drinking water Subpart $F$

\section{quality goals at levels of no known or anticipated}

40 CFR Part 141

40 CFR Part 149 SMCLs are not federally enforceable but are intended as guidelines for the states. adverse health effects, with an adequate margin of safety. The MCLG for carbon tetrachloride is zero.

Provides treatment requirements for public water supply systems (i.e., systems that serve at least 25 people or have at least 15 connections).

Provides for protection of underground sources of Applicable if a response drinking water.

Prohibits activities, including drilling, in an area designated a sole-source aquifer without special permission of the U.S. Environmental Protection Agency (EPA) appropriate in the establishment of cleanup

goals for groundwater contamination.

SDWR have been standards by the state.

May be relevant and appropriate if a more stringent standard is

required to protect human health and the environment.

\section{alternative involves} underground injection.

Applicable if the aquife

A, C Relevant and appropriate

C Relevant and appropriate

in the area is a solesource aquifer. 


\begin{tabular}{|c|c|c|}
\hline Title & Citation $^{\mathrm{a}}$ & Description \\
\hline $\begin{array}{l}\text { Clean Water Act (CWA) (Federal } \\
\text { Water Pollution Control Act) }\end{array}$ & $\begin{array}{l}33 \text { USC } 1251 \\
\text { et seq. }\end{array}$ & \\
\hline Ambient Water Quality Criteria & 40 CFR Part 131 & $\begin{array}{l}\text { Establishes ambient water quality criteria } \\
\text { (AWQCs) reflecting "the latest scientific } \\
\text { knowledge ... on the kind and extent of all } \\
\text { identifiable effects on health and welfare } \\
\text { including, but not limited to, plankton, fish, } \\
\text { shellfish, wildlife, plant life... . which may be } \\
\text { expected from the presence of pollutants in any } \\
\text { body of water. ..." Water quality criteria are } \\
\text { based solely on data and scientific judgments on } \\
\text { the relationship between pollutant concentrations } \\
\text { and environmental and human health effects. } \\
\text { These recommended criteria provide guidance for } \\
\text { states and tribes in adopting water quality } \\
\text { standards under Section 303(c) of the CWA [33 } \\
\text { USC } 1313(\mathrm{c}) \text { ]. }\end{array}$ \\
\hline
\end{tabular}

National Pollutant Discharge $\quad 40$ CFR Parts Elimination System (NPDES)
40 CFR Parts

$122-125$
Establishes NPDES permit procedures, criteria, and standards governing the discharge of

pollutants from any point source into U.S. waters [Sections 318, 402, and 405 of the CWA (33 USC $1328,1342,1345)]$. Most storm water discharges require coverage by an NPDES permit.
Comment

Type $^{\text {b }}$ Determination

\section{A, C Applicable}

Developed for some organic constituents in

groundwater; may be relevant and appropriate.
Discharge limits will be established if effluent is discharged to a surface water body. No permit is required for on-site response actions under CERCLA, but the

substantive requirements apply if a response alternative involves discharge into a creek or other surface water onsite. A permit is required if the discharge is to a creek or other surface water off-site.
C Applicable

\section{A, C Applicable}




\begin{tabular}{|c|c|c|c|c|c|}
\hline Title & Citation $^{\mathrm{a}}$ & Description & Comment & Type ${ }^{b}$ & Determination \\
\hline \multicolumn{6}{|l|}{ Clean Water Act (cont.) } \\
\hline $\begin{array}{l}\text { Storm Water Discharge } \\
\text { Requirements }\end{array}$ & 40 CFR 122.26 & $\begin{array}{l}\text { Establishes requirements to obtain a permit to } \\
\text { discharge storm water under the NPDES } \\
\text { program. }\end{array}$ & $\begin{array}{l}\text { Applicable to surface } \\
\text { water discharges of } \\
\text { storm water. }\end{array}$ & $A$ & $\begin{array}{l}\text { Relevant and } \\
\text { appropriate }\end{array}$ \\
\hline Water Quality Standards & 40 CFR Part 131 & $\begin{array}{l}\text { Defines goals for a water body by designating the } \\
\text { water body's uses, setting criteria to protect those } \\
\text { uses, and establishing provisions to protect water } \\
\text { bodies from pollutants. Forms the foundation of } \\
\text { the water-quality-based pollution control program } \\
\text { mandated by the CWA. }\end{array}$ & $\begin{array}{l}\text { Applicable to surface } \\
\text { water discharges. }\end{array}$ & C & Applicable \\
\hline $\begin{array}{l}\text { National Pretreatment } \\
\text { Standards }\end{array}$ & 40 CFR Part 403 & $\begin{array}{l}\text { Provides general pretreatment standards and } \\
\text { regulations for existing and new sources of } \\
\text { pollution; establishes standards to control } \\
\text { pollutants that pass through or interfere with } \\
\text { treatment processes in publicly owned treatment } \\
\text { works (POTWs) or that may contaminate sewage } \\
\text { sludge. }\end{array}$ & $\begin{array}{l}\text { Applicable if a response } \\
\text { alternative involves } \\
\text { discharge to POTWs. }\end{array}$ & $A, C$ & $\begin{array}{l}\text { Relevant and } \\
\text { appropriate }\end{array}$ \\
\hline Dredge or Fill Requirements & $\begin{array}{l}40 \text { CFR Parts 230- } \\
233 \\
{[40 \text { CFR Part }} \\
6.302(a)]\end{array}$ & $\begin{array}{l}\text { Requires permits for discharge of dredged or fill } \\
\text { material into navigable waters. }\end{array}$ & $\begin{array}{l}\text { Applicable if a response } \\
\text { alternative requires } \\
\text { discharge of dredged or } \\
\text { fill material into } \\
\text { navigable waters. }\end{array}$ & A & Not an ARAR \\
\hline $\begin{array}{l}\text { Executive Order }(\mathrm{EO}) \text { on } \\
\text { Protection of Wetlands }\end{array}$ & $\begin{array}{l}\text { EO } 11990 \\
{[40 \text { CFR Part }} \\
6.302(a)]\end{array}$ & $\begin{array}{l}\text { Requires federal agencies to avoid, to the extent } \\
\text { possible, adverse impacts associated with the } \\
\text { destruction or loss of wetlands and to avoid } \\
\text { support of new construction in wetlands if a } \\
\text { practicable alternative exists. }\end{array}$ & $\begin{array}{l}\text { Applicable if a response } \\
\text { alternative has a } \\
\text { negative effect on } \\
\text { wetlands. }\end{array}$ & $A, L$ & Not an ARAR \\
\hline
\end{tabular}

Storm Water Discharge

Water Quality Standards ater discharges of

Applicable to surface uses, and establishing provisic odies from pollutants. Forms the foundation of the water-quality-based pollution control program

Provides general pretreatment standards and that pass through or interfere with Requires permits for discharge of dredged or fill terial into

Applicable if a response negative effect on destruction or loss of 


\begin{tabular}{|c|c|c|c|c|c|}
\hline Title & Citation $^{\mathrm{a}}$ & Description & Comment & Type $^{\text {b }}$ & Determination \\
\hline Rivers and Harbors Act of 1899 & 33 USC 401 et seq. & & & $A$ & Not an ARAR \\
\hline Section 10 Permit & $\begin{array}{l}33 \text { USC } 403 \\
33 \text { CFR Parts 320- } \\
330 \\
{[40 \text { CFR Part }} \\
6.302(a)]\end{array}$ & $\begin{array}{l}\text { Requires a permit for structures for work in or } \\
\text { affecting navigable waters. }\end{array}$ & $\begin{array}{l}\text { Applicable if a response } \\
\text { alternative affects a } \\
\text { navigable waterway. }\end{array}$ & $A, L$ & Not an ARAR \\
\hline $\begin{array}{l}\text { Executive Order on Floodplain } \\
\text { Management }\end{array}$ & $\begin{array}{l}\text { EO } 11988 \\
{[40 \text { CFR Part }} \\
6.302(b)]\end{array}$ & $\begin{array}{l}\text { Requires federal agencies to evaluate the } \\
\text { potential effects of actions in a floodplain to avoid, } \\
\text { to the extent possible, the adverse impacts } \\
\text { associated with direct and indirect development of } \\
\text { a floodplain. }\end{array}$ & $\begin{array}{l}\text { Applicable if activities } \\
\text { are located in a 100-yr } \\
\text { floodplain. }\end{array}$ & $A, L$ & Not an ARAR \\
\hline $\begin{array}{l}\text { National Environmental Policy Act } \\
\text { of } 1969 \text { (NEPA) }\end{array}$ & $\begin{array}{l}42 \text { U.S.C. } 4321- \\
4370(c)\end{array}$ & $\begin{array}{l}\text { Requires federal agencies to consider significant } \\
\text { environmental impacts arising from projects under } \\
\text { agency jurisdiction and to establish a procedure } \\
\text { giving members of the public an opportunity for } \\
\text { meaningful participation in consideration of the } \\
\text { proposed action. }\end{array}$ & $\begin{array}{l}\text { Applicable for major } \\
\text { federal actions. The } \\
\text { CERCLA-like procedures } \\
\text { in the CAS process - } \\
\text { including public } \\
\text { participation, the } \\
\text { development of } \\
\text { corrective action } \\
\text { alternatives, and the } \\
\text { corrective action } \\
\text { alternative evaluation } \\
\text { process - are } \\
\text { equivalent to the NEPA } \\
\text { process. }\end{array}$ & A & $\begin{array}{l}\text { Relevant and } \\
\text { appropriate }\end{array}$ \\
\hline Clean Air Act (CAA) & $\begin{array}{l}42 \text { USC } 7401 \\
\text { et seq. }\end{array}$ & & & $A$ & Applicable \\
\hline $\begin{array}{l}\text { Standards of Performance for } \\
\text { New Stationary Sources }\end{array}$ & 40 CFR 60 & $\begin{array}{l}\text { Describes standards for the performance of new } \\
\text { stationary sources of air emissions. }\end{array}$ & $\begin{array}{l}\text { Applicable if emissions } \\
\text { thresholds are } \\
\text { exceeded. }\end{array}$ & $A, C$ & Applicable \\
\hline
\end{tabular}

33 USC $403 \quad$ Requires a permit for structures for work in or 330

[40 CFR Part

42 U.S.C. 4321 4370(c)

42 USC 7401

et seq.

Describes standards for the performance of new exceeded. 


\begin{tabular}{l} 
Title \\
\hline Clean Air Act (cont.) \\
National Primary and \\
Secondary Ambient Air Quality \\
Standards \\
National Emissions Standards \\
for Hazardous Air Pollutants \\
(NESHAPs)
\end{tabular}

Solid Waste Disposal Act, as amended by the Resource Conservation and Recovery Act

(RCRA), the Hazardous and Solid Waste Amendments of 1984, the Federal Facility Compliance Act of 1992, and the Land Disposal

Program Flexibility Act of 1996
40 CFR Part 50

40 CFR Parts 61 and 63

40 USC 6901

et seq.
Establishes national primary and secondary ambient air quality standards under Section 109 of the Clean Air Act (42 USC 7409) to protect public health and welfare.

Implements the federal control program for hazardous air pollutants (HAPs). Identifies emission standards for HAPs that originate from specific categories of sources, including site remediation. NESHAPs are technology based and are issued to limit the release of specified HAPs from specific industrial sectors. Federal Register notices published for carbon tetrachloride [50 FR 32621 (August 13, 1985)] and chloroform [50 FR 39626 (September 27, 1985)] included

consideration of serious health effects, such as cancer, due to ambient exposures.

Regulates the characterization, generation,

transportation, treatment, storage, and disposal of hazardous waste and establishes a framework for the management of nonhazardous waste.
Applicable if

contaminants are discharged to the air during treatment.

\section{Applicable if the} identified HAPs are emitted from a specific source category at amounts regulated by the program (for example, if on-site treatment units with emissions are part of response actions).
Type $^{\text {b Determination }}$

\section{A, C Applicable}

A, C Relevant and appropriate

(n)




\begin{tabular}{|c|c|c|c|c|c|}
\hline Title & Citation $^{a}$ & Description & Comment & Type $^{\text {b }}$ & Determination \\
\hline \multicolumn{6}{|l|}{ Solid Waste Disposal Act (cont.) } \\
\hline \multirow[t]{2}{*}{$\begin{array}{l}\text { Criteria for Classification of } \\
\text { Solid Waste Disposal Facilities } \\
\text { and Practices }\end{array}$} & 40 CFR Part 257 & $\begin{array}{l}\text { Establishes classification criteria for sanitary } \\
\text { landfills and prohibits open dumps. At a minimum, } \\
\text { facilities meet the sanitary landfill classification } \\
\text { "only if there is no reasonable probability of } \\
\text { adverse effects on health or the environment ...." } \\
\text { [Section 4004(a) of RCRA (42 USC } 6944(a) \text { )]. }\end{array}$ & $\begin{array}{l}\text { Applicable if a response } \\
\text { alternative involves land } \\
\text { disposal of solid waste } \\
\text { on-site. }\end{array}$ & $A$ & Not an ARAR \\
\hline & & $\begin{array}{l}\text { Provides for protection of surface water and } \\
\text { groundwater at solid waste disposal facilities } \\
\text { (40 CFR 257.3-3 and }-4 \text { ). }\end{array}$ & $\begin{array}{l}\text { Applicable if a response } \\
\text { action includes } \\
\text { provisions for an on-site } \\
\text { landfill. }\end{array}$ & & \\
\hline $\begin{array}{l}\text { Criteria for Municipal Solid } \\
\text { Waste Landfills }\end{array}$ & 40 CFR Part 258 & $\begin{array}{l}\text { Establishes minimum national criteria for } \\
\text { municipal solid waste landfill units. }\end{array}$ & $\begin{array}{l}\text { Applicable if municipal } \\
\text { solid waste is placed in a } \\
\text { municipal solid waste } \\
\text { landfill. }\end{array}$ & $A$ & Not an ARAR \\
\hline $\begin{array}{l}\text { Identification and Listing of } \\
\text { Hazardous Wastes }\end{array}$ & 40 CFR Part 261 & $\begin{array}{l}\text { Identifies solid wastes that are subject to } \\
\text { regulation as hazardous wastes under } 40 \text { CFR } \\
\text { Parts } 124,262-265,268,270 \text {, and } 271 .\end{array}$ & $\begin{array}{l}\text { Applicable if a material at } \\
\text { the site is defined as a } \\
\text { solid and hazardous } \\
\text { waste; requires handling } \\
\text { as a hazardous waste. }\end{array}$ & $A, C$ & Applicable \\
\hline $\begin{array}{l}\text { Standards Applicable to } \\
\text { Generators of Hazardous } \\
\text { Waste }\end{array}$ & 40 CFR Part 262 & $\begin{array}{l}\text { Establishes standards for generators of } \\
\text { hazardous waste. }\end{array}$ & $\begin{array}{l}\text { Applicable if hazardous } \\
\text { wastes are generated as } \\
\text { a result of on-site } \\
\text { activities. }\end{array}$ & $A$ & Applicable \\
\hline $\begin{array}{l}\text { Standards Applicable to } \\
\text { Transporters of Hazardous } \\
\text { Waste }\end{array}$ & 40 CFR Part 263 & $\begin{array}{l}\text { Establishes standards that apply to transporters } \\
\text { of hazardous waste within the United States if the } \\
\text { transportation requires a manifest under } 40 \text { CFR } \\
\text { Part } 262 \text {. }\end{array}$ & $\begin{array}{l}\text { Applicable if a response } \\
\text { alternative involves off- } \\
\text { site transportation of } \\
\text { hazardous wastes. }\end{array}$ & $A$ & Applicable \\
\hline
\end{tabular}
Solid Waste Disposal Facilities and Practices

\section{Criteria for Municipal Solid}

dentification and Listing of

Hazardous Wastes

Standards Applicable to

Transporters of Hazardous

Waste transportation requires a manifest under 40 CFR

Part 262 roundwater at solid waste disposal facilities

Establishes minimum national criteria fo

astes under 40 CFR

solid and hazardous

waste; requires handling

Applicable if hazardous

are generated as

a result of on-site

hazardous wastes. 


\begin{tabular}{ccc}
\hline Title & Citation $^{\mathrm{a}}$ Description & Determination \\
\hline
\end{tabular}

\section{Solid Waste Disposal Act (cont.)}

Standards for Owners and Operators of Hazardous Waste

Treatment, Storage, and

Disposal Facilities

Standards for Management of Specific Hazardous Wastes and Specific Types of

Hazardous Waste

Management Facilities

Land Disposal Restrictions

Hazardous Waste Permit Program

40 CFR Part 270

Universal Wastes

40 CFR Part 273 waste lamps). materials.
Establishes requirements governing universal wastes (hazardous waste batteries, hazardous waste pesticides that are either recalled or collected in waste pesticide collection programs, hazardous waste thermostats, and hazardous

Applicable or relevant

Establishes minimum national standards that wastes for owners and operators of facilities that treat, store, or dispose of hazardous waste.

Provides for groundwater protection standards, general monitoring requirements, corrective action requirements, and technical requirements.

Establishes requirements that apply to recyclable

Identifies hazardous wastes that are restricted from land disposal; defines limited circumstances under which an otherwise prohibited waste may continue to be land disposed.

Establishes provisions covering basic EPA permitting requirements.

hazardous waste is

disposed of on-site.

RCRA standards can be relevant and appropriate

for groundwater at a site if an on-site landfill is constructed.

No substances are expected to be present at CCC/USDA sites in quantities to warrant recycling.

Applicable or relevant and appropriate if hazardous waste is disposed of on-site.

No permit is required for on-site CERCLA

response actions.

Substantive

requirements are addressed in $40 \mathrm{CFR}$

Part 264.

Applicable if universa wastes are generated or managed on-site in the course of investigation or response operations.
A Applicable

A Applicable

A, C Applicable

A Applicable

A Applicable 


\begin{tabular}{|c|c|c|c|c|c|}
\hline Title & Citation $^{a}$ & Description & Comment & Type $^{b}$ & Determination \\
\hline \multicolumn{6}{|l|}{ Solid Waste Disposal Act (cont.) } \\
\hline $\begin{array}{l}\text { Technical Standards and } \\
\text { Corrective Action } \\
\text { Requirements for Owners and } \\
\text { Operators of Underground } \\
\text { Storage Tanks }\end{array}$ & 40 CFR Part 280 & $\begin{array}{l}\text { Establishes regulations related to underground } \\
\text { storage tanks. }\end{array}$ & $\begin{array}{l}\text { Applicable if a response } \\
\text { alternative involves use } \\
\text { of underground storage } \\
\text { tanks. }\end{array}$ & $A$ & Not an ARAR \\
\hline $\begin{array}{l}\text { Occupational Safety and Health } \\
\text { Act (OSHA) }\end{array}$ & 29 USC 651 et seq. & & & $A$ & Applicable \\
\hline $\begin{array}{l}\text { Occupational Safety and } \\
\text { Health Standards }\end{array}$ & 29 CFR Part 1910 & $\begin{array}{l}\text { Establishes safety and health standards for } \\
\text { workers. OSHA has set a limit of } 10 \text { ppm for } \\
\text { carbon tetrachloride in workplace air for an 8-hr } \\
\text { time-weighted average ( } 29 \text { CFR } 1910.1000 \text { Table } \\
\text { Z-2). }\end{array}$ & $\begin{array}{l}\text { Under } 40 \text { CFR Section } \\
300.150 \text {, response } \\
\text { actions under the NCP } \\
\text { will comply with OSHA } \\
\text { requirements for the } \\
\text { safety and health of } \\
\text { response action workers. }\end{array}$ & $A$ & Applicable \\
\hline Regulations for Construction & 29 CFR 1926 & $\begin{array}{l}\text { Provides standards for work practices, safety } \\
\text { equipment, fall protection, equipment operation, } \\
\text { excavation, use of power tools, and other } \\
\text { activities related to construction. }\end{array}$ & $\begin{array}{l}\text { Applicable if construction } \\
\text { activities are required for } \\
\text { a corrective action. }\end{array}$ & $A$ & Applicable \\
\hline Noise Control Act of 1972 & $\begin{array}{l}42 \text { USC Sect. } 4901 \\
\text { et seq. }\end{array}$ & $\begin{array}{l}\text { Prohibits federal activities resulting in noise that } \\
\text { would jeopardize the health or welfare of the } \\
\text { public. }\end{array}$ & $\begin{array}{l}\text { Applicable for activities } \\
\text { such as drilling near a } \\
\text { public access point. }\end{array}$ & $A$ & Applicable \\
\hline $\begin{array}{l}\text { Hazardous Materials } \\
\text { Transportation Act }\end{array}$ & $\begin{array}{l}49 \text { USC } 5101 \\
\text { et seq. }\end{array}$ & & & $A$ & Not an ARAR \\
\hline
\end{tabular}




\begin{tabular}{lll}
\hline Title & Citation $^{\mathrm{a}}$ Description & Determination \\
\hline
\end{tabular}

Hazardous Materials

Transportation Act (cont.)

Hazardous Materials

Transportation Regulations

49 CFR Parts 106 180

National Historic Preservation Act of 1966

Protection of Historic Properties

Executive Order on Protection and Enhancement of Cultural Environments

36 CFR Parts 800 [40 CFR 6.301(b)]
Protects against the risks to life and property inherent in the transportation of hazardous material by listing the materials deemed hazardous and describing required labeling, placarding, and training. Hazardous materials are chemicals that the U.S. Department of

Transportation has determined pose

unreasonable risks to health, safety, and property during transportation activities.

16 USC 470 et seq. Establishes criteria for the creation and management of a National Registry of Historic Places composed of districts, sites, buildings, structures, and objects significant in American history, architecture, archaeology, engineering, and culture.

Defines the way federal agencies meet the statutory responsibilities. Requires federal agencies to consider the effects of any federally assisted undertaking (including those carried out with federal financial assistance and those requiring a federal permit, license, or approval) on any district, site, building, structure, or object that is listed in the National Register of Historic Places or eligible for such listing; requires agencies to give the Advisory Council on Historic Preservation a reasonable opportunity to comment on those undertakings.

Requires federal agencies to preserve, restore, and maintain the nation's historic and cultural environment in their activities.

EO 11593
Applicable if an alternative involves

transportation of

hazardous materials.

Does not apply to on-site

response operations.

Applicable if an

alternative involves a site on the National Registry

of Historic Places.

Applicable if a district, site, building, structure, or object listed on or eligible for the National Register is on or adjacent to the site.

Applicable if an alternative involves the disturbance of significant cultural resources.
A Not an ARAR

L Not an ARAR

\section{A, L Not an ARAR}

A, L Not an ARAR 


\begin{tabular}{ccc}
\hline Title & Citation & Description $\quad$ Determination \\
\hline
\end{tabular}

National Historic Preservation Act

of 1966 (cont.)

\section{Executive Order on Preserve America}

Historic Sites, Buildings and Antiquities Act (Historic Sites Act) and Regulations

Archaeological and Historic Preservation Act of 1974 and Regulations
EO 13287

16 USC 461 et seq. Establishes a national policy to preserve historic [40 CFR 6.301(a)]

sites and objects of national significance,
including those located on refuges. Provides procedures for designation, acquisition, administration, and protection of such sites.

Requires federal agencies to consider the existence and location of landmarks on the National Registry of Natural Landmarks and avoid undesirable impacts to such landmarks.

16 USC 469 et seq. Carries out policy established by the Historic Sites [40 CFR 6.301(c)] Act. Establishes procedures for preservation of historical and archaeological data that might be lost or destroyed through alteration of terrain as a result of a federal construction project or a federally licensed activity or program. Directs federal agencies to notify the Secretary of the Interior whenever they find that a federal or federally assisted, licensed, or permitted project may cause loss or destruction of significant scientific, prehistoric, or archaeological data.

16 USC 431 et seq. Authorizes the President to designate as national monuments objects or areas of historic or scientific interest on lands owned or controlled by the United States. Requires a permit for examination of ruins, excavation of archaeologica sites, and the gathering of objects of antiquity on lands under the jurisdiction of the Secretaries of Interior, Agriculture, and Army. Provides penalties for violations.
Applicable if an alternative involves a historic property.

Applicable if an entity on the National Register of National Landmarks is on or adjacent to the site.

Applicable if historical or archaeological data are on or adjacent to the site and if construction projects or alteration of terrain at the site could destroy historical or archaeological materials.

Applicable if an alternative involves the gathering of objects of antiquity on lands under the jurisdiction of the federal agencies noted.
A, L Not an ARAR

A, L Not an ARAR

A, L Not an ARAR

A, L Not an ARAR 


\begin{tabular}{|c|c|c|c|c|c|}
\hline Title & Citation ${ }^{a}$ & Description & Comment & Type $^{b}$ & Determination \\
\hline \multicolumn{6}{|l|}{ Antiquities Act (cont.) } \\
\hline $\begin{array}{l}\text { Preservation of American } \\
\text { Antiquities }\end{array}$ & $\begin{array}{l}43 \text { CFR } 3 \\
\text { [40 CFR Sect. } \\
6.301(b)] \\
\text { Executive Order } \\
11593\end{array}$ & $\begin{array}{l}\text { Protects all historic and prehistoric sites on } \\
\text { federal lands and prohibits excavation or } \\
\text { destruction of such antiquities without the } \\
\text { permission (Antiquities Permit) of the secretary of } \\
\text { the department that has the jurisdiction over those } \\
\text { lands; authorizes the President to declare areas } \\
\text { of public lands as national monuments and to } \\
\text { reserve or accept private lands for that purpose. }\end{array}$ & $\begin{array}{l}\text { Applicable if site } \\
\text { operations affect } \\
\text { antiquities on federal } \\
\text { lands. }\end{array}$ & $A, L$ & Not an ARAR \\
\hline $\begin{array}{l}\text { Archaeological Resources } \\
\text { Protection Act }\end{array}$ & $\begin{array}{l}16 \text { USC 470aa } \\
\text { et seq. }\end{array}$ & $\begin{array}{l}\text { Supplements the provisions of the Antiquities Act } \\
\text { of } 1906 \text {. Establishes detailed requirements for } \\
\text { issuance of permits for any excavation or for } \\
\text { removal of archaeological resources from federal } \\
\text { or Indian lands. Also establishes civil and criminal } \\
\text { penalties for the unauthorized excavation, } \\
\text { removal, or damage of such resources. }\end{array}$ & & $A, L$ & Not an ARAR \\
\hline $\begin{array}{l}\text { Protection of Archaeological } \\
\text { Resources }\end{array}$ & $\begin{array}{l}43 \text { CFR Part } 7 \text {, } \\
36 \text { CFR Part } 296 \\
\text { [40 CFR 6.301(b)] }\end{array}$ & $\begin{array}{l}\text { Establishes uniform definitions, standards, and } \\
\text { procedures to be followed by all federal land } \\
\text { managers in providing protection for } \\
\text { archaeological resources located on public or } \\
\text { Indian lands. }\end{array}$ & $\begin{array}{l}\text { Applicable if site } \\
\text { operations affect } \\
\text { archaeological resources } \\
\text { on public or Indian lands. }\end{array}$ & $A, L$ & Not an ARAR \\
\hline $\begin{array}{l}\text { American Indian Religious } \\
\text { Freedom Act }\end{array}$ & $\begin{array}{l}42 \text { USC } 1996 \\
\text { et seq. }\end{array}$ & $\begin{array}{l}\text { Protects and preserves the right of American } \\
\text { Indians to have access to their sacred places; } \\
\text { directs federal agencies to consult with Indian } \\
\text { religious practitioners if a place of religious } \\
\text { importance to American Indians may be affected } \\
\text { by an undertaking. }\end{array}$ & $\begin{array}{l}\text { Applicable if site } \\
\text { operations affect access } \\
\text { to sacred Indian sites. }\end{array}$ & $A, L$ & Not an ARAR \\
\hline
\end{tabular}

Preservation of American

3 CFR 3

6.301(b)]

(b)

11593

16 USC 470aa

Archaeological Resources

Protection of Archaeological

36 CFR Part 296

Indian lands.

by an undertaking.$$
\text { ( }
$$ 


\begin{tabular}{ccc}
\hline Title & Citation $^{\mathrm{a}}$ Description & Determination \\
\hline
\end{tabular}

American Indian Religious

Freedom Act (cont.)

Executive Order on Indian Sacred Sites

Native American Grave Protection and Repatriation Act

25 USC 3001

et seq.

Native American Graves Protection and Repatriation Regulations

Endangered Species Act

EO 13007
Develops a systematic process for determining the rights of linear descendants and Indian tribes to certain Native American human remains, funerary objects, sacred objects, or objects of cultural patrimony. Defines items included under the Native American Grave Protection and Repatriation Act. Describes the consultation procedure applicable to intentional excavation or inadvertent discovery of remains or objects covered.

16 USC 1531 et seq.

Requires agencies managing federal lands to accommodate access to and ceremonial use of ndian sacred sites by Indian religious

physical integrity of such sacred sites; also requires agencies to develop procedures for reasonable notification of proposed actions.

Native American cultural items excavated or discovered on federal or tribal lands after 1990 possession; allows the intentional removal or excavation of Native Americ from federal or tribal lands only with a permit or upon consultation with the appropriate tribe.

Provides for the conservation of threatened and endangered plants and animals and the habitats in which they are found.

\section{Applicable if site}

operations affect access

to sacred Indian sites.
A, L Not an ARAR

A, L Not an ARAR operations involve excavation or discovery of Native American cultural items on federal or tribal lands.

Applicable if actions involve intentional excavation or inadvertent discovery of remains or objects subject to the regulations.

Applicable if actions involve threatened and endangered species. 


\begin{tabular}{|c|c|c|c|c|c|}
\hline Title & Citation ${ }^{\mathrm{a}}$ & Description & Comment & Type $^{b}$ & Determination \\
\hline \multicolumn{6}{|l|}{ Endangered Species Act (cont.) } \\
\hline Interagency Cooperation & $\begin{array}{l}50 \text { CFR Part } 402 \\
\text { [40 CFR } 6.302(\mathrm{~h})]\end{array}$ & $\begin{array}{l}\text { Requires action to conserve threatened and } \\
\text { endangered species within critical habits upon } \\
\text { which endangered species depend, including } \\
\text { consultation and conferencing with the } \\
\text { Department of the Interior (U.S. Fisheries and } \\
\text { Wildlife Service or U.S. National Marine Fisheries } \\
\text { Service). }\end{array}$ & $\begin{array}{l}\text { Applicable if threatened } \\
\text { or endangered species } \\
\text { or critical habitats are } \\
\text { identified at the site. }\end{array}$ & $A$ & Not an ARAR \\
\hline Migratory Bird Treaty Act & 16 USC 703 et seq. & & & $A$ & Not an ARAR \\
\hline Migratory Bird Permits & $\begin{array}{l}50 \text { CFR Parts } 10 \\
\text { and } 21\end{array}$ & $\begin{array}{l}\text { Requires a permit from the U.S. Fisheries and } \\
\text { Wildlife Service for the taking of protected } \\
\text { migratory birds. }\end{array}$ & $\begin{array}{l}\text { Applicable if a response } \\
\text { alternative will affect a } \\
\text { migratory pathway. }\end{array}$ & $A$ & Not an ARAR \\
\hline $\begin{array}{l}\text { Executive Order on } \\
\text { Responsibilities of Federal } \\
\text { Agencies to Protect Migratory } \\
\text { Birds }\end{array}$ & EO 13186 & $\begin{array}{l}\text { Directs federal agencies taking actions having or } \\
\text { likely to have a negative effect on migratory bird } \\
\text { populations to work with the U.S. Fisheries and } \\
\text { Wildlife Service to develop an agreement to } \\
\text { conserve those birds. }\end{array}$ & & $A$ & Not an ARAR \\
\hline $\begin{array}{l}\text { Bald and Golden Eagle Protection } \\
\text { Act }\end{array}$ & 16 USC 668 et seq. & & & $A$ & Not an ARAR \\
\hline Eagle Permits & $\begin{array}{l}50 \text { CFR Parts } 10 \\
\text { and } 22\end{array}$ & $\begin{array}{l}\text { Requires a permit from the U.S. Fisheries and } \\
\text { Wildlife Service to move nests because of } \\
\text { construction or operation of project facilities. }\end{array}$ & $\begin{array}{l}\text { Applicable if project } \\
\text { activities affect bald and } \\
\text { golden eagle } \\
\text { populations, including } \\
\text { construction or operation } \\
\text { of facilities that call for } \\
\text { the moving of nests. }\end{array}$ & $A, L$ & Not an ARAR \\
\hline Fish and Wildlife Conservation Act & $\begin{array}{l}16 \text { USC } 2901 \\
\text { et seq. }\end{array}$ & $\begin{array}{l}\text { Encourages states to develop conservation plans } \\
\text { for nongame fish and wildlife of ecological, } \\
\text { educational, aesthetic, cultural, recreational, } \\
\text { economic, or scientific value. }\end{array}$ & $\begin{array}{l}\text { Applicable if significant } \\
\text { populations are present } \\
\text { at a site or are affected } \\
\text { by site response } \\
\text { activities. }\end{array}$ & $A$ & Not an ARAR \\
\hline
\end{tabular}

Department of the Interior (U.S. Fisheries and

Wildlife Service or U.S. National Marine Fisheries

Service)

Wildlife Service for the taking of protected ikely to have a negative effect on migratory bird populations to work with the U.S. Fisheries and

develop an agreement to

Agencies to Protect Migratory

Birds

Bald and Golden Eagle Protection

50 CFR Parts 10

Wildlife Service to move nests because of 


\begin{tabular}{|c|c|c|c|c|c|}
\hline Title & Citation $^{\mathrm{a}}$ & Description & Comment & Type ${ }^{b}$ & Determinatior \\
\hline Fish and Wildlife Coordination Act & $\begin{array}{l}16 \text { USC } 661 \text { et seq. } \\
\text { [40 CFR } 6.302(\mathrm{~g})]\end{array}$ & $\begin{array}{l}\text { Requires consultation with the U.S. Fish and } \\
\text { Wildlife Service when a federal department or } \\
\text { agency proposes, authorizes, permits, or licenses } \\
\text { any modification of any stream or other water } \\
\text { body. Requires adequate provision for protection } \\
\text { of fish and wildlife resources. }\end{array}$ & $\begin{array}{l}\text { Applicable if a response } \\
\text { alternative will cause } \\
\text { damage to or loss of } \\
\text { wildlife by modifying a } \\
\text { stream or body of water. }\end{array}$ & A & Not an ARAR \\
\hline Wilderness Act & $\begin{array}{l}16 \text { USC } 1311 \\
\text { et seq. }\end{array}$ & & & A & Not an ARAR \\
\hline $\begin{array}{l}\text { Wilderness Preservation and } \\
\text { Management }\end{array}$ & 50 CFR Part 35 & $\begin{array}{l}\text { Describes the activities allowed and banned in } \\
\text { wilderness areas and uses requiring } \\
\text { authorization. }\end{array}$ & $\begin{array}{l}\text { Applicable if a } \\
\text { wilderness area exists } \\
\text { on-site or adjacent to the } \\
\text { site. }\end{array}$ & A & Not an ARAR \\
\hline $\begin{array}{l}\text { Management of Designated } \\
\text { Wilderness Areas }\end{array}$ & 43 CFR Part 6300 & & $\begin{array}{l}\text { Applicable if actions } \\
\text { involve a Designated } \\
\text { Wilderness Area. }\end{array}$ & A & Not an ARAR \\
\hline $\begin{array}{l}\text { National Wildlife Refuge System } \\
\text { Administration Act }\end{array}$ & 16 USC 668dd & & $\begin{array}{l}\text { Applicable if actions } \\
\text { involve a National } \\
\text { Wildlife Refuge. }\end{array}$ & A & Not an ARAR \\
\hline $\begin{array}{l}\text { Executive Order on } \\
\text { Management and General } \\
\text { Public Use of the National } \\
\text { Wildlife Refuge System }\end{array}$ & EO 12996 & $\begin{array}{l}\text { Directs preservation of a national network of lands } \\
\text { and waters for the conservation and management } \\
\text { of fish, wildlife, and plant resources for the benefit } \\
\text { of present and future generations. Recognizes } \\
\text { compatible uses, while ensuring maintenance of } \\
\text { biological integrity and environmental health. }\end{array}$ & $\begin{array}{l}\text { Applicable if a wildlife } \\
\text { refuge area exists on- } \\
\text { site or adjacent to the } \\
\text { site. }\end{array}$ & $A, L$ & Not an ARAR \\
\hline Wild and Scenic Rivers Act & $\begin{array}{l}16 \text { USC } 1271 \\
\text { et seq. }\end{array}$ & $\begin{array}{l}\text { States that a federal agency may not assist, } \\
\text { through grant, loan, license, or otherwise, the } \\
\text { construction of a water resources project that } \\
\text { would have a direct and adverse effect on the } \\
\text { values for which a river in the National Wild and } \\
\text { Scenic Rivers System or a study river on the } \\
\text { National Rivers Inventory was established. }\end{array}$ & & $A, L$ & Not an ARAR \\
\hline
\end{tabular}

agency proposes, authorizes, permits, or licenses wildlife by modifying a body. Requires adequate provision for protection stream or body of water.

Describes the activities allowed and banned in wilderness areas and uses requiring on-site or adjacent to the Applicable if actions involve a Designated Applicable if actions involve a National

Applicable if a wildlife and waters for the conservation and management refuge area exists onof fish, wildlife, and plant resources for the benefit site or adjacent to the of present and future generations. Recognizes compatible uses, while ensuring maintenance of

National Rivers Inventory was established. 


\begin{tabular}{lll}
\hline Title & Citation & Description \\
\hline
\end{tabular}

Wild and Scenic Rivers Act (cont.)

Wild and Scenic Rivers

36 CFR Part 297

(40 CFR 6.302(e))

Requires a notification process for federally assisted water resource projects in any portion of a designated river.

Federal Insecticide, Fungicide and Rodenticide Act of 1972

Pesticide Management Program Regulations

Toxic Substances Control Act (TSCA) of 1976

Guidance for Conducting Remedial Investigations and Feasibility

Studies under CERCLA, EPA 540-

G-89-004, October 1988

Draft Guidance for Evaluating the Vapor Intrusion to Indoor Air Pathway from Groundwater and Soils (Subsurface Vapor Intrusion)
16 USC 2901-2911 Establishes a pesticide regulatory program.

40 CFR 150-189

Creates a federal program for the registration, control, distribution, and use of pesticides.

15 USC 2601

Authorizes the EPA to track, screen, and require reporting or testing of chemicals that might pose an environmental or human health risk.

Describes the procedures used to characterize the nature and extent of contamination and risk posed by the release of chemical constituents at a site. Also describes the procedures for evaluating potential remedial alternatives.

67 FR 71169 (Nov. Serves as a screening tool to aid in determining 29, 2002) whether a vapor intrusion pathway is complete and, if so, whether the complete pathway poses an unacceptable risk to human health at cleanup sites. For sites with a complete pathway, guidance is provided to evaluate whether the pathway poses a potential significant risk to human health.
Applicable to on-site

A, L Not an ARAR water resource projects located within, above, below, or outside a wild and scenic river or study river.

A Not an ARAR

Applicable if pesticides will be used as part of corrective action activities.

Applicable if site activities involve substances regulated under TSCA, such as polychlorinated biphenyls.

Suggested for use at NPL and Superfund Alternative Sites. 


\begin{tabular}{|c|c|c|c|c|c|}
\hline Title & Citation $^{\mathrm{a}}$ & Description & Comment & Type $^{b}$ & Determination \\
\hline $\begin{array}{l}\text { Guidance for Quality Assurance } \\
\text { Project Plans, EPA 240-R-02-009, } \\
\text { December } 2002\end{array}$ & & $\begin{array}{l}\text { Describes the form and content of a Quality } \\
\text { Assurance Project Plan. }\end{array}$ & & $A$ & TBC \\
\hline $\begin{array}{l}\text { Use of Monitored Natural } \\
\text { Attenuation Remedies for VOCs in } \\
\text { Groundwater, April } 2004\end{array}$ & & $\begin{array}{l}\text { Describes the procedures for performing and } \\
\text { evaluating monitored natural attenuation (MNA). }\end{array}$ & & $A$ & TBC \\
\hline $\begin{array}{l}\text { Technical Protocol for Evaluating } \\
\text { Chlorinated Solvents in } \\
\text { Groundwater, October } 1998\end{array}$ & & $\begin{array}{l}\text { Describes protocols that can be used to evaluate } \\
\text { whether MNA is occurring in groundwater. }\end{array}$ & & $A$ & TBC \\
\hline $\begin{array}{l}\text { Guide to Discharging CERCLA } \\
\text { Aqueous Wastes to Publicly } \\
\text { Owned Treatment Works, EPA } \\
\text { OSWER Directive 9330.2-13 FS, } \\
\text { March } 1991\end{array}$ & & $\begin{array}{l}\text { Describes the process of discharging CERCLA } \\
\text { wastes to a publicly owned treatment works } \\
\text { (POTW). }\end{array}$ & $\begin{array}{l}\text { Applicable to the } \\
\text { discharge of CERCLA } \\
\text { wastes to a POTW. }\end{array}$ & $A, C$ & TBC \\
\hline
\end{tabular}

a Abbreviations for citations:

CFR, Code of Federal Regulations

FR, Federal Register

Sect., Section

USC, United States Code

b Types:
A, Action specific
C, Chemical specific
L, Location specific 
TABLE B.2 Potential state applicable or relevant and appropriate requirements (ARARs) and guidance to be considered for former CCC/USDA facilities in Kansas.

\begin{tabular}{|c|c|c|c|c|c|}
\hline Title & Citation $^{a}$ & Description & Comment & Type $^{b}$ & Determination \\
\hline Radiation & $\begin{array}{l}\text { KAR 28-35-1 to } \\
28-35-363\end{array}$ & $\begin{array}{l}\text { Addresses the registration of radiation-producing } \\
\text { devices and the licensing of sources of radiation. }\end{array}$ & $\begin{array}{l}\text { Applicable if radiation-producing } \\
\text { devices are used as part of a } \\
\text { corrective action. }\end{array}$ & A, C & Not an ARAR \\
\hline Spill Reporting & $\begin{array}{l}\text { KAR 28-48-1 to } \\
28-48-2\end{array}$ & $\begin{array}{l}\text { Addresses reporting requirements for the } \\
\text { accidental releases of unpermitted discharges. }\end{array}$ & $\begin{array}{l}\text { Applicable if an unpermitted } \\
\text { discharge occurs during the } \\
\text { performance of a corrective action. }\end{array}$ & A, C & Applicable \\
\hline $\begin{array}{l}\text { Emergency Planning } \\
\text { and Right-to-Know } \\
\text { Regulations }\end{array}$ & $\begin{array}{l}\text { KAR 28-65-1 to } \\
28-65-4\end{array}$ & $\begin{array}{l}\text { Requires facilities storing hazardous substances } \\
\text { above threshold quantities to report the presence } \\
\text { of the materials and any releases of the materials. } \\
\text { Creates emergency planning and response } \\
\text { procedures. }\end{array}$ & $\begin{array}{l}\text { Applicable if regulated hazardous } \\
\text { chemicals are stored as part of the } \\
\text { corrective action. }\end{array}$ & A, C, L & Applicable \\
\hline \multirow[t]{2}{*}{$\begin{array}{l}\text { Kansas Air Quality } \\
\text { Control Act; Kansas } \\
\text { Air Quality } \\
\text { Regulations }\end{array}$} & $\begin{array}{l}\text { KSA, Chapter } \\
65 \text {, Article 30; } \\
\text { KAR, Title 28, } \\
\text { Article } 19\end{array}$ & $\begin{array}{l}\text { Requires permitting and preconstruction notices for } \\
\text { air contaminant sources. Provides for reporting and } \\
\text { inspections. Establishes state emission standards } \\
\text { for listed hazardous air pollutants (HAPs) and state } \\
\text { air quality standards. HAPs include carbon } \\
\text { tetrachloride and chloroform emitted above a } \\
\text { threshold (e.g., } 10 \text { tons/yr of a single HAP or } 25 \\
\text { tons/yr of any combination of HAPs). }\end{array}$ & $\begin{array}{l}\text { Applicable if any listed pollutants } \\
\text { are discharged to the air during } \\
\text { investigation or response through } \\
\text { air stripping, thermal destruction, } \\
\text { handling of contaminated soil, } \\
\text { gaseous waste treatment, aeration, } \\
\text { or disposal in a municipal solid } \\
\text { waste landfill. }\end{array}$ & A & Applicable \\
\hline & & $\begin{array}{l}\text { Specifically requires the following: } \\
\text { - For emissions above threshold amounts, } \\
\text { (1) construction permits (e.g., for } 25 \text { tons/yr of } \\
\text { particulate matter [PM], } 15 \text { tons/yr of PM } 10 \text {, } \\
100 \text { tons/yr of carbon monoxide, } 40 \text { tons/yr of } \\
\text { volatile organic compounds [VOCs]) or } \\
\text { (2) preconstruction approval (e.g., for } 5 \mathrm{lb} / \mathrm{hr} \text { of } \\
\mathrm{PM}, 2 \mathrm{lb} / \mathrm{hr} \text { of PM } 10,50 \mathrm{lb} \text { of carbon } \\
\text { monoxide per } 24-\mathrm{hr} \text { period, or } 50 \mathrm{lb} \text { of VOCs } \\
\text { per } 24-\mathrm{hr} \text { period - alternatively, in a } \\
\text { nonattainment area, either } 15 \mathrm{lb} \text { per } 24-\mathrm{hr} \\
\text { period or } 3 \mathrm{lb} / \mathrm{hr} \text { ) (KAR } 28-19-300) \text {. } \\
\text { Operating permits for certain stationary } \\
\text { sources (28-19-500 et seq.). }\end{array}$ & & & \\
\hline
\end{tabular}




\begin{tabular}{|c|c|c|c|c|c|}
\hline Title & Citation $^{a}$ & Description & Comment & Type ${ }^{b}$ & Determination \\
\hline $\begin{array}{l}\text { Kansas Air Quality } \\
\text { Control Act; Kansas } \\
\text { Air Quality } \\
\text { Regulations (cont.) }\end{array}$ & & $\begin{array}{l}\text { Prohibits open burning (28-19-645 et seq.). } \\
\text { Establishes emission standards for major source } \\
\text { HAPs (28-19-750 et seq.). }\end{array}$ & & & \\
\hline $\begin{array}{l}\text { Underground } \\
\text { Storage, Disposal } \\
\text { Wells and Surface } \\
\text { Ponds }\end{array}$ & $\begin{array}{l}\text { KSA, Chapter } \\
65 \text {, Article 1; } \\
\text { KAR, Title } 28 \text {, } \\
\text { Article } 13\end{array}$ & $\begin{array}{l}\text { Regulates the construction and use of } \\
\text { underground storage reservoirs, disposal wells, } \\
\text { and surface ponds for the confinement, storage, } \\
\text { and disposal of industrial fluids. Establishes } \\
\text { approval and permitting requirements. }\end{array}$ & $\begin{array}{l}\text { Applicable if a response alternative } \\
\text { involves the need for underground } \\
\text { storage reservoirs, disposal wells, } \\
\text { or surface ponds. }\end{array}$ & $\mathrm{L}, \mathrm{A}$ & $\begin{array}{l}\text { Relevant and } \\
\text { appropriate }\end{array}$ \\
\hline $\begin{array}{l}\text { Washington County } \\
\text { RWD \#1 Cross- } \\
\text { Connection } \\
\text { Regulations }\end{array}$ & $\begin{array}{l}\text { Section } 3 \\
\text { (Requirements, } \\
\text { Item } 4 . \\
\text { Individual Water } \\
\text { Supplies) (RWD } \\
\text { 2009b) }\end{array}$ & $\begin{array}{l}\text { Precludes a landowner from cross-connecting a } \\
\text { private water supply with an RWD public supply. }\end{array}$ & $\begin{array}{l}\text { Applicable if a residence } \\
\text { connected to the RWD supply also } \\
\text { has a private water supply. }\end{array}$ & A & Applicable \\
\hline $\begin{array}{l}\text { Drinking Water } \\
\text { Regulations }\end{array}$ & $\begin{array}{l}\text { KSA, Chapter } \\
65 \text {, Article 33; } \\
\text { KAR, Title 28, } \\
\text { Article } 15\end{array}$ & $\begin{array}{l}\text { Establishes maximum contaminant levels (MCLs) } \\
\text { pertaining to public water supplies. The MCLs for } \\
\text { carbon tetrachloride, total trihalomethanes } \\
\text { (including chloroform), nitrate, and nitrite are } \\
0.005 \mathrm{mg} / \mathrm{L}, 0.1 \mathrm{mg} / \mathrm{L}, 10 \mathrm{mg} / \mathrm{L} \text {, and } 1 \mathrm{mg} / \mathrm{L} \text {, } \\
\text { respectively (KAR } 28-15 \mathrm{a}-61 \text { and } 28-15 \mathrm{a}-62 \text { ). }\end{array}$ & $\begin{array}{l}\text { Applicable if waste derived from an } \\
\text { investigation or response enters a } \\
\text { public water system. Not applicable } \\
\text { to investigative wells, as such, that } \\
\text { are not used for drinking water } \\
\text { supply; however, relevant for } \\
\text { establishing sampling and analysis } \\
\text { parameters and analytical } \\
\text { detection limits during investigation } \\
\text { activities. }\end{array}$ & C & $\begin{array}{l}\text { Relevant and } \\
\text { appropriate }\end{array}$ \\
\hline
\end{tabular}


TABLE B.2 (Cont.)

\begin{tabular}{|c|c|c|}
\hline Title & Citation $^{a}$ & Description \\
\hline $\begin{array}{l}\text { Water Pollution } \\
\text { Control Regulations }\end{array}$ & $\begin{array}{l}\text { KSA, Chapter } \\
65 \text {, Article 33; } \\
\text { KAR, Title 28, } \\
\text { Article } 16\end{array}$ & $\begin{array}{l}\text { Protects public health and welfare and the use of } \\
\text { surface water for aquatic life; for agricultural, } \\
\text { domestic, and industrial water supply; and for } \\
\text { recreation. Controls surface water use designation. } \\
\text { Establishes surface water quality standards (KAR } \\
\text { 28-16-28 et seq.). MCL is defined as "any of the } \\
\text { enforceable standards for finished drinking water } \\
\text { promulgated by the U.S. Environmental Protection } \\
\text { Agency [KAR 28-16-28b(hh)]." When the KDHE } \\
\text { finds that these criteria are underprotective or } \\
\text { overprotective for a given surface water segment, } \\
\text { the KDHE may, in accordance with KAR 28-16- } \\
28 f(f) \text {, make appropriate site-specific } \\
\text { determinations [KAR 28-16-28e(a)]. Surface water } \\
\text { must be free from the harmful effects of } \\
\text { substances that produce any public health hazard; } \\
\text { hazardous substances must not occur in surface } \\
\text { water at concentrations that jeopardize public } \\
\text { health and other protected life [KAR 28-16-28e(b)]. }\end{array}$ \\
\hline
\end{tabular}

Applicable if contaminated effluent

from investigative or response

operations is discharged into

surface water; also possibly

applicable to alluvial aquifers

demonstrated to be hydraulically

connected to surface water bodies. 


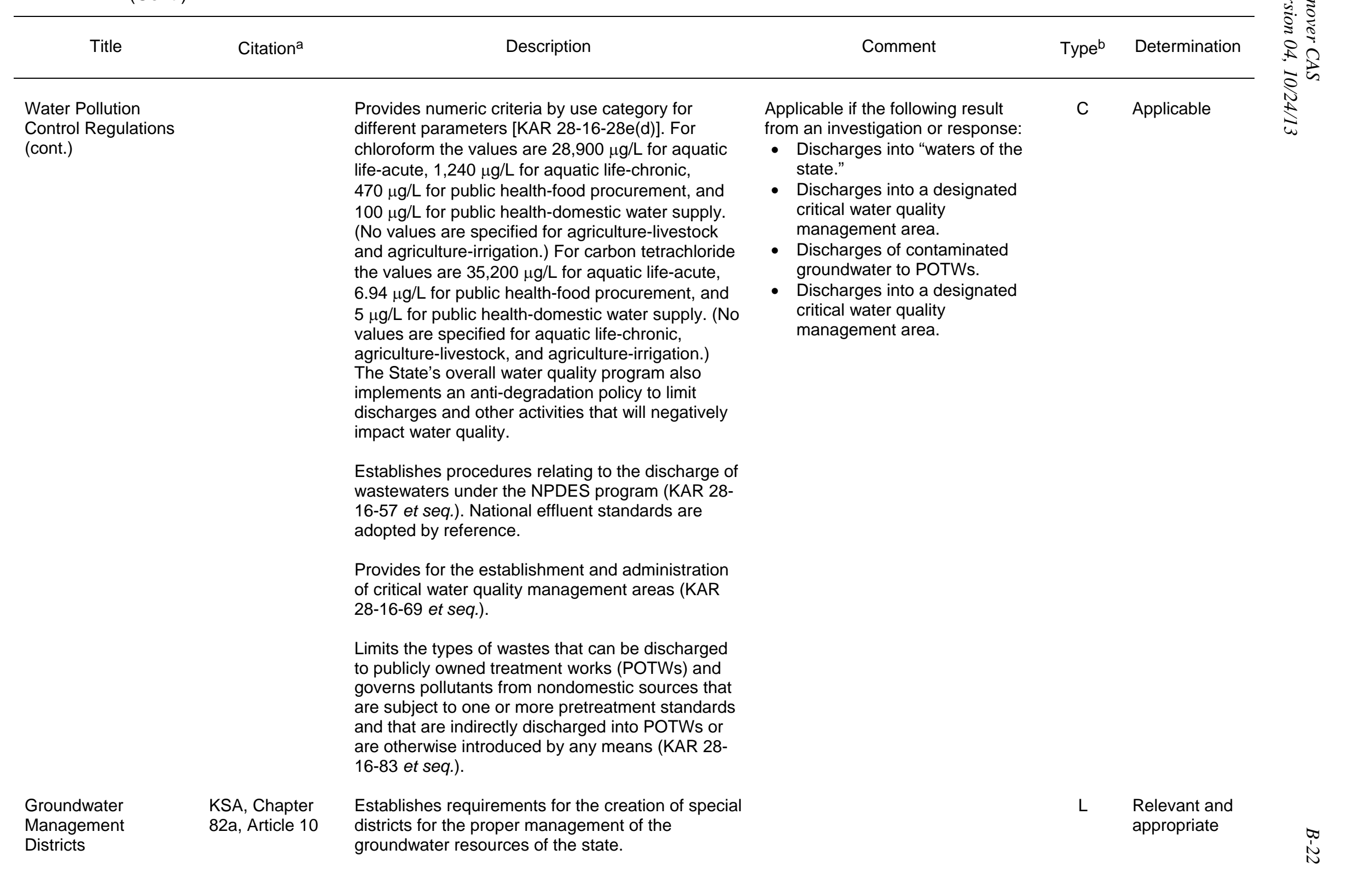




\begin{tabular}{|c|c|c|}
\hline Title & Citation $^{a}$ & Description \\
\hline $\begin{array}{l}\text { Kansas Drycleaner } \\
\text { Environmental } \\
\text { Response Act }\end{array}$ & $\begin{array}{l}\text { KSA 65-34, } \\
141\end{array}$ & $\begin{array}{l}\text { Authorizes creation of a drycleaner site } \\
\text { management program; funds assessment and } \\
\text { corrective action activities at former and existing } \\
\text { drycleaner facilities. }\end{array}$ \\
\hline $\begin{array}{l}\text { Kansas } \\
\text { Drycleaner } \\
\text { Environmental } \\
\text { Response } \\
\text { Regulations }\end{array}$ & $\begin{array}{l}\text { KAR 28-68-1 to } \\
28-68-9\end{array}$ & $\begin{array}{l}\text { Regulations created pursuant to the Kansas } \\
\text { Drycleaner Environmental Response Act. }\end{array}$ \\
\hline $\begin{array}{l}\text { Kansas } \\
\text { Environmental Use } \\
\text { Controls }\end{array}$ & $\begin{array}{l}\text { KSA, chapter } \\
65-1221 \text { to } 65- \\
1235\end{array}$ & $\begin{array}{l}\text { Defines the Environmental Use Control (EUC) as a } \\
\text { legal mechanism for applying restrictions, } \\
\text { prohibitions, and conditions on land use for a } \\
\text { property that has environmental contamination at } \\
\text { levels prohibiting unrestricted use (i.e., exceeding } \\
\text { residential standards). An EUC can be voluntarily } \\
\text { applied to a property by the landowner as part of a } \\
\text { corrective action to assure adequate protection of } \\
\text { public health and the environment from } \\
\text { contamination on the subject property. The } \\
\text { protection offered by an EUC can provide a } \\
\text { landowner relief from environmental liability } \\
\text { concerns, making property more attractive for } \\
\text { redevelopment or to prospective buyers. }\end{array}$ \\
\hline $\begin{array}{l}\text { Kansas Water Well } \\
\text { Contractor's License } \\
\text { Regulations; Water } \\
\text { Well Construction } \\
\text { and Abandonment } \\
\text { Regulations }\end{array}$ & $\begin{array}{l}\text { KSA, Chapter } \\
82 \mathrm{a} \text {, Article 12; } \\
\text { KAR, Title 28, } \\
\text { Article } 30\end{array}$ & $\begin{array}{l}\text { Establishes requirements for licensing of well } \\
\text { drillers and standards for construction, operation, } \\
\text { and abandonment of wells (KAR 28-30-3 et seq.). }\end{array}$ \\
\hline $\begin{array}{l}\text { Underground } \\
\text { Injection Control } \\
\text { Regulations }\end{array}$ & $\begin{array}{l}\text { KSA, Chapter } \\
65 \text {, Article 1; } \\
\text { KAR, Title 28, } \\
\text { Article } 46\end{array}$ & $\begin{array}{l}\text { Governs discharges into underground injection } \\
\text { wells (KAR 28-46-1 et seq.). In general, federal } \\
\text { Safe Drinking Water Act regulations are adopted } \\
\text { by reference. }\end{array}$ \\
\hline
\end{tabular}

May be applicable if a drycleaner operated at the site of the former CCC/USDA facility.

\section{Applicable if corrective action}

includes an EUC.
Type $^{\mathrm{b}} \quad$ Determination

L Relevant and appropriate

A, C Relevant and appropriate

Applicable if investigation or response involves drilling and installing wells that intercept the water table.

Applicable if investigative or response wastes are introduced into wells for discharge or disposal.
A, C Relevant and appropriate 


\begin{tabular}{|c|c|c|c|c|c|}
\hline Title & Citation $^{\mathrm{a}}$ & Description & Comment & Type $^{\text {b }}$ & Determination \\
\hline \multirow[t]{2}{*}{$\begin{array}{l}\text { Solid Waste Act and } \\
\text { Regulations }\end{array}$} & $\begin{array}{l}\text { KSA, Chapter } \\
65 \text {, Article } 34 \\
\text { KAR, Title 28, } \\
\text { Article } 29\end{array}$ & $\begin{array}{l}\text { Establishes standards for management activities } \\
\text { and facilities relative to solid wastes (KAR 28-29-1 } \\
\text { et seq.). }\end{array}$ & $\begin{array}{l}\text { Applicable if nonhazardous } \\
\text { materials discarded as a result of } \\
\text { an investigation or response are } \\
\text { landfilled on-site. }\end{array}$ & $A, C, L$ & Not an ARAR \\
\hline & & $\begin{array}{l}\text { Establishes location restrictions, design standards, } \\
\text { operating standards, groundwater monitoring, } \\
\text { corrective action, and financial assurance for } \\
\text { municipal solid waste landfill units, during and after } \\
\text { closure (KAR 28-29-100 et seq.). }\end{array}$ & $\begin{array}{l}\text { Applicable if a municipal solid } \\
\text { waste landfill is used. }\end{array}$ & & \\
\hline \multirow[t]{3}{*}{$\begin{array}{l}\text { Hazardous Waste } \\
\text { Management } \\
\text { Standards and } \\
\text { Regulations }\end{array}$} & $\begin{array}{l}\text { KSA, Chapter } \\
65 \text {, Article 34; } \\
\text { KAR, Title 28, } \\
\text { Article } 31\end{array}$ & $\begin{array}{l}\text { Requires generators of solid waste to make a } \\
\text { hazardous waste determination. For a waste that is } \\
\text { not excluded from hazardous waste regulations } \\
\text { and not listed as a hazardous waste, the } \\
\text { determination is generally made through testing by } \\
\text { a laboratory certified for such analyses by the } \\
\text { KDHE [KAR 28-31-4(b)]. }\end{array}$ & $\begin{array}{l}\text { Applicable if investigation or } \\
\text { response operations generate solid } \\
\text { wastes. }\end{array}$ & $A, C$ & $\begin{array}{l}\text { Relevant and } \\
\text { appropriate }\end{array}$ \\
\hline & & $\begin{array}{l}\text { Establishes standards for hazardous waste } \\
\text { generators and transporters and for facilities that } \\
\text { treat, store, or dispose of hazardous waste (KAR } \\
\text { 28-31-4 et seq.). }\end{array}$ & $\begin{array}{l}\text { Applicable to response-generated } \\
\text { wastes that are determined to be } \\
\text { hazardous and that are managed } \\
\text { on-site through treatment, storage, } \\
\text { and disposal or are transported. }\end{array}$ & & \\
\hline & & $\begin{array}{l}\text { Adopts by reference federal regulations governing } \\
\text { universal wastes (KAR 28-31-15). }\end{array}$ & $\begin{array}{l}\text { Applicable if universal wastes are } \\
\text { generated or managed on-site in } \\
\text { the course of an investigation or } \\
\text { response operation. }\end{array}$ & & \\
\hline $\begin{array}{l}\text { Kansas Board of } \\
\text { Technical } \\
\text { Professions }\end{array}$ & $\begin{array}{l}\text { KAR } 66-6-1 \\
\text { through } 66-14- \\
12\end{array}$ & $\begin{array}{l}\text { Establishes requirements for the licensing of } \\
\text { surveyors, geologists, and architects. }\end{array}$ & $\begin{array}{l}\text { Applicable if these professionals } \\
\text { are required for implementation of } \\
\text { the selected corrective action. }\end{array}$ & $A$ & Applicable \\
\hline $\begin{array}{l}\text { Kansas Storage } \\
\text { Tanks Act }\end{array}$ & $\begin{array}{l}\text { KSA Chapter } \\
65 \text {, Article } 34\end{array}$ & $\begin{array}{l}\text { Establishes standards for the registration and } \\
\text { permitting of nonexempt aboveground tanks used } \\
\text { to store a regulated substance (KAR 28-44-29). }\end{array}$ & $\begin{array}{l}\text { Applicable if a response alternative } \\
\text { involves use of storage tanks to } \\
\text { contain an accumulation of } \\
\text { regulated substances, associated } \\
\text { piping and ancillary equipment, } \\
\text { and a containment system. }\end{array}$ & $A, L$ & Not an ARAR \\
\hline
\end{tabular}

Establishes location restrictions, design standards, perating standards, groundwater monitoring, municipal solid waste landfill units, during and after closure (KAR 28-29-100 et seq.)

determination is generally made through testing by

a laboratory certified for such analyses by the

Establishes standards for hazardous waste

generators and transporters and for facilities that reat, store, or dispose of hazardous waste (KAR

Adopts by reference federal regulations governing universal wastes (KAR 28-31-15).

$$
\begin{aligned}
& \text { piping and ancillary equipment, } \\
& \text { and a containment system. }
\end{aligned}
$$




\begin{tabular}{|c|c|c|}
\hline Title & Citation $^{a}$ & Description \\
\hline \multicolumn{3}{|l|}{$\begin{array}{l}\text { Kansas Storage } \\
\text { Tanks Act (cont.) }\end{array}$} \\
\hline $\begin{array}{l}\text { Petroleum } \\
\text { Products Storage } \\
\text { Tanks }\end{array}$ & $\begin{array}{l}\text { KAR } 28-44-1 \text { to } \\
28-44-29\end{array}$ & $\begin{array}{l}\text { Provides requirements for permitting, installing and } \\
\text { testing underground storage tanks and for } \\
\text { licensing installation contractors. }\end{array}$ \\
\hline $\begin{array}{l}\text { Kansas Water } \\
\text { Appropriations Act }\end{array}$ & $\begin{array}{l}\text { KSA } 82 a-701 \\
\text { et seq. }\end{array}$ & $\begin{array}{l}\text { Addresses the appropriation and distribution of } \\
\text { water. }\end{array}$ \\
\hline $\begin{array}{l}\text { Kansas Water } \\
\text { Appropriations } \\
\text { Act Rules and } \\
\text { Regulations }\end{array}$ & $\begin{array}{l}\text { K.A.R. 5-1-1 } \\
\text { through 5-10-6 } \\
\text { and KAR 5-50-1 } \\
\text { through 5-50-8 }\end{array}$ & $\begin{array}{l}\text { Establishes a framework for the control, } \\
\text { conservation, regulation, allotment, and distribution } \\
\text { of water resources. }\end{array}$ \\
\hline $\begin{array}{l}\text { Kansas Nongame } \\
\text { and Endangered } \\
\text { Species } \\
\text { Conservation Act; } \\
\text { Kansas Nongame } \\
\text { and Endangered } \\
\text { Species } \\
\text { Conservation } \\
\text { Regulations }\end{array}$ & $\begin{array}{l}\text { KSA, Chapter } \\
32 \text {, Article 9; } \\
\text { KAR, Title } 115 \\
\text { Article } 15\end{array}$ & $\begin{array}{l}\text { Designates endangered and threatened species, } \\
\text { as well as nongame species in need of } \\
\text { conservation. Requires consultation with the } \\
\text { Kansas Department of Wildlife and Parks } \\
\text { pertaining to actions that might affect listed species } \\
\text { and their critical habitats. Projects that affect listed } \\
\text { species or their habitats and that are publicly } \\
\text { funded, state or federally assisted, or require a } \\
\text { permit from another state or federal agency require } \\
\text { review and action permits (KSA 32-957 through } \\
-963,32-1009 \text { through } 32-1012 \text {, and 32-1033; KAR } \\
115-15-1,-2,-3 \text {, and -4). }\end{array}$ \\
\hline $\begin{array}{l}\text { Kansas Levee Law } \\
\text { and Regulations }\end{array}$ & $\begin{array}{l}\text { KSA, Chapter } \\
\text { 24, Article 1; } \\
\text { KAR, Title } 5 \text {, } \\
\text { Article } 45\end{array}$ & $\begin{array}{l}\text { Requires prior approval of chief engineer before } \\
\text { construction of floodplain fills and levees (KSA 24- } \\
\text { 126). "Floodplain fill" means material, usually soil, } \\
\text { rock, or rubble, placed in a floodplain to an } \\
\text { average height of more than } 1 \mathrm{ft} \text { above the existing } \\
\text { ground, which has the effect of diverting, } \\
\text { restricting, or raising the level of floodwaters on a } \\
\text { stream (KAR 5-45-1). }\end{array}$ \\
\hline
\end{tabular}

Type $^{b} \quad$ Determination

A, L Not an ARAR

A, L Not an ARAR

Applicable if water appropriations are required for a corrective action.

A, L Not an ARAR

Applicable if threatened or endangered species are identified

Not an ARAR at or near the site.

Applicable if site activities involve construction of floodplain fills. 


\begin{tabular}{|c|c|c|c|c|c|}
\hline Title & Citation $^{\mathrm{a}}$ & Description & Comment & Type $^{b}$ & Determination \\
\hline $\begin{array}{l}\text { Kansas Historic } \\
\text { Preservation Act and } \\
\text { Regulations }\end{array}$ & $\begin{array}{l}\text { KSA, Chapter } \\
75 \text {, Article } 27 \text {; } \\
\text { KAR, Title 118, } \\
\text { Article } 3\end{array}$ & $\begin{array}{l}\text { Provides for protection and preservation of sites } \\
\text { and buildings listed on state or federal historic } \\
\text { registries (KSA 75-2715 through 75-2726; KAR } \\
\text { 118-3-1 through 118-3-16). }\end{array}$ & $\begin{array}{l}\text { Applicable if the investigation or } \\
\text { response site is a listed state or } \\
\text { federal historic site or is adjacent to } \\
\text { such a site and if activities } \\
\text { requiring permitting are initiated at } \\
\text { the site. }\end{array}$ & A & Not an ARAR \\
\hline $\begin{array}{l}\text { Kansas Unmarked } \\
\text { Burial Sites } \\
\text { Preservation Act }\end{array}$ & $\begin{array}{l}\text { KSA Chapter } \\
75 \text {, Article } 27 \\
\text { KAR Title } 126 \\
\text { Article } 1\end{array}$ & $\begin{array}{l}\text { Establishes the Burial Sites Preservation Board; } \\
\text { prohibits unauthorized disturbance; requires } \\
\text { permits for excavation of any unmarked burial site, } \\
\text { registered or unregistered (KSA 75-2741 through } \\
\text { 75-2754; KAR 126-1-1 through 126-1-2). }\end{array}$ & $\begin{array}{l}\text { Applicable if investigation or } \\
\text { remediation activities encounter a } \\
\text { burial site. }\end{array}$ & $L, A$ & Not an ARAR \\
\hline $\begin{array}{l}\text { Agricultural and } \\
\text { Specialty } \\
\text { Remediation Act }\end{array}$ & $\begin{array}{l}\text { KSA Chapter } 2 \text {, } \\
\text { Article } 37 \\
\text { KAR Title } 124, \\
\text { Article } 1\end{array}$ & $\begin{array}{l}\text { Provides for the reimbursement of corrective action } \\
\text { costs resulting from an incident involving a rupture, } \\
\text { leak, spill, emission, discharge, disposal, or any } \\
\text { other event that releases an agricultural or } \\
\text { specialty chemical accidentally or otherwise into } \\
\text { the environment. Releases resulting from the } \\
\text { normal use of a product or practice in accordance } \\
\text { with the law are not covered. }\end{array}$ & $\begin{array}{l}\text { Applicable if remediation activities } \\
\text { involve the release of an } \\
\text { agricultural or specialty chemical. } \\
\text { Costs to the federal government } \\
\text { are considered ineligible. }\end{array}$ & $C, A$ & $\begin{array}{l}\text { Relevant and } \\
\text { appropriate }\end{array}$ \\
\hline $\begin{array}{l}\text { Guidelines for } \\
\text { Obtaining an } \\
\text { Alternative Public } \\
\text { Drinking Water } \\
\text { Source }\end{array}$ & BER-032 & - & Formerly BER-RS-032. 2005. & A & $\mathrm{TBC}^{\mathrm{C}}$ \\
\hline $\begin{array}{l}\text { Kansas Vapor } \\
\text { Intrusion Guidance } \\
\text { Chemical Vapor } \\
\text { Intrusion and } \\
\text { Residential Indoor } \\
\text { Air }\end{array}$ & & - & No number provided. 2007. & A & TBC \\
\hline $\begin{array}{l}\text { Public Information } \\
\text { Program }\end{array}$ & BER-RS-002 & - & Adopted 1993. & $A$ & $\begin{array}{l}\text { TBC } \\
\text { TBC }\end{array}$ \\
\hline
\end{tabular}

federal historic site or is adjacent to

the site.

encounter a

permits for excavation of any unmarked burial site registered or unregistered (KSA 75-2741 through 75-2754; KAR 126-1-1 through 126-1-2)

the environment. Releases resulting from the

normal use of a product or practice in accordance

with the law are not covered.

\section{Obtaining an \\ Alternative Public \\ Drinking Water}

Residential Indoo

ublic Information 


\begin{tabular}{|c|c|c|c|c|c|}
\hline Title & Citation $^{a}$ & Description & Comment & Type ${ }^{b}$ & Determination \\
\hline $\begin{array}{l}\text { Characterization and } \\
\text { Management of } \\
\text { Contaminated Soil } \\
\text { Cuttings }\end{array}$ & BER-RS-003 & - & Revised 1996. & $A, C$ & \\
\hline $\begin{array}{l}\text { Cost Recovery of } \\
\text { EPA's Past Costs }\end{array}$ & BER-RS-004 & - & Revised 2005. & $A$ & Not a TBC \\
\hline $\begin{array}{l}\text { Evaluating Future } \\
\text { Land Use }\end{array}$ & BER-RS-005 & - & Revised 2005. & $A$ & TBC \\
\hline $\begin{array}{l}\text { Final Guidance for } \\
\text { Verification Sampling } \\
\text { of Non-Hazardous } \\
\text { Industrial } \\
\text { Wastewater Ponds }\end{array}$ & BER-RS-006 & - & Revised 1996. & $A, C$ & Not a TBC \\
\hline $\begin{array}{l}\text { Minimum Standards } \\
\text { for Model Use }\end{array}$ & BER-RS-007 & - & Revised 2005. & $A$ & TBC \\
\hline $\begin{array}{l}\text { Development of Draft } \\
\text { CADs }\end{array}$ & BER-RS-009 & - & Revised 2005. & $A$ & TBC \\
\hline $\begin{array}{l}\text { Utilization of Funding } \\
\text { Through the State } \\
\text { Water Plan }\end{array}$ & BER-RS-011 & - & Revised 2001. & $A$ & TBC \\
\hline $\begin{array}{l}\text { Recommended } \\
\text { Remedial Levels for } \\
\text { Nitrate and Ammonia } \\
\text { in Soils }\end{array}$ & BER-RS-012 & - & Revised 2002. & $A, C$ & TBC \\
\hline $\begin{array}{l}\text { Investigation and } \\
\text { Remediation of Salt } \\
\text { (Chloride)-Impacted } \\
\text { Soil and } \\
\text { Groundwater }\end{array}$ & BER-RS-013A & - & Revised 2005. & $A, C$ & TBC \\
\hline
\end{tabular}

Contaminated Soil

Cost Recovery of

Evaluating Future

Industrial

ewater Ponds

Minimum Standard 
TABLE B.2 (Cont.)

\begin{tabular}{|c|c|c|c|c|c|}
\hline Title & Citation $^{\mathrm{a}}$ & Description & Comment & Type $^{b}$ & Determination \\
\hline $\begin{array}{l}\text { Potential Applicable } \\
\text { or Relevant and } \\
\text { Appropriate } \\
\text { Requirements } \\
\text { ARARs }\end{array}$ & BER-RS-015 & - & Revised 2005 & A & TBC \\
\hline $\begin{array}{l}\text { Scope of Work } \\
\text { (SOW) for a } \\
\text { Preliminary } \\
\text { Investigation }\end{array}$ & BER-RS-017 & - & Revised 2005. & A & TBC \\
\hline $\begin{array}{l}\text { Scope of Work } \\
\text { (SOW) for a } \\
\text { Comprehensive } \\
\text { Investigation }\end{array}$ & BER-RS-018 & - & Revised 2005. & A & TBC \\
\hline $\begin{array}{l}\text { Scope of Work } \\
\text { (SOW) for a } \\
\text { Corrective Action } \\
\text { Study }\end{array}$ & BER-RS-019 & - & Revised 3-29-01. & A & TBC \\
\hline $\begin{array}{l}\text { Scope of Work } \\
\text { (SOW) for a } \\
\text { Comprehensive } \\
\text { Investigation } \\
\text { (CI)/Corrective } \\
\text { Action Study (CAS) }\end{array}$ & BER-RS-020 & - & Revised 2005. & A & TBC \\
\hline $\begin{array}{l}\text { Scope of Work } \\
\text { (SOW) for a } \\
\text { Corrective Action } \\
\text { Plan } \\
\text { (CAP)/Corrective } \\
\text { Action (CA) }\end{array}$ & BER-RS-023 & - & Revised 2005 & A & TBC \\
\hline Reclassification Plan & BER-RS-024 & - & Revised 2001. & A & TBC \\
\hline
\end{tabular}


TABLE B.2 (Cont.)

\begin{tabular}{|c|c|c|c|c|c|}
\hline Title & Citation $^{a}$ & Description & Comment & Type $^{b}$ & Determination \\
\hline $\begin{array}{l}\text { Scope of Work } \\
\text { (SOW) for a } \\
\text { Remedial } \\
\text { Investigation } \\
\text { (RI)/Feasibility Study } \\
\text { (FS) }\end{array}$ & BER-RS-025 & - & Revised 2005. & A & TBC \\
\hline $\begin{array}{l}\text { Scope of Work } \\
\text { (SOW) for a } \\
\text { Remedial Design } \\
\text { (RD)/Remedial } \\
\text { Action (RA) }\end{array}$ & BER-RS-026 & - & Revised 2005. & A & TBC \\
\hline $\begin{array}{l}\text { Reimbursement of } \\
\text { Costs for use of } \\
\text { KDHE Direct-Push } \\
\text { and Mobile } \\
\text { Laboratory }\end{array}$ & BER-RS-027 & - & Revised 2005. & A & TBC \\
\hline $\begin{array}{l}\text { Consideration for } \\
\text { Hydraulic } \\
\text { Containment }\end{array}$ & BER-RS-028 & - & Revised 2005. & $A$ & TBC \\
\hline $\begin{array}{l}\text { Removal Site } \\
\text { Evaluation } \\
\text { (RSE)/Removal } \\
\text { Action Design } \\
\text { (RAD)/Removal } \\
\text { Action (RA) }\end{array}$ & BER-RS-031 & - & Revised 1996. & A & TBC \\
\hline $\begin{array}{l}\text { Guidelines for } \\
\text { Obtaining an } \\
\text { Alternative Public } \\
\text { Drinking Water } \\
\text { Source (changed to } \\
\text { BER-032, 2005) }\end{array}$ & BER-RS-032 & - & Adopted 1995. & A & TBC \\
\hline $\begin{array}{l}\text { Considerations for } \\
\text { Remedial Standards }\end{array}$ & BER-RS-033 & - & Revised 2005. & $A, C$ & TBC \\
\hline
\end{tabular}


TABLE B.2 (Cont.)

\begin{tabular}{|c|c|c|c|c|c|}
\hline Title & Citation $^{a}$ & Description & Comment & Type $^{b}$ & Determination \\
\hline $\begin{array}{l}\text { Mercury } \\
\text { Contamination } \\
\text { Characterization at } \\
\text { Gas Pipeline Sites }\end{array}$ & BER-RS-034 & - & Revised 2005 & $A, C$ & Not a TBC \\
\hline $\begin{array}{l}\text { Mercury } \\
\text { Contamination } \\
\text { Remediation at Gas } \\
\text { Pipeline Sites }\end{array}$ & BER-RS-035 & - & Revised 2005. & $A, C$ & Not a TBC \\
\hline $\begin{array}{l}\text { Scope of Work for } \\
\text { Site Monitoring }\end{array}$ & BER-RS-036 & - & Revised 2005 & A & TBC \\
\hline $\begin{array}{l}\text { State Cooperative } \\
\text { Program }\end{array}$ & BER-RS-037 & - & Adopted 2005. & A & TBC \\
\hline $\begin{array}{l}\text { Scope of Work for a } \\
\text { Qualitative Risk } \\
\text { Assessment }\end{array}$ & BER-RS-039 & - & Revised 2005 & A & TBC \\
\hline $\begin{array}{l}\text { Clean-up Levels for } \\
\text { Total Petroleum } \\
\text { Hydrocarbons }\end{array}$ & BER-RS-041 & - & Adopted 2000. & $A, C$ & TBC \\
\hline Addendum & BER-RS-041 & - & Adopted 2001. & $A, C$ & TBC \\
\hline $\begin{array}{l}\text { Monitored Natural } \\
\text { Attenuation }\end{array}$ & BER-RS-042 & - & Revised 2005. & $A, C$ & TBC \\
\hline $\begin{array}{l}\text { Considerations for } \\
\text { Groundwater Use } \\
\text { and Applying RSK } \\
\text { Standards to } \\
\text { Contaminated } \\
\text { Groundwater }\end{array}$ & BER-RS-045 & - & Adopted 2004. & $A, C$ & TBC \\
\hline $\begin{array}{l}\text { Filtering Water } \\
\text { Samples Collected } \\
\text { for Metal Analysis }\end{array}$ & BER-RS-046 & - & Adopted 2006. & A & TBC \\
\hline
\end{tabular}




\begin{tabular}{|c|c|c|c|c|c|}
\hline Title & Citation $^{a}$ & Description & Comment & Type $^{b}$ & Determination \\
\hline $\begin{array}{l}\text { Scope of Work } \\
\text { (SOW) For a Nitrate } \\
\text { Presumptive } \\
\text { Remedy }\end{array}$ & BER-RS-047 & - & Adopted 2003. & $A, C$ & TBC \\
\hline $\begin{array}{l}\text { Consideration and } \\
\text { Selection of Borrow } \\
\text { Sites }\end{array}$ & BER-RS-048 & - & Adopted 2007. & A & TBC \\
\hline $\begin{array}{l}\text { Cost Recovery } \\
\text { Guidance for } \\
\text { KDHE/BER Activities } \\
\text { at Sites Determined } \\
\text { to have Responsible } \\
\text { Parties }\end{array}$ & BER-RS-049 & - & Adopted 2007. & $A$ & TBC \\
\hline $\begin{array}{l}\text { Remediating Soil } \\
\text { From Agricultural } \\
\text { Chemical Incidents } \\
\text { by Excavation \& } \\
\text { Land Applications } \\
\text { Interim Measures }\end{array}$ & BER-RS-050 & - & Adopted 2007. & $A, C$ & TBC \\
\hline $\begin{array}{l}\text { VCPRP Initial } \\
\text { Deposits For } \\
\text { Grouped Properties }\end{array}$ & $\begin{array}{l}\text { BER-RS-VCP- } \\
001\end{array}$ & - & Adopted 2004. & A & TBC \\
\hline $\begin{array}{l}\text { Eligibility } \\
\text { Determinations } \\
\text { Concerning Public or } \\
\text { Private Drinking } \\
\text { Water Well } \\
\text { Situations }\end{array}$ & $\begin{array}{l}\text { BER-RS-VCP- } \\
002\end{array}$ & - & Adopted 2000. & A & TBC \\
\hline $\begin{array}{l}\text { Standards for } \\
\text { Property } \\
\text { Identification For } \\
\text { Issuance of NFA } \\
\text { Determinations }\end{array}$ & $\begin{array}{l}\text { BER-RS-VCP- } \\
003\end{array}$ & - & Adopted 2002. & A & TBC \\
\hline
\end{tabular}


TABLE B.2 (Cont.)

\begin{tabular}{|c|c|c|c|c|c|}
\hline Title & Citation ${ }^{a}$ & Description & Comment & Type & Determination \\
\hline $\begin{array}{l}\text { Transfer of } \\
\text { Contaminated Sites } \\
\text { From the State } \\
\text { Cooperative Program } \\
\text { to the Voluntary } \\
\text { Cleanup and } \\
\text { Property } \\
\text { Redevelopment } \\
\text { Program }\end{array}$ & $\begin{array}{l}\text { BER-RS-VCP- } \\
004\end{array}$ & - & Adopted 2003. & $A$ & TBC \\
\hline $\begin{array}{l}\text { Property Eligibility for } \\
\text { Assessments } \\
\text { Conducted by the } \\
\text { Brownfields Program }\end{array}$ & $\begin{array}{l}\text { BER-RS-BF- } \\
001\end{array}$ & - & Adopted 2004. & $A$ & TBC \\
\hline $\begin{array}{l}\text { Natural Resource } \\
\text { Damage } \\
\text { Assessments }\end{array}$ & BER-ARS-044 & - & Adopted 2002. & $A$ & TBC \\
\hline Sediment Policy & BER-ARS-045 & - & Adopted 2004. & A & TBC \\
\hline $\begin{array}{l}\text { Kansas Petroleum } \\
\text { Storage Tank } \\
\text { Release Trust Fund } \\
\text { Policy and } \\
\text { Procedures Manual }\end{array}$ & - & - & - & $A$ & Not a TBC \\
\hline $\begin{array}{l}\text { Kansas Storage } \\
\text { Tank Program } \\
\text { Aboveground } \\
\text { Storage Tank } \\
\text { Overview }\end{array}$ & - & - & - & $A$ & Not a TBC \\
\hline $\begin{array}{l}\text { Updated Policy and } \\
\text { Procedures Manual } \\
\text { for the } \\
\text { Preventative/UST } \\
\text { Unit Storage Tank } \\
\text { Section }\end{array}$ & - & - & - & $A$ & TBC \\
\hline
\end{tabular}

From the State

to the Voluntary

Cleanup and

Property

Redevelopmen

Property Eligibility for

sessments

0

Adopted 2004.

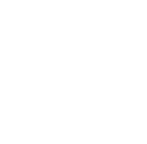

Natural Resource

BER-ARS-044

Adopted 2002.

A TBC

Assessments

Sediment Policy

BER-ARS-045

Adopted 2004.

Kansas Petroleum

Policy and

Aboveground

Storage Tank

Updated Policy and

cedures Manual

Section 


\begin{tabular}{|c|c|c|c|c|c|}
\hline Title & Citation $^{\mathrm{a}}$ & Description & Comment & Type & Determination \\
\hline $\begin{array}{l}\text { Kansas Geological } \\
\text { Survey Public } \\
\text { Information } \\
\text { Circular } 23- \\
\text { Drilling a Water Well } \\
\text { on Your Land; What } \\
\text { You Should Know }\end{array}$ & $\begin{array}{l}\text { Suchy et al. } \\
2011\end{array}$ & $\begin{array}{l}\text { Includes a primer on groundwater systems; } \\
\text { describes how to evaluate the potential for a water } \\
\text { well; advises that a yield of } 4-5 \text { gpm is considered } \\
\text { the minimum amount necessary for domestic } \\
\text { household use; references the need to select a } \\
\text { reputable and responsible driller, and points out } \\
\text { the need to check with local and state regulatory } \\
\text { agencies for permitting and construction } \\
\text { regulations. }\end{array}$ & Adopted in 2005; amended in 2011 & A & TBC \\
\hline
\end{tabular}

a Abbreviations for citations:

KAR, Kansas Administrative Regulations

KSA, Kansas Statutes Annotated

b Types:

A, action specific

$C$, chemical specific

$\mathrm{L}$, location specific

c To be considered. 


\section{Appendix C:}

\section{Phytotechnology Review}




\section{Appendix C:}

\section{Phytotechnology Review}

Phytotechnology is a generic term referring to the use of plants to remediate contaminated environmental media. Processes that can occur during phytoremediation include the following (ITRC 2009):

- Phytosequestration - Isolation of certain contaminants in the rhizosphere through exudation of phytochemicals and on the root through transport proteins and cellular processes.

- Rhizodegradation - Enhancement of microbial biodegradation of contaminants in the rhizosphere by exuded phytochemicals.

- Phytohydraulics - Uptake of water into the plant, with subsequent transpiration and evaporation.

- Phytoextraction - Uptake of contaminants into the plant with the transpiration stream.

- Phytodegradation - Uptake and breakdown of contaminants in the transpiration stream through internal enzymatic activity and photosynthetic oxidation/reduction.

- Phytovolatilization - Uptake, translocation, and subsequent transpiration of VOCs in the transpiration stream.

\section{C.1 Phytoremediation Case Studies}

The EPA (2005) has described 79 field-scale phytotechnology projects throughout the United States and Canada. At 27 of the 43 sites where phytotechnology is being used to address groundwater contamination, the contaminants of concern are chlorinated organics. Because the corrective action goals for the Hanover site involve groundwater, the most relevant 
phytoremediation approach involves the use of plants that can successfully root at depths where contamination is present. Although grasses and forbs can establish effective root systems as deep as $15 \mathrm{ft} \mathrm{BGL}$, the most relevant case studies involve the use of natural or hybrid tree species. Phytoremediation using groves of single or multiple tree species as a component of the cleanup remedy is ongoing at sites including the following:

- Altus Air Force Base, Altus, Oklahoma

- Air Force Plant 4 and Carswell Air Force Base, Fort Worth, Texas

- Edward Sear Sites, Gretna, New Jersey

- Travis Air Force Base, Fairfield, California

- Chevron, Ogden, Utah

- Oak Ridge National Laboratory, Oak Ridge, Tennessee

- Aberdeen Pesticide Dump, Aberdeen, North Carolina

- Naval Undersea Warfare Station, Keysport, Washington

- Tibbets Road, Barrington, New Hampshire

- Aberdeen Proving Ground, Aberdeen, Maryland

- Argonne National Laboratory, Argonne, Illinois

- Staten Island, New York (Negri et al. 2003)

In addition to the above-noted sites, and noteworthy because of a contamination scenario similar to that at Hanover, is the use of phytoremediation as a remedy component at the former CCC/USDA grain storage facility in Murdock, Nebraska (Argonne 2009b). 


\section{C.2 Baseline Study at Hanover}

Factors that influence the applicability and success of phytoremediation include the contaminant type being remediated, climate, soil conditions (including soil type, physical condition, $\mathrm{pH}$, oxygen level, mechanical impedance to root growth, moisture and soil nutrients), depths where the contamination is present, the availability of suitable plant species, and the rhizosphere microbes associated with the plant species selected. These site-specific characteristics necessitate site-specific assessment, design, and installation techniques. With a view toward evaluating the feasibility of implementing phytoremediation at the Hanover site, Argonne conducted a baseline vegetation sampling program, according to procedures in the Master Work Plan (Argonne 2002), as part of the site investigation process, with the approval of the KDHE (2009d).

The identification of carbon tetrachloride in tree tissue has been shown to qualitatively correlate with the occurrence of the contaminant in soil or groundwater near the tree roots. For example, the uptake of carbon tetrachloride by vegetation was evaluated at the former CCC/USDA grain storage facility in Murdock, Nebraska. Commercial fumigants containing carbon tetrachloride used to treat grain stored at the Murdock site between 1950 and the early 1960s resulted in the contamination of soil, groundwater, and surface water. Argonne identified both carbon tetrachloride and chloroform in the branch tissues of native trees growing in an area of contaminated groundwater discharge at Murdock (Argonne 2005).

Although the presence of a contaminant in natural vegetation is a probable indicator of the contaminant's presence in the subsoil or groundwater, a "not detected" result might have several explanations: (1) no contamination is present; (2) the roots are not developed to the depth of the contamination, and thus no uptake is observed; and (3) concentrations in the subsoil or groundwater are too low for a recordable signature in plant tissue. Past experience has shown that leaf samples are more susceptible than branch tissue to airborne background levels of contaminants and thus are a less useful indicator. The Hanover site baseline investigation provided valuable information about contamination in the subsoil and groundwater and the natural occurrence of site-specific phytoremediation that can potentially be exploited in the remedy design process if factors such as climate, soil conditions, and contamination depth are suitable. 
On July 23 and 24, 2009, Argonne conducted initial baseline sampling and analysis of selected existing vegetation. Samples of branches and leaves were collected from more than 25 different varieties of trees and bushes along city streets and in private yards. Sample locations were selected to include vegetation above and adjacent to inferred areas of carbon tetrachloride contamination and in areas inferred to not be contaminated (for background reference). Sample locations are depicted in Figure C.1. Since volatile contaminants (such as carbon tetrachloride) tend to dissipate via diffusion with height above the ground and with increasing distance from the tree trunk, the plant tissue sampling was performed as close as possible to the ground and to the tree trunk, to maximize chances of detection.

In all, 341 leaf samples and 340 branch samples were collected and analyzed. Analytical results for branch samples ranged from not detected to $9.6 \mu \mathrm{g} / \mathrm{kg}$ (at location V-308, south of the former CCC/USDA facility; Figure C.2). Analytical results for leaf samples ranged from not detected to $13.5 \mu \mathrm{g} / \mathrm{kg}$ (at location $\mathrm{V}-712$, at the southeastern limit of the sample area; Figure C.3).

Leaf samples with carbon tetrachloride concentrations above the detection limits were found within the footprint of the former facility, as well as to the west and the southeast (Figure C.3). Interestingly, low but detectable levels were also found in junipers growing along the southern edge of the cemetery, in an area at a distance from known contamination, selected to represent background concentrations. This finding suggests the presence of carbon tetrachloride in ambient air and makes drawing conclusions from leaf sample results problematic.

Branch samples containing carbon tetrachloride above the detection limits were also found southeast of the former CCC/USDA facility, but not generally within the former facility (Figure C.2). Except for a few scattered points, most of the branch samples with detectable concentrations were found immediately south, southwest, and west of the former facility, near wells MW7, MW28, MW29, MW39, MW17, MW 15, and MW25. The highest concentrations in both branches and groundwater were found immediately south of the former facility. No evident correlation was found between the detection of carbon tetrachloride in tree branch tissue and either specific species or the detection of carbon tetrachloride in sub-slab soil vapors sampled as part of the VI investigation. Furthermore, a lack of correlation between carbon tetrachloride concentrations in tree branch tissues and known contamination in groundwater was particularly noticeable in the northern portion of the former CCC/USDA property, where the highest 
concentrations were found in groundwater Zone 1. These results raised concerns about the potential effectiveness of phytoremediation as a treatment option for Zone 1.

\section{C.3 Evaluation of the Effectiveness and Implementability of Phytoremediation at Hanover}

The generally recommended target remediation depth for phytoremediation technology is less than $15 \mathrm{ft} \mathrm{BGL}$, while the maximum practical depth is generally $25 \mathrm{ft}$ BGL (ITRC 2009) for planting techniques specifically developed to focus and extend root growth into the subsurface. However, deeper target remediation zones have been achieved. Even though the groundwater at the Hanover site is deep (roughly $17 \mathrm{ft} \mathrm{BGL}$ in Zone 1), the detections of carbon tetrachloride in branch tissue samples suggest that phytoremediation technologies might have some potential. Increasingly complex planting designs are required as the depth targeted for remediation increases. Designs can include the selection of deep-rooting species (phreatophytes such as poplar and willow species or hybrids), finishing borings with backfill materials that foster root growth, use of aeration tubes to supply deeply residing roots with oxygen, and configuring casings to prevent developing roots from using near-surface water and to direct root growth to the targeted remediation zone. The complexity of the planting designs that would be required at Hanover in order to reach the affected water-bearing zones would increase the cost of the phytoremediation option.

At the Murdock, Nebraska, site, some 2,000 trees representing six species (Niobe willow, black willow, eastern cottonwood, hybrid poplar, green ash, and northern catalpa) cover an area of approximately 4.5 acres. Trees are planted at conventional planting depths over about 2.5 acres. Over a 1.9-acre plot, at locations where the static groundwater level is typically more than 4-5 ft BGL, the special TreeWell ${ }^{\circledR}$ technique was used to plant the trees in 24-in.-diameter boreholes lined with plastic sleeves. This technique limits the availability of shallow soil water and directs precipitation downward, thus promoting vertical root growth and the uptake of deeper (contaminated) groundwater. At the Murdock site, TreeWell ${ }^{\circledR}$ borings as deep as $12 \mathrm{ft}$ BGL were used to plant a number of trees (Argonne 2009b).

At the Argonne site near Chicago, Illinois, special planting methods were used to achieve a target remediation depth of $30 \mathrm{ft}$ BGL. The planting design involved allowing groundwater in the targeted artesian aquifer to enter the 30-ft-deep planting borehole from the bottom of the borehole by means of the capillarity of the backfill and the confined aquifer condition. A casing- 
like structure was used to force the taproots of the planted trees away from surface water sources and down to the target remediation depth. The planting strategy has resulted in a luxury water condition, given the large leaf size observed during the growing season (Quinn 2010).

At Hanover, groundwater in Zone 1 is deeper than the generally recommended target remediation depth for phytoremediation. However, groundwater in portions of Zone 1 could perhaps be targeted with engineered deep planting methods. A viable phytoremediation remedy for Zone 1 groundwater would likely involve the establishment of one or more phytoremediation groves, placed and oriented to have an impact on preferential migration pathways (Figure 2.10). Since placement of groves would be constrained by the presence of cultural features like residences, roads, sidewalks, sanitary and storm water sewers, and water supply infrastructure, candidate locations and configurations would be limited. Phytoremediation treatment in the area of highest contamination in Zone 1 would not be feasible.

The estimated permeability in Zone 1 ranges from $0.001 \mathrm{ft} / \mathrm{day}$ to $100 \mathrm{ft} / \mathrm{day}$. In general, each of the candidate locations for the phytoremediation groves is in the portion of Zone 1 with low permeability ( $1 \mathrm{ft} / \mathrm{day}$ ). Even in portions of Zone 1 with the higher permeability values, combined slug test results suggest that the few discrete, thin, moist-wet intervals present in Zone 1 have limited capacity to provide water for a phytoremediation grove. In areas having lower permeability values (i.e., the candidate grove locations), even less water would be available to sustain the groves.

Although depths greater than the recommended groundwater remediation depth of $15 \mathrm{ft}$ BGL were targeted at the Argonne site, site characteristics (climate, stratigraphy, and the aquifer characteristics [a permeable glacial drift unit under artesian pressure; Quinn 2010]) almost guaranteed that sufficient water would be available to support the growth of the phytoremediation groves. In view of the site characteristics at Hanover, adequate water is not likely to be available. The groundwater at the Hanover site is beyond the recommended target remediation depth. Moreover, the water availability for a phytoremediation grove is restricted to the effective thickness of the few thin horizons that form the water-bearing interval. 


\section{C.4 Summary}

- In view of the site characteristics at Hanover, adequate water is not likely to be available to support a healthy and viable phytoremediation option.

- The high potential for tree mortality, especially early in the life cycle, could lead to the perception by the community that the trees were negatively affected by the contaminant, rather than by the limited availability of water to support the phytoremediation grove. In fact, the levels of contamination at Hanover are far below concentrations that would affect the mortality of any vegetation.

- The CCC/USDA and Argonne collaborated with recognized experts in the field of phytoremediation in the design and implementation of the baseline Hanover field study. The assessment of these experts led to the recommendation to eliminate phytoremediation as a potentially viable technology, on the basis of inadequate availability of groundwater, limited land accessibility, and the risk of unfavorable public perceptions in the face of anticipated high levels of tree mortality.

- Costs for the phytoremediation technology would be moderate to high. 


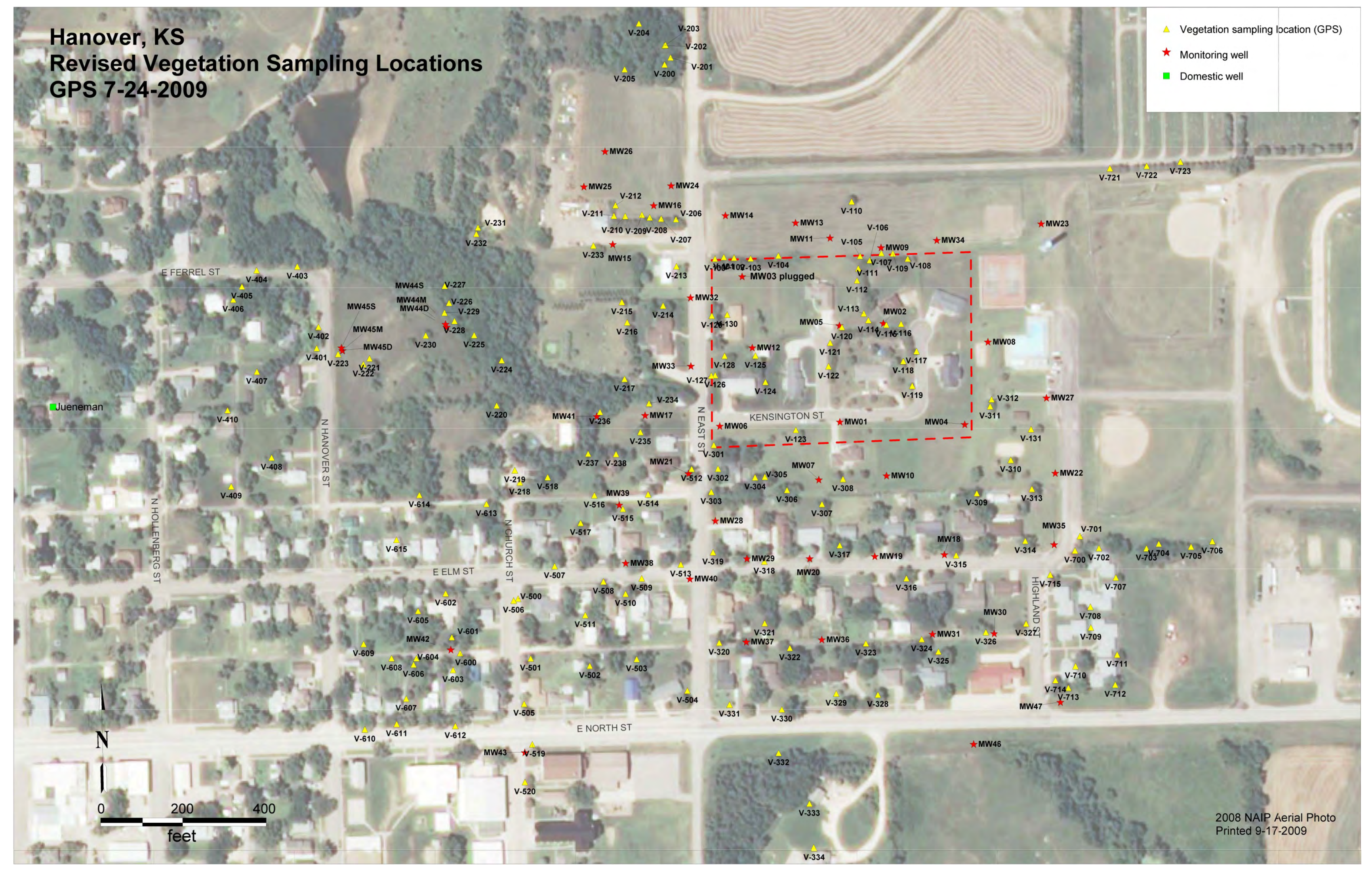

FIGURE C.1 Vegetation sampling locations. Source of photograph: NAIP (2008). 


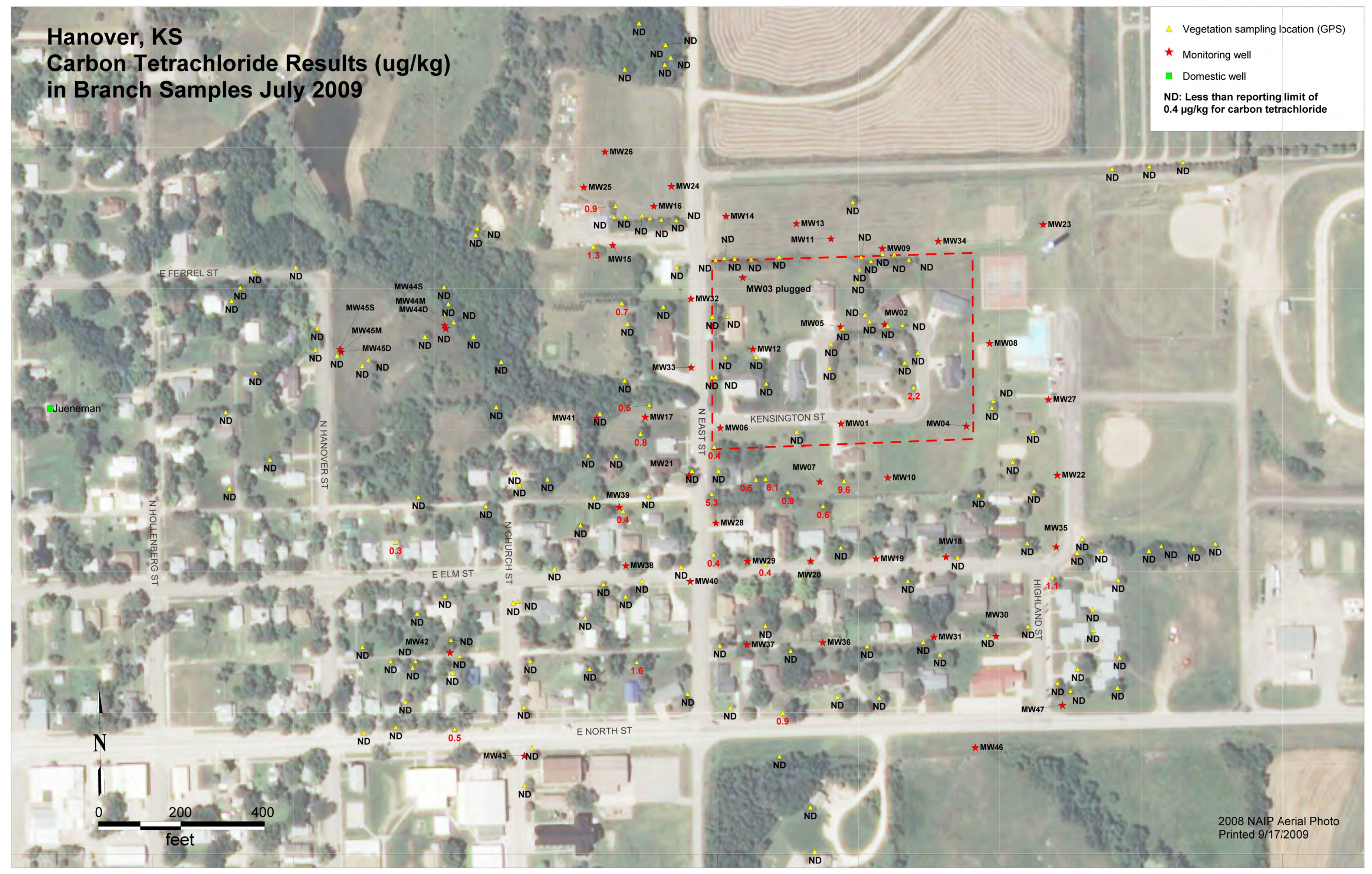

FIGURE C.2 Analytical results for carbon tetrachloride in branch tissue samples collected in July 2009. Source of photograph: NAIP (2008). 


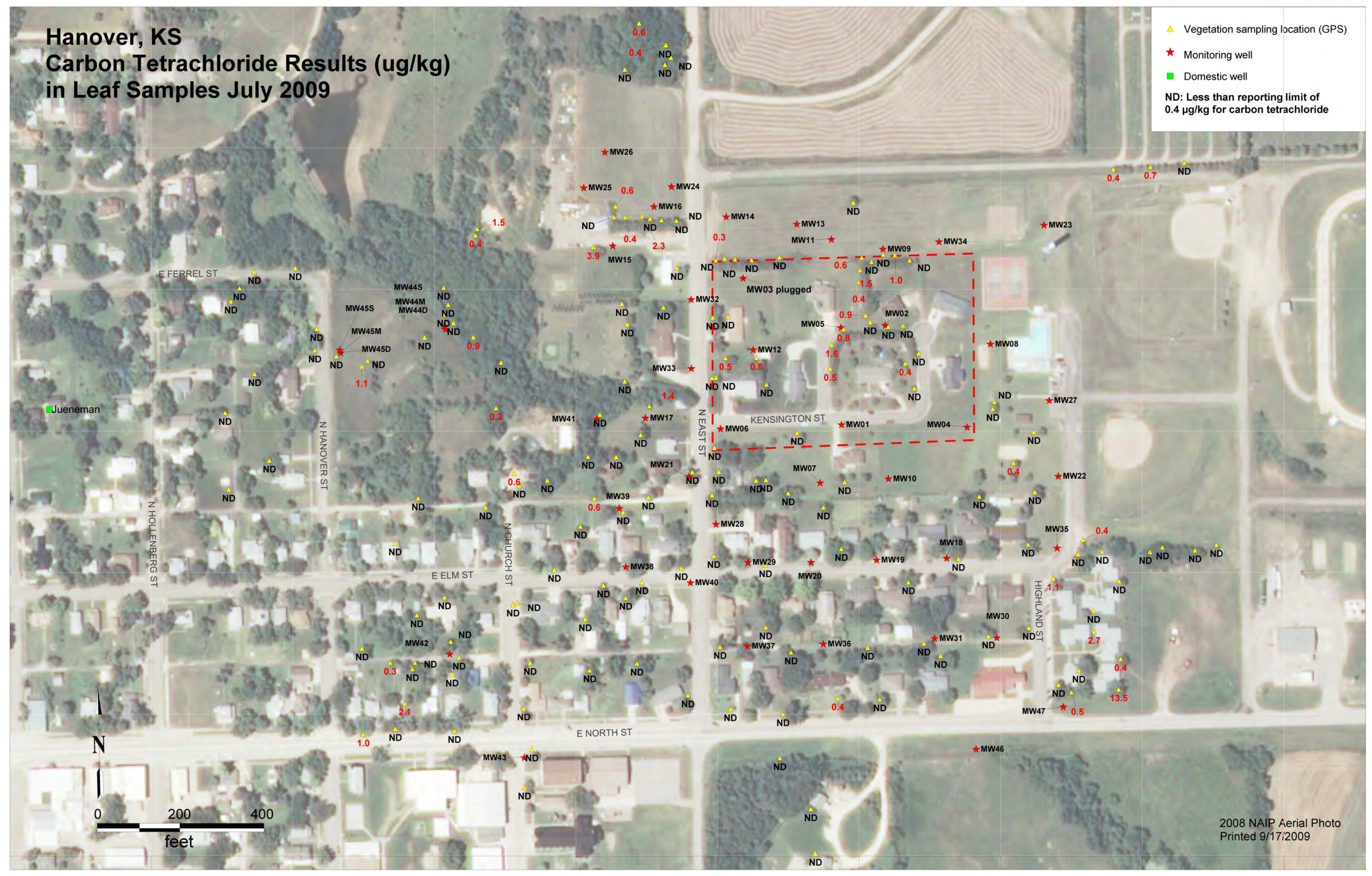




\section{Appendix D:}

\section{Estimation of the Operation Time Period for} Groundwater Extraction in Alternative 3 


\section{Appendix D:}

\section{Estimation of the Operation Time Period for Groundwater Extraction in Alternative 3}

\section{D.1 Estimation Method}

A component of Alternative 3 is groundwater extraction by a horizontal well in waterbearing Zone 1 . The characteristics of the water-bearing units at Hanover, the nature of the contamination, and results of previous studies indicate that carbon tetrachloride concentrations in groundwater are likely to decrease to asymptotic levels after the contaminated water-bearing units have been flushed with several pore volumes ${ }^{1}$ of water. For purposes of cost estimation, a simplified volumetric method (described here) was used to estimate the extraction well operation time required for the carbon tetrachloride concentrations to reach asymptotic levels in groundwater Zone 1. Estimation by numerical modeling was not attempted. The modeling approach requires a number of parameters having high uncertainty because of the great heterogeneity of hydrogeologic properties in the area.

In Zone 1, the groundwater extraction component of Alternative 3 involves placing a horizontal well in the most permeable area, which is also the hot-spot area (carbon tetrachloride concentrations $>500 \mu \mathrm{g} / \mathrm{L}$; Figure D.1). Pumping of the horizontal well will induce a cone of depression $^{2}$ (the radius of influence ${ }^{3}$ ) and will remove a significant amount of carbon tetrachloride from this portion of Zone 1.

An additional advantage of this component of Alternative 3 is that pumping of the Zone 1 horizontal well will reduce the source contribution to contamination in Zone 2, because the most permeable part of Zone 1 appears to be the location where leakage occurs from Zone 1 to Zone 2.

1 Pore volume: The aggregate volume of the void spaces between soil grains.

2 Cone of depression: The depression in the potentiometric surface (or water table) caused by the pumping of a well.

3 Radius of influence: For remedial alternatives involving pumping, the radial distance from the center of a wellbore to the point where no lowering of the water table or potentiometric surface occurs (i.e., the edge of the cone of depression). For other alternatives, the area influenced by the treatment. 


\section{D.2 Zone 1 Configuration and Parameters}

The operating time estimate for Zone 1 is based on (1) the well's pumping rate, (2) the volume of the cone of depression generated in Zone 1 by the well at this rate, and (3) the number of pore volumes required to remove most of the contamination. The estimated well configuration and system parameters are as follows:

- $\quad$ Pumping well: Horizontal well screened over $480 \mathrm{ft}$.

- Estimated radius of influence from the pumping well: $100 \mathrm{ft}$.

- Estimated cone of depression: (1) approximately $100 \mathrm{ft}$ outward from the centerline of the horizontal borehole and (2) $100 \mathrm{ft}$ from the ends of the horizontal borehole. As Figure D.2 shows, the anticipated cone of depression covers the most permeable part of Zone 1 (Subsystem 1 [ $K=34-75 \mathrm{ft} /$ day] and neighboring Subsystem $2[K>1-10 \mathrm{ft} /$ day]) and the hot-spot area (carbon tetrachloride $>500 \mu \mathrm{g} / \mathrm{L})$.

- The horizontal pumping well will be placed near the groundwater divide, where the potentiometric surface is relatively flat and the hydraulic gradient is low; hence, the capture zone ${ }^{4}$ of the well is expected to be generally similar in shape and orientation to the cone of depression. The volume of the capture zone for a horizontal well (at any point in time) cannot be estimated easily by a simple analytical solution, however.

- $\quad$ Estimated range of porosity for Zone 1: 0.1-0.3.

- $\quad$ Measured porosity for a sample collected from Zone 1 at MW47: 0.217.

4 Capture zone: The area of a water-bearing unit from which all water will be removed by a pumping well within a certain time period. 


\section{D.3 Estimated Operating Time for a Horizontal Well in Groundwater Zone 1}

In general, the performance of groundwater extraction in removing contaminants from an aquifer is influenced by known factors, such as non-aqueous phase liquid (NAPL) dissolution, contaminant sorption and desorption, matrix diffusion, and variations in groundwater velocity (Cohen et al. 1994). These factors typically contribute to a "tailing” effect (Boulding 1996) that results in persistent low-level (asymptotic) concentrations of the target contaminants. The operation time required to reach an asymptotic concentration of carbon tetrachloride in Zone 1 was estimated through the following evaluation:

- The results from the 2009-2010 investigation indicate that no carbon tetrachloride is present in the form of NAPL, and no significant source of carbon tetrachloride in the vadose zone soil is contributing to a potential soilto-groundwater pathway. Contamination in Zone 1 is limited to the dissolved phase, with no continuous, significant contaminant source contribution from the overlying vadose zone soil.

- Palmer and Fish (1992) found that, in the absence of free product (NAPL), the number of pore volumes required to remove an organic contaminant from a homogeneous aquifer is approximately equal to the retardation factor. ${ }^{5}$ The retardation factor reflects the overall processes by which contaminants from groundwater tend to be adsorbed onto the solid phase of the water-bearing unit, thus retarding contaminant migration.

- In work conducted in 2003, Argonne estimated carbon tetrachloride retardation factors ranging from 1.5 to 1.8 for soil samples collected from sites in Nebraska and Kansas. In another study, Pacific Northwest National Laboratory identified a carbon tetrachloride retardation factor of 1.71-3.44 for soil samples collected from the aquifer unit at the U.S. Department of Energy Hanford site (Riley et al. 2005).

5 Retardation factor: The ratio of the groundwater flow rate to the contaminant migration rate, which is an indicator of sorption of groundwater contaminants onto the solid phase of the water-bearing unit. 
- Variations in migration time along different path lines will delay contaminant removal (Cohen et al. 1994). Groundwater flowing along path lines at the edge of the capture zone travels a greater distance and has a longer migration time than groundwater that flows along the center of the capture zone.

- A "tailing" effect is typically observed after initial flushing in laboratory soil column tests and field studies (Boulding 1996), even when initial flushing of the contaminated water-bearing unit with a number of pore volumes equal to the retardation factor reduces contamination significantly.

- The persistent low level (asymptotic level) of contamination remaining after a reasonable period of flushing appears to result from (1) diffusion and desorption from less permeable porous media and/or dead spots and (2) variations in groundwater velocities due to variable permeability of the porous matrix (Keely 1989; Palmer and Fish 1992; Cohen et al. 1994), in the absence of NAPL. The mechanisms causing the tailing effect will be enhanced by the pronounced heterogeneity of Zone 1, which varies over several orders of magnitude.

The assessment above indicates that 10 pore volumes is a conservative estimate of the flushing required to remove a significant amount of carbon tetrachloride by pumping water through the impacted area (cone of depression zone or capture zone) and reach an asymptotic level of contamination in Zone 1. On the basis of the highest reported carbon tetrachloride retardation factor of 3.44 for Hanover soils (Riley et al. 2005) and the finding of Palmer and Fish (1992) that the retardation factor is approximately equal to the number of pore volumes required to remove an organic compound from a homogeneous aquifer, approximately 3.5 pore volumes are expected to bring the carbon tetrachloride concentration to an asymptotic level. The value of 10 pore volumes used for the operating time estimates for Alternative 3 is greater by approximately a factor of 3 than the baseline adequate flow volume.

The operation time for the horizontal well in Zone 1 (Table D.1) was estimated by using a volumetric analysis based on the configuration of the cone of depression induced by pumping, relevant parameters for Zone 1 (Section D.2), and the assumption of flushing with 10 pore volumes. 
TABLE D.1 Summary of volumetric analysis for Zone 1.

\begin{tabular}{cccccccc}
\hline $\begin{array}{c}\text { Area of } \\
\begin{array}{c}\text { Cone of } \\
\text { Depression } \\
\left(\mathrm{ft}^{2}\right)\end{array}\end{array}$ & $\begin{array}{c}\text { Water- } \\
\text { Bearing } \\
\text { Zone } \\
\text { Thickness } \\
(\mathrm{ft})\end{array}$ & Porosity & $\begin{array}{c}\text { One } \\
\text { Pore } \\
\left(\mathrm{ft}^{3}\right)\end{array}$ & $\begin{array}{c}\text { One } \\
\text { Pore } \\
\text { Volume } \\
(\mathrm{gal})\end{array}$ & $\begin{array}{c}\text { Pumping } \\
\text { Rate, Q } \\
(\mathrm{gpm})\end{array}$ & $\begin{array}{c}\text { Time } \\
\text { to Flush One } \\
\text { Pore Volume } \\
(\text { day) }\end{array}$ & $\begin{array}{c}\text { Time } \\
\text { to Flush Ten } \\
\text { Pore Volumes } \\
(\mathrm{yr})\end{array}$ \\
\hline 127,416 & 2 & 0.1 & 25,483 & 190,627 & 2 & 66 & 1.8 \\
127,416 & 2 & 0.3 & 76,450 & 571,882 & 2 & 199 & 5.4 \\
127,416 & 2 & 0.217 & 55,299 & 413,662 & 2 & 144 & 3.9 \\
\hline
\end{tabular}

\section{D.4 Conclusions}

- The cone of depression induced by pumping of the proposed horizontal well covers (1) the most permeable area (Subsystem 1) of Zone 1, where vertical leakage is most likely to occur from Zone 1 to Zone 2, and (2) the hot-spot area (carbon tetrachloride $>500 \mu \mathrm{g} / \mathrm{L}$ ).

- The estimated time period required to flush the potentially impacted area (cone of depression) with 10 volumes of groundwater ranges from 2 yr to $5 \mathrm{yr}$.

- The suggested time period for groundwater extraction in Zone 1 is 5 yr. This value can be used as the basis for cost estimation. 


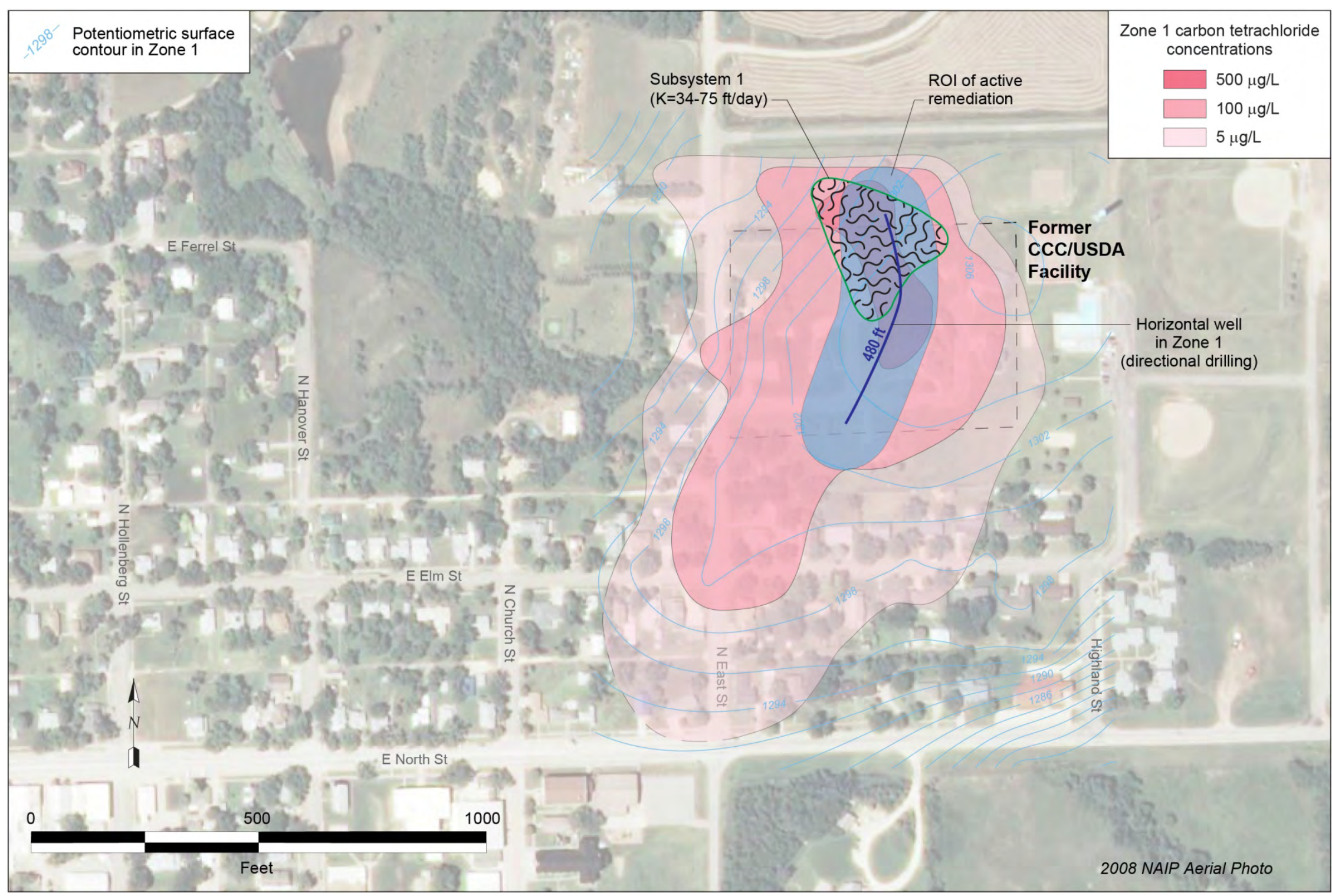

FIGURE D.1 Proposed location for a horizontal well in the most permeable area of groundwater Zone 1, which is also the hot-spot area. Source of photograph: NAIP (2008). 


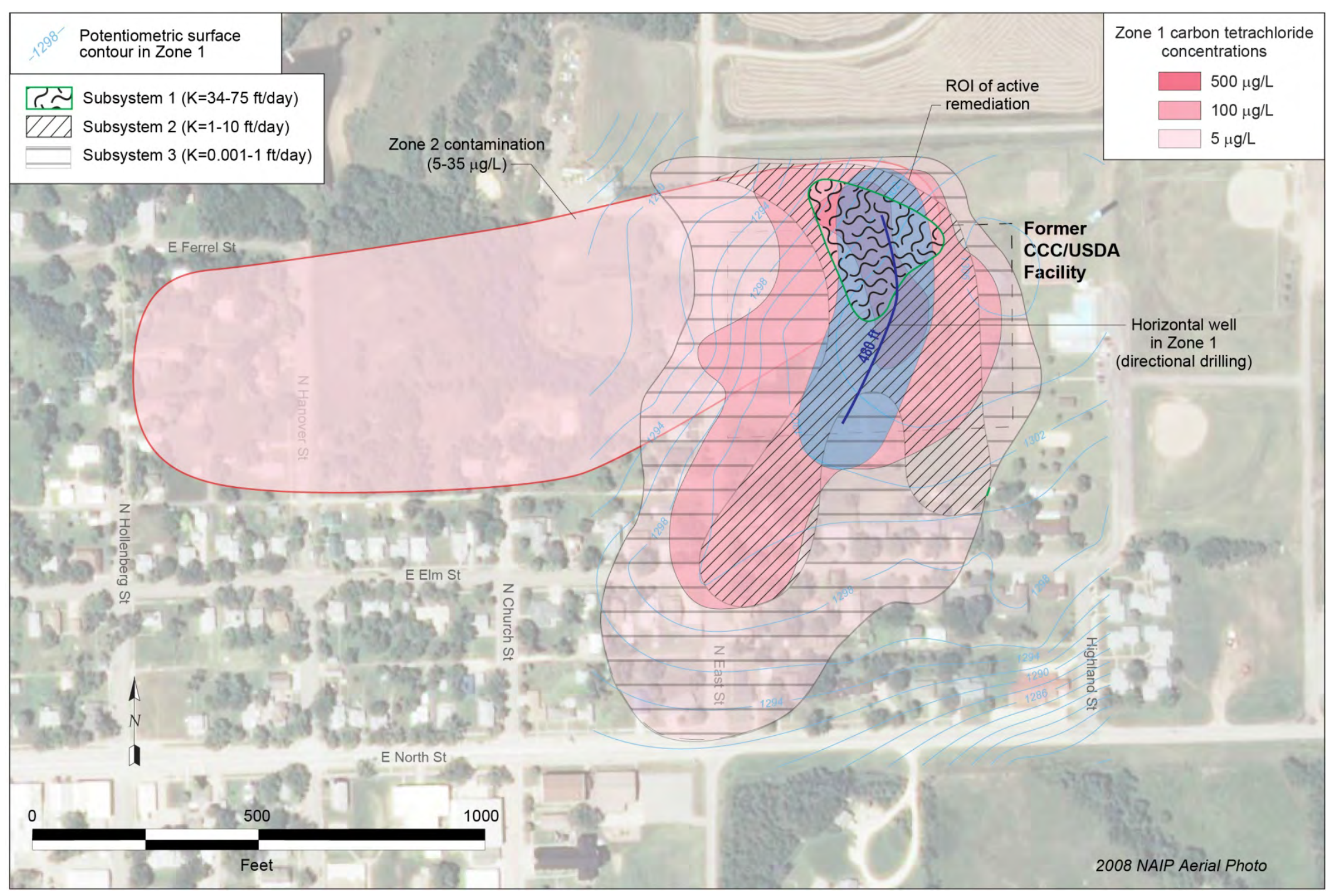

FIGURE D.2 Estimated radius of influence for the proposed horizontal well in the most permeable area of groundwater Zone 1. Source of photograph: NAIP (2008). 
Appendix E:

\section{Basis for Cost Estimation}




\section{Appendix E:}

\section{Basis for Cost Estimation}

The costs presented here were estimated by using actual costs, real-world estimates from prospective vendors, and the Remedial Action Cost Engineering and Requirements (RACER) model (AECOM 2009), a tool for accurate cost estimation for all phases of remediation. RACER is a Windows-based, verified, validated, accredited cost-estimating tool designed to provide a total cost to investigate and clean up a site. RACER has been accredited by Price-Waterhouse Coopers, LLP (2001), for the following intended use:

To provide an automated, consistent and repeatable method to estimate and document the program cost for the environmental cleanup of contaminated sites and to provide a reasonable cost estimate for program funding purposes consistent with the information available at the time of the estimate preparation.

The model was developed specifically for estimating costs associated with investigating and cleaning up contaminated sites, costs also known as “environmental liabilities.” The system can be used for the early order-of-magnitude estimating stage of a project or can provide a more detailed cost estimate. The RACER model has been employed by hundreds of users, including the U.S. Department of Defense, Department of Energy, Department of the Interior, and Environmental Protection Agency; consultants; and state regulatory agencies. The accuracy of the RACER system has been determined to be within $10 \%$ of completed projects costs.

The RACER model is a parametric cost-estimating system with two components that work in tandem: (1) an expert system that can estimate the amount and nature of work to be performed to address environmental liabilities and (2) a detailed database of unit prices. The user can enter site-specific information that customizes generic engineering solutions and results in the calculation of the quantities of labor, equipment, and materials necessary to complete the project. The work quantities and the database of unit prices are then used to calculate costs. The RACER system is structured to calculate costs for the following project life cycle phases: prestudy, study (site investigation or corrective action study), design, removal/interim action, corrective action, long-term monitoring, and site closeout. 
The RACER system is used to calculate environmental liabilities in connection with mergers, acquisitions, divestitures, and legal disputes, but one of its primary uses is for the development of cost estimates for feasibility studies and Corrective Measures Studies under the Resource Conservation and Recovery Act, corollaries to the KDHE CAS (EarthTech 2005). Users can select from among many cleanup technologies (32 for treatment and 13 for removal), as well as multiple long-term monitoring technologies, to develop a cost estimate for site remediation. For example, the U.S. Army Corps of Engineers-Baltimore District used RACER to develop costs for 6 alternatives in a feasibility study for the cleanup of a former Atomic Energy Commission site (Fatherly et al. 2008).

Additional information is linked at the following location:

http://www.afcee.af.mil/resources/restoration/racer/index.asp 
Argonne

\section{Environmental Science Division}

Argonne National Laboratory

9700 South Cass Avenue, Bldg. 203

Argonne, IL 60439-4843

www.anl.gov 